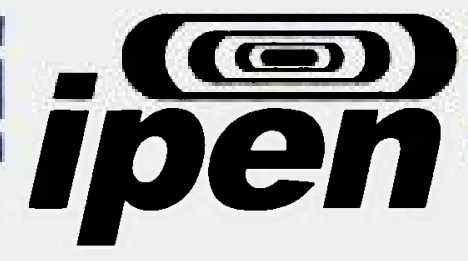

AUTARQUIA ASSOCIADA À UNIVERSIDADE DE SÃO PAULO

\title{
ESTUDOS MICRODOSIMÉTRICOS USANDO UM SISTEMA DE IRRADIAÇÃO DE NÊUTRONS RÁPIDOS FILTRADOS DE REATOR DE PESQUISA PARA APLICAÇÃO EM RADIOBIOLOGIA
}

\section{PEDRO PEREIRA RODRIGUES}

Tese apresentada como parte dos requisitos para obtenção do Grau de Doutor em Ciências na Área de Tecnologia Nuclear - Aplicações.

Orientadora:

Dra. Letícia L.C. Rodrigues 


\section{INSTITUTO DE PESQUISAS ENERGÉTICAS E NUCLEARES}

Autarquia associada à Universidade de São Paulo

Estudos Microdosimétricos usando um Sistema de Irradiação de Nêutrons Rápidos Filtrados de Reator de Pesquisa para Aplicação em Radiobiologia.

Pedro Pereira Rodrigues

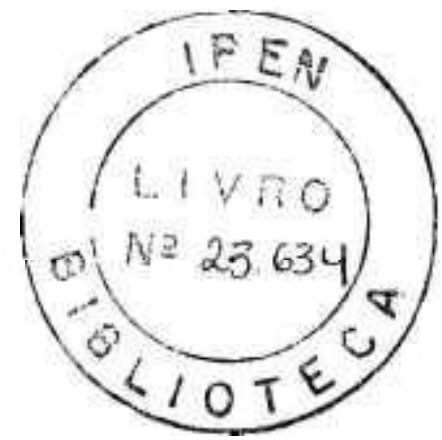

Tese apresentada como parte dos requisitos para obtenção do Grau de Doutor em Ciências na Área de Tecnologia Nuclear - Aplicações.

Orientadora:

Dra. Leticia L.C. Rodrigues

SĂO PAULO 
Aos meus filhos Pedro e Ingrid e à minha esposa Luci. 


\section{AGRADECIMENTOS}

Ao IPEN. na pessoa do Sr. Superintendente, Dr. Claudio Rodrigues. pela oportunidade para o desenvolvimento deste trabalho.

A Dr ${ }^{a}$. Leticia Lucente Campos Rodrigues por tornar possível a realização deste trabalho. pela orientação firme e apoio nos momentos de decisão.

Ao Dr. Leslie A. Braby pela amizade, oportunidade, paciência, atenção e disposição na co-orientação deste trabalho.

Ao Dr. Warren D. Reece, diretor do Centro de Ciência Nuclear, da Texas A\&M University. que disponibilizou os recursos instrumentais e operacionais do reator de pesquisa para a realização deste trabalho.

Ao Dr. Paul M. Bergstrom pelas aulas, compreensão e dicas importantes no inicio deste trabalho.

Ao National Institute of Standard and Technology (NIST), pelo apoio durante o periodo em que estive lá como bolsista pesquisador, no departamento de física da radiação.

Ao CNPq pelo apoio financeiro.

À minha esposa Luci e aos meus filhos pelo amor, paciência, compreensão e cooperação constantemente demonstradas durante todo o desenvolvimento deste trabalho.

A todos os colegas do CEFET-GO pela amizade e atenção.

Ao $\mathrm{CNPq}$ pelo suporte financeiro, sem o qual não seria possível esse trabalho.

Ao CEFET-GO, pelo apoio moral, financeiro, me dispensando para a realização desse trabalho durante os anos que foram necessários.

A todos que. de alguma forma, colaboraram para a elaboração deste trabalho, o meu muito obrigado! 


\title{
ESTUDOS MICRODOSIMÉTRICOS USANDO O SISTENA DE IRRADIACCÃO DE NÊUTRONS RÁPIDOS FILTRADOS DE REATOR DE PESQUISA PARA APLICACÃO EM RADIOBIOLOGIA
}

\author{
Pedro Pereira Rodrigues
}

\begin{abstract}
RESUMO
Neste trabalho, medidas microdosimétricas foram realizadas usando um contador proporcional equivalente à tecido - TEPC, com uma cavidade esférica de diâmetro de $1,27 \mathrm{~cm}$. O TEPC foi preenchido com gás propano puro, $\mathrm{C}_{3} \mathrm{H}_{8}$, à pressão de $5,6 \mathrm{kPa}$ (42 Torr), que é equivalente a 1,3 u um em diâmetro de unidade de densidade do tecido. O instrumento de medida microdosimétrica foi irradiado com radiação de nêutrons rápidos do reator de pequisa do Nuclear Science Center da Texas A\&M University, em College Station, Texas. Os feixes de nêutrons rápidos foram emitidos com três diferentes valores de potencia, $0,5,1,0$, e $2,0 \mathrm{~kW}$, durante I hora para alto ganho e o mesmo tempo para baixo ganho, totalizando 2 horas para cada potencia, com $0,0083 \mathrm{~Gy} / \mathrm{min}$ de taxa de dose. O nêutron foi filttrado usando o sistema de irradiaçào de nèutrons rápidos fortemente filluados (FNIS). do Nuclear Science Center, para obter uma redução da contaminação da radiação de nêutron por radiação gama e assim obter espectros microdosimétricos de nèutrons como, distribuiç̃ão de freqüência de energia lineal e distribuição de dose de energia lineal, com boa precisão, e outras grandezas como, freqüència média de energia lineal, dose média de energia lineal, dose absorvida, dose equivalente e fator de qualidade médio de nêutron rápido. Os resultados obtidos foram satisfatórios, com os espectros microdosimétricos de nêutrons mostrando uma contaminação de radiação gama abaixo de $5 \%$, especialmente para distribuição de dose de energia lineal. Os resultados obtidos neste trabalho foran comparados com outros da literatura cièntifíca, que usaram outros procedimentos para a redução da contaminação do nêutron por radiação gama. estando em concordancia com eles.
\end{abstract}




\title{
MICRODOSIMETRIC STUDIES USING A FILTERED FAST NEUTRON IRRADIATION SYSTEM OF RESEARCH REACTOR TO APPLICATION IN RADIATION BIOLOGY
}

\author{
Pedro Pereira Rodrigues
}

\begin{abstract}
In this work, microdosimetric measurements were performed using a Wall-less Tissue Equivalent Proportional Counter - TEPC with spherical cavity with an inner diameter of $1.27 \mathrm{~cm}$. The TEPC was filled with pure propane gas, $\mathrm{C}_{3} \mathrm{H}_{8}$ at $5.6 \mathrm{kPa}$ (42 Torr) pressure. which is equivalent to $1.3 \mu \mathrm{m}$ in diameter of unit density tissue. The microdosimetric measurement device was irradiated with fast neutron radiation from Texas A\&M University Nuclear Science Center research reactor, in College Station, Texas. The fast neutron beams were emitted with three different power values, $0.5,1.0$ and $2.0 \mathrm{~kW}$, during Ih for both high gain and low gain, totalizing two hours for each power with $0.0083 \mathrm{~Gy} / \mathrm{min}$ of dose rate. The neutron was filtered using the heavily filtered fast neutron irradiation system (FNIS), from Nuclear Science Center; to obtain a decrease of neutron radiation contamination by gamma ray and so, to gain the neutron microdosimetric spectra as. frequency distribution of lineal energy, dose distribution of lineal energy with good precision, and another quantities as frequency-mean of lineal energy, dose- mean of lineal energy: absorbed dose, equivalent dose and average quality factor of fast neutron. The obtained results were satisfactory, with the neutron microdosimetric spectra showing a gamma ray contamination under $5 \%$, especially to dose distribution of lineal energy. The results obtained in this work were in agreement when compared with another results from scientific literature, which used another procedure to reduce the neutron contamination by gamma ray.
\end{abstract}




\section{INDICE}

Páginas

DEDICATÓRIA

AGRADECIMENTO

RESUMO

ABSTRACT

I- INTRODUÇÃO 01

II - OBJETIVOS 06

2.1 - Objetivos Gerais 06

2.2 - Objetivos Específicos 06

III - FUNDAMENTOS TEÓRICOS 07

3.1 - Microdosimetria 07

3.1.1 - Grandezas e Unidades 12

3.1.1.1 - Sobre as limitações do LET 16

3.1.1.2 - Energia lineal e Energia especifica . 17

3.1.1.3 - Análise da informação espectral * 20

3.1 .2 - Métodos de medidas 22

3.1 .3 - Simulação teórica 23

3.1.4 - Contador Proporcional - Fazendo medidas microdosimétricas 25

3.1.4.1. - Efeito Parede 27

3.1.4.2 - Simulação do volume de tecido real em um contador proporcional 29

3.1.4.3 - Distribuição dos traços no interior da cavidade 32

3.1.4.4 - Espectro em Microdosimetria 34

3. I.4.5 - Tipos Contadores proporcionais Equivalentes a tecido 40

3.1.4.5.1 - Contador Proporcional Equivalente a tecido com paredes 41

3.1.4.5.2 - Contadores proporcionais equivalentes a tecido sem-paredes $\quad 42$

3.1.4.5.2.1 - Contador proporcional equivalente a tecido sem-paredes esférico 43

3.1.4.5.3-Contador proporcional equivalente a tecido cilindrico 44

3.1 .5 - Tipos de amostras $\quad 46$

3.2 - Radiação de nêutrons 46 
3.2.1 - Fontes de nêutrons $\quad 46$

3.2.2 - Interação do nêutron com a matéria 47

3.2.2.1 - Interação do nêutron com moléculas - Energia lineal 48

IV - MATERIAIS E MÉTODOS 53

4.1 - Equipamentos $\cdots$

4.1 .1 - Contador proporcional equivalente à tecido - (TEPC) esfërico - LET-1/2 53

4.1 .2 - Material suporte ao TEPC 56

4.1.2.1 - Pre- amplificador Camberra modelo-2006 56

4.1.2.2 - Amplificador de espectroscopia - ORTEC - Modelo 451

4.1.2.3 - Fornecedor de alta tensão 56

4.1.2.4 - Bomba de gás

4.1.2.5 - Gás Propano

4.1.2.6 - Analisador de Multicanal APTEC 57

4.2- Reator do Centro de Ciência Nuclear da Texas A\&M University 57

4.3 - Sistema de Irradiação de Nêutrons Rápidos Severamente Filtrados 59

4.5 - Método de medidas microdosimétricas . 64

V-RESULTADOS E DISCUSSÕES 71

5.1 - Cálculos microdosimétricos para alto ganho - Potência de $0,5 \mathrm{~kW} \quad 71$

5.2 - Cálculos microdosimétricos para baico ganho - Potência $=0.5 \mathrm{~kW} \quad 80$

5.3 - Medidas microdosimétricas para poténcia do reator de $0.5 \mathrm{~kW}$. 87

5.4 - Cálculos microdosimétricos para a Potència do reator de $1,0 \mathrm{~kW}$

5.5 - Cálculos microdosimétricos para a potência do reator de $2,0 \mathrm{~kW} \quad 99$

5.6 - Freqüència média $\left(y_{\mathrm{F}}\right)$ e dose média $\left(y_{\mathrm{D}}\right)$ de energia lineal $\quad 106$

5.6.1 - Freqüêencia média de energia lineal $\left(y_{F}\right) \quad 106$

5.6.2 - Dose média de energia lineal $\left(y_{D}\right)$ * $\quad 106$

5.7 - Cálculos da Dose absorvida, Fator de qualidade, Dose equivalente

$\begin{array}{ll}\text { e Fator de qualidade médio } & 107\end{array}$

$\begin{array}{ll}\text { 5.7.1- Dose absorvida total (D) } & 107\end{array}$

5.7 .2 - Taxa de dose absorvida (D/t) 108

5.7.3- Fator de qualidade (Q(y)) 108

5.7.4- Dose equivalente $(\mathrm{H}) \quad 110$ 
5.7 .5 - Taxá de dose equivalente $(\mathrm{H} / \mathrm{t})$

5.7.6- Fator de qualidade médio $(\bar{Q})$

VI - CONCLUSÕES

VII - REFERÊNCIAS BIBLIOGRÁFICAS 


\section{I - INTRODUÇÃO}

A radiação ionizante deposita energia em pacotes discretos, os quais são o resultado das interações com os átomos do meio através do qual ela passa. Estes pacotes são distribuídos de forma não uniforme pelo volume irradiado, ou seja, algumas regiões podem ser bastante irradiadas e outras bem menos. Não somente a quantidade de energia depositada por unidade de massa (dose absorvida, D), mas o número de depósitos de energia, sua magnitude e distribuição espacial podem influenciar o efeito da radiação sobre estruturas biológicas e outras.

O conhecimento da dose absorvida não permite nenhuma afirmação sobre a energia realmente transferida para a célula individualmente ou para as estruturas subcelulares (Kellerer, 1985). Os desvios são mais substanciais para pequenos volumes, pequenas doses ou para radiações densamente ionizantes; em alguns casos, a energia transferida a uma determinada dose absorvida pode ser zero, ou ela pode exceder ao valor esperado por ordens de magnitude. Portanto, são requeridas novas grandezas e conceitos adicionais para especificar a concentração de energia em regiões microscópicas. Essa flutuação de natureza estocástica de deposição de energia é o objeto de estudo da Microdosimetria.

A constatação deste comportamento estocástico de deposição de energia sobre a matéria irradiada tornou a Microdosimetria de importância capital para o estudo dos mecanismos de ação da radiação em nível celular e subcelular. O arcabouço teórico e experimental surgido a partir do desenvolvimento deste novo sistema de conceitos de grandezas físicas e suas medidas foi relevante para o avanço da pesquisa em radiobiologia, radioterapia, radioproteção e medicina nuclear, além de ter aplicações também em química da radiação e microeletrônica.

Portanto, quando precisamos conhecer mais precisamente sobre a interação entre radiação e matéria, e ir além da análise da radiação de corpo todo ou de algum órgão, é necessário recorrer aos recursos presentes na microdosimetria. 
A radiobiologia de nêutrons é de fundamental importância para o entendimento dos mecanismos primários na ação da radiação ionizante na célula. Os nêutrons nos oferecem uma ferramenta particularmente poderosa para investigações em radiobiologia ao nível de tecido, porque permitem aplicar uma dose de radiação densamente ionizante a objetos de dimensão macroscópica. Radiações esparsamente ionizantes como raios $\mathrm{X}$, radiação gama ou elétrons rápidos afetam a célula em uma gradual acumulação de danos, geralmente, um grande número de partículas são necessárias para matar a célula. Uma célula de mama, por exemplo, mesmo após o seu núcleo ser atravessado por cerca de 2000 elétrons rápidos, possui $50 \%$ de chance de sobreviver (Kellerer, 1974). A célula, portanto, é capaz de tolerar pequenas doses de radiação esparsamente ionizante. Com os nêutrons, caracterizados como radiação de transferência de energia linear alta (alto LET), a situação é completamente diferente, porque são produzidos recuos densamente ionizantes que, se apenas uma dessas partículas atravessar o núcleo de uma célula de mama, terá uma chance substancial de inativar essa célula ou produzir uma ou várias aberrações cromossômicas.

Como o DNA é o principal alvo para os efeitos biológicos da radiação, incluindo a promoção de morte celular, bem como carcinogênesis e mutações (Hall e Giaccia, 2006), a passagem de radiação ionizante pode provocar um efeito direto sobre o DNA, promovendo quebras de fitas simples ou quebras de fitas duplas, associados a danos na base, ou todos esses tipos de danos podem ocorrer conjuntamente. O nêutron, com uma alta densidade de ionização, como outras partículas pesadas, pode promover agrupamentos de danos, onde algumas ligações moleculares são rompidas no tecido ao longo de sua trajetória.

Além da importância do estudo da radiação de nêutrons para o entendimento dos mecanismos básicos em radiobiologia, há o aumento da exposição humana, pois com o avanço da tecnologia no transporte aéreo é possível vôos cada vez mais altos, reduzindo com isto, a cobertura de proteção contra radiações cósmicas oferecida pela atmosfera terrestre. $O$ crescimento do uso do nêutron em radioterapia também estimulou a realização de medidas microdosimétricas para especificar a qualidade dos feixes em campos de tratamento. Essas medidas experimentais têm sido acompanhadas por avanços em cálculos teóricos, objetivando um melhor entendimento das interações do nêutron com os tecidos, bem como dos processos de excitação e 
ionização ocorridos no interior da matéria. Outros experimentos microdosimétricos da radiação de nêutrons têm dado uma contribuição fundamental em estudos de radioproteção, ajudando na avaliação do fator de qualidade de radiação.

A microdosimetria tornou-se um ferramental teórico-experimental fundamental em todas as áreas da biologia onde a análise dos danos celulares e subcelulares sejam necessárias. Áreas como Radiobiologia, Radioterapia e Radioproteção e Medicina Nuclear vêm obtendo avanços teóricos e experimentais através das pesquisas usando a microdosimetria. Outras como Química da Radiação e Microeletrônica, em menor grau, também recorrem à microdosimetria para compreenderem melhor os fenômenos físicos que ocorrem no interior da matéria irradiada em nível microdosimétrico.

A radiobiologia experimental envolve partículas aleatórias transversais carregadas incidindo sobre as células, e a especificação numérica dos efeitos é geralmente expressa em termos da fração de células afetadas dos tecidos ou de todo organismo. Esta é uma determinação estocástica dos efeitos das doses absorvidas, e a principal aplicação da microdosimetria consiste em tentar correlacionar estas probabilidades com as de deposição de energia em volumes subcelulares, nos quais os danos elementares, chamados lesões, são produzidos. Em princípio, o objetivo desse esforço é determinar a disposição geométrica da porção sensitiva da radiação sobre as células. Na prática, o alvo presumido geralmente será o DNA da célula, e o objetivo teórico é limitado à contabilidade dos efeitos da radiação em termos da energia absorvida ou confirmar a configuração prevista do DNA. Considerações baseadas na microdosimetria podem envolver não somente a distribuição da energia absorvida no espaço, mas também no tempo, isto é, a dependência da eficiência biológica com a taxa de dose absorvida como também com a qualidade da radiação.

As pesquisas na área de radiobiologia visam entender o dano provocado pela radiação à célula. A microdosimetria foi usada para verificar o dano provocado pela inalação de aerossóis radioativos em célula alveolar de tipo II de pulmão de ratos (Shen, Ye e Wu; 1989), esta pesquisa é de fundamental importância para o estudo do câncer, já que os estudos oncológicos têm mostrado que esta célula é responsável pela formação dos 
tumores pulmonares. Para relacionar Microdosimetria e Radiobiologia foi obtida uma Função de Eficiência da dimensão do choque (Hit-Size) através de uma estimativa probabilística (Morstin; Bond e Baum, 1989). Ela é usada para derivar, e subseqüentemente aplicar, função de resposta celular baseada em microdosimetria para diferentes pontos de extremidade (end points) de relevância para proteção radiológica. Outro ramo de pesquisa muito explorado é o que busca encontrar protetores ao DNA contra os danos provocados pela ação da quebra de dupla-fita (double-strand break (DBS)) (Walicka; Adelstein e Kassis, 1998) induzido pelo decaimento do radionuclídeo ${ }^{125} \mathrm{I}$ emitindo elétron Auger.

Para facilitar a análise quantitativa das propriedades da resposta adaptativa celular, um modelo biofísico foi desenvolvido e aplicado, usando os conceitos microdosimétricos de célula básica, proposto pela Comissão Internacional sobre Medidas e Unidades em Radiação (ICRU, 1983) (Leonard, 2007). Para determinar a radiação mínima necessária para ativar e manter a proteção de resposta adaptativa, e então ser capaz de comparar os resultados com outras espécies de radiações e células, é necessário recorrer à microdosimetria de nível celular. O modelo concebido proporciona uma representação acurada dos processos de ativação in vitro e in vivo expostos a feixes mais espessos, com uma acumulação de Poisson de deposição de energia específica de radiação induzida.

Para se investigar as diferenças as respostas elétricas de membranas de células em convencional e supra-eletroporação (Gowrishankar et al, 2006) foi usado um modelo ilustrativo de uma célula biológica com organelas explícitas (mitocôndria, núcleos e retículo endoplasmático). As respostas foram em termos da microdosimetria de campos elétricos, com uma descrição dos campos e potenciais de membranas que ocorrem em nível celular em resposta a um campo aplicado externamente. Além do que, os sítios de membranas locais que são eletroporado, e o número de poros na membrana de plasma e de organelas são usados para distinguir a resposta celular a campos de supra-eletroporação convencional.

Em radiobiologia as amostras biológicas podem ser usadas em microdosimetria, como por exemplo, DNA em solução para comparar os efeitos diretos e indiretos das radiações de energias alta e baixa no dano do DNA (Stanton e outros 1990). Células mamárias foram usadas para avaliar a distribuição de deposição de energia em 
regiões micrométricas (Wilson e outros 2001). Foram avaliadas, também, células cancerosas humanas, para estudar a radioimunoterapia com emissores de partículas alfa (Kvinnsland, Stokke e Aurlier, 2001). Células de intestino delgado foram usadas para a investigação microdosimétrica na eficiência biológica relativa (Tilikidis e outros 1994). Vários outros trabalhos com diferentes amostras como, células de pulmão (ICRU Report36), de músculo (ICRU Report-36) e de osso (ICRU Report-36) são citados na literatura.

A microdosimetria é amplamente utilizada em radioterapia, vários trabalhos realçam a sua importância, entre eles o que determina os efeitos biológicos da Terapia de Captura de Nêutron pelo Boro (BNCT) (Vliet-Vroegindeweij e outros, 2001), que descreve a determinação de várias grandezas microscópicas tais como, número de colisões, deposição de energia no núcleo da célula e distribuição da deposição linear e específica de energia. A microdosimetria foi empregada em radioterapia com feixes de múltiplos píons (Schuhmacher e outros, 1985), foi também utilizada para investigar a terapia com nêutrons rápidos (Langen, 1997).

A radiação gama está sempre associada com nêutrons. A contaminação por radiação gama dificulta a determinação exata do espectro microdosimétrico do nêutron, bem como o cálculo da sua Eficiência Biológica Relativa (RBE). A dependência da energia na eficiência biológica é muito mais importante em nêutrons do que em fótons e a RBE de nêutrons em relação a fótons pode exceder a 100 (Rossi e Zaider, 1996). Reduzir essa contaminação é o objetivo, principalmente para melhorar as aplicações em radiobiologia, radioproteção e radioterapia.

Com o objetivo de reduzir essa contaminação e permitir a avaliação de mecanismos biológicos de danos em células em cultura e animais vivos como ratos e camundongos, foi construído no Reator Nuclear do Nuclear Science Center da Texas A\&M University em College Station, Texas, EUA, o Sistema de Irradiação de Nêutrons Rápidos fortemente Filtrados (FNIS) (Jang et al, 2004).

Com esse equipamento foi realizada pela primeira vez a detecção de radiação de nêutrons rápidos usando um contador proporcional equivalente a tecido. São os resultados desta pesquisa que serão apresentados nesse trabalho. 


\section{II - OBJETIVOS}

\section{1 - Objetivos Gerais}

O objetivo deste trabalho é a realização de medidas microdosimétricas usando um Contador Proporcional Equivalente à Tecido (TEPC) irradiado com nêutrons rápidos.

\section{2 - Objetivos Específicos}

- Realizar testes de desempenho e efetuar a adequação dos equipamentos empregados na técnica de medidas microdosimétricas para a irradiação com nêutrons

- Calibrar os equipamentos para medidas microdosimétricas com radiação de nêutrons;

- Definir e adequar a potência adequada do reator de pesquisa para medidas microdosimétricas;

- Preparar o Sistema de Irradiação de Nêutrons Rápidos Fortemente Filtrados (FNIS), para a redução da radiação gama

- Obter os espectros de distribuição de freqüência de energia lineal;

- Obter os espectros de distribuição de dose de energia lineal;

- Calcular a freqüência média de energia lineal;

- Calcular a dose média de energia lineal;

- Calcular a dose absorvida;

- Calcular a dose equivalente de nêutrons rápidos;

- Calcular o fator de qualidade médio para nêutrons rápidos de reator. 


\section{III - FUNDAMENTOS TEÓRICOS}

\section{1 - Microdosimetria}

A microdosimetria pode ser definida como um conjunto de métodos matemáticos e procedimentos experimentais capazes de tornar possível o entendimento de como ocorre em nível microdosimétrico a deposição de energia no interior dos corpos. Mais precisamente, pode ser definida como o estudo das propriedades físicas microscópicas da radiação ionizante, suas interações e seus padrões de deposição de energia, com particular ênfase às interações de natureza não-homogênea e estocástica (Goodhead, 1987), diferentemente da dosimetria convencional, baseada em grandezas macroscópicas médias, como a dose absorvida.

A principal aplicação da microdosimetria é em radiobiologia, porque contribui na compreensão do que está ocorrendo no interior de estruturas celulares durante a deposição de energia.

A microdosimetria é um ramo de pesquisa da Física que teve sua origem com a publicação de um trabalho por Rossi e colaboradores em 1955. Nesse trabalho foi apresentado um instrumento para determinação experimental de distribuição de LET fornecida por partículas carregadas mais pesadas que o elétron, em função da ionização 'específica (Rossi e Rosenzweig, 1955a). Com esse instrumento, que mais tarde seria referência para outros contadores proporcionais desenvolvidos durante os anos seguintes, chamados "Tipo Rossi", foi iniciado um novo modo de olhar dentro da matéria. Em outro trabalho publicado no mesmo ano, os autores apresentam melhoramentos do instrumento e compararam os resultados experimentais de medidas de dose de nêutrons, usando esse novo equipamento, com resultados teóricos (Rossi e Rosenzweig, 1955b).

As limitações do conceito de distribuição de dose, LET, foram tratadas em um trabalho onde é proposta uma nova grandeza alternativa a ser usada para expressar 
qualidade de radiação em substituição ao LET (Rossi, 1959). Essa grandeza é a energia lineal, $\mathbf{y}$, a qual é certamente uma das mais importantes grandezas estocásticas em microdosimetria. O conceito de energia específica, $z$, que como y, é uma grandeza microdosimétrica estocástica, definida como a taxa entre a energia transmitida e a massa de um volume microdosimétrico (Rossi et al, 1961), foi desenvolvido para descrever melhor como a energia é depositada em volumes muito pequenos e contribuir com o conceito, não-estocástico, de dose absorvida.

Apesar da primeira motivação para os estudos microdosimétricos serem para aplicação em sistemas biológicos, a microdosimetria pode ser considerada como uma atividade puramente física. Suas técnicas e métodos são oriundos das descrições de campos de radiação e suas interações com a matéria, mas, o maior interesse de aplicação está relacionado com problemas biológicos, o que tem motivado a busca da melhoria dos modelos físicos relacionados com a microdosimetria.

A primeira formulação de microdosimetria, chamada de microdosimetria regional, iniciada por Rossi e colaboradores, foi baseada em conceitos de sítios, que são regiões de dimensões específicas na qual a energia absorvida da radiação ionizante é considerada sem levar em conta sua distribuição microscópica dentro do sítio. Esta abordagem continua a receber maior atenção porque envolve grandezas, que em primeira aproximação, estão relacionadas aos efeitos da radiação, que são freqüentemente objeto de acuradas medidas.

Uma alternativa mais avançada que a microdosimetria regional, desenvolvida inicialmente por Kellerer, é a microdosimetria estrutural, que permite uma descrição mais detalhada dos padrões microscópicos de absorção de energia (Rossi e Zaider, 1996). Isto é de uma importância básica, porque o efeito imediato da radiação é essencialmente determinado pela interação desses padrões com os componentes sensiveis da matéria irradiada.

A abordagem experimental é especialmente adaptada para a microdosimetria regional, embora os resultados obtidos possam ser analisados para prover de informações a microdosimetria estrutural. 
Para descrever a deposição de energia no interior da matéria podemos recorrer às estruturas de traços simulados, onde cada traço simulado é único e não representa algum traço real.

Alguns modelos usam essa estrutura, de forma diferenciada, para descrever a exposição à radiação.

Um deles, desenvolvido por Kellerer, usa o conceito de função de proximidade para calcular a distância entre todos os pares de ionizações em um traço, ou entre traços. A função de proximidade de deposição de energia é apresentada na equação 3.1, e a função de proximidade do sítio, na equação 3.2. Este modelo é pouco usado em pesquisas em biologia da radiação.

$$
\begin{aligned}
& t(r)=(\text { energia total }) P_{\text {trạ̧o }}(r) \\
& \text { c } \\
& s(r)=(\text { volume do sitio }) P_{\text {sitio }}(r)
\end{aligned}
$$

onde $P_{\text {traço }}$ é a distribuição de distância ponto-par dos traços e $P_{\text {sitio }}$ é a distribuição de distância ponto-par dos sítios.

Uma segunda alternativa seria determinar quais agrupamentos de ionizações seriam significativos para o processo de interesse, danos biológicos, por exemplo, e então determinar o número de agrupamentos e a distância entre eles. Acontece que é impossível dizer quais agrupamentos são importantes. Além disso, pode ser que diferentes quantidades de ionizações são requeridas para o início de diferentes tipos de danos. Provavelmente, seria necessário saber a distribuição dos agrupamentos dentro e entre traços. E, como uma última razão que torna difícil a adoção desse modelo, é que diferentes métodos de análise de agrupamentos dão resultados diferentes.

Uma solução amplamente usada em aplicações biológicas é a distribuição de energia transferida (c) em volumes arbitrários, a qual tem uma conexão direta, $\epsilon$, com a 
dosimetria convencional. Os métodos de medidas são fáceis, fornece alguma informação sobre os agrupamentos, que pode ser usada para uma ampla variedade de diâmetros de sítios ou formas. Com algumas desvantagens, como por exemplo, o de não permitir informações sobre espectros de fluência ou função de proximidade, além de envolver seleção arbitrária de formas e tamanhos de volumes.

A estrutura de traços simulados e o modelo de distribuição de energia, comunicada em volumes arbitrários, são utilizados para compreender os efeitos de exposição à radiação ionizante. As radiações ionizantes incluem:

- partículas sem carga, como os nêutrons e fótons, que ionizam indiretamente;

- partículas carregadas, como os elétrons, prótons, núcleos atômicos, etc., que promovem ionizações diretamente.

Para produzir um efeito a radiação precisa interagir com o alvo de algum modo, pois esta interação, de alguma forma, envolve transferência de energia. Desta forma, é esperado que a energia transferida para o alvo, como materiais biológicos, materiais inanimados, ou mesmo detectores de radiação, inicie uma seqüência de mudanças químicas e físicas, revelando assim o efeito observado.

Para entender os efeitos da radiação ionizante, através da observação dessas mudanças físicas e químicas, ocorridas no interior da matéria irradiada, foram desenvolvidas algumas propostas, entre as quais, a 'dosimetria', que procura oferecer um modo de caracterizar e prever as consequiências de uma exposição a essa radiação. Quando a radiação atravessa a matéria vem sendo observado que toda energia é depositada por partículas carregadas ao longo de seus traços. Como também, que igual quantidade de energia depositada por diferentes tipos de energia ou cargas, de partículas carregadas, podem suscitar conseqüências diferentes. Geralmente, é aceito que a distribuição microscópica de deposição de energia em volumes de dimensões celulares e subcelulares é de significado crítico em danos biológicos.

As abordagens que procuram investigar a ação da radiação ionizante, são duas: uma é a dosimetria convencional que enfatiza a quantidade total de energia por unidade de massa do alvo. A outra é a microdosimetria, que privilegia os traços de 
partículas individuais, o número de traços e os detalhes físicos de cada um, como massa, velocidade e carga, além da energia depositada por cada pequeno segmento de um traço.

$\mathrm{O}$ modelo de energia por unidade de massa funciona bem para prever efeitos em tecido, quando o número de traços de partículas carregadas é grande. A concentração de produtos tóxicos, por exemplo, é proporcional à energia depositada por unidade de massa. Se o número de traços em dois volumes idênticos é grande, a variação na energia depositada será pequena. Isto faz com que a energia por unidade de massa seja muito apropriada para aplicações em radioterapia.

Outra grandeza muito estudada e importante é a fluência, que é uma função da massa, da velocidade (ou energia) e da carga da partícula, bem como do ângulo de incidência do feixe, ou seja, $\Phi(\mathrm{m}, \mathrm{K}, \mathrm{c}, \Omega)$. A fluência é usada para calcular algumas outras propriedades da radiação como, distribuição de matéria no espaço e informações sobre a secção de choque da radiação. O problema é que fluência é difícil de se medir, especialmente em campos de radiação misto. A maioria dos tipos de detectores é muito mais eficiente para alguns tipos de radiação do que para outras. É quase impossível distinguir partículas betas de outras secundárias provenientes de radiação gama, quando se mede fluência. E finalmente é muito difícil provar que não se negligenciou alguma parte significativa do espectro de radiação durante a realização das medidas.

Se a opção é medir a energia depositada em um pequeno segmento de um traço de partícula carregada, que parece ser muito complicado de ser realizado, isso pode ser feito medindo ou calculando a distribuição de deposição de energia, quando traços de partículas carregadas atravessam um pequeno volume de material. Este é o papel da microdosimetria. O conceito de tamanho do sítio envolve a definição de volumes de interesse chamados sítios, nos quais a energia absorvida pela radiação ionizante é considerada, sem levar em consideração a distribuição microscópica de energia dentro do sítio. A microdosimetria regional está preocupada com medidas de deposição de energia em sítios e é o principal objetivo da microdosimetria experimental (Rossi e Zaider, 1996).

Para a medida da distribuição de deposição de energia em algum volume é necessário fazer algumas considerações sobre o seu tamanho e forma: 
- quando se considera a física da radiação ionizante, torna-se óbvio que a distribuição de

deposição de energia depende do tamanho do volume;

- é necessário especificar o tamanho e a forma do volume do material onde ocorre a deposição de energia.

Alguns tamanhos podem ser mais relevantes que outros quando se avalia os efeitos da radiação à saúde, vejamos:

- o átomo - 0,1 nm - provavelmente não, porque este é o domínio da secção de choque;

- rotação da hélice do DNA - $10 \mathrm{~nm}$ - provavelmente sim, quebra de fita dupla (DSB) e sítios danificados multiplicados localmente (LMDS);

- núcleo celular - $10.000,00 \mathrm{~nm}$ - provavelmente sim, danos em todo um núcleo celular parece estar apto para interagir;

- agrupamento celular $-10^{6} \mathrm{~nm}$ - provavelmente sim, Efeito Bystander tem sido mostrado na maioria dos experimentos;

- órgão - $10^{7} \mathrm{~nm}$ - provavelmente não, maior que o alcance da maioria dos traços de partículas carregadas.

Além de municiar-nos com conhecimentos teóricos e práticos para entender os efeitos das interações entre a radiação e materiais biológicos, a microdosimetria nos fornece informações adicionais sobre interações com pequenos alvos como transistores e capacitores, em circuitos integrados e grandes moléculas, nos processos químicos.

Como em microdosimetria a distribuição de deposição de energia é dada em um alvo, ela é mais aplicada em experimentos com doses baixas. Ela pode ser usada em doses altas, mas não dará mais informações que a dosimetria convencional, por isso não é geralmente usada para esses níveis de doses.

\subsection{1 - Grandezas e Unidades}

Sabe-se que para radiação gama e raios $\mathrm{X}$, com energias abaixo de $\mathrm{MeV}$, a partícula carregada secundária produzida pelos processos de interação primário é $\mathrm{O}$ elétron. A transferência de energia de radiação do campo de radiação para o meio absorvedor é realizado através da ação de elétrons secundários com um amplo espectro de 
energia. Para nêutrons a situação é mais complicada, pois mais de um tipo de partícula carregada pode ser gerada, cada um tendo seu próprio espectro de energia e propriedades de interação (Waker, 1995).

A figura 3.1(a) resume esquematicamente esta situação. Comprimentos de linhas diferentes representam partículas carregadas de diferentes energias, e as suas espessuras as diferentes taxas de perdas de energia. Projetado randomicamente sobre a figura estão uma série de círculos que representam sítios de poucos micrômetros de diâmetro. Se essa figura é usada para representar o tempo integral do processo de deposição de energia, então a dose absorvida em cada um dos sítios pode ser calculada somando a energia depositada ao longo de cada traço e dividindo pela massa do material do sítio.

Considere-se agora a situação representada na figura 3.1.b, onde o tempo sobre o qual os sítios são observados, ou a taxa em qual a radiação é entregue, foi reduzido para um tamanho que a probabilidade de ter mais que uma partícula carregada interagindo com o sítio microscópico é desprezível.
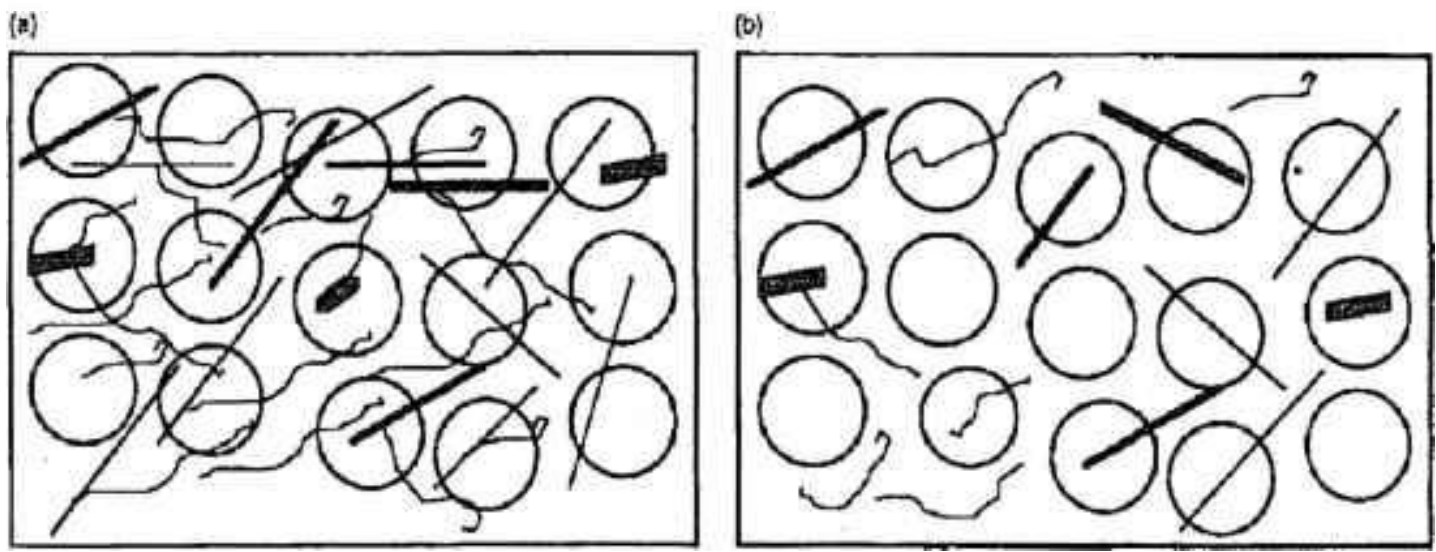

Figura 3.1 - (a) Representação esquemática de um campo de radiação de nêutron interagindo com um meio. As linhas representam partículas carregadas secundárias de diferentes alcances (comprimentos) e diferentes taxas de perdas de energia (espessura). Os círculos representam sítios esféricos de dimensões microscópicas dentro do meio. (b) Representação esquemática de um campo de radiação como em (a), mas sob condições que resultam em não mais que um evento de deposição de energia em cada um dos sítios (após Waker, 1995). 
Como visto, determinar e analisar os depósitos de energia são os objetivos principais da microdosimetria. Para isso, é preciso uma discussão sobre as grandezas e unidades que são envolvidas nesse campo de pesquisa.

Segundo a Comissão Internacional de Unidades de Radiação - ICRU Report (ICRU Report 36, 1983), a grandeza elementar usada em microdosimetria é deposito de energia, $\boldsymbol{\varepsilon}_{\mathbf{i}}$, que é a energia depositada em uma simples interação, i, a qual é necessária para a descrição da distribuição espacial rudimentar em traços de partículas carregadas. É definida como:

$$
\varepsilon_{\mathrm{i}}=\varepsilon_{\text {in }}-\varepsilon_{\text {out }}+Q
$$

onde,

- $\varepsilon_{\text {in }}$ é a energia da partícula ionizante incidente, excluindo a energia de repouso.

- $\varepsilon_{\text {out }}$ é a soma de todas as energias de todas as partículas ionizantes deixando a interação, excluindo a energia de repouso.

- Q é a energia líquida derivada de massa de repouso ou reações nucleares envolvidas na interação.

- $\varepsilon_{\mathrm{i}}$ é uma grandeza estocástica, pode ser considerada como a energia depositada no ponto de interação, o qual é chamado de ponto de transferência, isto é, o local onde uma partícula ionizante transfere sua energia cinética. As incertezas da mecânica quântica para esse ponto são ignoradas. A unidade de $\varepsilon_{\mathrm{i}}$ é o Joule (J), mas é normalmente expressa em elétron volt $(\mathrm{eV})$.

Os depósitos de energia e pontos de transferência, sem mais detalhes da interação que o provoca, são suficientes para a descrição da distribuição espacial de deposição de energia para partículas ionizantes. Assim, há um $\boldsymbol{\varepsilon}_{\mathbf{i}}$ para cada ionização e excitação ao longo do caminho da partícula carregada. 
A energia transmitida, $\varepsilon$, à matéria em um dado volume, é a soma de todos os depósitos de energia existentes no interior desse volume. Pode ser representada como,

$$
\varepsilon=\Sigma \varepsilon_{\mathrm{i}}
$$

onde a soma é realizada sobre todos os depósitos de energia, $\boldsymbol{\varepsilon}_{\mathrm{i}}$, naquele volume.

Os depósitos de energia sobre os quais a soma é realizada podem pertencer a um ou mais eventos de deposição de energia. O termo evento significa as transmissões de energia à matéria por partículas correlacionadas estatisticamente. A energia transmitida, $\boldsymbol{\varepsilon}$, é também uma grandeza estocástica. A unidade de $\boldsymbol{\varepsilon}$ é o Joule (J), mas pode ser expressa também em eV.

A grandeza $\boldsymbol{\varepsilon}_{\mathbf{s}}$, é definida pelo ICRU report (ICRU Report 60, 1998), como a energia transmitida à matéria em um dado volume por um simples evento de deposição de energia. Esta definição requer apenas que haja um volume definido, mas não diz nada sobre o tamanho e a forma do volume. Um evento é a deposição de energia em um volume sensível por uma partícula carregada e seus raios delta, ou por outras partículas carregadas associadas.

As energias $\varepsilon$ e $\varepsilon_{s}$ podem apresentar uma dificuldade para aplicações porque suas magnitudes dependem fortemente do tamanho do volume. Pode-se atenuar essa variação dividindo-se pela medida do tamanho do sítio.

$$
y=\frac{\varepsilon_{r}}{\bar{l}}
$$

onde:

y é chamada energia lineal e $\bar{l}$ o comprimento da corda média dos traços que atravessam o volume. 
A definição de $\bar{l}$ acima, refere-se a material líquido ou sólido. Quando o experimento é realizado em um meio gasoso, $\bar{l}$ é entendido como sendo o diâmetro médio multiplicado pela densidade do gás, relativo ao meio condensado (Kellerer e Rossi, 1969).

\subsubsection{1 - Sobre as limitações do LET}

Como a energia lineal é a mais importante grandeza em microdosimetria, juntamente com energia específica, vamos comentar um pouco mais sobre ela. É necessário discorrer antes sobre o LET, porque foi por limitações desse conceito, que foi desenvolvido o conceito de energia lineal.

A dose absorvida e a transferência de energia linear (LET), este último definido como a transferência de energia por unidade de distância ao longo do caminho de uma partícula carregada (Attix, 1986), são juntas as grandezas mais comumente usadas para a previsão de lesões. Os padrões microscópicos de distribuição de energia são usados para avaliar a eficiência biológica relativa (RBE). Os efeitos biológicos podem não ser os mesmos para radiações que possuem estruturas de traços primário-secundários diferentes, com a mesma dose absorvida. Partículas carregadas pesadas e nêutrons são caracterizados como radiações com alta transferência de energia linear, ou seja, eles produzem um traço lineal extremamente denso de eventos de ionização e excitação. Radiação gama e de elétrons, por sua vez, produzem uma distribuição mais uniforme de eventos de ionização e são considerados radiações de baixo LET. Um LET de poucos décimos de $\mathrm{keV}_{\mu} \mathrm{m}^{-1}$ é o que pode dividir a linha entre radiação de baixo e alto LET. Apesar do conceito de LET ser usado para descrever tipos de radiações e RBE, ele possui limitações, que foram discutidas por Rossi (Rossi, 1959).

Primeiramente, LET é uma grandeza que descreve mais as propriedades médias de partículas incidentes do que as interações com o alvo irradiado individualmente. Transferências de energia não são sempre iguais no local de deposição de energia. Para um pequeno alvo ou para uma partícula de energia alta, raios Deltas escapam do alvo e depositam energia fora do sítio. A energia depositada no alvo é menor que a perda total de energia, e a dose será superestimada, a menos que o equilíbrio de partículas carregadas 
exista. Tampouco, o tamanho do alvo é uma boa medida de comprimento do traço, a dificuldade vem principalmente da extensão do espalhamento. Outra situação, é que para um alvo grande ou para uma partícula de energia baixa, a dose pode ser subestimada se há traços chegando ou saindo no sítio. Quando o LET tem mudanças observáveis no interior do alvo, a situação torna-se mais complicada. Além disso, o mesmo LET não significa mesma distribuição espacial de dose. LET é uma função fortemente associada a carga e a velocidade da partícula. Assim, partículas com mesmo LET podem ter diferentes intervalos de energia de raios delta, que resulta em diferentes distribuições espaciais de dose.

Em segundo lugar, como o LET não é uma grandeza média estocástica, através dele não se é possível perceber as flutuações de deposição de energia e a extensão do espalhamento. Há consideráveis dificuldades em medir estes dois fatores experimentalmente. Pode se perceber, que o LET é uma grandeza de macroescala e, portanto inadequado para descrever um evento em microescala. Tais eventos estão relacionados a detalhes de estruturas de traços no nível celular.

\subsubsection{2 - Energia Lineal e Energia Específica}

A energia lineal, y, como uma grandeza estocástica, nos oferece ferramentas para a análise de eventos com flutuações randômicas. Ela não é restringida por uma limitação de energia, mas sim, por um corte geométrico baseado no tamanho do volume estudado. Similar a energia específica, z, a energia lineal, y, é sujeita à distribuição de densidade de probabilidade $\mathrm{f}(\mathrm{y})$, possui um valor médio, $\bar{y}$, que tem um significado específico, é a freqüência média da energia lineal e é representado por $\mathrm{y}_{\mathrm{F}}$. Diferente de $\mathrm{z}$, portanto, y refere-se somente à energia transferida em um simples evento e tem como unidade $\mathrm{J} / \mathrm{m}$ ou $\mathrm{keV} / \mu \mathrm{m}$.

Energia Lineal, y, descreve a interação de um traço com um sitio. Uma vez que dois traços não são exatamente semelhantes, y é uma variável randômica. Por isso, normalmente, se refere à densidade de probabilidade de $\mathrm{y}, \mathrm{f}(\mathrm{y})$, que é a probabilidade do valor de y estar entre y e $y+d y$. Sabe-se, que por definição, funções de densidade de probabilidade são normalizadas, portanto, 


$$
\int f(y) d y=1
$$

Isto é muito conveniente para comparar $\mathrm{f}(\mathrm{y})$ para diferentes radiações, porque as áreas são as mesmas e é possível avaliar onde um espectro é mais alto ou mais baixo que o outro.

A outra grandeza que é freqüentemente usada em microdosimetria é energia específica, $\mathrm{z}$, que é mais sensível ao tamanho do sítio que $\varepsilon$, mas é usada pela mesma razão que "dose absorvida". É definida como,

$$
\mathrm{z}=\varepsilon / \mathrm{m}
$$

onde:

$\varepsilon$ é a energia transmitida e m é a massa do volume onde $\varepsilon$ foi absorvido.

As unidades para $\mathrm{z}$ são $\mathrm{J} / \mathrm{kg}$, que possui o nome especial de Gray (Gy). Como $\mathrm{z}$ é uma função de $\varepsilon$, então se refere a toda energia depositada no volume durante o tempo considerado. Por causa da natureza randômica das interações da radiação com a matéria, $\mathrm{z}$ pode ser qualquer número, inclusive zero. Em uma dada dose, um tempo fixado em um campo de taxa de dose constante, o número de eventos será uma variável randômica de Poisson. Se volumes idênticos são expostos à mesma dose, haverá um número médio de eventos, $\mathrm{n}$, por volume. $\mathrm{O}$ n não precisa ser um inteiro, e geralmente não é. Portanto, é conveniente, algumas vezes, considerar z para números específicos de eventos, $z_{1}, z_{2}, z_{3}$, etc. Assim, $z$ sem subscrito, refere-se a uma irradiação específica, como dose absorvida.

Desde que a energia específica é devida à convoluções de múltiplos eventos ocorrendo na massa $\mathrm{m}$, ela não pode ser escalonada de grandezas de simples eventos. Portanto, a variância de $\mathrm{z}$ é uma função da dose $\mathrm{D}$ e de $\mathrm{y}_{\mathrm{D}}$. Porém, ela pode ser usada para extrair o valor médio da dose de distribuição, o qual é um parâmetro de um simples evento. A energia específica de um simples evento, $z_{1}$, é o quociente da energia transmitida por uma simples partícula ionizante em uma massa, $\mathrm{m}$, de um dado volume $\mathrm{e}$, 
conseqüentemente, é aplicada a definição macroscópica de dose absorvida (energia transmitida por unidade de massa) para volumes microscópicos. A energia específica é o análogo estocástico da dose absorvida.

Como z é o resultado da quantidade de energia depositada por cada um dos eventos de um número randômico, como a energia lineal, é mais bem descrito por uma função de densidade probabilidade, $f(z)$. E como $f(y), f(z)$ também pode ser normalizada, então,

$$
\int f(z) d z=1
$$

Quando determinamos um espectro microdosimétrico em termos de energia lineal, a geometria do detector precisa ser conhecida para se definir o comprimento da corda média. Para alguns corpos convexos, com uma superfície de área $\mathrm{S}$ e volume $\mathrm{V}$, cortado por cordas isotrópicas, o comprimento da corda média, $\bar{l}$, pode ser determinado geralmente pelo teorema de Cauchy (Cauchy 1908) (Rossi e Zaider, 1996).

$$
\bar{l}=4 \mathrm{~V} / \mathrm{S}
$$

Para volumes esféricos, que é caso da cavidade interna do contador proporcional equivalente a tecido, que usaremos, o comprimento da corda média é:

$$
\bar{l}=2 \mathrm{~d} / 3
$$

A relação entre a distribuição de um evento simples $z, f_{1}(z)$, e $f(y)$ depende do tamanho do sítio simulado e é dada pela seguinte relação:

$$
z=4 y / \rho S
$$


Para superfícies esféricas, com diâmetro d, e considerando um tecido com densidade de $1 \mathrm{~g} / \mathrm{cm}^{3}$, a relação entre energia específica e energia lineal se torna (Kellerer, 1985):

$$
z(G y)=0,204 y / d^{2}
$$

\subsubsection{3 - Análise da informação espectral}

A medição da distribuição das alturas de pulsos observadas é proporcional a y e $z$, e depende da natureza estocástica dos eventos de deposição de energia. $O$ espectro obtido é controlado pela estatística de Poison e é, portanto, determinado por um número de fatores randômicos. A variância $V_{\mathrm{T}}$ é basicamente devida a seis processos, cada qual está sujeito a estas flutuações estatísticas (Kellerer, 1985). São elas:

1. a distribuição do número de eventos de deposição de energia;

2. a distribuição do LET das partículas;

3. a distribuição dos comprimentos dos caminhos das partículas no sítio;

4. a distribuição do número de colisões;

5. a distribuição da energia comunicada em colisões individuais;

6. a distribuição da fração da energia retida no sítio.

As análises de espectros são baseadas na soma das variâncias desses processos individuais, $\mathrm{V}_{\mathrm{T}}$. Para sítios extremamente pequenos, da ordem de centenas de nanômetros ou menos, onde a variação no LET pode ser negligenciada, o efeito predominante é devido à energia perdida por espalhamento (Kellerer, 1985). A variância relativa, $\mathrm{V}$, de um espectro medido, pode ser encontrada determinando o primeiro e o segundo momentos da distribuição e é definido por:

$$
\mathrm{V}=\sigma^{2} / \mathrm{m}_{1}^{2}=\left(\mathrm{m}_{2} / \mathrm{m}_{1}^{2}\right)-1
$$

onde: 
$\mathrm{m}_{1}$ é o primeiro momento de uma distribuição $\mathrm{f}(\mathrm{x})$; e

$\mathrm{m}_{2}$ é o segundo momento de uma distribuição $\mathrm{f}(\mathrm{x})$.

O primeiro momento, $\mathrm{m}_{1}$, é o valor esperado, e é definido pela relação:

$$
\mathrm{m}_{1}=\int x f(x) d x
$$

O segundo momento, $\mathrm{m}_{2}$, é então:

$$
m_{2}=\int x^{2} f(x) d x
$$

Em termos de distribuição microdosimétrica, as médias de $\mathrm{f}(\mathrm{y})$, definida como freqüência média de energia lineal, e $\mathrm{f}_{1}(\mathrm{z})$, freqüência de energia específica média, que é igual à dose absorvida, $\mathrm{D}$, são os primeiros momentos do espectro.

$$
\begin{gathered}
\mathrm{y}_{\mathrm{F}}=\int y f(y) d y \\
\mathrm{e} \\
\mathrm{z}_{\mathrm{F}}=\int z f_{1}(z) d z
\end{gathered}
$$

A dose média de energia lineal, $\mathrm{y}_{\mathrm{D}}$, e a dose média de energia específica, $\mathrm{z}_{\mathrm{D}}$, são as razões entre os segundos e primeiros momentos, isto é,

$$
\begin{gathered}
\mathrm{y}_{\mathrm{D}}=\frac{1}{y_{F}} \int y^{2} f(y) d y \\
\mathrm{e} \\
\mathrm{z}_{\mathrm{D}}=\frac{1}{z_{\dot{r}}} \int z^{2} f_{\mathrm{l}}(z) d z
\end{gathered}
$$


onde:

$f_{1}(z)$ é o espectro microdosimétrico de simples eventos e é, por definição, a distribuição de probabilidade $\mathrm{z}$, sob a condição, de que somente eventos simples sejam considerados.

Portanto, a variância relativa se reduz a:

$$
\begin{gathered}
\mathrm{V}_{\mathrm{y}}=\frac{y_{D}}{y_{F}}-1 \\
\mathrm{c} \\
\mathrm{V}_{\mathrm{z}}=\frac{z_{D}}{2_{F}}-1
\end{gathered}
$$

\subsubsection{Métodos de Medida}

Os métodos de medida empregados em microdosimetria são vários, apesar de todos serem fundamentados no contador de Rossi, que foi o primeiro aparelho construído para medidas microdosimétricas. Os tipos de contadores mais usados são:

\section{1 - Contador de parede sólida}

Este contador utiliza uma espiral cilíndrica para obter uma multiplicação uniforme ao longo do comprimento do eletrodo central (ICRU 36).

\section{2 - Contador de agulha de parede fina}

O sistema é montado dentro de uma casca esférica, constituída de material tecido equivalente. Tais contadores são dispositivos práticos usados para alguns tipos específicos de radiação (ICRU 36). 


\section{3 - Contador de íon pesado}

O contador de íons pesados é um contador proporcional simples, com uma parede fina, cilíndrico, rígido, desenhado para trabalhar com feixes paralelos de íons pesados (ICRU 36).

\section{4-Contador não metálico}

O contador não metálico, como o próprio nome indica, não emprega nenhum material metálico na construção deste contador, o qual é muito utilizado para fótons de energia baixa (ICRU 36).

\section{5- Contador proporcional de baixa pressão}

O contador proporcional de baixa pressão, também chamado de Contador de Rossi, já é manufaturado pela empresa americana Far West Technology, Goleta, Califórnia, USA(Langen, 1997).

\section{6 - Detector de silicone}

O detector de silicone é um diodo isolado com silicone (SOI), com uma profundidade sensível de $10 \mu \mathrm{m}$, desenvolvido para aplicações em microdosimetria protonterápica.

\subsection{3 - Simulação Teórica}

O método de simulação de Monte Carlo é de fundamental importância como método de verificação dos resultados experimentais em microdosimetria. Este é um. programa de computador que permite simulação detalhada da estrutura dos traços de 
particulas carregadas ao atravessarem a matéria. No cálculo de Monte Carlo, uma partícula primária e todas as secundárias são acompanhadas em sua passagem através da matéria, considerando todas as interações, até que toda energia da partícula original seja dissipada. Esta é uma característica do método de Monte Carlo fazendo com que o processo de seleção de cada interação individual seja obtido por meio de uma série de números randômicos, denominados, geradores de números randômicos. $\mathrm{O}$ método pode ser dividido em quatro diferentes etapas: seleção de uma partícula primária, seleção de um tipo de interação, cálculo dos ângulos e energias da partícula primária e das secundárias após a interação e avaliação da energia transferida ao volume observado.

Aplicando o software de simulação de Monte Carlo Crystal Ball (Scott e Schöllnberger, 2000) foi realizada uma aproximação para microdosimetria biológica para relacionar os dados dos efeitos biológicos (ex. sobrevivência de célula, mutagênese, transformação neoplástica), para os quais há um segmento linear inicial para a curva de dose-resposta. Existem outros programas de simulação de Monte Carlo para aplicação em microdosimetria, como o PENELOPE, (Stewart e outros, 2002), que recorre à teoria do múltiplo espalhamento para o tratamento de interações "soft", para simular a trajetória de elétrons de energia muito baixa, que são importantes para aplicações em radiobiologia. Neste experimento foi mostrado que o sistema de código PENELOPE tem uma vantagem potencial sobre os códigos de Monte Carlo evento por evento, tais como OREC e PITS, já que com ele é possível estimar quantidades microdosimétricas em materiais diferentes da água.

Em outro trabalho, usando um microfeixe de elétrons de $25 \mathrm{keV}$ em água, o sistema de código de Monte Carlo PENELOPE (PENetration and Energy LOss of Positron and Electrons) foi novamente comparado com o código de Monte Carlo PITS (Positive Ion Track Structure (Mainardi et al, 2004). Nessa comparação o objetivo foi avaliar qual dos dois códigos tem um melhor desempenho para se estimar grandezas microdosimétricas. A conclusão desta comparação foi que os resultados obtidos, usando o PENELOPE, estavam de acordo com aqueles obtidos usando o PITS. Mostrando assim, que o PENELOPE é eficiente para obtenção de grandezas microdosimétricas, apesar de não ter sido criado para esse fim como foi o PITS.

Um código de Monte Carlo foi usado para quantificar os efeitos de distribuição, não-uniforme, de atividades de progênies de radônio nas superfícies dos 
brônquios, sobre micrométricas doses celulares, para muitas configurações de fonte-alvo (Fakir et al, 2005). Os resultados obtidos podem prover orientação construtiva para uma avaliação mais realística do risco de câncer de pulmão por inalação de progênie de radônio. Demonstrou, também, o efeito de distribuição de atividade não-uniforme sobre quantidades dosimétricas, levantando questões como, se estas mudanças nas quantidades fisicas possam provocar uma correspondente variação que venha resultar em efeitos biológicos celulares, tais como transformações oncogênicas ou sobrevivência celular.

Para se obter um melhor entendimento da influência de energia de nêutron, sobre a qualidade da radiação, foram realizadas simulações de Monte Carlo para calcular espectro de nêutrons rápidos em diferentes posições de irradiação (Pignol et al, 2001). Para a simulação de rendimento de nêutron primário para alvos de berílio bombardeado com prótons foi usado o código de Monte Carlo Fluka, já a simulação com transporte de nêutron foi realizada com o código MCNP - 4A. Os resultados obtidos mostraram que as variações na Eficiência Biológica Efetiva devidas às mudanças no tamanho do campo $\mathrm{e}$ por diferentes profundidades no objeto Simulador, poderiam, também, ser explicados pela variação de nêutrons com energias entre 3 e $15 \mathrm{MeV}$ e, concluindo que a função eficiência parece ser apropriada para predizer mudanças na estimação da energia lineal média.

Para simular medidas de microdosimetria em silicone em terapia de nêutron rápido foi usado o código de Monte Carlo GEANT4 (Cornelius et al, 2004). O objetivo dessa simulação foi mostrar a possibilidade do uso de microdosímetros de silicone para a verificação de sistemas de planejamento de tratamento baseado em Monte Carlo em terapia de hádron. Ele concluiu sugerindo o uso do detector não equivalente à tecido para a verificação de cálculos de Monte Carlo em terapia de hádron.

\subsection{4 - Contador Proporcional - Fazendo medidas Microdosimétricas}

Microdosimetria experimental é o estudo e interpretação de medidas de espectros de energia de deposição de eventos simples usando contadores proporcionais de baixa pressão, para simular sítios microscópicos de tecido (Waker, 1995). Contadores proporcionais de baixa pressão são usados como uma ferramenta extremamente versátil em Física da Radiação, Radioproteção e Radiobiologia. 
A escolha por usar um contador proporcional para a determinação de deposição de energia em volumes subcelulares é devido à versatilidade desse instrumento de detecção de radiação. A sua principal característica é a capacidade de distinguir eventos, baseados numa quantidade de energia, depositada, no interior do detector, diferente dos tubos Geiger-Mueller, que simplesmente grava o acontecimento de um evento sem fornecer alguma informação espectral da energia depositada (Knoll, 2000; Waker, 1995). Ionizações no contador proporcional são amplificadas acima do ruído do sistema relacionado ao potencial do anodo. Esta multiplicação de eventos primários permite operações em situações, onde o número de pares de íons gerados seria também pequeno para permitir o uso de câmaras de íons.

A multiplicação de gás dentro do detector é um processo dependente de alguns fatores, mas é geralmente o resultado do aumento do campo elétrico do detector para um valor suficientemente alto para gerar ionizações secundárias com elétrons livres sofrendo colisões no gás neutro (Knoll, 2000). Quando elétrons livres são acelerados em um determinado campo elétrico para energias maiores que a energia de ionização do gás que preenche a cavidade, uma avalanche de íons secundários é produzida por colisões dos elétrons livres com as moléculas do gás. Sob condições próprias, o número de elétrons na avalanche é proporcional ao número de elétrons primários. Isto é conhecido como uma avalanche de Towsend. O sinal vindo do contador na forma de pulso de tensão terá uma magnitude que é proporcional às ionizações criadas por uma simples partícula carregada atravessando o volume sensível e assim transferindo energia.

A característica fundamental de um contador proporcional, oposta a outros detectores de gás, é sua habilidade para amplificar a ionização proveniente da travessia de uma simples partícula (evento), em um sinal, que é proeminente o bastante para não ser confundido com ruído eletrônico e, portanto, ser detectado (Kliauga et al, 1995).

O princípio da equivalência à tecido repousa sobre observações empíricas, de que a transferência de energia de radiação depende primariamente da composição atômica de um dado material. Isto significa que materiais com propriedades de absorção de energia equivalente à tecido, pode ser feito de misturas de quatro elementos mais comuns, Hidrogênio $(\mathrm{H})$, Carbono $(\mathrm{C})$, Nitrogênio $(\mathrm{N})$ e Oxigênio $(\mathrm{O})$. As paredes ou catodo de contador proporcional equivalente à tecido é geralmente feito de plástico A-150. 
Este material foi usado, inicialmente, para medidas em campos de radiação mista de nêutrons rápidos e raios gama, onde a troca de uma alta quantidade de oxigênio em um tecido real, por outra grande quantidade de carbono no plástico tem um pequeno efeito sobre a absorção de energia de radiação, mas confere ao plástico uma propriedade de condutividade elétrica. É muito importante se evitar gases eletronegativos, como o oxigênio, quando se quer obter um bom ganho de gás no interior dos contadores proporcionais, mas sim usar gases eletropositivos como por exemplo, Carbono e Hidrogênio. Dois gases são muito usados para preencher contadores proporcionais equivalentes à tecido, os equivalente à tecido baseados em metano e os baseados em propano, que são geralmente misturados com dióxido de carbono e nitrogênio. Geralmente os baseados em propano dão uma resposta melhor quando se objetiva um melhor ganho.

Experimentos onde foi usado apenas o gás propano, sem outros elementos misturados, e foram conseguidos bons resultados, foram realizados com baixa contaminação. Nesse trabalho foi usado o propano, $\mathrm{C}_{3} \mathrm{H}_{8}$, sem nenhuma mistura.

\subsubsection{1 - Efeito parede}

O primeiro contador proporcional construído para uso em microdosimetria, o chamado contador Rossi, é até hoje usado em alguns trabalhos de medidas microdosimétricas, o qual possui paredes feitas de tecido equivalente à plástico com a cavidade preenchida com tecido equivalente a gás. As formas mais comumente usadas são as esféricas e as cilíndricas. Se a altura do cilindro for a mesma do diâmetro, o cilindro terá o mesmo comprimento médio de corda da esfera com o mesmo diâmetro, $\frac{2}{3} d$. Os princípios básicos para uso destes instrumentos para simular volumes microscópicos é o teorema de Fano (Fano 1954):

Em um meio de uma dada composição, exposto a um fluxo de radiação primária, tais como, raios $X$ ou nêutrons, ofluxo de radiação secundária, é também uniforme, e é independente da densidade do meio, como também, da variação de densidade de ponto a ponto.

Estas condições são difíceis de serem atendidas, por causa dos efeitos da polarização em sólidos. As deficiências dos detectores de parede encorajaram os estudos de um contadores proporcionais sem paredes (Glass e Braby, 1969), que podem ser 
construídos usando eletrodos formadores de campo ou paredes de grade. O tamanho do detector de paredes de grade podem ser construídos tão pequeno quanto um cilíndrico de $1 \mathrm{~mm}$ de altura por $1 \mathrm{~mm}$ de diâmetro, capaz de simular sítios celulares tão pequenos como 10 nanômetros (Rayadurgam, 2005). Os limites do detector com eletrodos criadores de campo não são bem definidos, e o de paredes de grade não é verdadeiramente sem paredes (Wall-less).

Apesar de ser possível usar detectores sem paredes para simular diferentes tamanhos de sítios, seria mais fácil usar um detector de paredes. Contador proporcional de paredes é mais fácil de construir do que um sem paredes, ele tem uma estrutura mais robusta e menos ruído provocado pela vibração da parede, a câmara que contém o detector pode ser menor, e as simulações de Monte Carlo necessitam de menos tempo para gerar um campo uniforme em um detector de paredes. Mas, seu uso é prejudicado pelos chamados efeitos de parede, que são classificados em quatros tipos (vide fig. 3.2) (ICRU Report, 1983; Kellerer, 1971):

1. efeito raio delta - Uma partícula carregada entra a cavidade juntamente com um raio delta (evento duplo) (Fig. 3.2a). No caso real, a distância entre eles é bastante grande, que somente um deles pode entrar no sítio com densidade uniforme. Em uma estimação teórica (Kellerer, 1971) percebeu que o efeito de raios delta seria mais importante para partículas carregadas pesadas e para elétrons de energia alta. Para prótons com energias acima de $5 \mathrm{MeV}$, os eventos duplos têm freqüência de $15 \%$ em sítio de $1 \mathrm{~mm}$ de tamanho. Pode-se prever que para partículas carregadas pesadas com a mesma velocidade, esta freqüência seria muito maior, entretanto, o efeito sobre $y_{D}$ é muito menor do que sobre $y_{F}$. Isto ocorre porque uma partícula carregada pesada normalmente deposita muito mais energia que o raio delta. A maior fração de dose é ainda devido à partícula carregada pesada.

2. efeito de reentrada - Um elétron pode reentrar uma cavidade após já tê-la atravessado, devido a seu caminho inverso sinuoso (Fig. 3.2b). Os pontos de saída e reentrada podem estar tão distanciados que dificultam a sua reentrada no sítio com densidade uniforme. Isto somente é aplicado a elétrons porque seus traços são mais tortuosos que os de partículas carregadas, por exemplo.

3. efeito V - É o efeito, onde duas ou mais partículas carregadas produzidas em uma interação nuclear não-elástica entram na cavidade juntas, conforme mostra a figura 3.2c. A geometria neste efeito é similar ao efeito raio delta. 
4. efeito espalhamento - É o efeito em que uma partícula primária sem carga pode produzir duas partículas carregadas, que se encontram tão próximas, que não conseguem entrar na cavidade juntas, conforme mostra a figura $3.2 \mathrm{~d}$. No caso real, seus traços podem estar distanciados o bastante para que somente uma delas possa entrar o sítio com uma densidade uniforme. Este efeito é relevante para fótons e nêutrons.

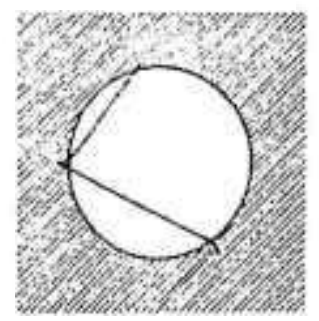

(a)

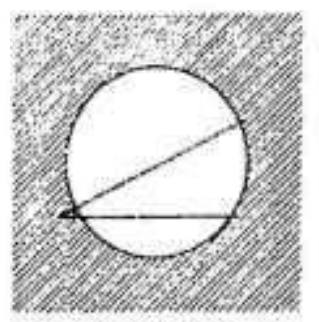

(c)
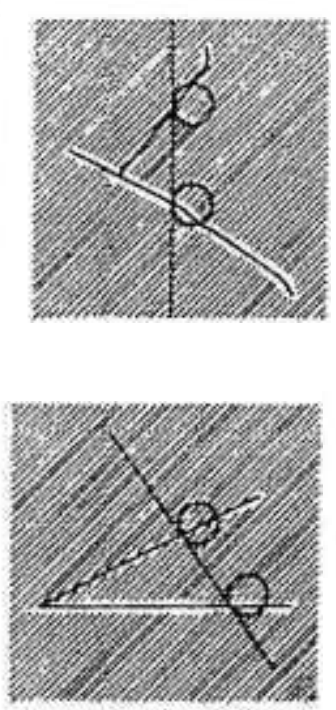
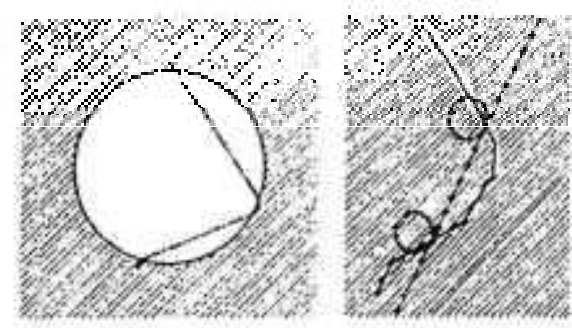

(b)

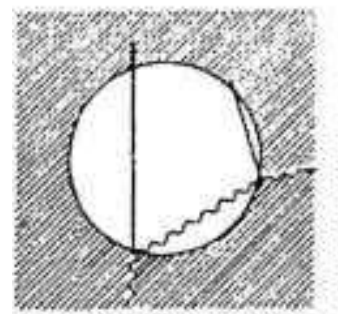

(d)

Figura 3.2 - Diagramas dos quatro tipos de efeitos de paredes. (a) Efeito raio delta, (b) Efeito reentrada, (c) Efeito V, e (d) Efeito espalhamento (ICRU report, 1983).

\subsubsection{2 - Simulação de um volume de tecido real em um contador proporcional}

Os contadores proporcionais equivalentes à tecido são constantemente requisitados em microdosimetria experimental. Nesses equipamentos, a pressão do gás que preenche a sua cavidade pode ser ajustada para que uma partícula carregada que atravessa o volume do contador, deposite neste, uma quantidade idêntica de energia, como se a partícula carregada estivesse atravessando um volume de tecido real de dimensões microscópicas. Essa situação é representada na Figura 3.3, onde dois volumes esféricos, um de tecido real e outro representando um volume de gás de um contador proporcional equivalente à tecido, sofrem depósitos de energia $E_{t}$ e $E_{g}$, por partículas carregadas que os atravessam. A energia $E_{\eta}$ do volume microscópico de tecido real é obtida através do produto entre o poder de freamento de massa de tecido, da densidade do tecido, $\rho_{t}$, e do 
comprimento do caminho que a partícula percorre enquanto atravessa o volume do tecido, $\Delta X_{t}$, ou seja,

$$
E_{t}=\left(\frac{1}{\rho} \frac{d E}{d x}\right)_{t} \rho_{\imath} \Delta X_{t}
$$

A energia depositada pela partícula quando atravessa o volume do gás, $E_{g}$, é também dada por,

$$
E_{g}=\left(\frac{1}{\rho} \frac{d E}{d x}\right)_{g} \rho_{g} \Delta X_{g}
$$

Se os dois eventos de deposição de energia são os mesmos, então podemos igualar as equações III.22 e III.23, com isso teremos,

$$
\left(\frac{1}{\rho} \frac{d E}{d x}\right)_{,} \rho_{t} \Delta X_{t}=\left(\frac{1}{\rho} \frac{d E}{d x}\right)_{g} \rho_{g} \Delta X_{g}
$$

Como o poder de freamento do tecido e o do gás equivalente à tecido são os mesmos, condição para a existência da equivalência de tecido, teremos a condição que garante a simulação de um volume de tecido real em um contador proporcional equivalente à tecido, ou seja,

$$
\rho_{t} \Delta X_{t}=\rho_{g} \Delta X_{g}
$$

Se existe uma igualdade entre o produto da densidade do gás e o diâmetro da cavidade do gás, e o produto do diâmetro do volume de tecido e a densidade média, a simulação do meio microscópico é realizada. 

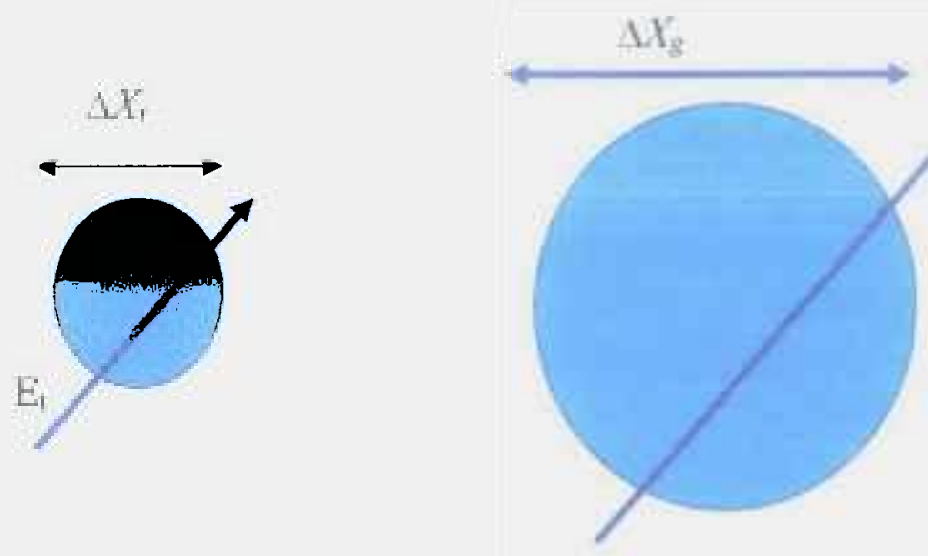

Figura 3.3 - Representação de uma simulação para sítio de tecido de tamanho microscópico, usando uma cavidade de gás equivalente à tecido.

Na prática, a simulação com o contador proporcional é realizada pela redução da pressão do gás, como consequeência a redução da densidade. A relação entre densidade e pressão pode ser obtida recorrendo a lei de gás ideal,

$$
p=\rho_{g} \frac{R \cdot T}{M}
$$

onde, $p$ é a pressão do gás, $\rho_{g}$ e a densidade do gás, $R$ é a constante do gás, $T$ é a temperatura e $M$ é a massa molar do gás. Da equação 3.25 , tem-se que

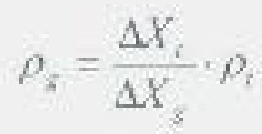

Substituindo este valor de $\rho_{g}$ da equação 3.27 na equação 3.26 , obtém-se,

$$
p=\frac{\Delta X_{t}}{\Delta X_{g}} \cdot \rho_{t} \cdot \frac{R \cdot T}{M}
$$

Quando se usa um gás puro como o propano, sem misturas, $M$ é a sua massa molar. Para a realização de uma simulação precisa de um volume microscópico de um tecido biológico é imprescindivel que o gás que preenche a cavidade do contador proporcional e a parede deste equipamento sejam equivalentes à tecido. Podemos citar 
como exemplo, que uma esfera de diâmetro de $1,27 \mathrm{~cm}$, a qual foi usada neste trabalho, preenchida com o gás propano à baixa pressão de $5,6 \mathrm{kPa}$ (42 Torr) é equivalente a uma esfera de diâmetro de $1,3 \mu \mathrm{m}$ de unidades de densidade do material. A dose absorvida é a mesma em ambas as esferas, mas o número de partículas carregadas por unidade de dose absorvida é multiplicada pelo quadrado da taxa obtida pela divisão entre o diâmetro do gás e o diâmetro do tecido, ou seja, por $\left(\left(\frac{\Delta X_{g}}{\Delta X_{t}}\right)\right)^{2}$.

\subsubsection{3 - Distribuição dos traços no interior da cavidade}

O contador proporcional equivalente à tecido é baseado na teoria de cavidade de Bragg-Gray. A medida da ionização em uma cavidade de gás produz a dose absorvida no interior do material da parede que circunda a cavidade. A espessura da parede pode ser escolhida de forma a obter-se indiretamente a radiação ionizante. $\mathrm{O}$ Equilíbrio de Partículas Carregadas (CPE) é obtido pela radiação de interesse. A espessura do material entre a parede da cavidade do contador e o volume sensível tem que ter pelo menos o alcance máximo das partículas carregadas secundárias, mas o suficiente para evitar a redução da fluência ao máximo possível. O CPE existe quando alguma partícula carregada de um dado tipo e energia deixa o volume sensível e é substituída por outra de mesma energia no interior desse volume, em função de valores esperados. Para $200 \mathrm{MeV}$ de radiação nêutron, por exemplo, que produz prótons de recuo como partícula carregada secundária, a espessura mínima será de cerca de $23 \mathrm{~cm}$ de plástico equivalente à tecido (Shonka A-150), que é o alcance para prótons de $200 \mathrm{MeV}$, nesse material.

No processo de transferência de energia ocorrido, no interior de um volume irradiado, é necessário reconhecer quatro classes de traços de partículas (Caswell e Coyne, 1989), para cada um dos tipos de partícula carregada secundária, dependendo da localização em relação ao volume sensivel, onde foram produzidas. Os tipos de traços são citados a seguir e suas representações estão na figura 3.4.

1. Partículas originadas no interior do volume podem perder toda a sua energia no volume (insiders). 
2. Particulas originadas no interior do volume podem sair do volume antes de perder toda a sua energia (starters).

3. Particulas originadas fora do volume podem entrar no volume e parar no interior do volume (stoppers).

4. Particulas originadas fora do volume podem cruzar o volume, depositando apenas a parte da energia no volume (crossers).

5. Partículas originadas fora do volume podem não entrar no volume em uma linha reta, mas por espalhamento ou por seus raios delta.

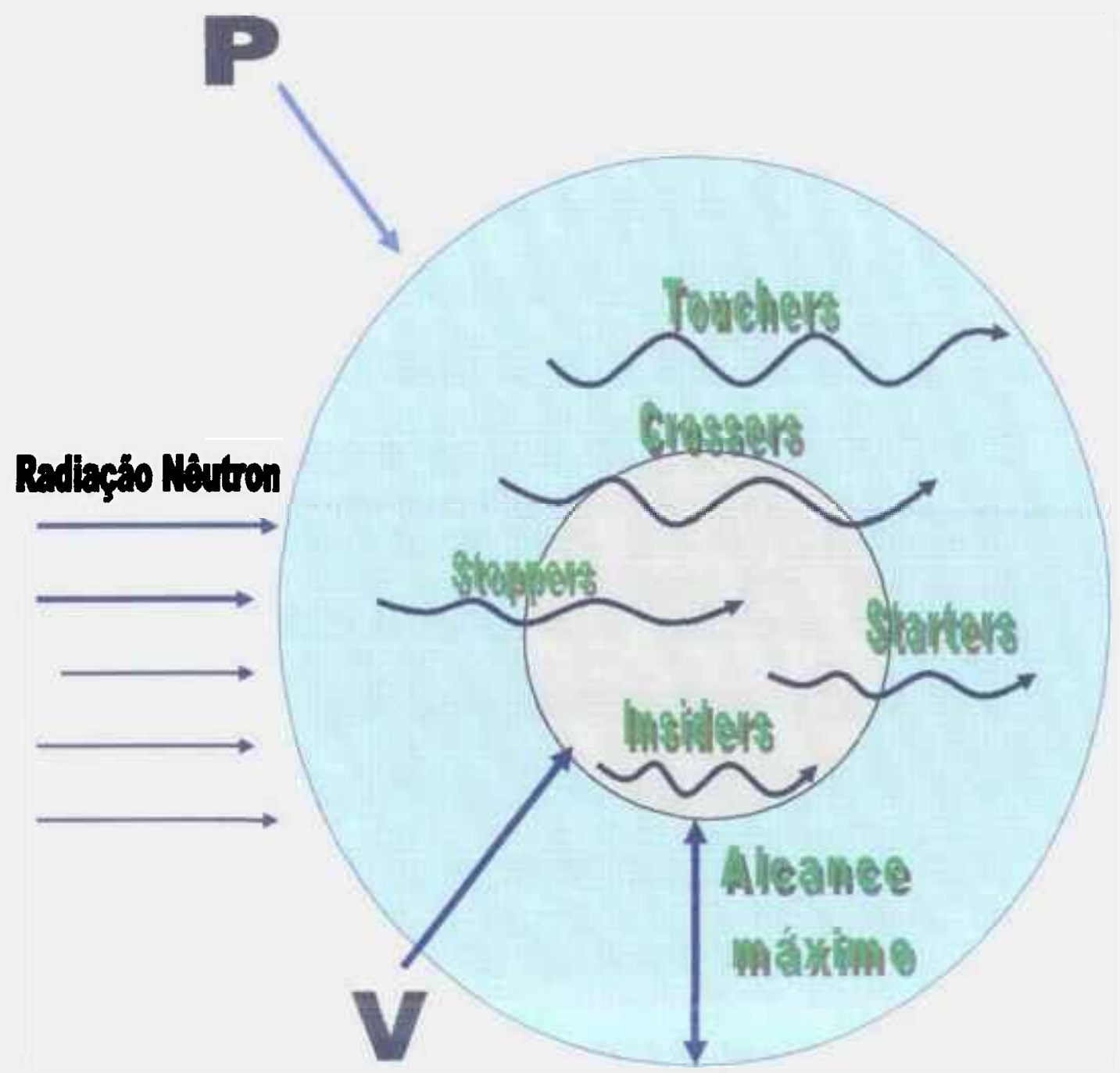

Figura 3.4 - Representação da classificação das interações de traços com o volume sensivel (V) (após Caswell e Coyne, 1989), mostrando a parede da cavidade do detector $(\mathrm{P})$. 
Uma das condições essenciais do aparelho Bragg-Gray, é que o tamanho da cavidade não deve modificar o espectro da partícula de energia secundária produzida pelas interações do campo de radiação primária com o material da parede da cavidade.

Na Figura 3.5 são apresentadas as contribuições de cada um dos traços, para cavidades esféricas de 1 a $32 \mu \mathrm{m}$ (Caswell e Coyne, 1976). Para a cavidade de $1 \mu \mathrm{m}$ os crossers estão tão próximos do total, que eles são confundidos com o gráfico, enquanto os insiders são negligenciados.

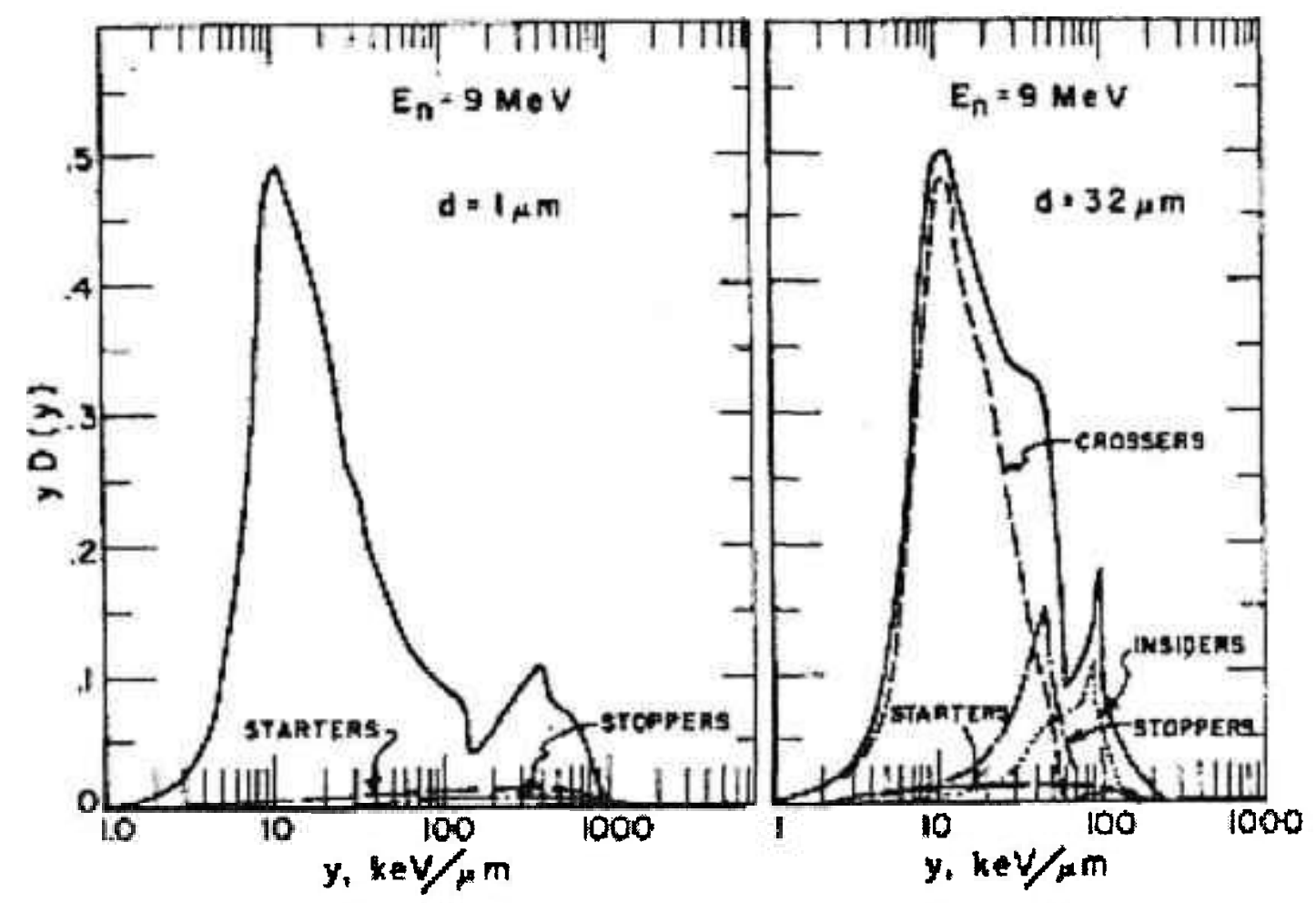

Figura 3.5 Cálculo de distribuição de deposição de energia de nêutrons de $9 \mathrm{MeV}$ em tecido para cavidades esféricas de 1 e $32 \mu \mathrm{m}$, mostrando as contribuições dos insiders, starters, stoppers e crossers (após Caswell e Coyne, 1976)

\subsubsection{4 - Espectros em Microdosimetria}

Uma característica da maioria das distribuições microdosimétricas é o fato que ambas energia lineal, $\mathrm{y}$, e sua distribuição, $\mathrm{f}(\mathrm{y})$, apresentarem uma grande variação de valores de espectros. Normalmente a função de distribuição de energia lineal, $\mathrm{f}(\mathrm{y})$, tem valores que alcançam mais de 8 ordens de magnitudes. Por esta razão, a representação linear, y x f(y), é raramente empregada (Rossi e Zaider, 1996). Conforme pode ser 
observado na figura 3.6, o gráfico de espectro de nêutrons rápidos com uma potência de reator de pesquisa de $0,5 \mathrm{~kW}$, usando uma cavidade esférica de um contador proporcional equivalente à tecido de $1,3 \mu \mathrm{m}$. Como pode ser visto, pouca informação pode ser obtida através dessa representação.

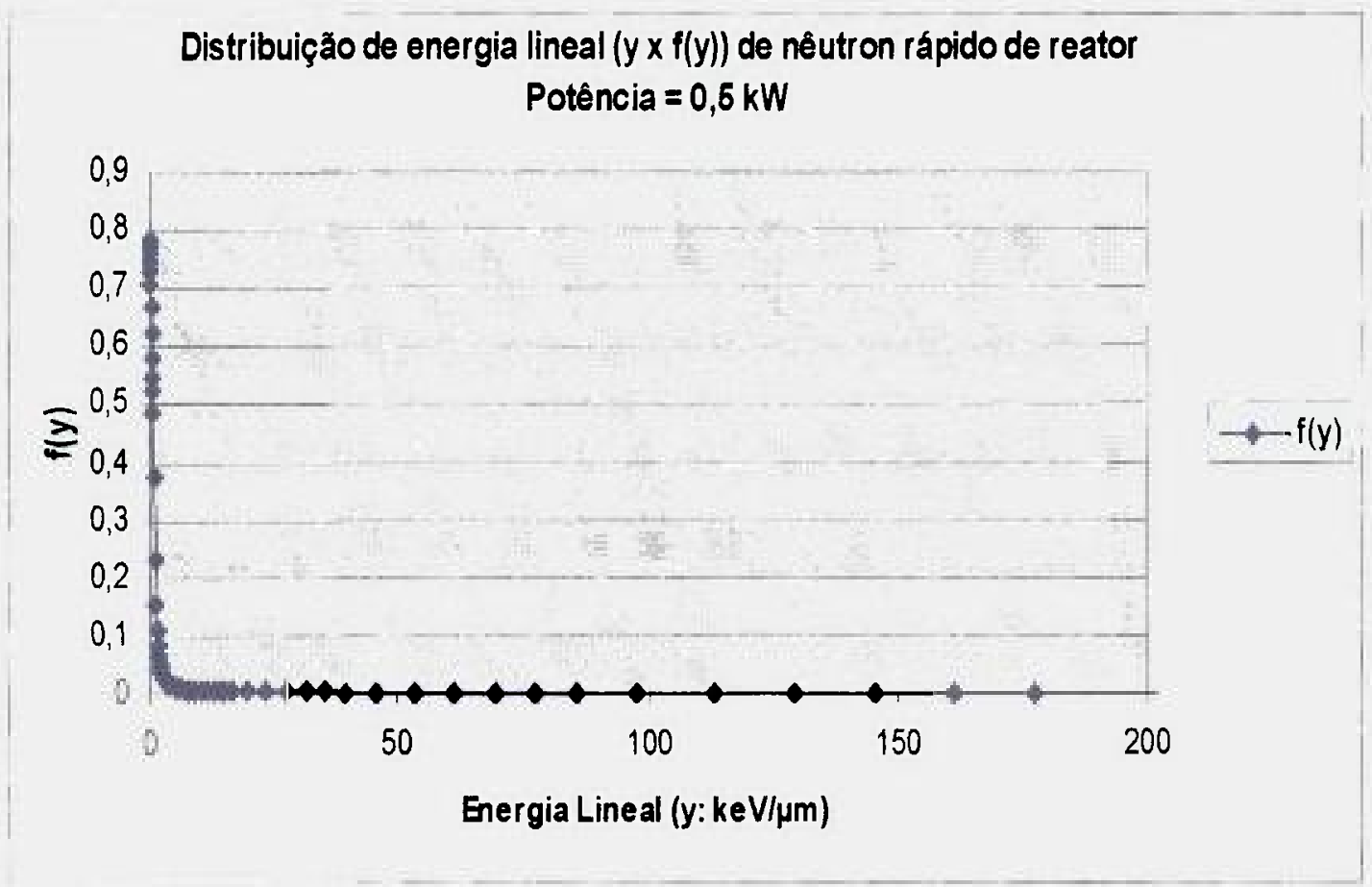

Figura 3.6 - Representação linear de y x $\mathrm{f}(\mathrm{y})$ de radiação de nêutrons rápidos de reator de pesquisa com potência de $0,5 \mathrm{~W}$, em uma cavidade esférica de $1,3 \mu \mathrm{m}$ de unidades de densidades de tecido.

Outra representação que foi tentada para o espectro de y x $f(y)$ foi log-log, mas se mostrou insuficiente para a extração de dados sobre a deposição de energia no interior da matéria. A figura 3.7, apresenta o gráfico $\log (\mathrm{y}) \times \log (\mathrm{f}(\mathrm{y}))$ para uma radiação de nêutrons rápidos de reator com potência de $0,5 \mathrm{~kW}$ e energia em torno de $0,5 \mathrm{MeV}$. Pode-se ver que há uma amplitude de 7 décadas para este espectro na frequiencia de distribuição de freqüência, $\mathrm{f}(\mathrm{y})$

As representações de espectros microdosimétricos mais comumente usadas são $\log (\mathrm{y}) \times \mathrm{yf}(\mathrm{y}) \mathrm{e} \log (\mathrm{y}) \times \mathrm{yd}(\mathrm{y})$ (vide figuras 3.8, e 3.9). Nesses dois gráficos pode ser avaliada a deposição de energia devida a cada tipo de radiação. O primeiro representa a distribuição de frequêencia de energia lineal e o outro a distribuição de dose de energia lineal. 


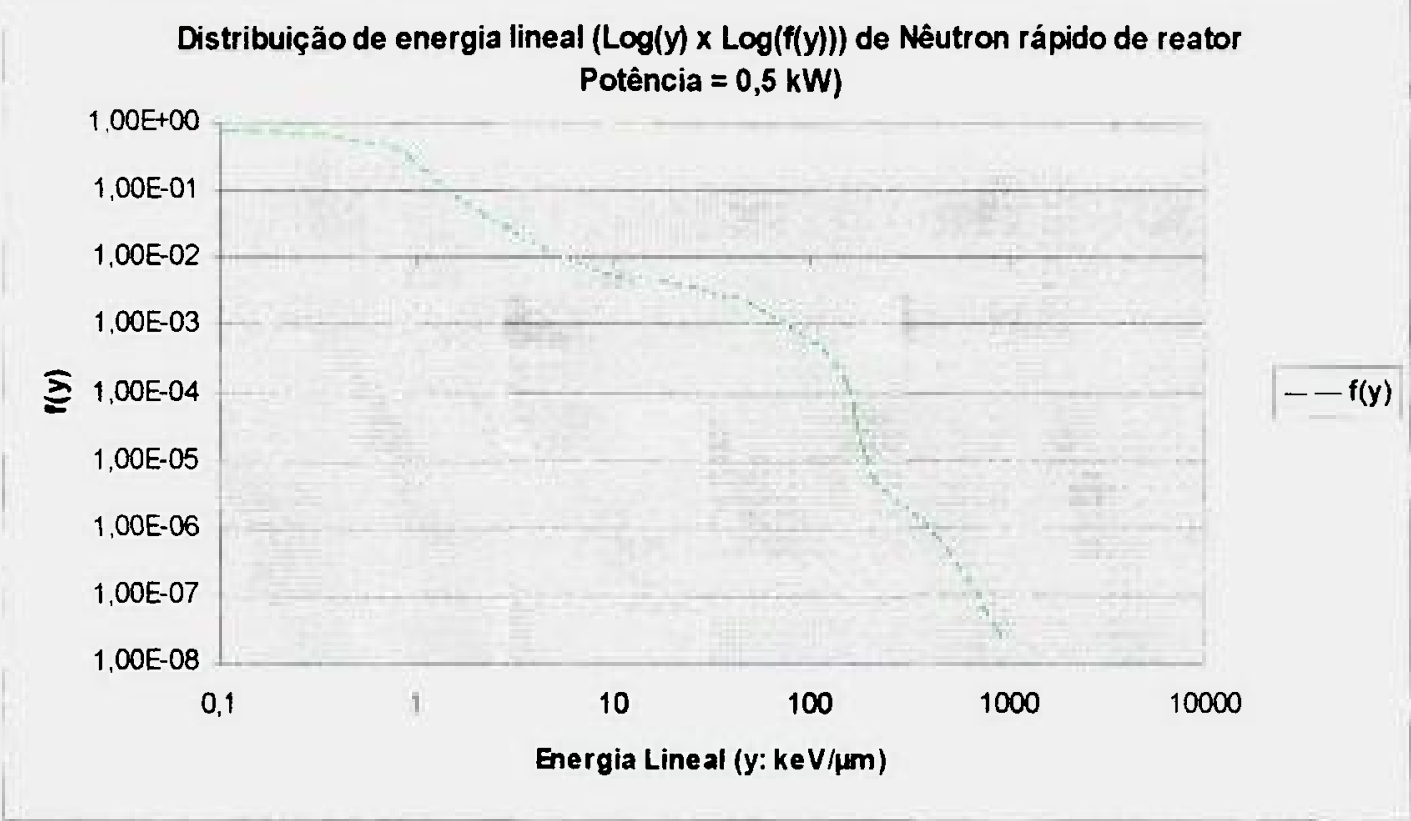

Figura 3.7 - Representação $\log (\mathrm{y}) \times \log (\mathrm{f}(\mathrm{y}))$ de radiação de nêutrons rápidos de reator de pesquisa com potência de $0,5 \mathrm{~W}$, em uma cavidade esférica de $1,3 \mu \mathrm{m}$ de unidades de densidade de tecido.

Distribuição de freqüência de energia lineal ( $\mathrm{y} \times \mathrm{y} f(y))$ de Néutron rápido de reator - Poténcia $=0.5 \mathrm{~kW}$

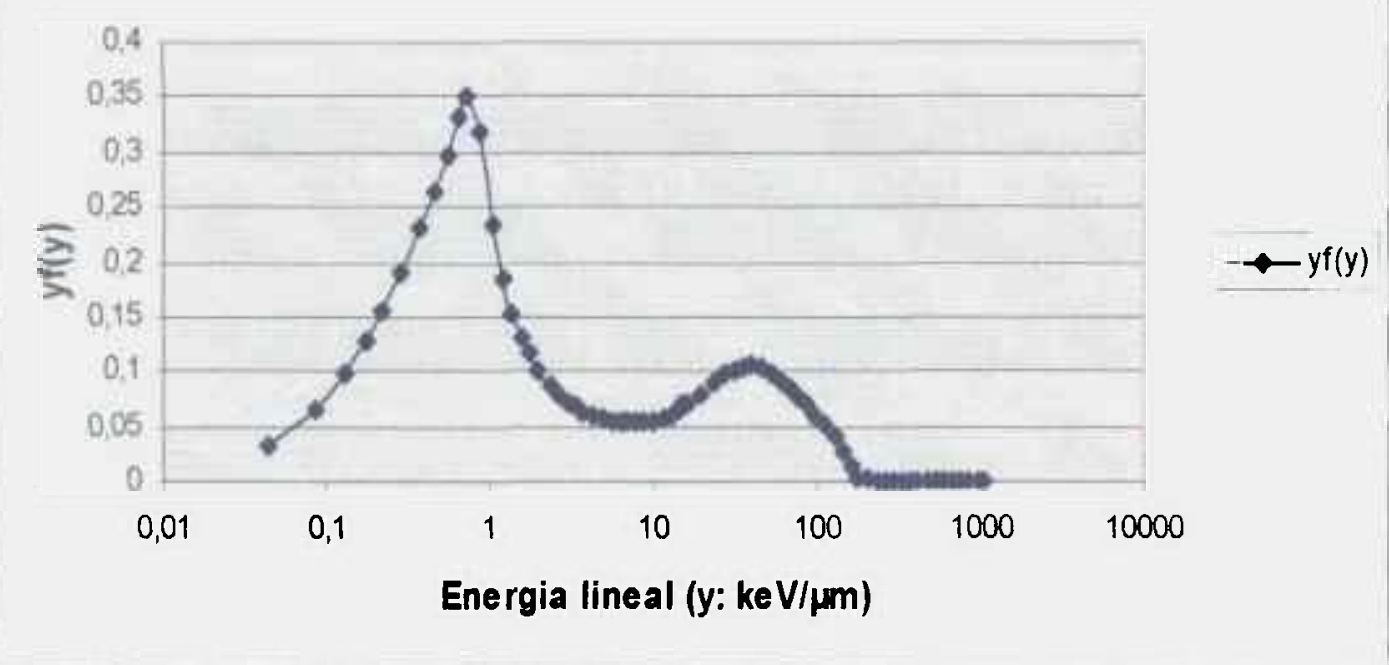

Figura 3.8 - Representação semi- $\log , \log (\mathrm{y})$ x yf(y) de uma distribuição de freqüência de energia lineal, de radiação de nêutrons rápidos de reator de pesquisa com potência de 0,5 $\mathrm{kW}$, em uma cavidade esférica de $1,3 \mu \mathrm{m}$ de unidades de densidade de tecido. A área sob a curva em uma variação de y é proporcional à fração de eventos nesse intervalo. 
Distribuição de dose de energia lineal $(y \times$ yd $(y))$ de nêutron rápido de

reator - Potência $=0.5 \mathrm{~kW}$

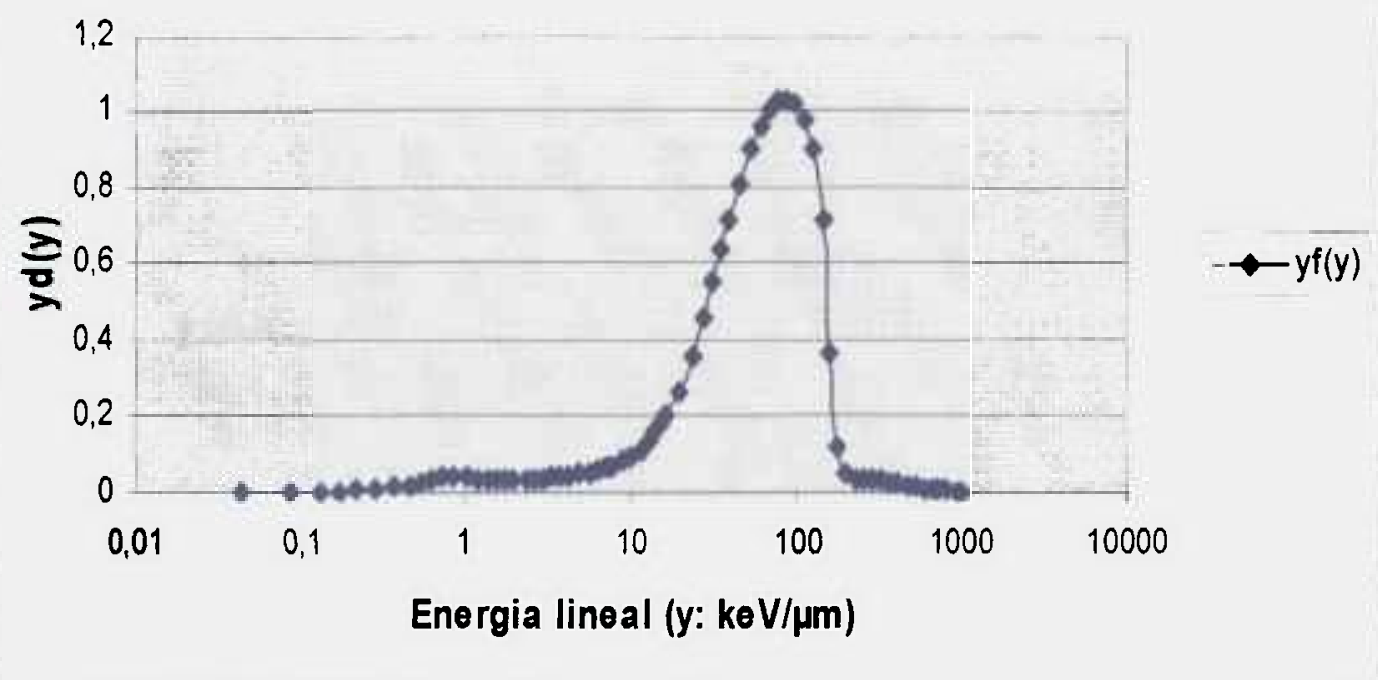

Figura 3.9 - A representação semi- $\log , \log (\mathrm{y})$ x yd(y) da distribuição de dose, d(y), de radiação de nêutrons rápidos de reator de pesquisa com potência de $0,5 \mathrm{~W}$, em uma cavidade esférica de $1,3 \mu \mathrm{m}$ de unidades de densidade de tecido. Note que a ordenada é yd(y). A área sob a curva em uma variação de y é proporcional à fração da dose nessa variação.

Em um gráfico $\log (\mathrm{y})$ x yf(y) a área sob a curva delimitada por dois valores de y quaisquer, é proporcional à fração de eventos nesta extensão (Fig. 3.8). Este gráfico é comumente usado para representar a freqüência de eventos. Já em um gráfico $\log (\mathrm{y}) \mathrm{x}$ $\mathrm{yd}(\mathrm{y})$, a área sob o curva delimitada por dois valores de y quaisquer é proporcional à fração de dose entregue pelo evento com energia lineal nessa variação (Fig. 3.9). Este gráfico é usado para representar a distribuição de dose de energia lineal.

A densidade de probabilidade de dose, $\mathrm{d}(\mathrm{y})$, é dada por,

$$
d(y)=\frac{y f(y)}{y_{F}}
$$

onde $y_{F}$, como já foi mostrado, é a freqüência média de energia lineal. E é o primeiro momento de y. Ou seja,

$$
y_{F}=\bar{y}=\int y f(y) d y
$$

A taxa entre o segundo e o primeiro momento de $y, y_{D}$, é chamada de dose média de energia lineal, e é dada por, 


$$
y_{D}=\frac{y^{2}}{y}=\frac{1}{y_{F}} \int y^{2} f(y) d y=\int y d(y) d y
$$

Para a visualização de cada diferente representação, se recorre a um importante recurso, que é a normalização. Ela nos permite fazer convenientes comparações de distribuições, proveniente de diferentes medidas.

Por definição, a densidade de probabilidade, $f(y)$, é normalizada a um evento de deposição de energia (ICRU Report 36, 1983):

$$
\int_{0}^{\infty} f(y) d y=1
$$

E similarmente,

$$
\int_{0}^{\infty} y d(y) d y=1
$$

Estas normalizações poderiam permanecer inalteradas, quando $f(y)$ e $y d(y)$ são desenhadas sobre uma escala logarítmica de y. Se y é o valor numérico de y, Então, o linear, logaritmo natural, e o diferencial logarítmico de base 10 , são relacionados por:

$$
\begin{gathered}
f(y) d y=y f(y) d(\ln y)=(\ln 10) y f(y) d(\log y) \\
e \\
d(y) d y=y d(y) d(\ln y)=(\ln 10) y d(y) d(\log y)
\end{gathered}
$$

Subdividindo a escala logarítmica de y em B incrementos por década, tal que o enésimo valor de y seja,

$$
y=y_{0} \cdot 10^{n / B}
$$


onde $y_{i}$ é o menor valor de y que tem que ser considerado no gráfico. então o incremento logarítmico de y será,

$$
\Delta(\log y)=\frac{1}{B}
$$

Se o número, B. de incrementos por década é grande o bastante, que a diferença entre $\mathrm{d}(\log y)$ e $\Delta(\log \mathrm{y})$ pode ser negligenciada, então.

$$
\int_{0}^{\infty} f(y) d y \approx \sum_{i=0}^{\infty} \frac{\ln 10}{B} y_{i} f\left(y_{i}\right)=1
$$

Assim. a normalização pode ser escrita como:

$$
\int_{0}^{*} y f(y) d(\ln y) \approx \frac{\ln 10}{B} \sum_{i=1}^{x} y_{i} f\left(y_{i}\right)=1
$$

e. similarmente.

$$
\int_{y} y d(y) d(\ln y) \approx \frac{\ln 10}{B} \sum_{i=1}^{\infty} y_{i} d\left(y_{i}\right)=1
$$

Pode-se simplificar, de forma significativa o problema, aplicando uma normalização numérica.

Fazendo, $x_{i+1 ; 2}$ e $y_{i-1 / 2}$. indicar as médias geométricas do intervalo $y_{1+1}-y_{1}$ e $y_{1}-y_{t-1}$, respectivamente. então teremos.

$$
\int_{i}^{\prime} f(y) d y=\sum_{i=0}^{\infty} f\left(y_{i}\right)\left(y_{i+1: 2}-y_{i-1 / 2}\right)=\sum_{i=0}^{3} y_{i} f\left(y_{i}\right)\left(10^{1 / 2 / 3}-10^{-1 / 2 / i}\right)=1
$$

e. para a distribuição de dose em yd(y), quando calculado numericamente, teremos. 


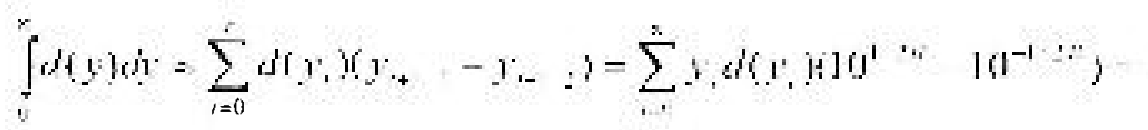

\subsubsection{5 - Tipos de Contadores Proporcionais Equivalentes à Tecido}

Alguns tipos de contadores proporcionais equivalentes à tecido são empregados para a realização de medidas microdosimétricas. A maioria dos contadores em uso atualmente são variações do contador original desenvolvido por Rossi. O desenho de um contador proporcional para experimentos microdosimétricos precisa ser preparado para receber várias modalidades de radiação com as quais ele será irradiado. O material mais usado em microdosimetria é o plástico equivalente à músculo, o qual é designado de A-150 (ICRU Report. 1983). Atualmente. o Shonka A-1 50 é o preferido na construção dos contadores proporcionais.

Quanto à forma, os contadores esféricos são os mais utilizados. Principalmente pela suạ completa simetria com respeito à radiação isotrópica ou direcional o que os torna uma escolha lógica por causa da deficiência de conhecimento ou independência de fatores geométricos na interação da radiação com estruturas biológicas.

Outra forma de grande importância é a cilindrica. a qual tem a rantagem de ser mais simples de se desenhar, além de mais fácil de se construir.

Um tipo de contador proporcional equivalente à tecido cilíndrico, com um desenho simples, foi testado com sucesso em experimentos usando raios gama e nêutrons com 14,8 MeV de energia (Martin et al, 2002). Sua simplicidade reside no fato de dispensar o uso de eletrodos formadores de campo ou de hélices. Este equipamento mostrou-se eficiente para o uso em campos de radiação misto, tais como aqueles produzidos em equipamentos de irradiação de nêutron e também para os propósitos de aplicações em radioproteção e radioterapia. Além dessas vantagens. ele permitiu medir variações completas de eventos de deposição de energia para radiações gama. fazendo dele una escolha prática para medidas microdosimétricas. 
A intensidade do campo elétrico em um ponto $r$, dentro de um detector cilíndrico dépende do diâmetro do anodo, do tamanho do detector, da tensão aplicada. é dado pela ralação (Knoll, 2000),

$$
E(r)=V / r(\ln [b / a])
$$

onde:

$$
\begin{aligned}
& V=\text { tensão aplicada entre o anodo e o catodo } \\
& a=\text { raio do fio do anodo } \\
& b=\text { raio interno do catodo. }
\end{aligned}
$$

Além da escolha da forma do contador a ser usado, outra escolha a ser feita. quando se pensa em realizar um experimento em microdosimetria, é se ele será com paredes (Walled), ou sem paredes (Wall-less). O contador, chamado de parede. já teve apresentadas neste trabalho as suas limitações de uso (vide seção 3.4). O outro. sem paredes. mais usado atualmente. foi muito bem comentado no trabalho de Glass e Braby (Glass e Braby. 1969). No qual os autores desenvolvem um novo desenho de contador proporcional que permita que a interface entre sólido e gás pudesse ser removida da vizinhança da região ativa do detector.

\subsubsection{1 - Contador Proporcional Equivalente à Tecido com paredes}

Um exemplo de um tipo de contador esférico com paredes é mostrado na Figura 3.10. Este contador utiliza uma hélice cilindrica para suprir uma multiplicação uniforme ao longo do comprimento do fio. Esse contador é do tipo Rossi e é do modelo que mantém o fluxo de entrada e saida de gás de forma contínua. procurando dessa forma reduzir os efeitos da contaminação do gás, que pode interferir de forma bastante expressiva nos resultados dos experimentos. Este tipo de contador proporcional quase não é usado nos dias atuais, sendo substituído por outros modelos mais modernos e mais eficientes. um desses é o modelo que foi usado nos experimentos realizados nesse trabalho. 


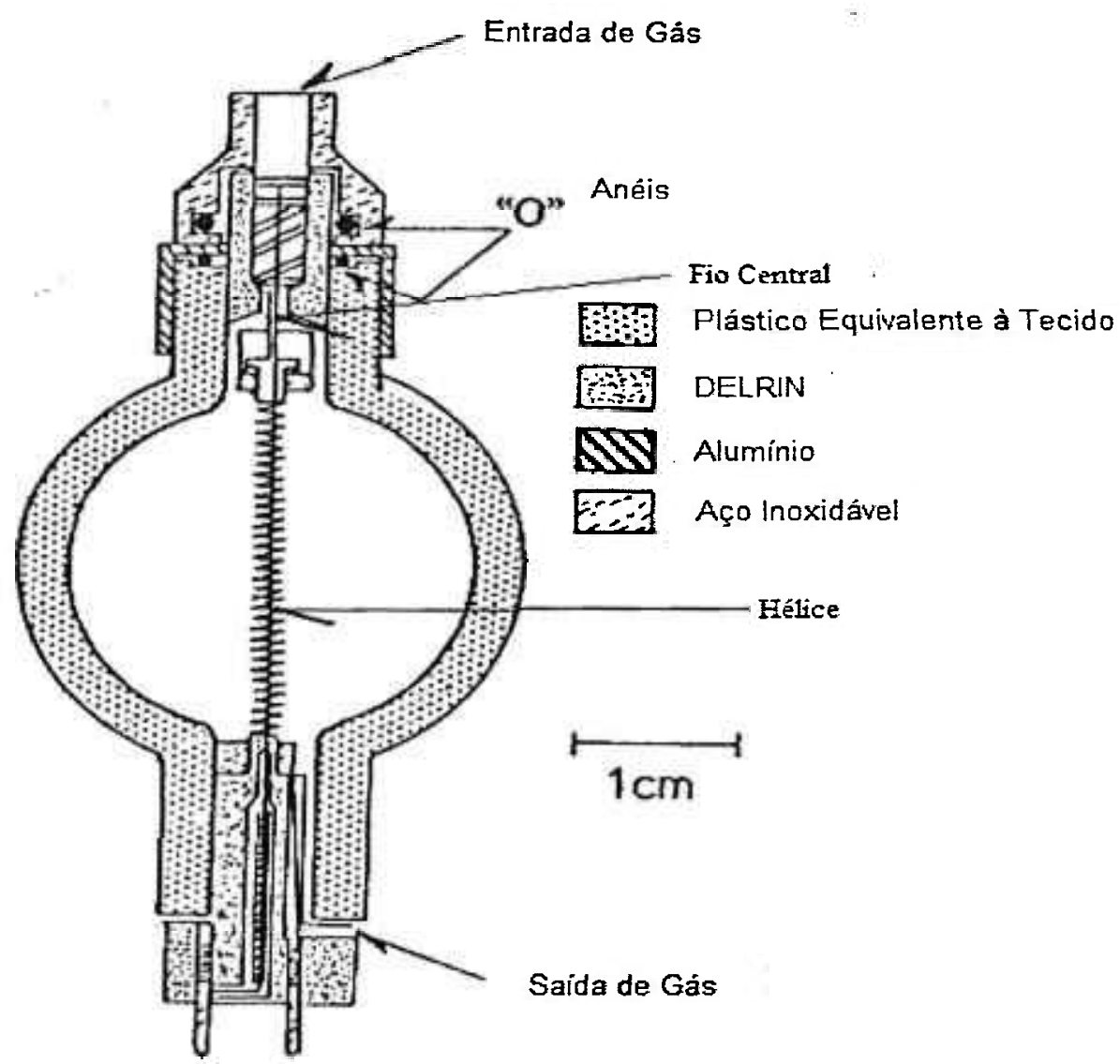

Figura 3.10 - Contador de Parede Sólida muito usado em medidas microdosimétricas.

A hélice é mantida em um potencial positivo em relação à casca mais externa, assim os elétrons são coletados através da região esférica. $O$ fio central é positivo em relação à hélice. Uma tensão é mantida no fio central por meio de uma mola no topo. Uma entrada de gás e uma saída são providenciadas, para um sistema de fluxo de gás.

\subsubsection{2 - Contadores proporcionais equivalente à tecido sem-paredes}

O contador sem-paredes consiste de um tipo montado em uma casca esférica de proteção. Um contador sem-paredes ainda tem uma parede, mas a parede fica distante o bastante para não interferir no volume sensível para que o equilíbrio de radiação seja estabelecido nessa região, sendo que o tamanho da esfera circundante protetora será determinado pelo tipo e energia da radiação. Contadores sem-paredes esféricos são frequentemente construídos usando uma grade de plástico equivalente à tecido moldado para o limite esférico (Figura 3.11). 


\subsection{1 - Contador proporcional equivalente à tecido sem-paredes esférico.}

A estrutura da grade è moldada em plástico equivalente à tecido. Ele é montado dentro de uma casca esférica de plástico equivalente à tecido. $O$ diâmetro da casca esférica é quatro vezes o diâmetro do contador. Tais contadores são equipamentos práticos sem paredes usados em várias modalidades de radiação.

Outro tipo de contador proporcional equivalente à tecido é apresentado na figura 3.12, que é o contador sem-paredes esférico não-metálico. Ele é desenhado para evitar as distorções de espectros de energia lineal de fótons com energias entre 20 e 100 $\mathrm{keV}$, que são provocadas, geralmente, pela presença do aço inoxidável usados nos eletrodos.

Como o nome já diz, não é usado metal em sua construção. Importante, principalmente, para experimentos com fótons de baixa energia. Ele possui um dupla hélice (Rossi et al, 1980) (ICRU Report, 1983).

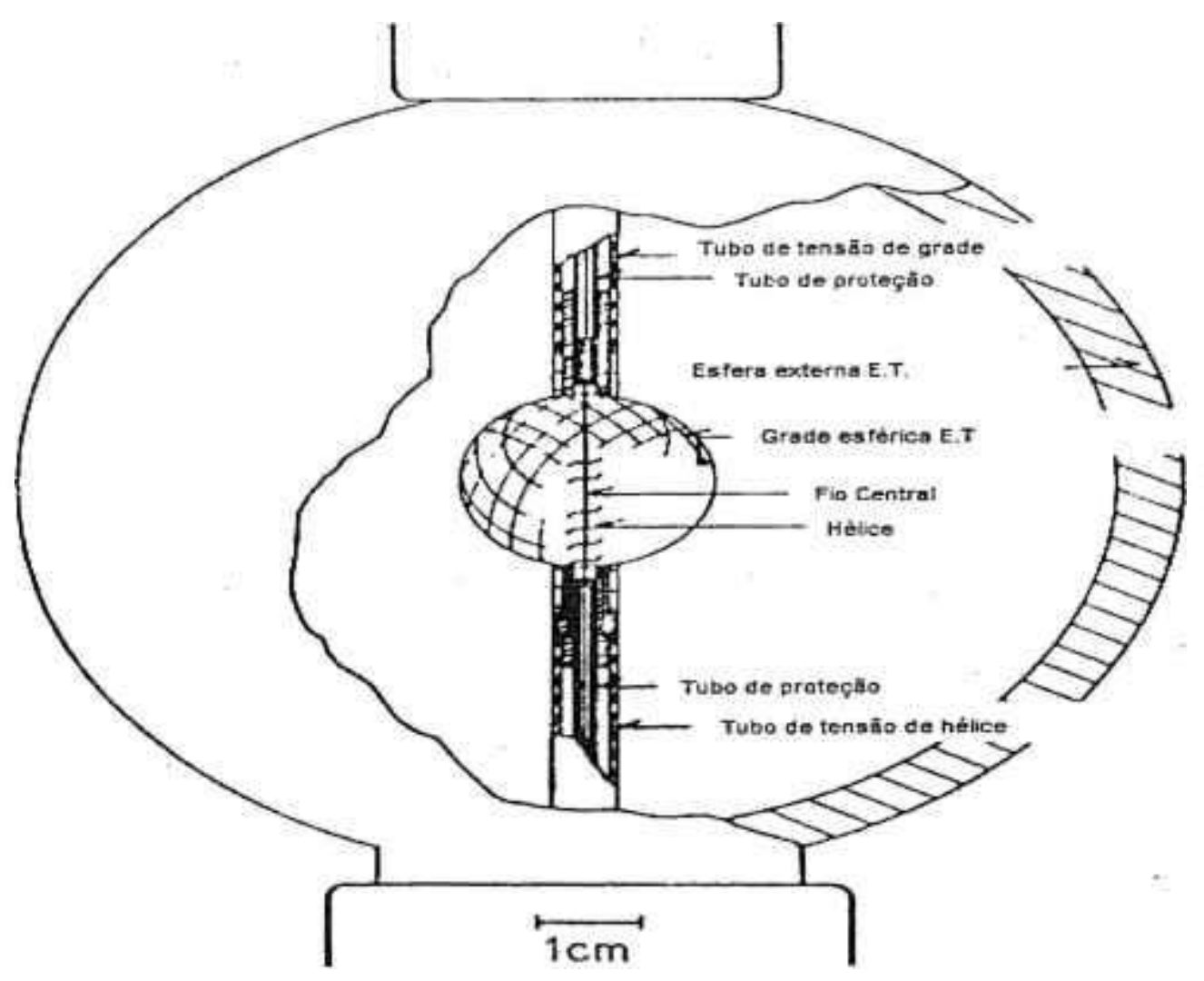

Figura. 3.11 Vista interior de um Contador de Grade sem Paredes. 


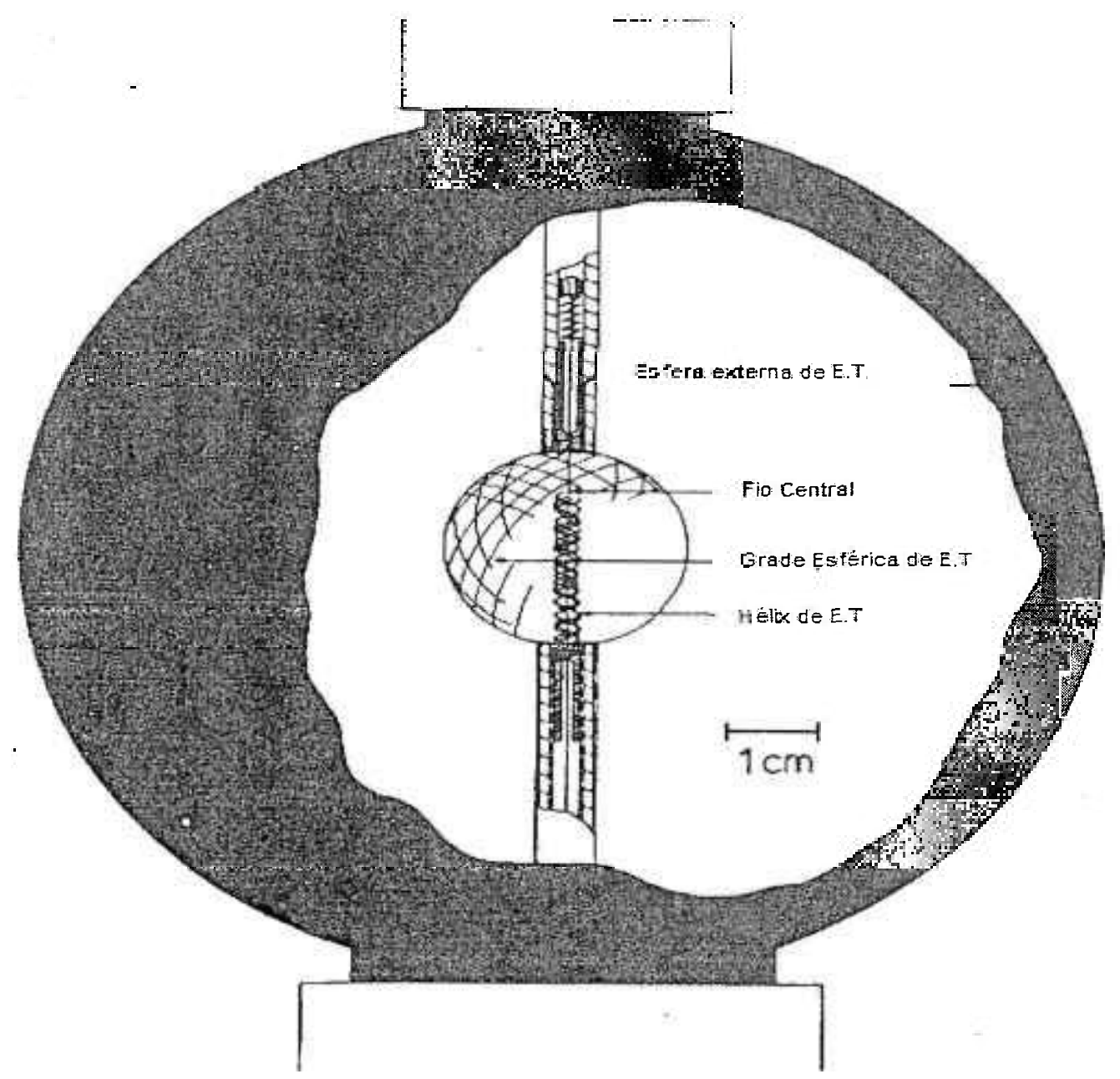

Fig. 3.12 Vista interior de um Contador não Metálico.

\subsubsection{3 - Contador proporcional equivalente à tecido cilíndrico}

$\mathrm{Na}$ figura 3.13 é mostrado um tipo de contador cilíndrico, usado em microdosimetria com objeto simulador de água e de fótons, com diâmetro de hélice de $0,16 \mathrm{~cm}$, o qual define o volume de coleta. O comprimento do diâmetro do volume de coleta do final dos tubos de campos é duas vezes o da hélice. Todo o contador é colocado dentro de um tubo plástico equivalente à tecido incluindo o pré-amplificador e os tubos para as vias de gás, o tubo é impermeável e o tamanho do equipamento é relativamente 
pequeno, de cerca de $3 \mathrm{~cm}$ de diâmetro, fazendo com que seja profícuo para aplicações em simuladores de água.

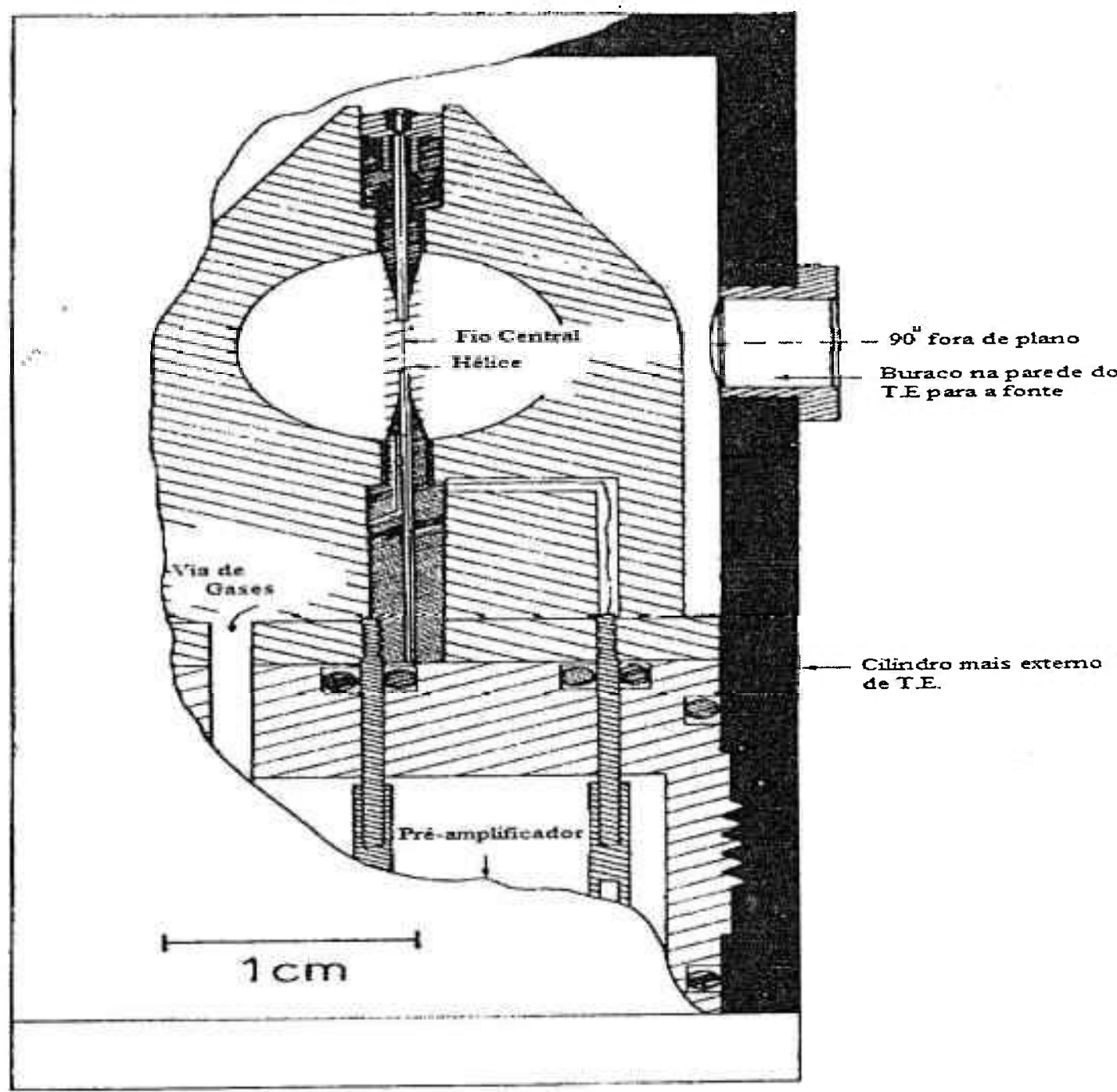

Figura 13 - Esquema de um Contador Proporcional Equivalente à Tecido Cilíndrico de $0,16 \mathrm{~cm}$. (ICRU 36, 1983) 


\subsection{5 - Tipos de Amostras}

Várias amostras biológicas podem ser usadas em microdosimetria, como por exemplo, DNA em solução para comparar os efeitos diretos e indiretos das radiações de energias alta e baixa no dano do DNA (Stanton e outros, 1990). Células mamárias foram usadas para avaliar a distribuição de deposição de energia em regiões micrométricas (Wilson e outros, 2001). Foram avaliadas, também, células cancerosas humanas, para estudar a radioimunoterapia com emissores de partículas alfa (Kvinnsland, Stokke e Aurlier, 2001). Células de intestino delgado foram usadas para a investigação microdosimétrica na eficiência biológica relativa ( Tilikidis e outros, 1994). Vários outros trabalhos com diferentes amostras como, células de pulmão, músculo e de osso são citados na literatura (ICRU Report-36).

\section{2 - Radiação de Nêutrons}

\subsection{1 - Fontes de nêutrons}

Os nêutrons são produzidos naturalmente por raios cósmicos, e também artificialmente de outras três formas:

- Reações com Radionuclídeos $((\alpha, n)$ e $(\gamma, n))$ ou fissão espontânea.

- Aceleradores Lineares.

- Re-processamento de combustíveis nucleares.

Os nêutrons são classificados de acordo com seus intervalos de energia em:

- Térmicos: En $\leq 0,5 \mathrm{eV}$;

- Intermediarios: $0,5 \mathrm{MeV} \leq \mathrm{En}<1,0 \mathrm{MeV}$;

- Rápidos: $1 \mathrm{MeV} \leq \mathrm{En}<10 \mathrm{MeV}$;

- Relativísticos: $\mathrm{E}_{\mathrm{n}} \geq 10 \mathrm{MeV}$; 


\subsection{2 - Interação do nêutron com a matéria}

Dentre os principais processos de interação estão:

\section{- Espalhamento elástico (n,n)}

Acontece pela interação dos nêutrons com núcleos pesados. O nêutron é momentaneamente capturado pelo núcleo e re-emitido com menor energia, deixando o núcleo alvo em estado excitado. O limiar de energia para esse processo é de aproximadamente $4 \mathrm{MeV}$.

Em processos $(n, n \gamma)$ a energia de excitação é liberada pelo núcleo através da emissão de um raio gama, enquanto que em processos ( $\left.n, n^{n}\right)$ o núcleo permanece durante certo tempo em um estado metaestável.

\section{- Captura radioativa $(\mathrm{n}, \gamma)$}

É um processo terminal, onde os nêutrons são completamente freados. A captura radioativa de nêutrons térmicos é possível em quase todos os nuclídeos. Nesse processo, o núcleo alvo captura o nêutron incidente e forma um núcleo composto em estado excitado. A energia de excitação pode ser liberada pela emissão de um ou mais raios gama.

A seção de choque para a captura radioativa é normalmente inversamente proporcional à velocidade do nêutron para energias acima de $0,025 \mathrm{eV}$.

- Reações não-elásticas (n, 2n), (n.p), (n,d), (n,a), (n,t), (n, ap)

Nestes processos o nêutron é capturado pelo núcleo alvo, que emite partículas carregadas como prótons, dêuterons, alfa, e trítios, para se estabilizar.

Como essas partículas precisam superar a barreira de potencial Coulombiano, os nêutrons devem possuir energias altas. Para energias acima de $10 \mathrm{MeV}$, podem ocorrer reações $(n, 2 n)$. 
Essas reações não ocorrem de maneira uniforme com a energia do nêutron, apresentando ressonâncias.

- Fissão $(\mathbf{n}, \mathbf{f})$

A interação de nêutron com materiais físseis provoca a formação de um núcleo composto que se divide em dois fragmentos de fissão, emitindo um ou mais nêutrons.

\section{- Fragmentação}

Neste caso, o núcleo bombardeado com nêutrons de energias iguais ou superior a $20 \mathrm{MeV}$ é fracionado em várias partículas e fragmentos nucleares.

\subsubsection{1 - Interação do nêutron com moléculas - Energia lineal}

Sabe-se que o nêutron é uma partícula sem carga e por isso quando irradia um corpo qualquer ele não interage de forma coulombiana com os átomos do material irradiado, como fazem partículas carregadas como prótons e elétrons, por exemplo. Se ele não se chocar com alguma molécula no interior do material que ele está atravessando, ele pode sair do corpo sem realizar nenhuma transmissão de energia. Quando o nêutron se choca diretamente com uma molécula, ele geralmente produz, principalmente, prótons de recuo, que muitas vezes chega a ser mais de $80 \%$ das partículas carregadas secundárias produzidas. O restante é geralmente radiação gama, partículas pesadas de recuo e radiação alfa. Mas como a interação entre nêutron e a matéria é dependente da quantidade da energia transmitida e da composição do material do corpo interagente, nem sempre é o próton de recuo que prevalece como resultado da interação.

Para energias de radiação de nêutrons acima de $15 \mathrm{MeV}$, a principal partícula secundária após a interação é o íon pesado, que excede suavemente o pico do próton de recuo entre 100 e $150 \mathrm{KeV} . \mu \mathrm{m}^{-1}$, além de dominar a contribuição na dose média de energia lineal, yD (ICRU REPORT 36, 1983). 
A radiação gama está invariavelmente associada a nêutrons. Sempre, quando nêutrons são gerados em uma reação nuclear que não envolve prompt, emissão de raios gamas atrasados, fótons gama são produzidos como resultado da captura de nêutrons dentro do ambiente dos aceleradores e blindagens, por exemplo, e quase todos os aceleradores emitem raios $\mathrm{X}$ gerados internamente por elétrons de energia alta ( Rossi e Zaider, 1996).

Apesar do kerma do fóton ser menor do que o do nêutron, a taxa de contagem devido a elétrons pode ser substancial, porque para kermas iguais, o número de elétrons é até 100 vezes maior. A subtração de pulsos de elétrons, que é maior quando a radiação gama é emitida na produção de nêutrons, em fissões, por exemplo, tem sido feita de várias formas, inclusive utilizando o espectro do ${ }^{60} \mathrm{Co}$. A mudança do espectro da energia lineal de nêutron de acordo com a energia emitida e tamanho do diâmetro do sítio foi demonstrado por vários trabalhos, iniciando com o primeiro estudo (Rossi e Rosenzweigh, 1959) e outros mais recentes (Srdoc et al, 1981, Srdoc e Marino, 1996 e Nunomya et al, 2002). Um deles (Srdoc et al, 1981), é mostrado nas figuras 3.13 e 3.14.

Nêutrons incidentes podem interagir com o meio celular através de dois processos (Alard et al, 2002):

1) Um processo "interno" pelo qual o nêutron interage dentro da célula, criando uma carga de recuo (próton, partículas alfa, núcleos de recuo).

2) Um processo "externo" através do qual o nêutron interage com o meio externo à célula, produzindo carga de recuo, e se esta é emitida com uma energia suficiente e em ângulo apropriado, pode penetrar o volume celular.

Em cada um dos casos teremos uma intensidade de deposição de energia e, como conseqüência, diferentes níveis de danos celulares.

Estudos com nêutrons monoenergéticos foram realizados em vários trabalhos, que analisaram como ocorre a deposição de energia no interior de um contador proporcional equivalente à tecido (TEPC). Quando nêutrons se chocam com átomos do gás que preenche a cavidade interna do detector, produzindo partículas secundárias 
carregadas, principalmente prótons de recuo que vão produzir ionizações, permitem o registro desse evento em espectros microdosimétricos, como a distribuição de freqüência de energia lineal e a distribuição de dose de energia lineal. Além de permitir a determinação da freqüência média de energia lineal, bem como a dose média de energia lineal, sendo essa última grandeza, fundamental no cálculo da dose absorvida por um corpo.

As primeiras medidas microdosimétricas de nêutrons usando o contador proporcional equivalente à tecido (TEPC) (Rossi and Rosenzweig, 1955b) foram realizadas com o objetivo de descrever mais detalhadamente as condições físicas de exposição, em especial a eficiência biológica relativa (RBE), visando atender os recentes avanços da radiobiologia naquele momento. O RBE é muito importante para os estudos de danos biológicos, porque se duas partículas carregadas de tipos diferentes depositarem a mesma quantidade de energia em um órgão, células vivas e tecidos, eles não responderão da mesma forma a esses dois tipos diferentes de radiação e a distinção é feita via $R B E$, que é uma medida de quão eficiente um dado tipo de partícula é quando comparado a uma dose absorvida de raios $\mathrm{X}$.

Um dos mais significativos trabalhos de apresentação de espectros microdosimétricos de nêutrons (Sdorc et al, 1980) usou um contador esférico sem paredes (Wall-less) para simular volumes de tecidos de diferentes diâmetros para o valor de nêutron monoenergético de $1.5 \mathrm{MeV}$ (vide gráfico 3.14), além de outro, que manteve fixo o tamanho do sítio em $1 \mu \mathrm{m}$ ( vide gráfico 3.13), mas variou os valores das energias provenientes da radiação de nêutrons. Esse trabalho foi motivado pelas grandes discrepâncias até ali existentes entre os resultados obtidos por diferentes trabalhos usando nêutron monoenergético. Objetivava, portanto, uniformizar as medidas microdosimétricas usando técnicas mais apuradas e instrumentos mais precisos. 


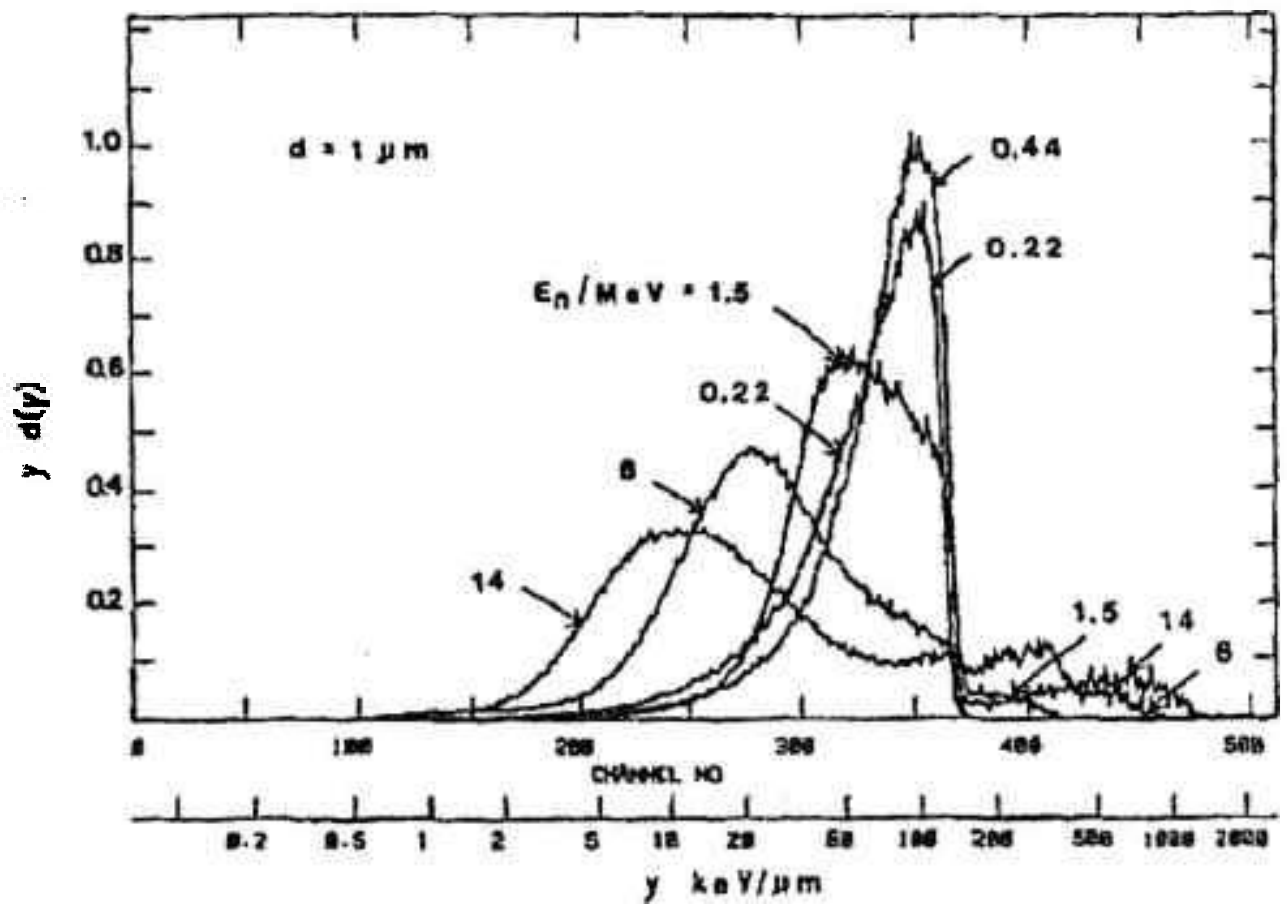

Figura 3.14- Espectro microdosimétrico para energias de nêutron de 0.22 a $14 \mathrm{MeV}$ medido em um contador sem-paredes (wall-less) para um diâmetro de sítio de $1 \mu \mathrm{m}$ ( após Srdoc e Marino).

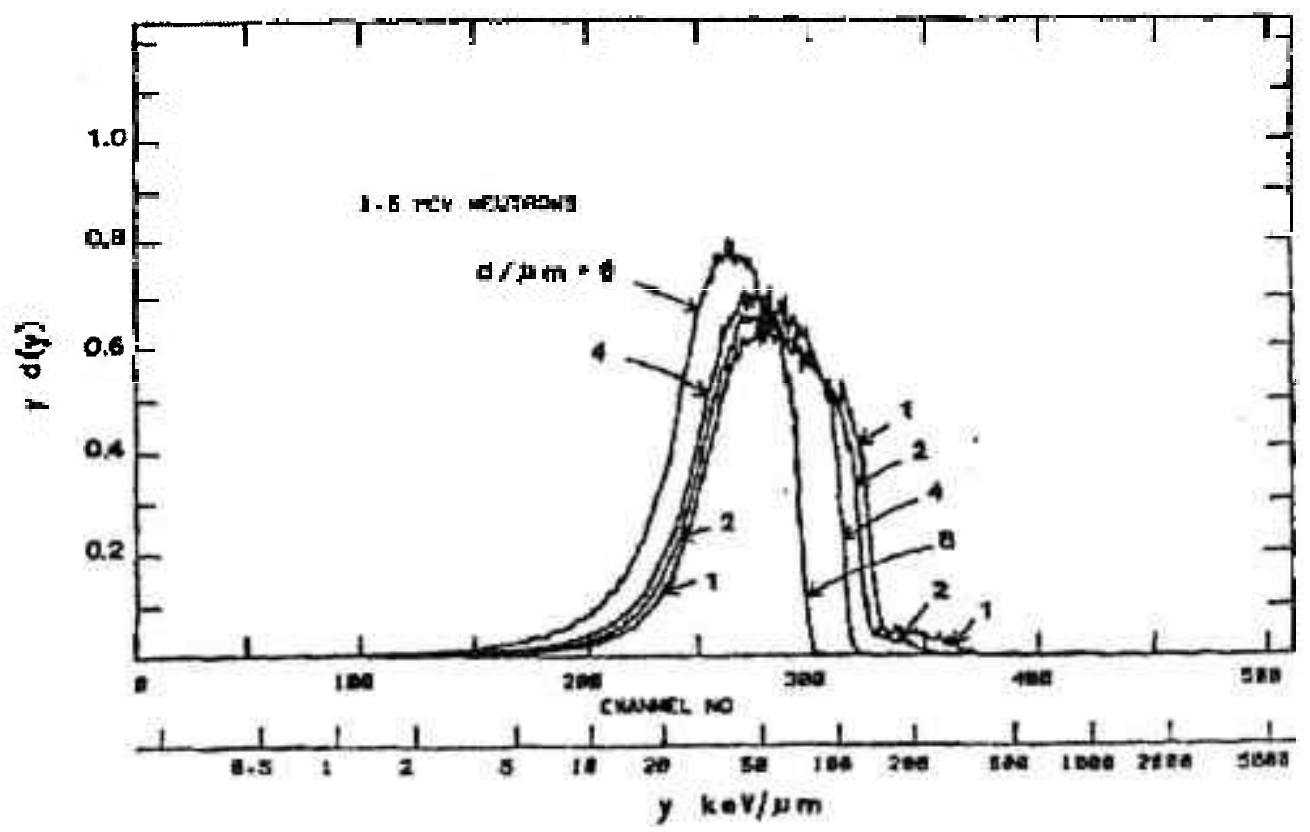

Figura 3.15 - Espectro microdosimétrico para nêutrons de energia de $1.5 \mathrm{MeV}$ medidos em um contador sem-paredes (wall-less) tamanhos de sítios de 1 a $8 \mu \mathrm{m}$ em diâmetro. 
Outro trabalho foi realizado 16 anos depois (após Srdoc e Marino, 1996), semelhante ao anterior, mas com um maior número de tamanhos de sítios, e como o acima citado, com energias de nêutrons de 0,22, 0,44, 1,5, 6 e 14 Mev. Os diâmetros dos volumes simulados foram: $0,25,0,5,1,0,2,0,4,0$ e $8,0 \mu \mathrm{m}$. E cada sítio foi irradiado com os nêutrons monoenergéticos referidos acima.

Os dois trabalhos citados usaram um Contador Proporcional Equivalente à Tecido com diâmetro interno de $0,635 \mathrm{~cm}$, sendo que o primeiro usou também outro de $2,54 \mathrm{~cm}$. O gás para preencher a cavidade interna dos detectores foi uma mistura baseada em propano, com 39,6\% de $\mathrm{CO}_{2}, 5,4 \%$ de $\mathrm{N}_{2}$ e $55 \%$ de propano. Para a retirada da contaminação da radiação gama foi usado, em ambos os trabalhos, o ${ }^{60} \mathrm{Co}$, e subtraído o espectro deste dos espectros das radiações de nêutron e gama juntos. 


\section{IV - MATERIAIS E MÉTODOS}

Para a realização desse trabalho foram usados os equipamentos do Laboratório de Microdosimetria do Nuclear Science Center (NSC) da Texas A\&M University, bem como o sistema de irradiação de nêutrons rápidos do reator de pesquisa do NSC.

\section{1- Equipamentos}

\subsection{1 - Contador proporcional equivalente à tecido - TEPC (Tissue Equivalent Proportional Counter) esférico - LET-1/2}

O TEPC, do tipo Rossi, é de fabricação da Far West Technology, Inc, Goleta, California, EUA, cujo esquema é apresentado na figura 4.2. O contador está no interior de uma caixa de alumínio fina, funcionando como uma cápsula hermética de vácuo. O volume ativo do detector possui um diâmetro de $1,27 \mathrm{~cm}$ e possui uma parede de plástico tecido equivalente de $0,127 \mathrm{~cm}$. Na extremidade da haste do contador é posicionado um bloco de alumínio com terminais de contato para a alta tensão e para o conector de sinal, como o pré-amplificador, além de um ajustador de vácuo. A figura 4.1 mostra todos os conectores ligados ao bloco do conector.

O contador é desenhado de forma a permitir que o próprio usuário possa evacuar e preencher a cavidade do contador proporcional com gás à baixa pressão, geralmente dentro de um parâmetro entre 25 Torr e 420 Torr. Com essas baixas pressões o volume do detector esférico fica capacitado a simular pequenos volumes de tecidos de menos de $1 \mu \mathrm{m}$ até maiores que $8 \mu \mathrm{m}$ de diâmetro.

A conexão do detector ao pré-amplificador e a um amplificador linear ou espectroscópico possibilita a formação de um espectro de uma função de probabilidade, $\mathrm{P}(\mathrm{y})$, apresentada em forma de alturas de pulsos quando o detector é exposto a uma fonte de radiação. A escolha do ganho certo no amplificador possibilitará a obtenção de valores 
de radiação. A escolha do ganho certo no amplificador possibilitará a obtenção de valores de energia lineal, y, que podem variar de poucos décimos até milhares de $\mathrm{keV}$ por micrômetro. Esses dados permitem a obtenção da dose, bem como de outras grandezas dosimétricas.

A fonte de radiação alfa $\left({ }^{244} \mathrm{Cm}\right)$ mostrada na figura 4.2 , no interior do detector, pode ser desativada, virando o detector de ponta-cabeça. Esse procedimento é necessário quando se usa o detector para medidas com outras radiações, como beta, gama e nêutrons, por exemplo. Essa fonte interna tem como principal aplicação a calibração do detector, já que o pico da radiação alfa é bem conhecido, o que facilita a calibração do aparelho.

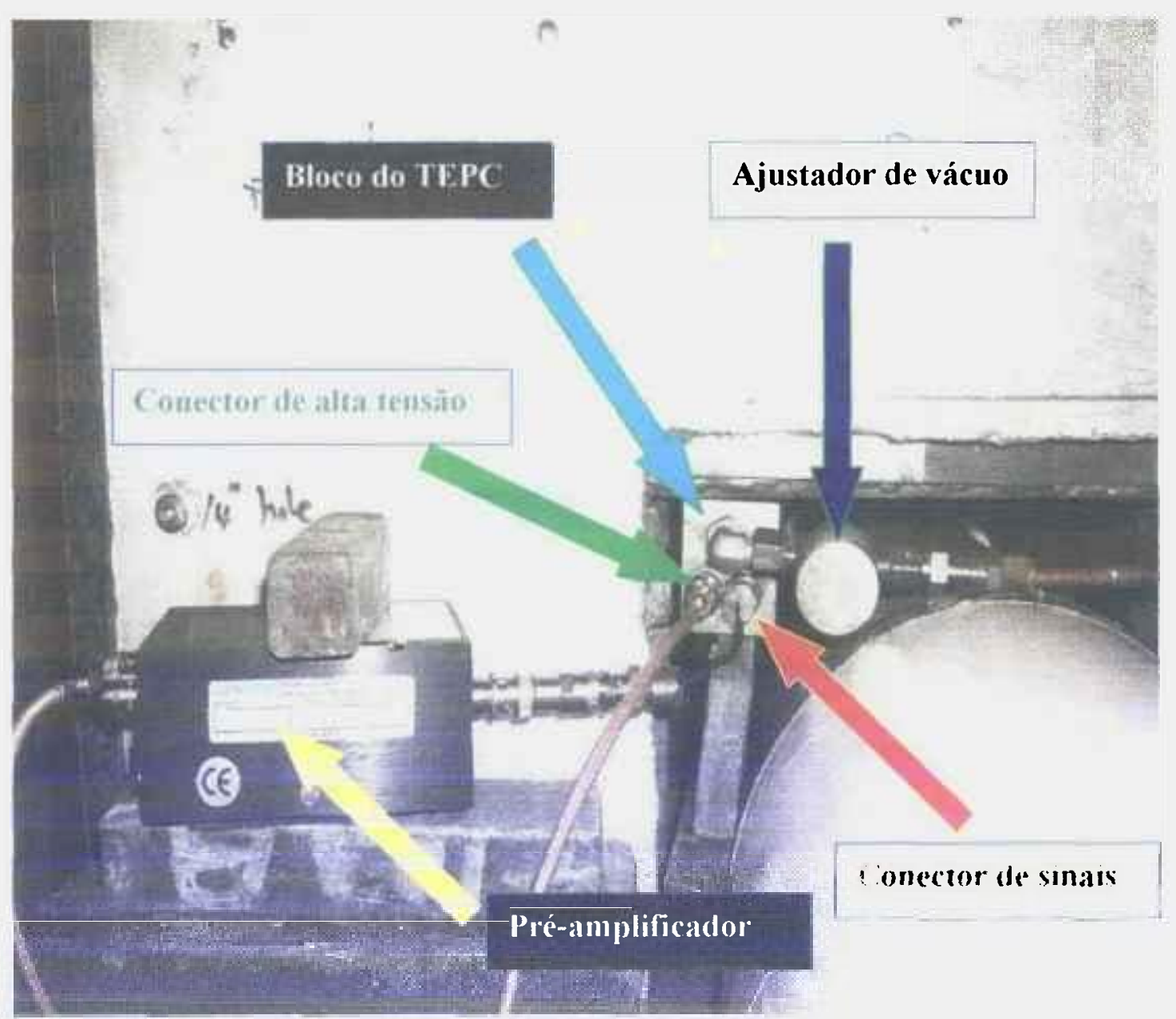

Figura 4.1 - Figura mostrando o pré-amplificador, os conectores de sinal e de alta tensão, além do ajustador de sinal do contador proporcional a tecido. 


\section{Características}

As características principais do contador proporcional equivalente à tecido, mostrado na figura 4.2 , são apresentados à seguir:

- Parede da esfera de plástico de material tecido equivalente de $0,127 \mathrm{~cm}$, feito com plástico A- 150 tipo Shonka de $1,12 \mathrm{~g} / \mathrm{cm}$; de diâmetro interno de $1,27 \mathrm{~cm}$;

- Casca externa de alumínio com espessura de $0,0178 \mathrm{~cm}$ com alto vácuo entre a parede de plástico da esfera interna e a referida casca;

- Haste interna de $12,7 \mathrm{~cm}$;

- Peso de $230 \mathrm{~g}$

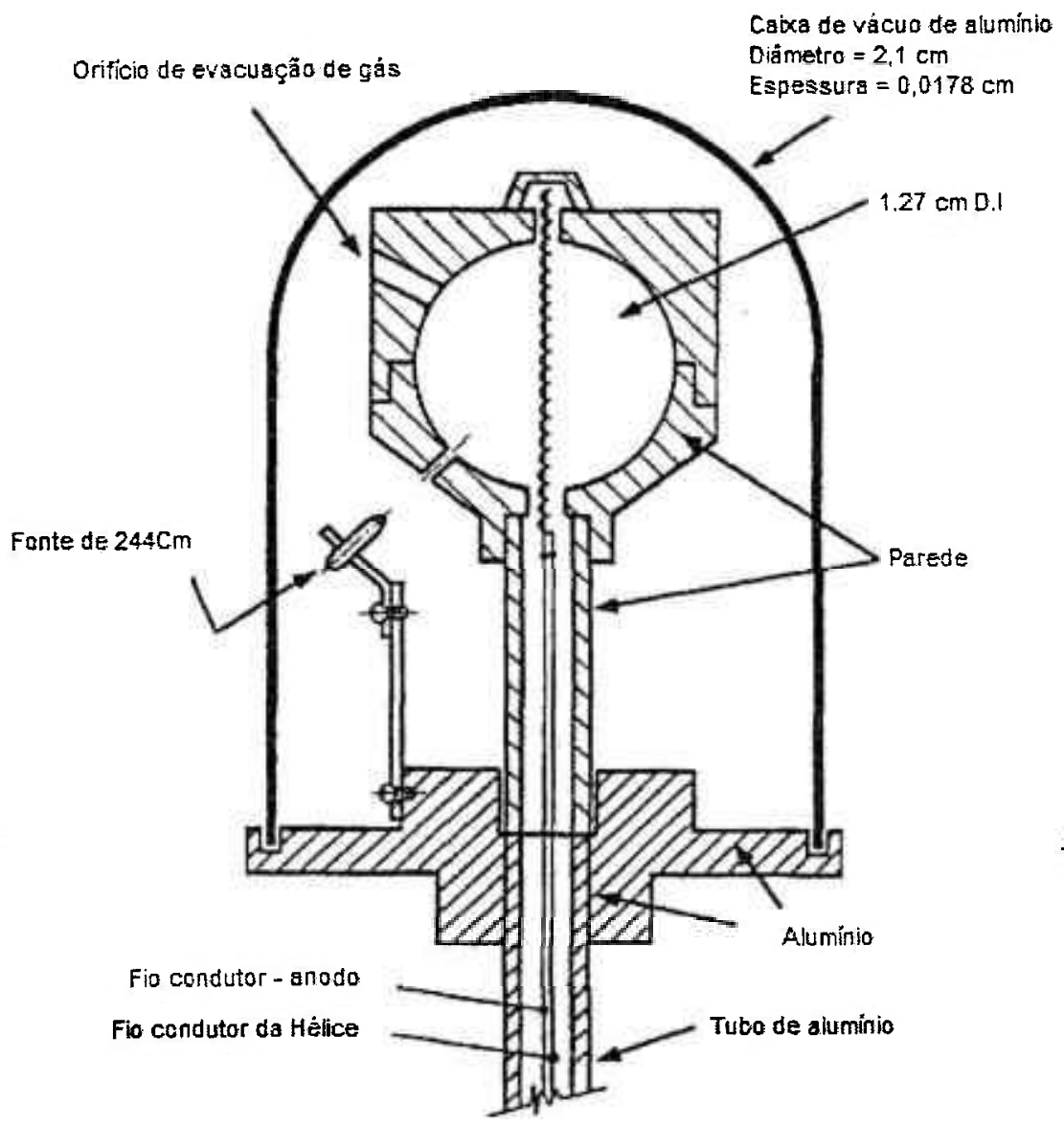

Figura 4.2 - Esquema de um contador proporcional equivalente a tecido como o que foi usado nesse trabalho. 


\subsection{2 - Material de suporte ao TEPC}

\subsubsection{1- Pré- amplificador Camberra-modelo 2006}

É um pré-amplificador sensivel de carga, com uma entrada de transistor de campo. Este é um tipo de equipamento definidamente de baixo ruído e pode ainda ser otimizado através do desenho do circuito, da preparação do experimento e da seleção para alto ganho e baixo ruído para fontes de detectores de alta impedância. A carga de entrada é integrada ao pré-amplificador sensível à carga para render um sinal de saída para a quantidade total de carga de entrada e a duração do evento. É um equipamento altamente eficiente, com baixo ruído, permitindo uma transmissão de sinal proveniente do contador para o amplificador com quase nenhuma distorção.

Para evitar ruídos provenientes de campos magnéticos de instrumentos elétricos no ambiente, o pré-amplificador precisa ser colocado o mais próximo possível do contador, portanto o cabo que liga os dois instrumentos precisa ter o menor tamanho possível.

\subsubsection{2 - Amplificador de espectroscopia - ORTEC - Modelo 451}

O amplificador é um dos mais importantes componentes em um sistema de processamento de pulsos para aplicações que envolvem contagem, regulação de tempo, ou espectroscopia de pulso-amplitude. É através dos comandos existentes no amplificador que se faz o controle da forma dos pulsos, necessário para otimizar o desempenho dos eletrônicos analógicos. É através desse equipamento que se controla o ganho que se quer obter no experimento.

\subsubsection{3 - Fornecedor de alta tensão - ORTEC - Modelo 459}

O modelo de alta tensão 459 da ORTEC fornece uma tensão de $0,5 \mathrm{kV}$ a $5,0 \mathrm{Kv}$, a qual é fundamental na produção do campo de radiação e na geração da avalanche de elétrons no interior da cavidade do detector. 


\subsubsection{4 - Bomba de gás}

Uma bomba de marca Wallace \& Teimam foi usada para o preenchimento e retirada do gás propano da cavidade do detector, funcionando também com uma bomba de vácuo, além de promover o vácuo dentro do contador.

\subsubsection{5 - Gás Propano.}

Nesse trabalho foi usado o gás propano no estado puro, sem nenhuma mistura, o qual é um gás eletropositivo, com uma densidade $\rho=1,879 \times 10^{-3} \mathrm{~g} . \mathrm{cm}^{-3}$, cuja fórmula química é $\mathrm{C}_{3} \mathrm{H}_{8}$. Em alguns experimentos é usado em conjunto com outros gases.

\subsubsection{6 - Analisador de Multicanal APTEC}

O analisador de Multicanal APTEC é responsável pela conversão do sinal analógico, como amplitude de pulsos em um número digital equivalente. $\mathrm{O}$ software da APTEC, que acompanha o MCA, permite controlar todos os experimentos através do monitor do computador. Com ele pode-se aumentar ou diminuir o número de canais que irão ser usados no experimento, discriminar o nível mais baixo de canal onde serão obtidas as contagens dos eventos, etc.

\section{2- Reator do Nuclear Science Center da Texas A\&M University}

O reator de pesquisa do Nuclear Science Center (NSCR) entrou em operação em 18 de Dezembro de 1961. Este reator tem uma potência máxima de $1 \mathrm{MW}$, ele é um TRIGA (Teaching, Research, and Isotopes, General Atomic) tipo piscina, e tem sido usado ativamente para produção de isótopos, Análises por Ativação de Nêutron Instrumental (INAA), e vários arranjos experimentais tais como, cálculo de nêutron atrasado, radiografia de nêutron em tempo real e experimentos com portas de feixes. $\mathrm{O}$ reator do Centro Nuclear de Ciência tem um núcleo móvel que pode ser colocado em qualquer posição ao longo de uma linha central da piscina. Em um dos lados da piscina do 
reator existe uma célula de irradiação para experimentos com objetos grandes, como mostram as figuras $4.3 \mathrm{a}$ e $4.3 \mathrm{~b}$. A célula de irradiação possui $5,49 \mathrm{~m}$ de largura, 4,9 $\mathrm{m}$ de profundidade e $3,05 \mathrm{~m}$ de altura, com tijolos de concreto de $0,6 \mathrm{~m}$ na parede entre a célula e a pecha do reator.

O reator, de 1973 até 2002, operou com um núcleo de FLIP( Programa de Melhoramento de Vida de Combustível) integral ou com núcleo mesclado FLIP-Padrão. A configuração corrente é baseada em grupos de 4 elementos com combustível TRIGA-FLIP (NSC 2003). Águas claras circulam através do núcleo do reator por convecção natural, agindo como um refletor de nêutron e de resfriamento no perímetro do núcleo, e grafite serve como um refletor adicional nos dois lados, para minimizar vazamentos de nêutrons. A estrutura de concreto da piscina, incluindo o revestimento de aço inoxidável e a água da piscina, proporciona uma blindagem de raios gama e nêutrons para o reator. A capacidade de blindagem é para um reator operando a uma potência de $5 \mathrm{MW}$, que é bem acima da potência máxima de operação de $1 \mathrm{MW}$ atualmente (NSCR, 2003). A ponte do reator móvel permite a operação do reator em qualquer posição da linha central da piscina, que roda aproximadamente de leste a oeste, como mostra a figura 4.4

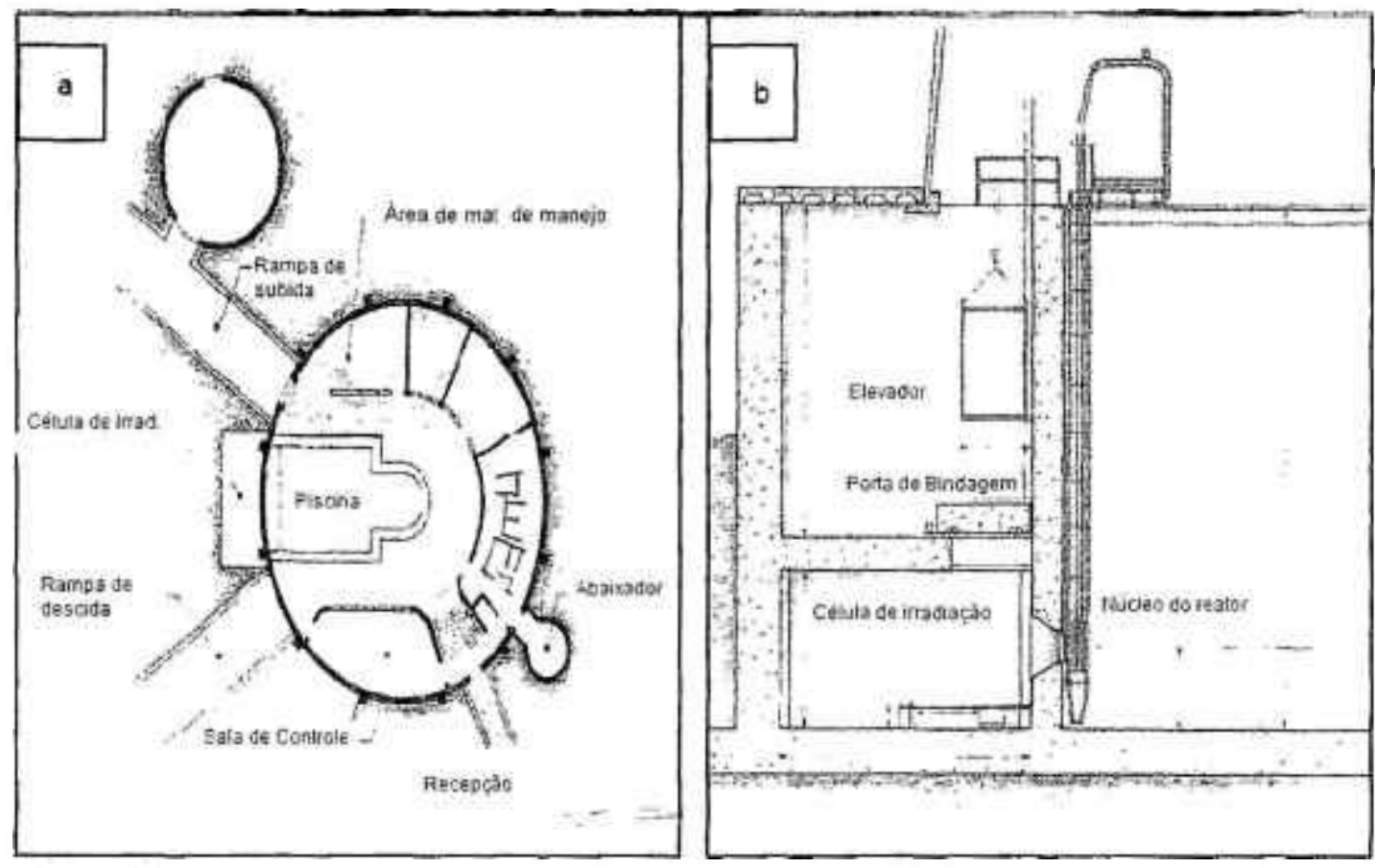

Figura 4.3. a) Vista superior do reator do Nuclear Science Center da Texas A\&M University, mostrando uma vasta célula de irradiação, a piscina e a sala de controle.

b) Corte lateral, mostrando o reator posicionado junto à entrada da célula de irradiação. 


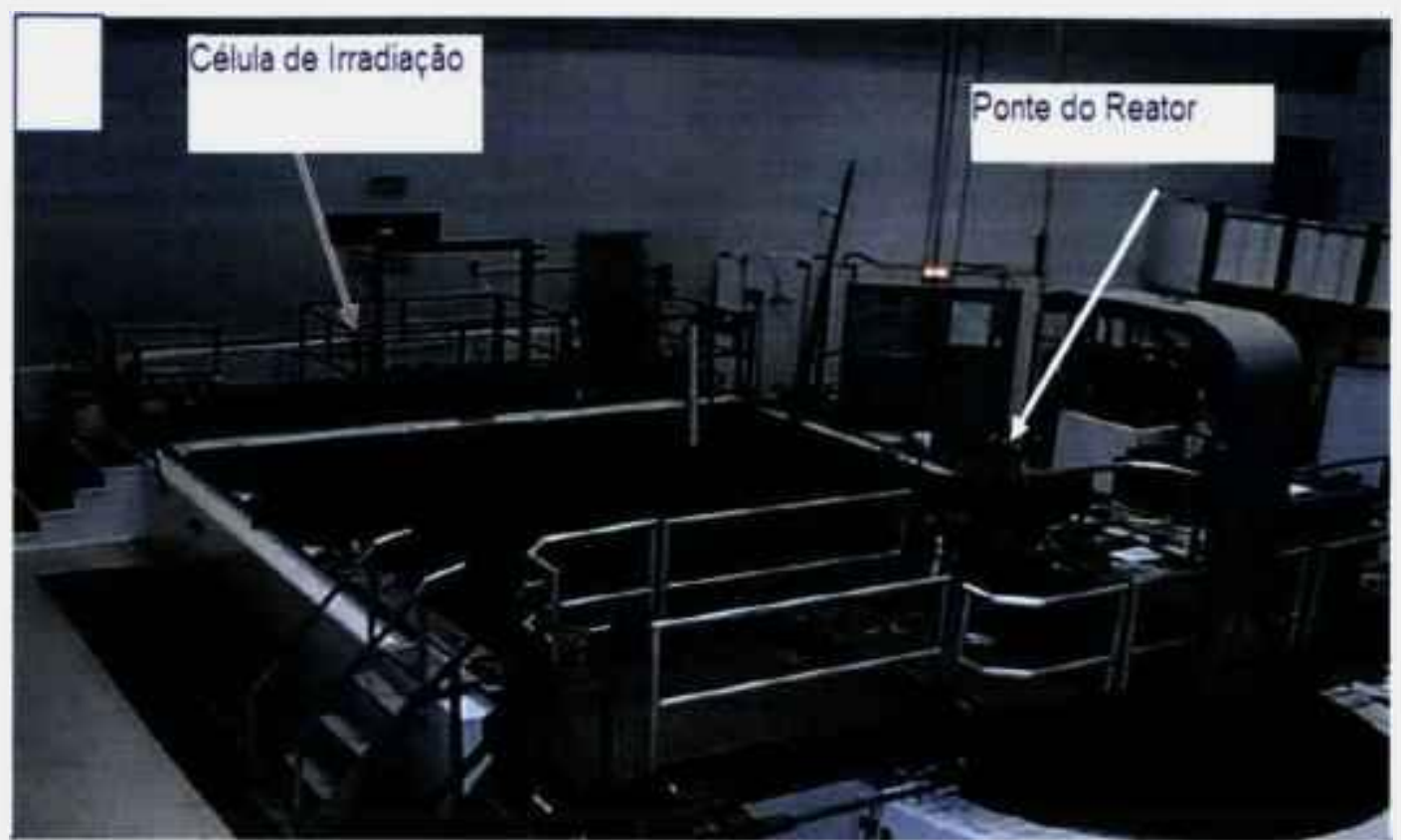

Figura 4.4 - Vista geral do Reator do Nuclear Science Center da I'exas A\&M University.

4.3 - Sistema de Irradiação de Nêutrons Rápidos Fortemente Filtrados (FNIS) do Nuclear Science Center da Texas A\&M University.

O sistema de irradiação de nêutrons rápidos severamente filtrados é composto de uma cavidade cúbica de dimensão interna de $38 \mathrm{~cm} \times 38 \mathrm{~cm}$ x $49 \mathrm{~cm}$, onde se pode colocar até pequenos animais roedores. Em frente à cavidade, por onde entram os feixes de nêutrons, são colocados tijolos de uma liga composta de chumbo e bismuto, com o objetivo de minimizar a incidência de radiação gama. O Sistema foi construído para permitir uma contaminação da amostra, de até $5 \%$ de dose de fótons.

O FNIS foi desenhado para cumprir seis principais funções ( Jang et al, 2004):

1) Fornecer feixes de nêutrons com energia média maior que $0,1 \mathrm{MeV}$, com uma grande distinção de diferentes espectros de energia dentro da cavidade de exposição.

2) Fornecer dose de nêutrons às amostras com menos que $5 \%$ de contaminação de radiação gama.

3) Produzir distribuição de dose uniforme no interior da cavidade exposta.

4) Ser capaz de conseguir uma ampla variação de taxas de dose, movendo o núcleo do reator em relação ao FNIS ou mesmo ajustando a potência do reator. 
5) Fornecer um sofisticado sistema de controle para transferência de amostras, pequenos animais vivos ou tecidos, recebendo o mínimo de dose possível, enquanto eles estão transitando através de ambientes de nêutrons não filtrados, e prevenção de danos que podem ser feitas por uma parada abrupta.

6) Efetuar a dosimetria de radiação gama e nêutrons.

Para atingir esses seis objetivos foi usado material com baixa absorção de secção de choque para nêutrons rápidos, como também, um espalhamento apropriado de seção de choque, que não degrade os feixes de nêutrons rápidos. Foram adicionados, também, absorvedores de nêutrons epitérmicos e térmicos, para cortar os indesejáveis nêutrons de energia baixa. Os absorvedores foram construídos usando uma liga de 54,9\% de bismuto e $44,5 \%$ de chumbo, para minimizar a captura de raios gama dentro do FNIS (F iguras 4.5, 4.6 e 4.7).

Com esse sistema pode-se aumentar a espessura da liga de chumbo-bismuto, com isso os espectros de energia de nêutrons são deslocados para energias mais baixas devido às interações de natureza elástica e inelástica dos nêutrons rápidos com a liga de chumbo-bismuto. Como essa liga tem uma seção de choque de espalhamento relativamente linear com o aumento da energia de nêutrons, e a contribuição de nêutrons lentos para o total da dose é desprezível comparado ao de nêutrons rápidos, é possível usar-se esse sistema de filtros para produzir diferentes espectros de energias de nêutrons em termos da dose de nêutron e disponibilizá-los no interior da cavidade do Sistema de Nêutrons Rápidos Fortemente Filtrados (FNIS) para experimentos biológicos. 


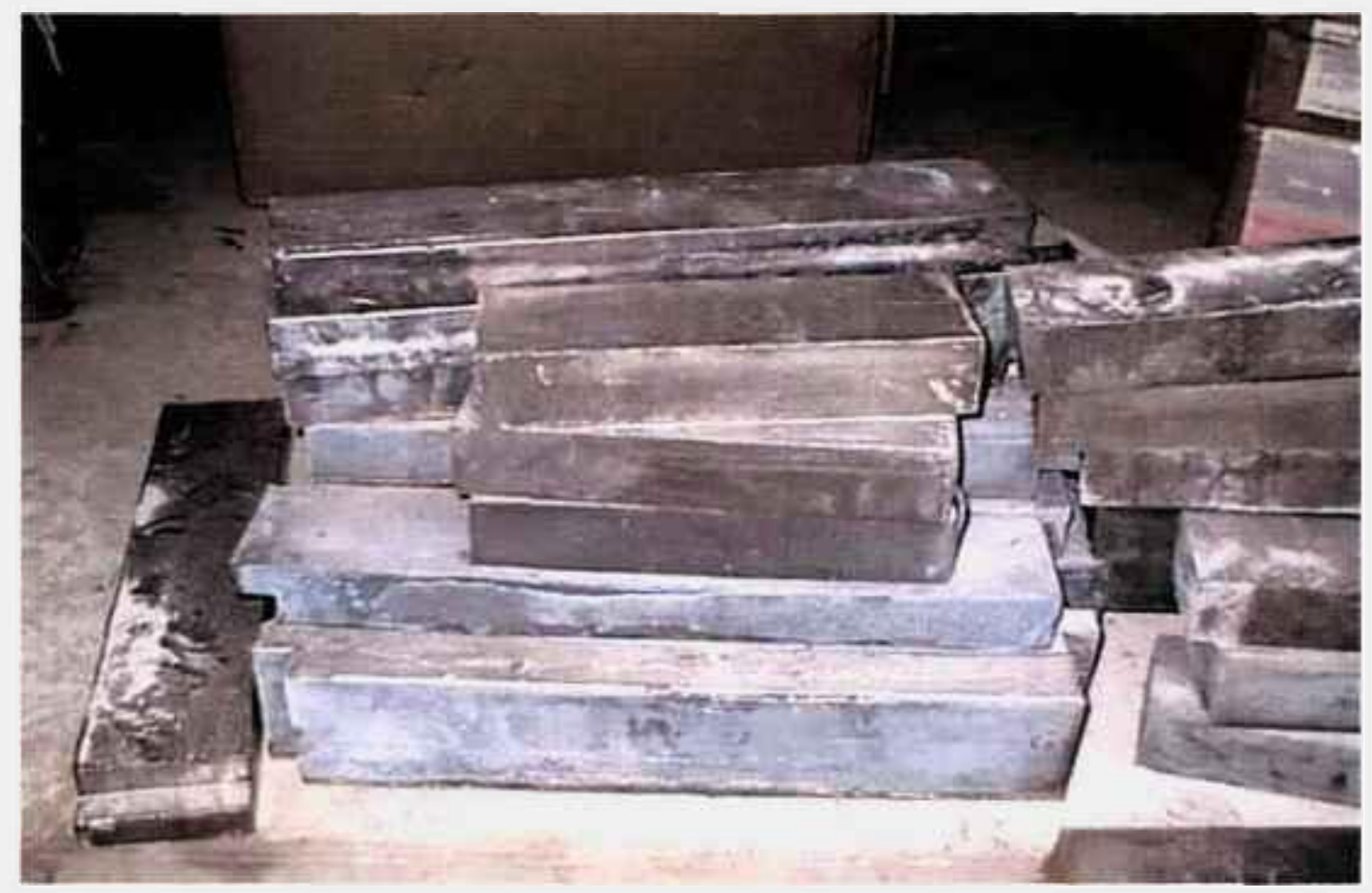

Figura 4.5 - Tijolos de Chumbo-Bismuto usados na construção do FNIS, as dimensões são de $10,16 \times 48,26 \times 5,08 \mathrm{~cm}^{3}$.

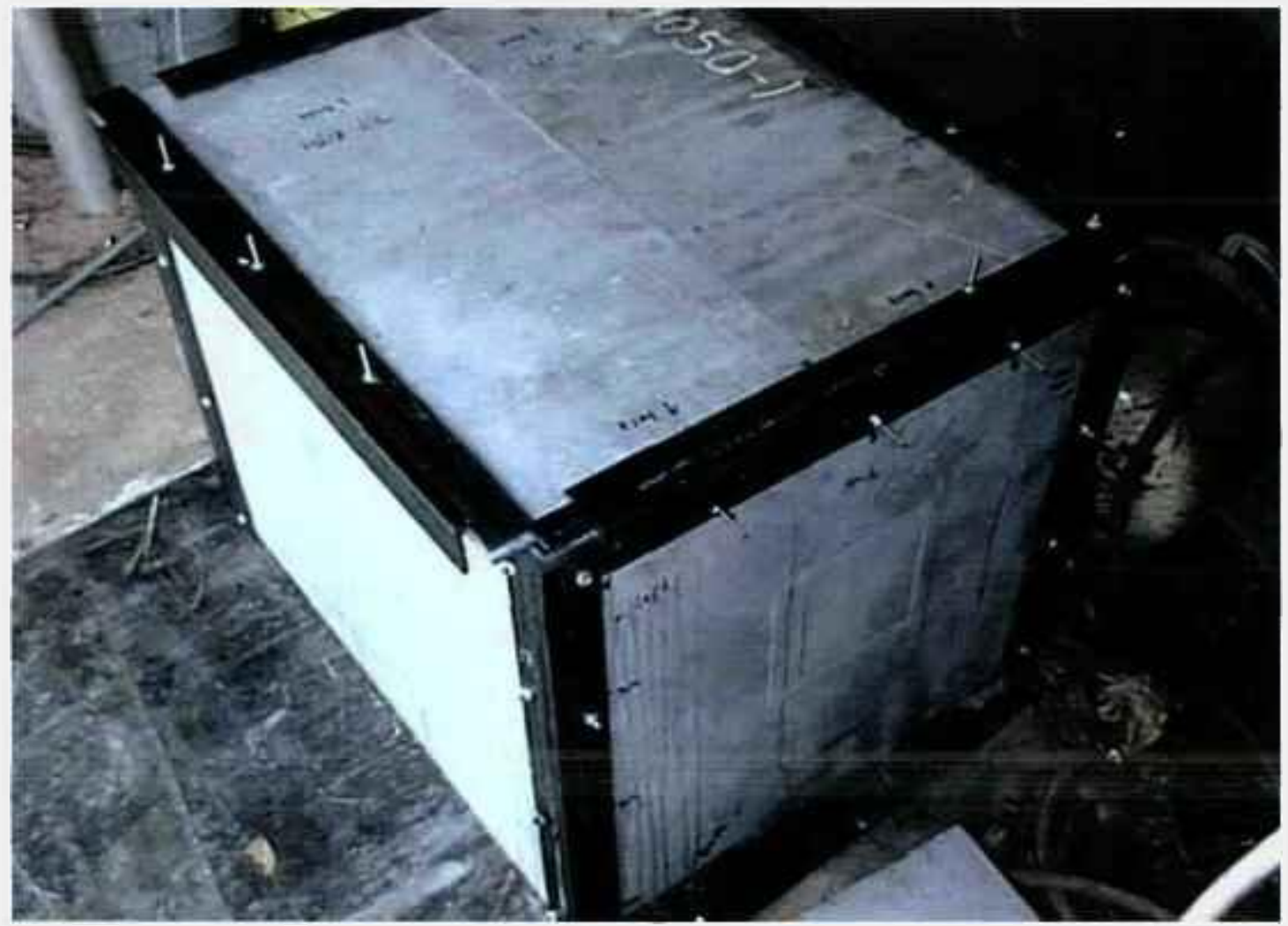

Figura 4.6 - Caixa de Boral construída para blindagem contra nêutrons térmicos. 


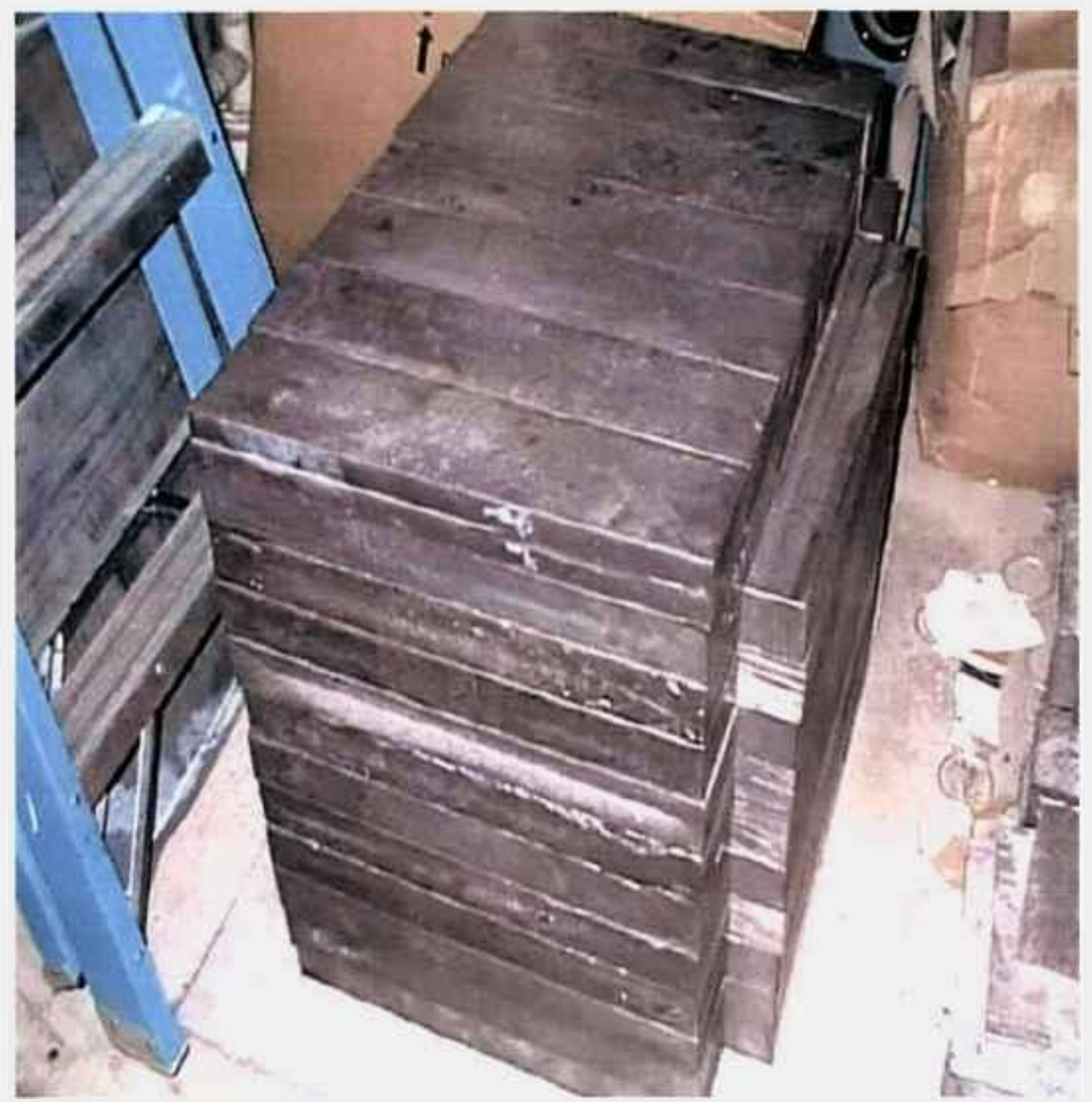

Figura 4.7 - Cavidade de exposição para irradiação de amostras construída com tijolos de liga de chumbo-bismuto.

As figuras 4.8 e 4.9 apresentam os arranjos experimentais para a realização de medidas no interior do reator. Nessas figuras podem ser vistos, a fonte de energia, a fonte de alta tensão, o pré-amplificador, o TEPC. o amplificador espectroscópico, bem como o cabo de conexão de alta tensão, que vai ligado ao detector, o cabo de recepção do sinal enviado pelo pré-amplificador, além do cabo cinza, que alimenta de energia o préamplificador. Pode-se ver ainda o monitor que apresenta os espectros coletados durante a interação do nêutron com o gás existente no interior da cavidade do contador. 


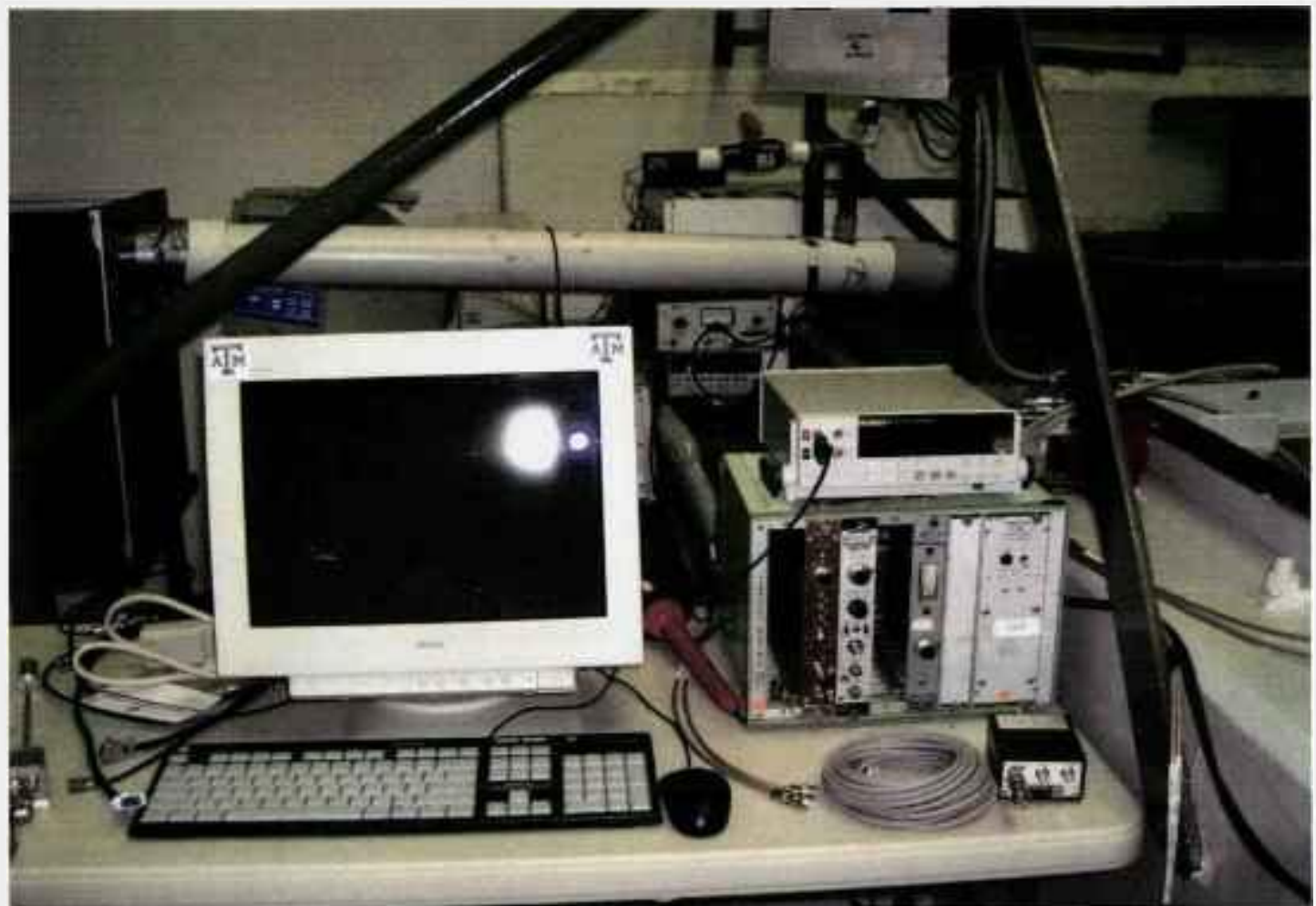

Figura 4.8 - Equipamentos usados em medidas microdosimétricas de nêutrons rápidos de reator.
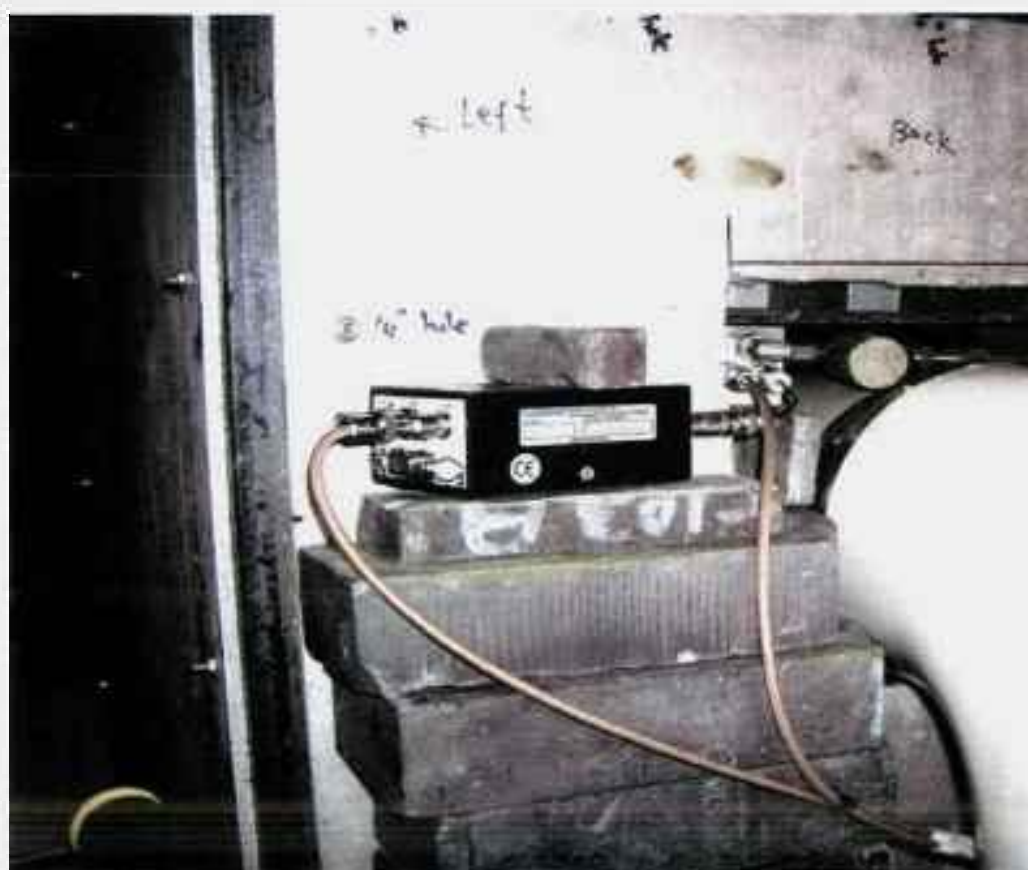

Figura 4.9 - Cavidade de exposição e o arranjo experimental montado no interior da cavidade com o Pré-amplificador e o TEPC. 


\section{5 - Método de medidas microdosimétricas}

O primeiro procedimento para a realização das medidas microdosimétricas foi preencher a cavidade do contador proporcional equivalente a tecido, TEPC, com gás propano à pressão $\mathrm{P}=42$ Torr. A densidade desse gás à condições normais de temperatura e pressão é igual a $\rho=1,8794 \times 10^{-3} \mathrm{~g} . \mathrm{cm}^{-3}$. Para o cálculo do diâmetro do volume simulado no interior da cavidade do TEPC foi usada a relação a seguir:

$$
S V=\rho \times \text { diâmetro interno da cavidade do TEPC } \times \frac{42}{760}
$$

Usando essa relação obteve-se o seguinte valor para o diâmetro do volume simulado:

$$
S V=1,3 \mu \mathrm{m} \times 1,0 \mathrm{~g} \cdot \mathrm{cm}^{-3}
$$

Com o objetivo de evitar a contaminação do gás, foi usada uma bomba de gás, que permite a retirada do conteúdo de gás já usado trocando-o por um novo na pressão que foi definida para a realização do experimento. Visando controlar o gás no interior da cavidade do contador proporcional equivalente a tecido. Além disso, foi usado também, um Analisador de gás quadrupolo da Ametex, que analisa a qualidade do gás, mantendo-o sempre em condições ideais de uso. O importante é evitar a contaminação por gases negativos, como por exemplo o oxigênio

Para a obtenção dos espectros produzidos pelos eventos ocorridos no interior de um Contador Proporcional Equivalente à Tecido são necessários os equipamentos representados no esquema da figura 4.10. 


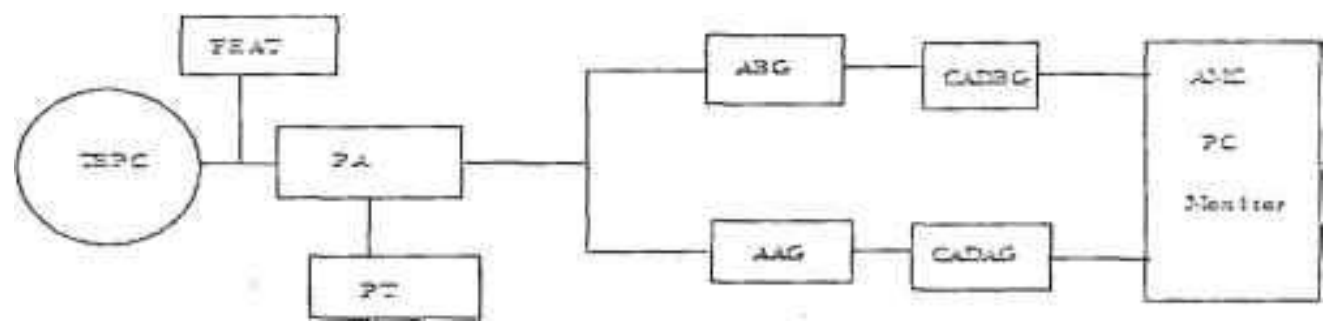

Figura 4.10 - Esquema de um arranjo para medidas microdosimétricas usando um contador proporcional de tecido equivalente.

Para a realização dos experimentos foram acoplados ao contador proporcional equivalente a tecido (TEPC), conforme esquema da figura 4.10, uma fonte de energia de alta tensão (FEAT), operando em uma tensão de $650 \mathrm{~V}$ e um pré-amplificador que realiza a primeira amplificação dos sinais emitidos pelo TEPC. Para a calibração do pré-amplificador foi usado um pulsador de teste (PT). Ligado ao pré-amplificador foi colocado um amplificador que vai amplificar novamente o sinal recebido em baixo ganho (ABG) e alto ganho (AAG). Esses sinais são enviados a um conversor de sinal analógico em digital (CADBG) que envia a um software analisador de multicanal (AMC) que finalmente transforma todos esses impulsos, inicialmente emitidos pelo TEPC, em um espectro que finalmente é apresentado no monitor. Tabelas com os números de eventos que ocorrem em cada canal, também são apresentadas.

\section{Calibração do TEPC}

Para a calibração do TEPC e dos equipamentos a ele associados foram realizados experimentos usando fonte de AmBe. Um deles usou uma fonte junto ao TEPC, conforme figura 4.12, e em outro a fonte foi colocada a uma distância de $15,24 \mathrm{~cm}$ e foram colocadas placas de plástico de $2,54 \mathrm{~cm}$ de espessura, cada uma, entre ela e o contador (figura 4.11), para verificar se existia uma atenuação da energia depositada e como conseqüência uma mudança nos espectros processados. Nessas medidas foram colocadas 1, 2, 3 e 6 placas. Os resultados dessa calibração não serão colocados nesse trabalho, porque ele foi usado apenas para testar o equipamento. Nas figuras 4.13 e 4.14 são apresentados dois espectros do experimento para calibração usando as placas de plástico. 
Na tabela 4.1 é apresentado os resultados de uma parte dos cálculos microdosimétricos realizados para a obtenção dos espectros, referidos acima.

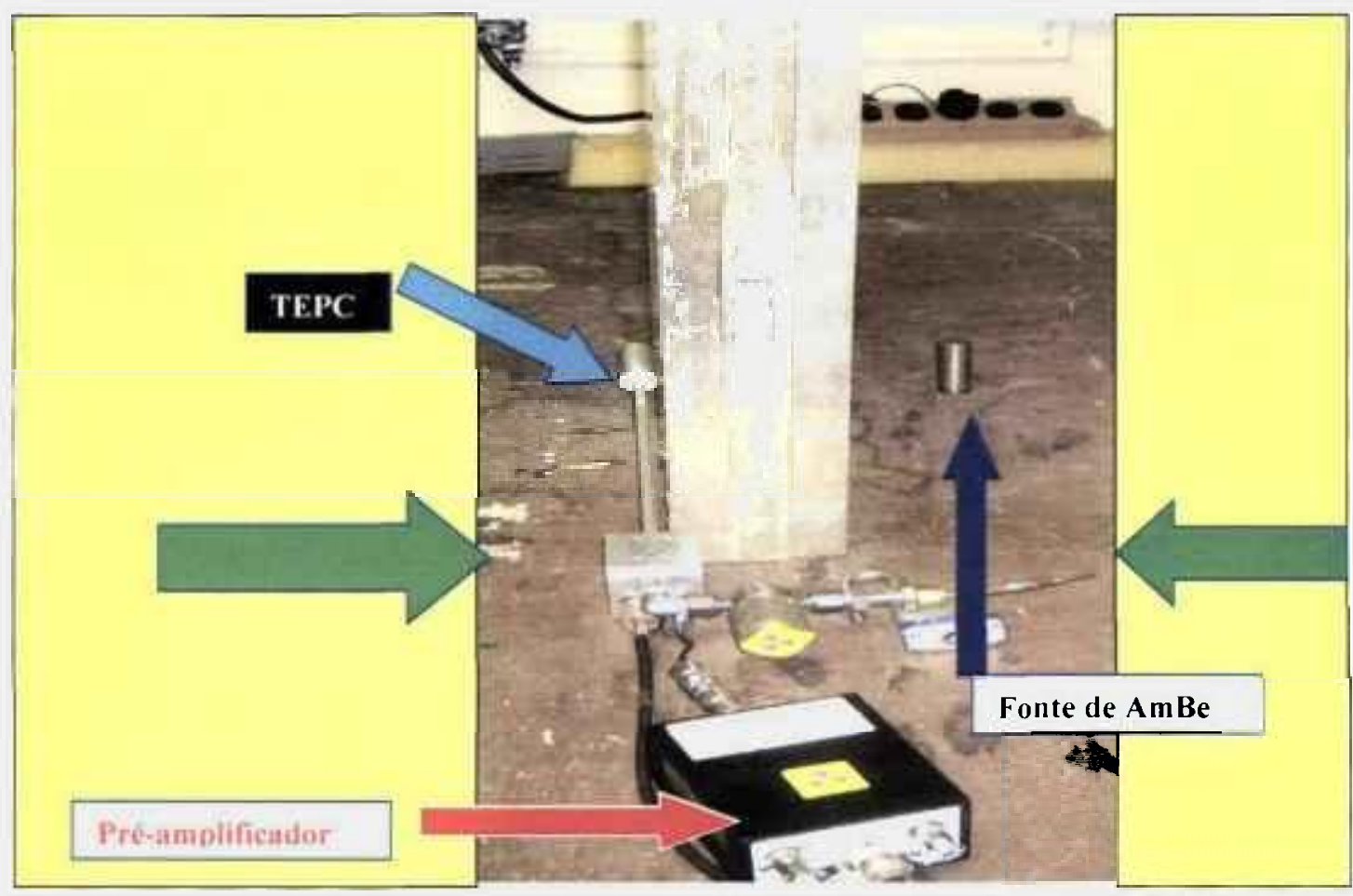

Figura 4.11 - Arranjo experimental para calibração do TEPC, mostrando as placas de plástico, a fonte de AmBe, o pré-amplificador e o contador proporcional.

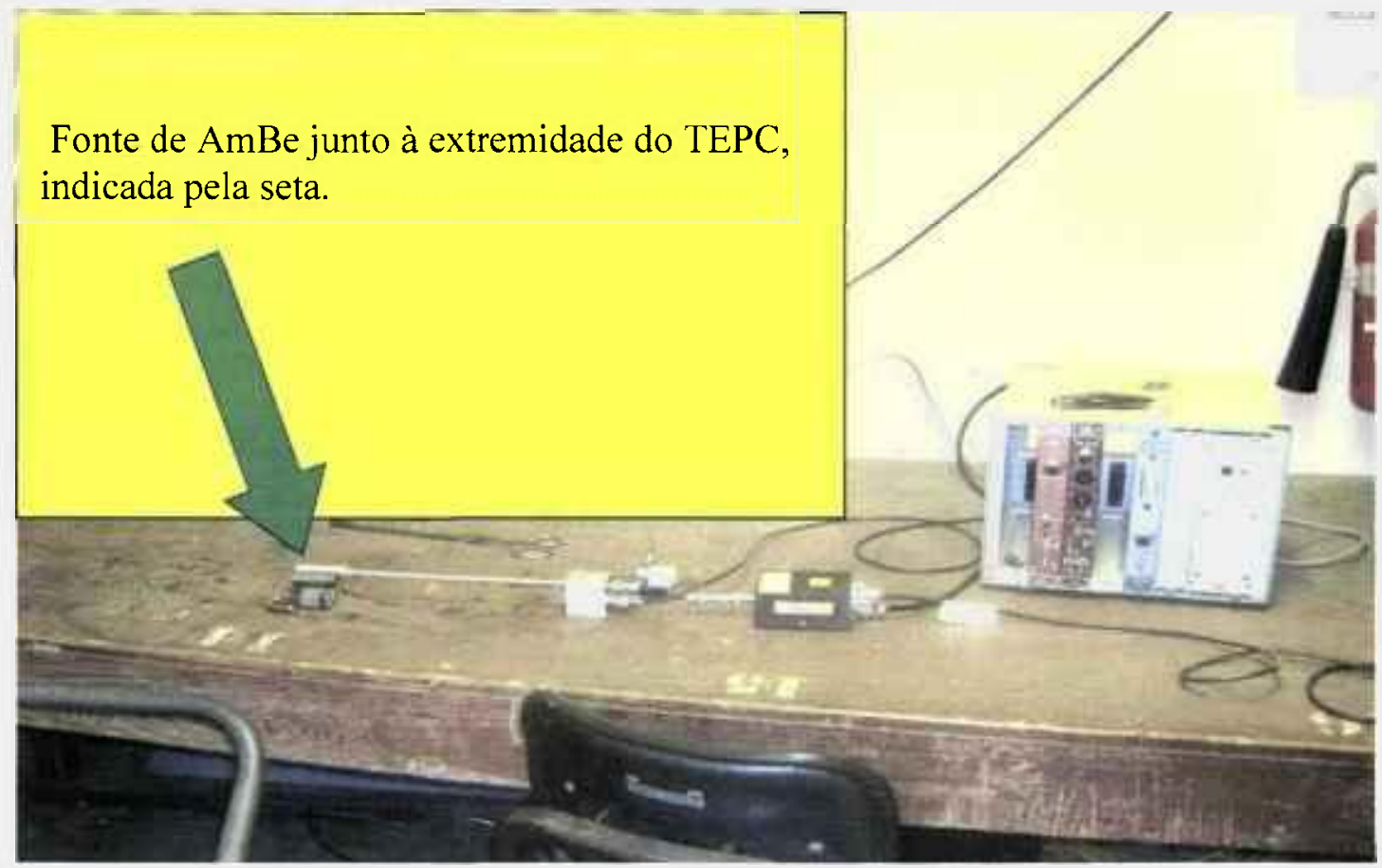

Figura 4.12 - Além da fonte de energia, a figura mostra o arranjo experimental utilizado constituindo de: TEPC, fonte de AmBe. junto ao TEPC. o pré-amplificador, o amplificador, a fonte de alta tensão, usados durante a calibração do equipamento. 
Quando alguma distorção ocorrer nos espectros, dere ser investigado a causa de tal ocorrência. Primeiramente deve-se aferir o pré-amplificador. usando o pulsador de teste, o qual deverá mostrar se o pré-amplificador está ou não respondendo ao pulso recebido e se este está coerente com a indicada pelo fabricante. O pulsador substitui o TEPC no fornecimento dos pulsos.

Se o pré-amplificador está operando corretamente, o passo seguinte é o de verificar se há alguma contaminação, por água ou oxigênio no interior do TEPC, isto é feito usando uma bomba de vácuo e logo após preenchendo a cavidade do contador com gás.

Podem ocorrer também problemas no amplificador. principalmente no fator de ganho do instrumento que, mesmo quando colocado um fator de ganho de 40 vezes entre o baixo ganho e o alto ganho, o amplificador, por não estar aferido, está na verdade processando um ganho de 23 vezes. Isto provoca sérias distorções que vão impedir a correta obtenção dos gráficos y $x$ yf(y) e y x yd(y).

Problemas no valor de alta tensão fornecida ao TEPC, podem também ocorrer, e dependendo da densidade do gás, vai fornecer um desprezivel ganho de gás . distorcendo com isto, os resultados apresentados. A alta tensão. além do valor necessário para a realização de experimento, pode provocar um empilhamento de pulsos, podendo até romper o anodo interno danificando com isto, o contador.

No experimento realizado no interior do reator, o TEPC foi colocado no interior da cavidade, como mostrado na figura 4.1, para ser bombardeado. por feixes de nêutrons rápidos, com três diferentes valores de potências. $0.5 \mathrm{~kW}, 1,0 \mathrm{~kW}$ e $2.0 \mathrm{~kW}$. A tensão aplicada ao TEPC foi de $650 \mathrm{~V}$. com baixo ganho de 2.5 e alto ganho de 100 . Uma medida da radiação de fundo. durante uma hora, foi feita antes de serem realizadas as medidas para cada potência.

Para a obtenção do fator de calibração foi identiticado, no espectro de baixo. ganho o canal onde ocorre o máximo poder de freamento (stopping power). que é onde se encontra a maior energia do próton de recuo. O nêutron deposita energ̣ia no tecido. primariamente, pela criação de prótons de recuo (Knoll. 2000). O poder de freamento 
máximo do próton é cerca de $100 \mathrm{keV} / \mu \mathrm{m}$. Assim, a energia máxima depositada pelo próton é de $100 \mathrm{x} \mathrm{d} \mathrm{keV/um.} \mathrm{A} \mathrm{energia} \mathrm{lineal} \mathrm{y}=\mathrm{E} / \vec{l}$, onde $\mathrm{E}$ é a energia e $\bar{l}$ é o comprimento da corda média dos traços que atravessam o volume irradiado. Como se está trabalhando com uma superfïcie esférica, $\bar{l}=(2 / 3)$ d, e dé o diâmetro do rolume irradiado. Então, se obtém um valor de $y=100 \mathrm{~d} \mathrm{keV} / \mu \mathrm{m} /(2 / 3) \mathrm{d}$, que fornece um valor de energia lineal máxima do próton de $150 \mathrm{keV} / \mu \mathrm{m}$.

O fator de calibração é obtido identificando no espectro de $\mathrm{N}$ (número de eventos) multiplicado pelo número do canal onde está ocorrendo a energia lineal. y. máxima do próton de recuo, e, usando a seguinte fórmula:

$\Delta y^{\prime}=y / n$. do canal onde ocorre a máxima energia lineal do próton de recuo.

Multiplicando cada número de canal pelo fator de calibração, é obtido o valor da energia depositada em cada um dos canais. e assim pode-se interpretar como a deposiçào de energia está ocorrendo na matéria.

Para a determinação de todos os gráficos de medidas microdosimétricas é fundamental o cálculo de y. energia lineal, e da função de densidade de probabilidade f(y). Parà o primeiro, já foi explicado como se obtém, já o segundo é obtido fazendo a nọmalização do número de eventos n. 


\section{y x yf(y)}

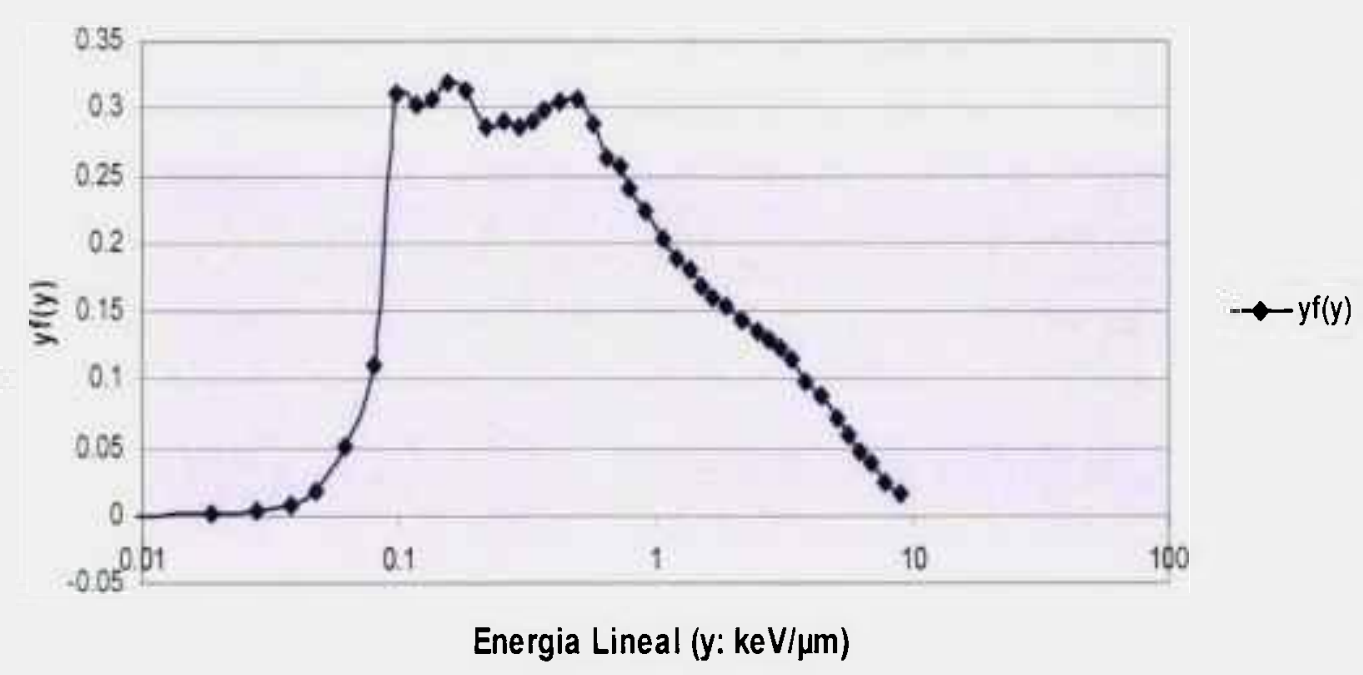

Figura 4.13 - Espectro de distribuição de freqüência de energia lineal para alto ganho, de uma fonte de AmBe com uma placa de plástico colocada entre a fonte e o TEPC

\section{y vs yd(y)}

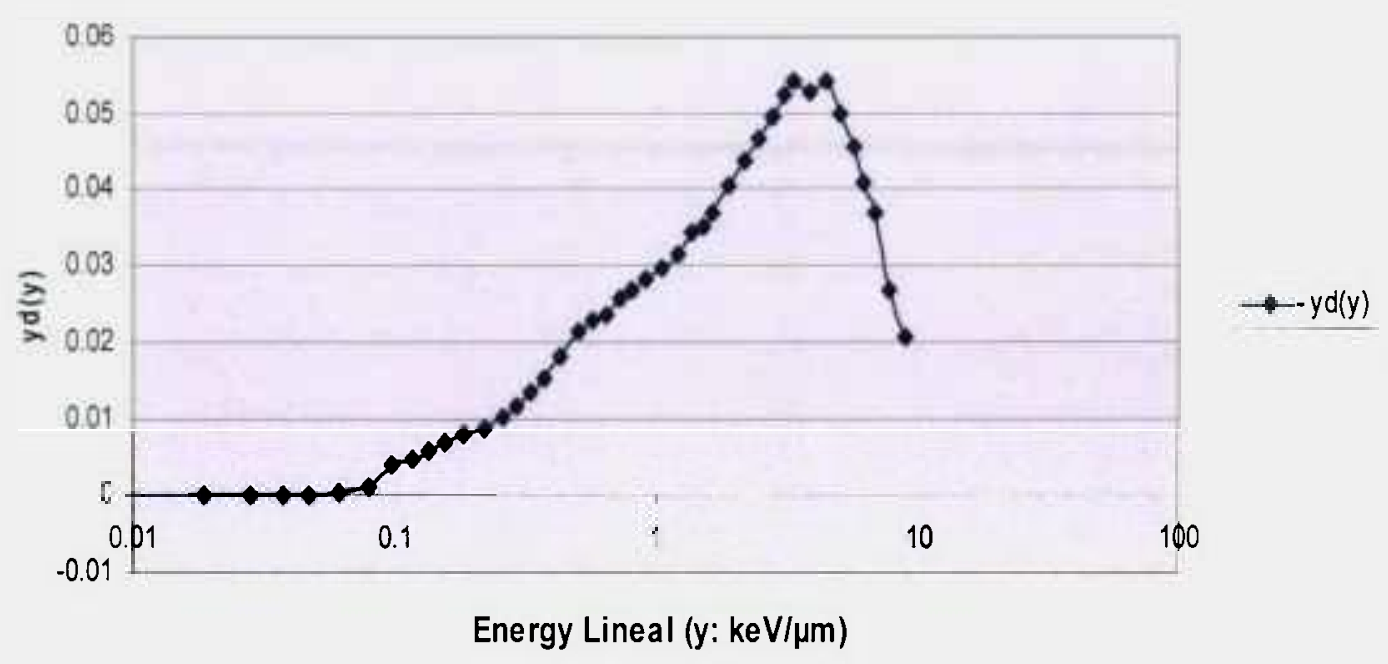

Figura 4.14 - Espectro de distribuição de dose de energia lineal para alto ganho, de uma fonte de $\mathrm{AmBe}$ com uma placa de plástico colocada entre a fonte e o TEPC. 
Tabela 4.1 - Parte de um planilha de cálculo de grandezas microdosimétricas para alto ganho com uma placa de plástico colocada entre a fonte de AmBe e o TEPC.

\begin{tabular}{|c|c|c|c|c|c|c|c|}
\hline canais & $n$ & $f(y) \Delta y$ & $f(y)$ & $y$ & $y f(y)$ & $d(y)$ & $y d(y)$ \\
\hline 0 & 1 & 0,0000 & 0,0003 & 0,0000 & 0,0000 & 0.0000 & 0,0000 \\
\hline 1 & 0 & 0,0000 & 0,0000 & 0.0094 & 0,0000 & 0.0000 & 0,0000 \\
\hline 2 & 1 & 0.0000 & 0,0003 & 0,0187 & 0,0000 & 0,0000 & 0,0000 \\
\hline 3 & 0 & 0,0000 & 0,0000 & 0,0281 & 0,0000 & 0,0000 & 0,0000 \\
\hline 4 & 0 & 0,0000 & 0,0000 & 0,0375 & 0,0000 & 0,0000 & $\overline{0,0000}$ \\
\hline 5 & 1 & 0,0000 & 0,0003 & 0,0468 & 0,0000 & 0,0000 & 0,0000 \\
\hline 6 & 3 & 0,0000 & 0,0010 & 0,0562 & 0,0001 & 0,0000 & 0,0000 \\
\hline 7 & 2 & 0,0000 & 0,0006 & 0,0655 & 0,0000 & 0,0000 & 0,0000 \\
\hline 8 & 10 & 0,0000 & 0,0032 & 0,0749 & 0,0002 & 0,0000 & 0,0000 \\
\hline 9 & 4989 & 0,0149 & 1,5911 & $0,08 \overline{43}$ & 0,1341 & 0,0013 & 0,0001 \\
\hline 10 & 10591 & 0,0316 & 3,3777 & 0,0936 & 0,3163 & 0,0031 & 0,0003 \\
\hline 11 & 9869 & 0,0295 & 3,1474 & 0,1030 & 0,3242 & 0,0032 & 0,0003 \\
\hline$\overline{12}$ & 8796 & 0,0263 & 2,8052 & 0,1124 & 0,3152 & 0,0031 & 0,0004 \\
\hline 13 & 7981 & 0,0238 & 2,5453 & 0,1217 & 0,3098 & 0,0031 & 0,0004 \\
\hline 14 & 7452 & 0,0223 & 2,3766 & 0.1311 & 0,3115 & 0.0031 & 0.0004 \\
\hline 15 & $7 \overline{765}$ & 0,0214 & 2,2851 & 0.1404 & 0,3209 & 0,0032 & 0,0004 \\
\hline 16 & 6673 & 0,0199 & 2,1282 & 0,1498 & 0,3188 & 0,0032 & 0,0005 \\
\hline 17 & 6755 & 0,0202 & 2,1543 & 0,1592 & 0,3429 & 0.0034 & 0,0005 \\
\hline 18 & 6290 & 0,0188 & 2,0060 & 0,1685 & 0,3381 & 0,0033 & 0,0006 \\
\hline$\overline{19}$ & 5696 & $0, \overline{0170}$ & 1,8166 & 0,1779 & 0,3232 & 0,0032 & 0,0006 \\
\hline 20 & 5350 & 0,0160 & 1,7062 & 0,1873 & 0,3195 & 0,0032 & 0,0006 \\
\hline 21 & 4900 & 0,0146 & 1,5627 & 0,1966 & 0,3073 & 0,0030 & 0.0006 \\
\hline 22 & 4645 & 0,0139 & 1,4814 & 0,2060 & 0,3052 & 0,0030 & 0,0006 \\
\hline 23 & 4248 & 0,0127 & 1,3548 & 0,2154 & 0,2918 & 0,0029 & 0,0006 \\
\hline 24 & 4042 & 0,0121 & 1,2891 & 0,2247 & 0,2897 & 0,0029 & 0,0006 \\
\hline 25 & 3964 & 0,0118 & 1,2642 & 0,2341 & 0,2959 & 0,0029 & 0,0007 \\
\hline 26 & 3899 & 0,0116 & 1,2435 & 0,2434 & 0,3027 & 0,0030 & 0,0007 \\
\hline 27 & 3727 & 0,0111 & 1,1886 & 0,2528 & 0,3005 & 0,0030 & 0,0008 \\
\hline 28 & 3583 & 0,0107 & 1,1427 & 0,2622 & 0,2996 & 0,0030 & 0,0008 \\
\hline 29 & 3448 & 0,0103 & 1,0996 & 0,2715 & 0,2986 & $0,00 \overline{30}$ & 0,0008 \\
\hline 30 & 3333 & 0,0100 & 1,0630 & 0,2809 & 0,2986 & 0,0030 & 0,0008 \\
\hline 31 & 3174 & 0,0095 & 1,0123 & 0,2903 & 0,2938 & 0,0029 & 0,0008 \\
\hline 32 & 3075 & 0,0092 & 0,9807 & 0,2996 & 0,2938 & 0,0029 & 0,0009 \\
\hline 33 & 3048 & 0,0091 & 0,9721 & 0,3090 & 0,3004 & 0,0030 & 0,0009 \\
\hline
\end{tabular}




\section{V - RESULT ADOS E DISCUSSÕES}

Os resultados de medidas microdosimétricas obtidos usando o sistema de TEPC e o reator de pesquisa da Texas A\&M University conjugado com o sistema de filtro de nêutron rápido severamente filtrado são apresentados a seguir.

Para a obtenção de um espectro microdosimétrico é necessário a obtenção dos espectros para alto e baixo ganho. que são depois agrupados para comporem um só espectro. As tabelas e os espectros serão todos apresentados. sendo que para a potência do reator de $0.5 \mathrm{~kW}$ serão apresentadas e comentadas todas as tabelas e espectros. Para as potências de $1,0 \mathrm{~kW}$ e $2.0 \mathrm{~kW}$ serão apresentados e comentados somente os espectros.

\section{1 - Cálculos microdosimétricos para alto ganho - Potência do reator de 0,5 KW}

Na Tabela 5.1 são apresentados dados provenientes do TEPC para nêutrons rápidos de reator operando a uma potência de $0,5 \mathrm{~kW}$ para alto ganho como o número de eventos com radiação de fundo (nerf). o número de eventos de radiação de fundo (lf) e o número de eventos. n. subtraida a radiação de fundo. Sào apresentadas, também, a energia lineal, $y$, e outras grandezas microdosimétricas calculadas como f(y). $y f(y), d(y)$ e $y d(y)$. Essa série de grandezas é imprescindivel para a obtenção dos espectros microdosimétricos, e, por conseguinte. a descrição da deposição de energia ao nivel microdosimétricos no interior da matéria. Nesse experimento foi usado um número de 1024 canais, que não estão todos apresentados aqui, mas que estão apresentados nos anexos. O número de eventos em cada canal é apresentado na coluna $n$, aqui para alto ganho. Os primeiros 15 canais não apresentam eventos, isso é definido pelo discriminador de nivel mais baiso (LLD). O LLD é suficientemente grande o bastante para se obter o melhor tempo morto possivel. Com um alto LLD, uma grande região do contador, que envolve os primeiros canais, não terá seus eventos registrados pelo MCA.

Para a obtenção de $f(y)$ delta. foi usado a seguinte relação: 


$$
f(y) d e l t a=\frac{n_{1}}{\sum_{v} n_{s}}
$$

onde $n_{j}$ representa o número de eventos, $n$. em cada canal.

Na obtenção de $\mathrm{f}(\mathrm{y})$, função de distribuição de energia lineal. recorre-se à relação:

$$
f_{1}(y)=\frac{f_{1}(y) d e l u a}{\Delta y}
$$

Nessa equação $\Delta y$ ' é dado pela equação 4.2.

Quando a energia lineal y é multiplicada por f(y) obtém-se o espectro y $x$ yf $(y)$ da figura 5.1. que apresenta a distribuição de freqüència de enerģia lineal para alto ganho para uma potência de reator de $0.5 \mathrm{~kW}$.

A obtenção da função de distribuição de dose absorvida de energ̣ia lineal. $d(y)$, é obtida através da seguinte relação:

$$
d(y)=\frac{x(y)}{\sum y, t ! n}
$$

Finalmente, a última grandeza fundamental para a descrição do depósito de energia no interior da matéria, $y d(y)$. com ela se obtém o espectro de y x yd( $(v)$. apresentado na figura 5.2. que fornece a distribuição de dose de energia lineal.

Os dois espectros apresentados nas figuras 5.1 e 5.2 são para alto ganho. onde são apresentados os resultados dos eventos em cada um dos 1024 canais usados. Só que. a forma como são apresentados, pouca informação pode ser retirada. Assim sendo. para uma melhor visualização do espectro há necessidade de se fazer um agrupamento de canais.

Um ganho de 100 significa que o amplificador espectroscópico amplia o sinal proveniente do pré-amplificador em 100 vezes. Isto se faz necessário porque permite 
captar os eventos numa região de energia haixa que vai de menos de $1 \mathrm{keV} / \mu \mathrm{m}$ até $10 \mathrm{keV} / u m$. que é a região onde a radiação gama se apresenta. Em baxo ganho. será mostrado. que não se consegue colher os eventos dessa região. Nesse experimento associou-se um alto ganho com um baixo ruido.

Tabela 5.1 - Dados provenientes do TEPC para nêutrons rápidos de reator operando a uma potència de $0.5 \mathrm{~kW}$ e alto ganho. Na tabela são apresentados: número de eventos com radiação de fundo (ncrf), número de eventos de radiação de fundo (rf). número de eventos. 11, subtraídos a radiação de fundo, energia lineal (y) e outras grandezas microdosimétricas calculadas como, $\mathrm{f}(\mathrm{y}), \mathrm{yf}(\mathrm{y}), \mathrm{d}(\mathrm{y})$ e $\mathrm{yd}(\mathrm{y})$.

\begin{tabular}{|c|c|c|c|c|c|c|c|c|c|}
\hline Canais & r.f & ncrf & $\mathrm{n}$ & $y$ & $f(y)$ delta & $f(y)$ & $y f(y)$ & $d(y)$ & $y d(y)$ \\
\hline 0 & 0 & 0 & 0 & 0,0000 & 0,0000 & 0,0000 & 0,0000 & 0,0000 & 0,0000 \\
\hline 1 & 0 & 0 & 0 & 0,0435 & 0,0000 & 0,0000 & 0,0000 & 0,0000 & 0,0000 \\
\hline 2 & 0 & 0 & 0 & 0,0870 & 0,0000 & 0,0000 & 0,0000 & 0,0000 & 0,0000 \\
\hline 3 & 0 & 0 & 0 & 0,1305 & 0,0000 & 0,0000 & 0,0000 & 0,0000 & 0,0000 \\
\hline 4 & 0 & 0 & 0 & 0,1740 & 0,0000 & 0,0000 & 0,0000 & 0,0000 & 0,0000 \\
\hline 5 & 0 & 0 & 0 & 0,2175 & 0,0000 & 0,0000 & 0,0000 & 0,0000 & 0,0000 \\
\hline 6 & 0 & 0 & 0 & 0,2610 & 0,0000 & 0,0000 & 0,0000 & 0,0000 & 0,0000 \\
\hline 7 & 0 & 0 & 0 & 0,3045 & 0,0000 & 0,0000 & 0,0000 & 0,0000 & 0,0000 \\
\hline 8 & 0 & 0 & 0 & 0,3480 & 0,0000 & 0,0000 & 0,0000 & 0,0000 & 0,0000 \\
\hline 9 & 125 & 0 & 0 & 0,3915 & 0,0000 & 0,0000 & 0,0000 & 0,0000 & 0,0000 \\
\hline 10 & 225 & 0 & 0 & 0,4350 & 0,0000 & 0,0000 & 0,0000 & 0,0000 & 0,0000 \\
\hline 11 & 183 & 0 & 0 & 0,4785 & 0,0000 & 0,0000 & 0,0000 & 0,0000 & 0,0000 \\
\hline$\overline{12}$ & $17 \overline{4}$ & 0 & 0 & 0,5220 & 0,0000 & 0,0000 & 0,0000 & 0,0000 & 0,0000 \\
\hline 13 & 133 & 0 & 0 & 0,5655 & 0,0000 & 0,0000 & 0,0000 & 0,0000 & 0,0000 \\
\hline 14 & 100 & $\overline{0}$ & 0 & 0,6090 & 0.0000 & 0,0000 & 0,0000 & 0,0000 & 0,0000 \\
\hline 15 & 84 & 44 & 0 & 0,6525 & 0,0000 & 0,0000 & 0,0000 & 0,0000 & 0,0000 \\
\hline 16 & 88 & 1050 & 962 & 0,6960 & 0,0001 & 0,0022 & $0, \overline{0016}$ & 0,0000 & 0,0000 \\
\hline 17 & 69 & 324242 & 324173 & 0,7395 & 0,0327 & 0,7521 & 0,5562 & 0,0027 & 0,0020 \\
\hline 18 & 60 & 459037 & 458977 & 0,7830 & 0,0463 & 1,0648 & 0,8338 & 0,0041 & 0,0032 \\
\hline 19 & 64 & 396589 & 396525 & 0,8265 & 0,0400 & 0,9200 & 0,7603 & 0,0037 & 0,0031 \\
\hline 20 & 48 & 345096 & 345048 & $\overline{0,8700}$ & $\overline{0.0348}$ & 0,8005 & 0,6965 & 0,0034 & 0,0030 \\
\hline 21 & 52 & 304263 & 304211 & 0,9135 & 0,0307 & 0,7058 & 0,6447 & 0,0032 & 0,0029 \\
\hline 22 & 52 & 268856 & 268804 & 0,9570 & 0,0271 & $0, \overline{6236}$ & 0,5968 & 0,0029 & 0,0028 \\
\hline 23 & 40 & 239907 & 239867 & 1,0005 & 0,0242 & 0,5565 & 0,5568 & 0,0027 & 0,0027 \\
\hline 24 & 45 & 215915 & 215870 & 1,0440 & 0,0218 & 0,5008 & 0,5229 & 0,0026 & 0,0027 \\
\hline 25 & 46 & 194534 & 194488 & 1,0875 & 0,0196 & 0,4512 & 0,4907 & 0,0024 & 0,0026 \\
\hline 26 & 45 & 175942 & 175897 & 1,1310 & 0,0178 & 0,4081 & 0,4615 & 0,0023 & 0,0026 \\
\hline 27 & 34 & 160360 & 160326 & 1,1745 & 0,0162 & 0,3720 & $0, \overline{4369}$ & 0,0022 & 0,0025 \\
\hline 28 & 37 & 147215 & 147178 & 1,2180 & 0,0149 & 0,3415 & 0,4159 & 0,0020 & 0,0025 \\
\hline 29 & $\overline{46}$ & 134675 & 134629 & 1,2615 & 0,0136 & 0,3123 & 0,3940 & 0,0019 & 0,0024 \\
\hline 30 & 47 & 124636 & 124589 & 1,3050 & 0,0126 & 0,2891 & 0,3772 & 0,0019 & 0,0024 \\
\hline 31 & 49 & 115440 & 115391 & 1,3485 & 0,0116 & 0,2677 & 0,3610 & 0,0018 & 0,0024 \\
\hline 32 & 46 & 107636 & 107590 & 1,3920 & 0,0109 & 0,2496 & $0, \overline{3475}$ & 0,0017 & 0,0024 \\
\hline 33 & 49 & 99848 & 99799 & 1,4355 & 0,0101 & 0,2315 & 0,3324 & 0,0016 & 0,0023 \\
\hline 34 & 34 & 93264 & 93230 & 1,4790 & 0.0094 & 0,2163 & 0,3199 & 0,0016 & 0,0023 \\
\hline 35 & 27 & 87570 & 87543 & 1,5225 & 0,0088 & 0,2031 & 0,3092 & 0,0015 & 0,0023 \\
\hline
\end{tabular}




\section{y $x$ yf(y) (de alto ganho de nêutron rápido de reator) \\ Potência $=0.5 \mathrm{~kW}$}

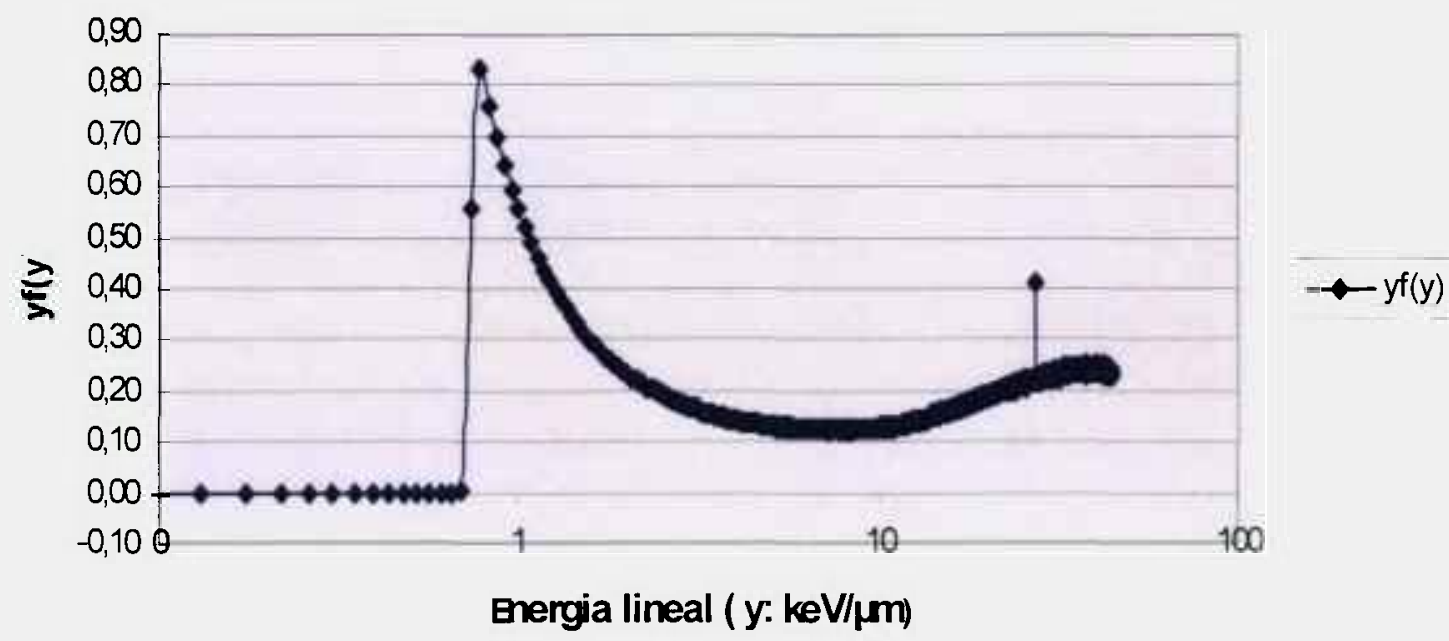

Figura 5.1 - Distribuição de freqüência de energia lineal. $\log (\mathrm{y})$ x yf(y), para alto ganho, para nêutrons rápidos de reator operando a uma potência de $0,5 \mathrm{~kW}$.

\section{y $x$ ydy) (y) (de alto ganho de nêutron rápido de reator) \\ Potência $=0.5 \mathrm{~kW}$}

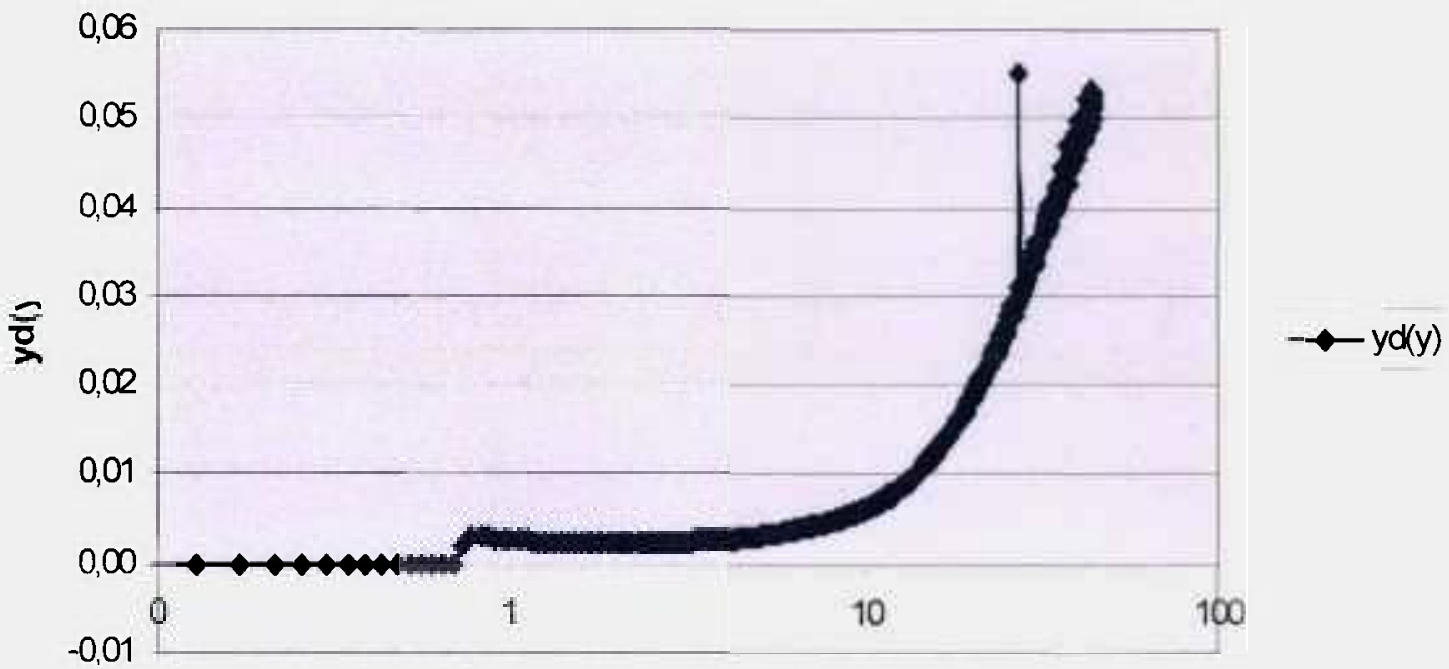

Energia lineal (y:keV//m)

Figura 5.2 - Distribuição de dose de energia lineal, $\log (\mathrm{y}) \mathrm{x} \mathrm{yd}(\mathrm{y})$, para alto ganho, para nêutrons rápidos de reator operando a uma potência de $0.5 \mathrm{~kW}$. 
Para se interpretar um espectro como os mostrados na figura 5.1 e 5.2 é preciso "limpar" o gráfico, deixando-o com menos pontos, para assim permitir uma melhor visualização de suas nuances. Para isso é usado o método de àgrupamento (binned). que agrupa vários canais em um binned, que são apresentados na tabela 2. Esse procedimento será discutido a seguir.

Um dos primeiros procedimentos para a realização do agrupamento é, após a obtenção do número de eventos sem radiação de fundo, fazer a extrapolação dos canais em que os eventos não são visiveis em conseqüência do discriminador de mais baixo nivel (LLD). Depois de realizada a extrapolação, o segundo passo é calcular o delta n. que vai determinar quantos canais serão agrupados em cada binned. Para isso foi usada a seguinte associação:

$$
\text { delia } n=2^{\text {imteiro(canallat) }}
$$

Com isso obtém-se uma variação na quantidade de agrupamento de canais a cada 6 binned, e, por fim, podem ser agrupados todos os 1024 canais em poucos agrupamentos (binned).

O canal inicial define qual é o primeiro canal a fazer parte de um determinado binned e o canal tỉnal qual será o último. as linhas inicial e final determinam a localização dos referidos canais.

A segunda parte da planilha para o cálculo dos agrupamentos de canais é apresentada na tabela 5.3. São mostrados nas primeiras duas colunas o yinicial e o y litual. que são calculados através do $\Delta y$, já apresentado na equação 4.2. Para isso foi usado o seguinte procedimento:

$$
\begin{gathered}
y_{\text {inicial }}=\text { Canal inicial } x \Delta y-\Delta y / 2 \\
\text { c } \\
y_{\text {tinil }}=\text { Canal tinal } x \Delta y+\Delta y / 2
\end{gathered}
$$


A energia lineal y foi calculada fazendo-se a média entre yinicial $y_{\text {linal }}$ ou

seja.

$$
y=\left(y_{\text {inicial }}+y_{\text {lintil }}\right) / 2
$$

Para o cálculo do novo n, que é a soma do número de eventos de um determinado número de canais. foi usada a seguinte equação:

$$
\text { novo } n=\sum_{i=}^{d} \text { canais }
$$

onde ci e cf são. respectivamente, os canais inicial e final de um determinado agrupamento de canais.

O cálculo de $f(y)$ delta foi feito da mesma forma que já foi apresentado na tabela 5.1. só que aqui tem uma pequena diferença nas grandezas do numerador e do denominador da divisão. ou seja.

$$
f(y) \text { dela } a=\frac{\operatorname{nowo}\left(n_{i}\right)}{\sum \operatorname{novo}\left(n_{t}\right)}
$$

No cálculo do $\mathrm{f}(\mathrm{y})$ da tabela 3 tem-se uma mudança muito importante. já que o $\Delta y$ da equação 5.2, que é o mesmo da equação 4.2, possui um valor constante, e a diferença de energ̣ia entre um canal e seu anterior ou entre o canal e o seu posterior tem sempre o mesmo valor, $\Delta y$. Aqui, quando se recorre aos agrupamentos, essa diferença não é mais constante. porque os agrupamentos podem ter difèrentes quantidades de canais. Assim a relação que fornece os valores de $f(y)$ será:

$$
f_{f}(y)=\frac{f_{i}(y) d d^{2} l a}{\left(y_{\text {firmal }}-y_{\text {mencial }}\right)}
$$

Os cálculos das outras grandezas como yf(y), d(y) e yd(y) seguem os mesmos procedimentos daqueles usados no cálculo das mesmas grandezas da tabela 5.1 . 
Tabela 5.2 - Primeira parte de uma planilha para agrupamento (binned) de canais de alto ganho para nêutrons rápidos de reator operando a uma potência de $0,5 \mathrm{~kW}$. Na tabela são apresentados os canais, o número de eventos sem radiação de fundo (nsrf). o número de eventos com extrapolação, n. o delta n, que define quantos canais estão sendo envolvidos no agrupamento (hinned). o canal inicial e final que estão sendo agrupados. e as linhas iniciais e fimais onde se situam os canais envolvidos.

\begin{tabular}{|c|c|c|c|c|c|c|c|}
\hline Canais & nsrf & $\mathbf{n}$ & delta $n$ & $\begin{array}{l}\text { Canal } \\
\text { inicial }\end{array}$ & $\begin{array}{c}\text { Canal } \\
\text { final }\end{array}$ & $\begin{array}{l}\text { Linha } \\
\text { inicial }\end{array}$ & $\begin{array}{c}\text { Linha } \\
\text { Final }\end{array}$ \\
\hline & 0 & 785000 & 1 & 0 & 0 & 2 & $\overline{2}$ \\
\hline 1 & 0 & 775000 & 1 & 1 & 1 & 3 & 3 \\
\hline 2 & 0 & 760000 & 1 & 2 & 2 & 4 & 4 \\
\hline 3 & 0 & 745000 & 1 & 3 & 3 & 5 & 5 \\
\hline 4 & 0 & 730000 & 1 & 4 & $\overline{4}$ & 6 & $\overline{6}$ \\
\hline 5 & 0 & 710000 & 1 & 5 & 5 & 7 & 7 \\
\hline 6 & 0 & 680000 & 2 & $\overline{6}$ & $\overline{7}$ & 8 & 9 \\
\hline 7 & 0 & 660000 & 2 & 8 & 9 & 10 & 11 \\
\hline 8 & 0 & 640000 & 2 & 10 & 11 & 12 & 13 \\
\hline 9 & 0 & 610000 & 2 & 12 & 13 & 14 & 15 \\
\hline 10 & 0 & 590000 & 2 & $\overline{14}$ & 15 & 16 & 17 \\
\hline 11 & 0 & 565000 & 2 & 16 & 17 & 18 & 19 \\
\hline$\overline{12}$ & 0 & 555000 & 4 & 18 & 21 & 20 & 23 \\
\hline 13 & 0 & 540000 & 4 & 22 & 25 & 24 & 27 \\
\hline 14 & 0 & 535000 & 4 & 26 & 29 & 28 & 31 \\
\hline 15 & 44 & 518000 & 4 & 30 & 33 & 32 & 35 \\
\hline$\overline{16}$ & 1050 & 498000 & 4 & 34 & 37 & 36 & 39 \\
\hline 17 & 324242 & 478000 & $\overline{4}$ & 38 & 41 & 40 & 43 \\
\hline 18 & 459037 & 458977 & 8 & $\overline{42}$ & 49 & 44 & 51 \\
\hline 19 & 396589 & 396525 & 8 & 50 & 57 & 52 & $\overline{59}$ \\
\hline 20 & 345096 & 345048 & 8 & 58 & 65 & 60 & 67 \\
\hline 21 & 304263 & 304211 & 8 & 66 & 73 & 68 & 75 \\
\hline$\overline{22}$ & 268856 & 268804 & 8 & 74 & 81 & 76 & 83 \\
\hline 23 & 239907 & 239867 & 8 & 82 & 89 & 84 & 91 \\
\hline 24 & 215915 & 215870 & 16 & 90 & 105 & 92 & 107 \\
\hline 25 & 194534 & 194488 & 16 & 106 & 121 & 108 & $12 \overline{123}$ \\
\hline 26 & 175942 & 175897 & 16 & 122 & 137 & 124 & 139 \\
\hline 27 & 160360 & 160326 & 16 & 138 & 153 & 140 & 155 \\
\hline 28 & 147215 & 147178 & 16 & 154 & 169 & 156 & 171 \\
\hline 29 & 134675 & 134629 & 16 & $17 \overline{70}$ & 185 & 172 & 187 \\
\hline 30 & 124636 & 124589 & 32 & 186 & 217 & 188 & 219 \\
\hline$\overline{31}$ & 115440 & 115391 & 32 & 218 & $\overline{249}$ & 220 & 251 \\
\hline 32 & 107636 & 107590 & 32 & 250 & 281 & 252 & 283 \\
\hline 33 & 99848 & $9 \overline{9799}$ & 32 & 282 & 313 & 284 & 315 \\
\hline $34=$ & 93264 & 93230 & 32 & 314 & 345 & 316 & 347 \\
\hline 35 & 87570 & 87543 & 32 & 346 & 377 & 348 & 379 \\
\hline
\end{tabular}


Tabela 5.3 - Segunda parte de uma planilha para agrupamento (binned) de canais de alto granho para nêutrons rápidos de reator operando a uma potência de $0.5 \mathrm{~kW}$. Na tabela são mostrados a energia lineal, y, inicial e final referente a um agrupamento de canais. a energia lineal. resultado da média entre as duas anteriores, além do novo 11 . soma dos eventos de um determinado agrupamento de canais, $f(y)$ delta, $f(y)$, yf(y). d(y) e yd(y).

\begin{tabular}{|c|c|c|c|c|c|c|c|c|}
\hline$y$ inicial & $y$ final & $y$ & novo $\mathrm{n}$ & $f(y)$ delta & $f(y)$ & $y f(y)$ & $d(y)$ & $y d(y)$ \\
\hline$-0,0218$ & 0,0218 & 0,0000 & 785000 & 0,0375 & 0,8611 & 0,0000 & 0,0000 & 0,0000 \\
\hline 0,0218 & 0,0653 & 0,0435 & 775000 & 0,0370 & 0,8501 & 0,0370 & 0,0064 & 0,0003 \\
\hline 0,0653 & 0,1088 & 0,0870 & 760000 & 0,0363 & 0,8337 & 0,0725 & 0,0125 & 0,0011 \\
\hline 0,1088 & 0,1523 & 0,1305 & 745000 & 0,0355 & $0, \overline{8172}$ & 0,1066 & 0,0183 & 0,0024 \\
\hline 0,1523 & 0,1958 & 0,1740 & 730000 & 0,0348 & 0,8007 & $0, \overline{1393}$ & $0, \overline{0239}$ & 0.0042 \\
\hline 0,1958 & 0,2393 & 0,2175 & 710000 & 0,0339 & 0,7788 & 0,1694 & 0,0291 & 0,0063 \\
\hline 0,2393 & 0,3263 & 0,2828 & 1340000 & 0,0639 & 0,7349 & 0,2078 & 0,0357 & 0,0101 \\
\hline 0,3263 & 0,4133 & 0,3698 & 1250000 & 0,0596 & 0,6856 & 0,2535 & 0,0436 & 0,0161 \\
\hline 0,4133 & 0,5003 & 0,4568 & 1155000 & 0,0551 & 0,6335 & 0,2893 & 0,0497 & 0,0227 \\
\hline 0,5003 & 0,5873 & 0,5438 & 1095000 & 0,0522 & 0,6006 & 0,3266 & 0,0561 & 0,0305 \\
\hline 0,5873 & 0,6743 & 0,6308 & 1053000 & 0,0502 & 0,5775 & 0,3643 & 0,0626 & 0,0395 \\
\hline 0,6743 & 0,7613 & 0,7178 & 976000 & 0,0466 & 0,5353 & 0,3842 & 0.0660 & 0,0474 \\
\hline 0,7613 & 0,9353 & 0,8483 & 1504761 & 0,0718 & 0,4126 & 0,3500 & 0.0601 & 0,0510 \\
\hline 0,9353 & 1,1093 & 1,0223 & 919029 & 0,0439 & 0,2520 & 0,2576 & 0,0443 & 0,0453 \\
\hline 1,1093 & 1,2833 & 1,1963 & 618030 & 0,0295 & 0,1695 & 0,2027 & 0,0348 & 0,0417 \\
\hline 1,2833 & 1,4573 & 1,3703 & 447369 & 0.0213 & 0,1227 & 0,1681 & 0,0289 & 0,0396 \\
\hline 1,4573 & 1,6313 & $1,54 \overline{43}$ & 340330 & 0,0162 & $0, \overline{0933}$ & 0,1441 & 0,0248 & 0,0382 \\
\hline 1,6313 & 1,8053 & 1,7183 & 272485 & 0,0130 & 0,0747 & 0,1284 & 0,0221 & 0,0379 \\
\hline 1,8053 & 2,1533 & 1,9793 & 410877 & 0,0196 & 0,0563 & 0,1115 & 0,0192 & $0, \overline{0379}$ \\
\hline 2,1533 & 2,5013 & 2,3273 & 301695 & 0,0144 & 0,0414 & 0,0963 & 0,0165 & 0,0385 \\
\hline 2,5013 & 2,8493 & 2,6753 & 235039 & 0,0112 & 0,0322 & 0,0862 & 0,0148 & 0,0396 \\
\hline 2,8493 & $3, \overline{1973}$ & 3,0233 & 190824 & 0.0091 & 0,0262 & 0,0791 & 0.0136 & 0,0411 \\
\hline 3,1973 & 3,5453 & 3,3713 & 159818 & 0,0076 & 0,0219 & 0,0739 & 0.0127 & 0,0428 \\
\hline 3,5453 & 3,8933 & 3,7193 & $13677 \overline{7}$ & $0, \widehat{0065}$ & 0.0188 & $0, \overline{0698}$ & 0.0120 & $0 . \overline{0446}$ \\
\hline 3,8933 & 4,5893 & 4,2413 & 227726 & 0,0109 & 0,0156 & 0,0662 & 0,0114 & 0,0483 \\
\hline $4, \overline{5893}$ & 5,2853 & 4,9373 & 183835 & 0,0088 & 0,0126 & 0,0622 & 0,0107 & 0,0528 \\
\hline $5,285 \overline{3}$ & 5,9813 & 5,6333 & 156904 & 0.0075 & 0,0108 & 0,0606 & 0,0104 & 0,0587 \\
\hline $5, \overline{9813}$ & $6, \overline{6773}$ & 6,3293 & 136771 & 0,0065 & 0,0094 & 0,0593 & 0.0102 & 0,0645 \\
\hline 6,6773 & 7,3733 & 7,0253 & 122035 & 0,0058 & 0,0084 & 0,0588 & 0,0101 & 0,0709 \\
\hline 7,3733 & 8,0693 & 7,7213 & 111169 & 0,0053 & 0,0076 & 0,0588 & 0.0101 & 0,0781 \\
\hline 8,0693 & 9,4613 & 8,7653 & 196309 & 0,0094 & 0,0067 & 0,0590 & 0.0101 & 0,0888 \\
\hline 9,4613 & 10,8533 & 10,1573 & 172882 & 0.0082 & 0,0059 & 0,0602 & 0,0103 & 0,1051 \\
\hline 10,8533 & 12,2453 & 11,5493 & 159523 & 0,0076 & 0,0055 & 0,0632 & 0,0109 & $0, \overline{1253}$ \\
\hline 12,2453 & 13,6373 & 12,9413 & 150911 & 0,0072 & 0,0052 & 0,0669 & 0,0115 & $0, \overline{1489}$ \\
\hline
\end{tabular}

As figuras 5.3 e 5.4 apresentam o espectro com os canais agrupados (binned) para alto ganho da distribuição de freqüência de energia lineal. $\log (y)$ x yf(y). para nèutrons rápidos de reator operando com potenncia de $0.5 \mathrm{~kW}$ e o espectro com os canais agrupados (binned) para alto ganho da distribuição de dose de energia lineal. $\log (y) x y d(y)$, para 
(binned) para alto ganho da distribuição de dose de energia lineal, $\log (\mathrm{y}) \mathrm{x} \mathrm{yd}(\mathrm{y})$, para nêutrons rápidos de reator com potência de $0.5 \mathrm{~kW}$, calculados através das planilhas apresentadas nas tabelas 5.2 e 5.3 .

\section{y $x$ yf(y) ("binned" de alto ganho de nêutron rápido de reator) Potência $=0.5 \mathrm{~kW}$}

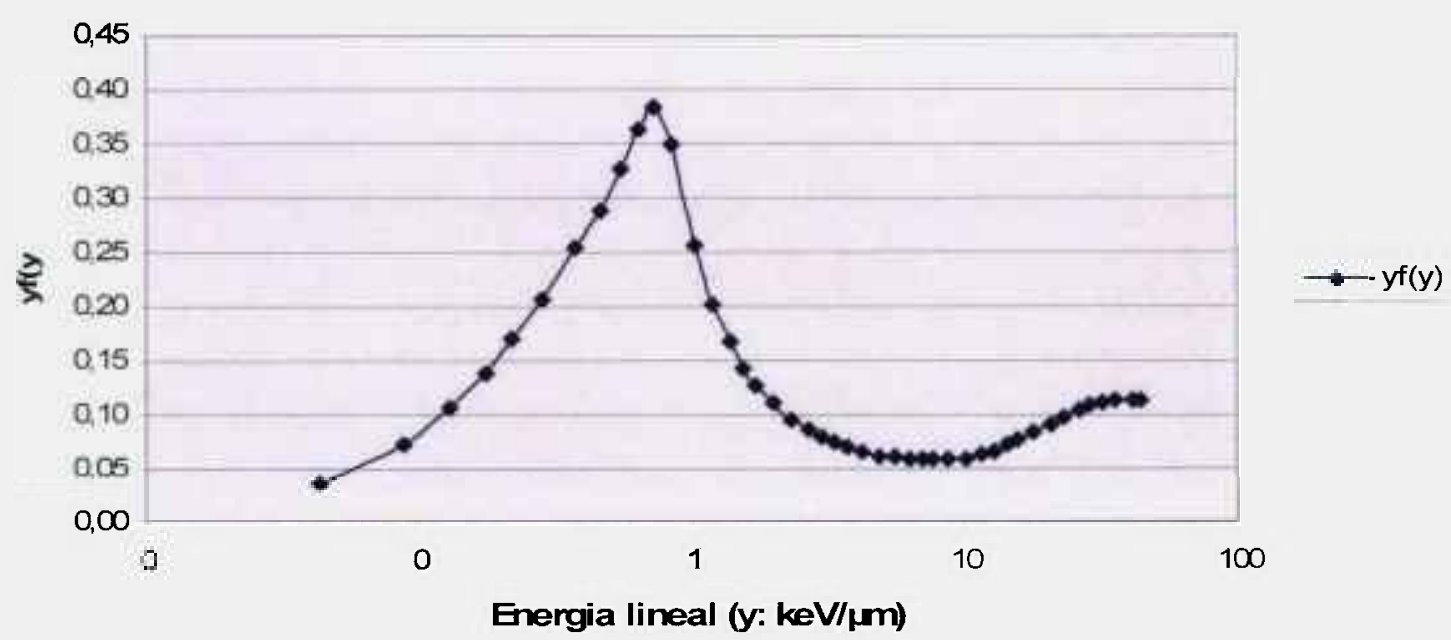

Figura 5.3 - Espectro com os canais agrupados (binned) para alto ganho da distribuição de freqüência de energia lineal, $\log (\mathrm{y})$ x yf(y), para nêutrons rápidos de reator operando com potência de $0,5 \mathrm{~kW}$ calculados através das planilhas apresentadas nas tabelas 5.2 e 5.3 .

y $x$ yd(y) ("binned" de alto ganho de nêutron rápido de reator) Potência $=0.5 \mathrm{~kW}$

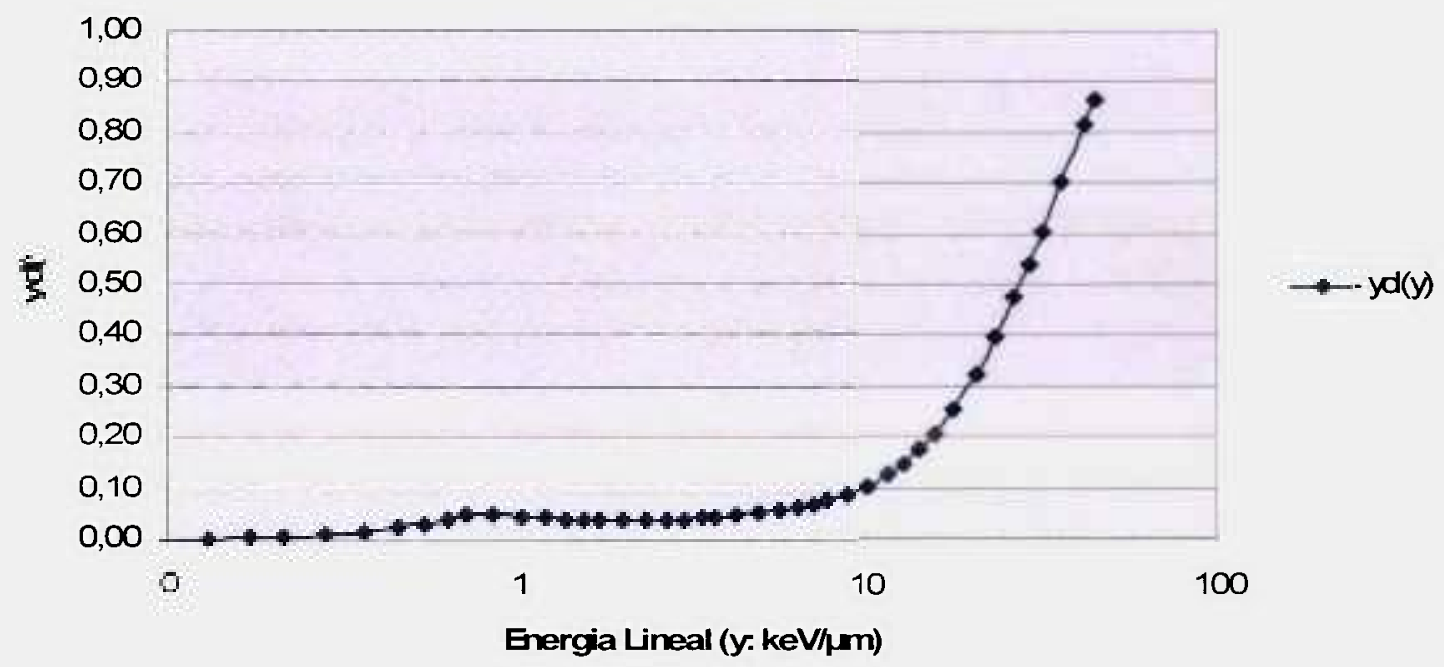




\section{2 - Cálculos microdosimétricos para baixo ganho - Potência do reator de $0,5 \mathrm{~kW}$}

Os procedimentos para os cálculos realizados para baixo ganho são os mesmos já apresentados para alto ganho. Existem alguns comentários a serem feitos. principalmente em relação ao número de canais quẹ não apresentam eventos. Enquanto que em alto ganho existe uma grande quantidade de canais que não apresentam eventos. em baixo ganho esse número é bem menor. Essa diferença é provocada pelos valores diversos do discriminador de mais baixo nível (LLD). Enquanto para baixo ganho o LL.D é de $1.12 \%$. para alto ganho ele é de $1,88 \%$. O ajuste correto desse fator é fundamental para evitar ruidos que possam prejudicar a obtenção de um bom espectro microdosimetrico.

Outra caracteristica a ser comentada é com respeito à região de energia coberta em baixo ganho. Pode-se ver que a região de radiação gama entre $1 \mathrm{keV}$ e $10 \mathrm{keV}$ não aparece no espectro, mas sim a região de mais alta energia, que é a região do próton de recuo. Nessa região, mesmo em baixo ganho. a obtenção de um bom espectro, havendo uma boa calibração do equipamento. é sempre possivel. Já a região de baixa energia. precisa de alto ganho, para a obtenção de um bom espectro, mas um alto ganho, precisa ter ajustado o melhor LLD possivel para evitar um alto ruido e com isso uma distorção no espectro. O LLD permite que apenas os sinais acima do nivel de ruido sejam registrados no espectro.

A tabela 5.4 mostra uma planilha usada para baixo ganho que possui as mesmas grandezas que em alto ganho, mas que difere em valores. Pode-se notar que o número de eventos por canal é muito menor que em alto ganho, porque se tem uma menor amplificação do sinal e, com isso, menos eventos serão registrados. Só que, com um menor LLD. o ruído será menor.

A extrapolação, como é feita em alto ganho, não se faz necessária em baixo ganho. já que todos os eventos na região de alta energia são todos registrados. Não é o que acontece em alto ganho, o que implica na necessidade da extrapolação. 
Tabela 5.4 - Dados provenientes do TEPC para nêutrons rápidos de reator com potência de $0.5 \mathrm{~kW}$ baixo ganho como: os canais. o número de eventos com radiação de fundo (ncrf). e o número de eventos, n. subtraidos a radiação de fundo. São apresentados. também, a energia lineal, $y$, e outras grandezas microdosimétricas calculadas como. $f(y)$. yf(y). d(y) e $y d(y)$.

\begin{tabular}{|c|c|c|c|c|c|c|c|c|}
\hline Canais & r.f. & ncrf & $n$ & $y$ & $f(y)$ delta & $y f(y)$ & $d(y)$ & $y d(y)$ \\
\hline 0 & 0 & 0 & 0 & 0 & 0,0000 & 0,0000 & 0,0000 & 0,0000 \\
\hline 1 & 0 & 0 & 0 & 1 & 0,0000 & 0,0000 & 0.0000 & 0,0000 \\
\hline 2 & 0 & 0 & 0 & 2 & 0,0000 & 0,0000 & 0.0000 & 0,0000 \\
\hline 3 & 0 & 0 & 0 & 3 & 0,0000 & 0,0000 & $0, \overline{0000}$ & 0,0000 \\
\hline 4 & 0 & 0 & 0 & 4 & 0,0000 & 0,0000 & 0.0000 & 0,0000 \\
\hline 5 & 0 & 0 & 0 & 5 & 0,0000 & 0,0000 & 0,0000 & 0,0000 \\
\hline 6 & 0 & 0 & 0 & 6 & 0,0000 & 0,0000 & 0,0000 & 0,0000 \\
\hline 7 & 0 & $\overline{0}$ & 0 & 7 & 0,0000 & 0,0000 & 0,0000 & 0,0000 \\
\hline 8 & 0 & 11958 & 11958 & 8 & 0,0023 & 0,0183 & 0,0004 & 0,0032 \\
\hline 9 & 125 & 180153 & 180028 & 9 & 0,0345 & 0,3106 & 0,0067 & 0,0606 \\
\hline$\overline{10}$ & 225 & 161693 & 161468 & 10 & 0,0309 & 0,3095 & 0,0067 & 0,0670 \\
\hline 11 & 183 & 138624 & 138441 & $\overline{11}$ & 0,0265 & $0, \overline{2919}$ & $0,0 \overline{0063}$ & 0,0696 \\
\hline 12 & 174 & 122761 & 122587 & 12 & 0,0235 & 0,2820 & 0.0061 & 0,0733 \\
\hline 13 & 133 & 113159 & 113026 & $\overline{13}$ & 0,0217 & $0, \overline{2816}$ & 0,0061 & 0,0793 \\
\hline 14 & 100 & 106925 & 106825 & 14 & 0,0205 & 0,2867 & 0,0062 & 0,0869 \\
\hline 15 & $\overline{84}$ & 102885 & 102801 & 15 & 0,0197 & 0,2956 & 0,0064 & 0,0960 \\
\hline 16 & 88 & 100026 & 99938 & 16 & 0,0192 & 0,3065 & 0.0066 & 0,1062 \\
\hline 17 & 69 & 98335 & 98266 & 17 & 0,0188 & 0,3202 & 0.0069 & 0,1179 \\
\hline 18 & 60 & 96826 & 96766 & 18 & 0,0185 & 0,3339 & 0,0072 & 0,1302 \\
\hline 19 & 64 & 94047 & 93983 & 19 & 0,0180 & 0,3423 & 0.0074 & 0,1409 \\
\hline 20 & $\overline{48}$ & 93120 & 93072 & 20 & 0,0178 & 0,3568 & 0.0077 & 0,1546 \\
\hline 21 & 52 & $91 \overline{18}$ & 91466 & 21 & 0,0175 & 0,3682 & 0,0080 & 0,1675 \\
\hline 22 & 52 & 89894 & 89842 & 22 & 0.0172 & 0,3788 & 0.0082 & 0,1806 \\
\hline 23 & 40 & 87811 & 87771 & 23 & $0,0 \overline{168}$ & 0,3869 & 0.0084 & 0,1928 \\
\hline 24 & 45 & 86731 & 86686 & 24 & 0,0166 & 0,3988 & 0.0086 & 0,2073 \\
\hline 25 & 46 & 85185 & 85139 & 25 & 0,0163 & 0,4080 & 0,0088 & 0,2210 \\
\hline 26 & 45 & 83363 & 83318 & 26 & 0,0160 & 0,4152 & 0,0090 & 0,2339 \\
\hline 27 & 34 & 81914 & 81880 & 27 & 0,0157 & 0,4237 & 0,0092 & 0,2479 \\
\hline 28 & 37 & 79971 & 79934 & 28 & 0,0153 & 0,4290 & 0,0093 & 0,2602 \\
\hline 29 & 46 & 78697 & 78651 & 29 & 0,0151 & 0,4372 & 0,0095 & 0,2747 \\
\hline 30 & 47 & 77031 & 76984 & 30 & 0,0148 & 0,4427 & 0,0096 & 0.2877 \\
\hline 31 & 49 & 74928 & 74879 & 31 & 0,0144 & 0,4449 & 0.0096 & 0,2988 \\
\hline 32 & 46 & 73245 & 73199 & 32 & 0,0140 & 0,4490 & $0,00 \overline{97}$ & 0,3112 \\
\hline 33 & 49 & 71900 & 71851 & 33 & 0,0138 & 0,4545 & 0,0098 & 0,3249 \\
\hline 34 & 34 & 70162 & 70128 & 34 & 0,0134 & 0,4570 & 0.0099 & 0,3366 \\
\hline 35 & 27 & 68546 & 68519 & 35 & 0,0131 & 0,4597 & $\overline{0,0100}$ & 0,3485 \\
\hline
\end{tabular}

A Figura 5.5 apresenta o espectro da freqüência de distribuição de energia lineal. $\log (y)$ x y $f(y)$, para baixo ganho para nêutrons rápidos de reator operando a uma potência de $0.5 \mathrm{~kW}$ e a Figura 5.6 o espectro da distribuição de dose de energia lineal. log(y) x 
yd(y) para baixo ganho para nêutrons rápidos de reator operando a uma potência de $0,5 \mathrm{~kW}$.

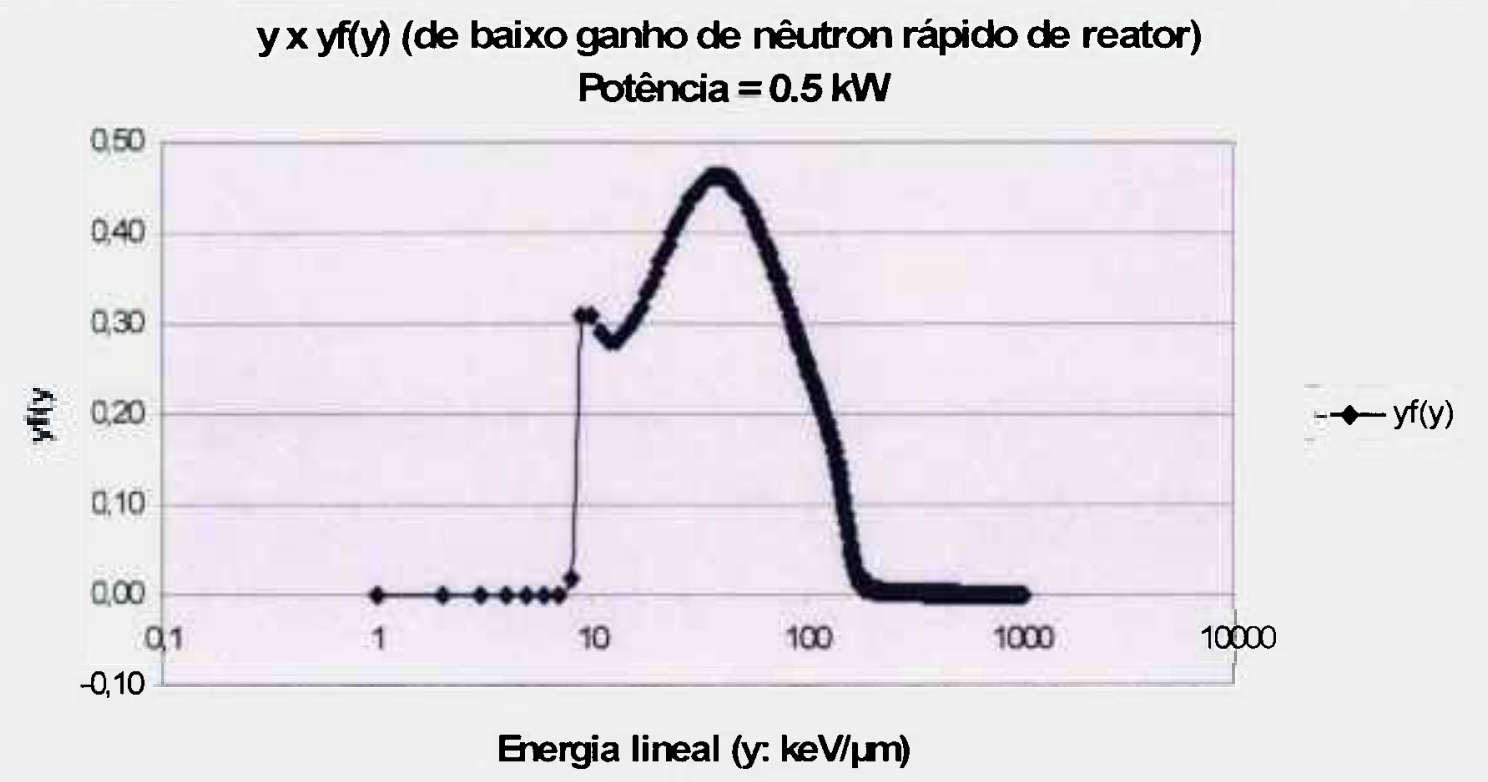

Figura 5.5 - Distribuição de freqüência de energia lineal, $\log (y)$ x yf(y), para baixo ganho, para nêutrons rápidos de reator operando a uma potência de $0,5 \mathrm{~kW}$.

y $x$ yd(y) (de baixo ganho de nêutron rápido de reator)

Potência $=0.5 \mathrm{~kW}$

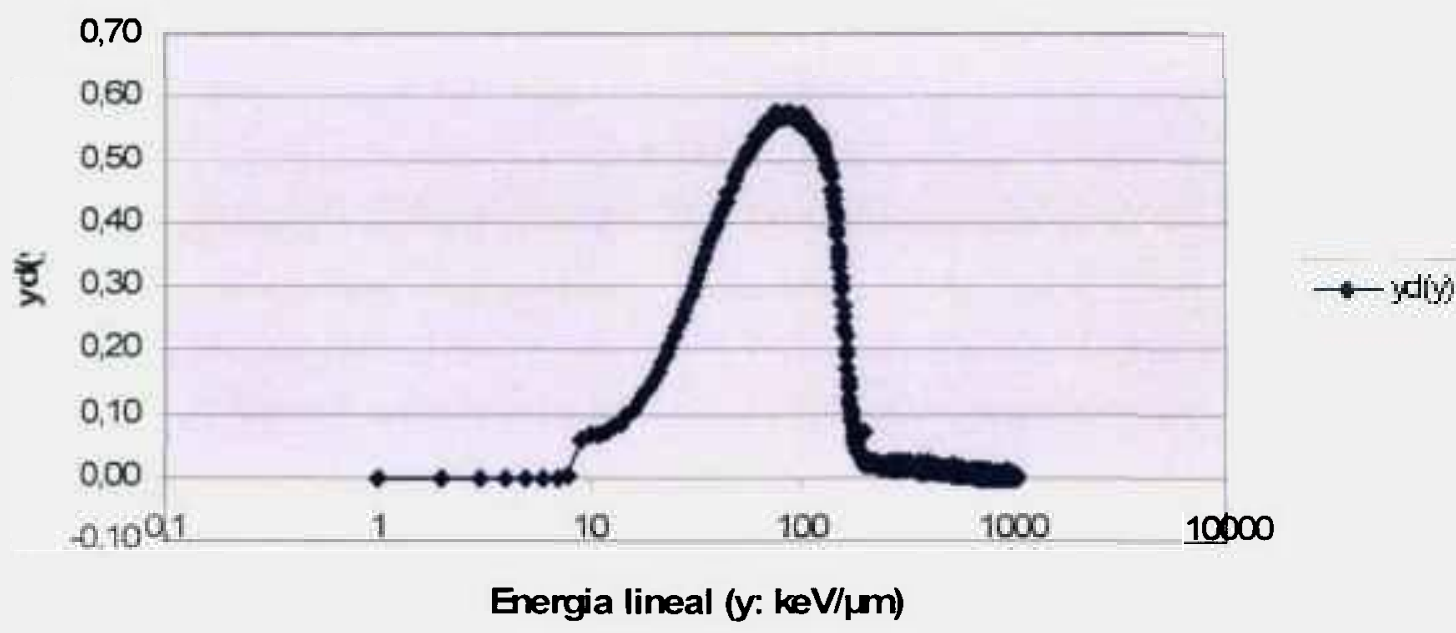

Figura 5.6 - Distribuição de dose de energia lineal, $\log (\mathrm{y}) \mathrm{x}$ yd(y), para baixo ganho, para nêutrons rápidos de reator operando a uma potência de $0.5 \mathrm{~kW}$. 
As tabelas 5.5 e 5.6 apresentam a planilha de cálculo das grandezas microdosimétricas necessárias para a obtenção dos espectros apresentados nas figuras 5.7 e 5.8. Todos os procedimentos e equaçòes referidos quando do cálculo das g̣randezas para alto ganho se aplicam às de baixo ganho. Portanto não serào novamente citados.

Pela mesma razão apresentada anteriomente em alto ganho, os agrupamentos em baixo ganho se fazem necessários para permitir uma melhor visualização dos detalhes presentes no espectro obtido como conseqüència do bombardeamento do gás propano no interior da cavidade do contador proporcional equivalente a tecido.

As figura 5.7 e 5.8 apresentain a parte referente ao próton de recuo. com o pico no gráfico $\log (y)$ x yd(y) próximo de $100 \mathrm{keV} / \mu \mathrm{m}$ e a extremidade direita da curva que define a região do próton em torno de $150 \mathrm{keV} / \mu \mathrm{m}$. O gráfico de distribuição de dose de energia lineal de baixo ganho da figura 5.8 já nos mostra que a maior parte da dose se encontra nessa região, e isso é esperado já que o próton de recuo é quem domina as ionizaçòes em radiações de nêutrons rápidos.

Na tabela 5.5 são mostrados para baixo ganho os canais. os eventos provenientes de radiação de fundo. os múmeros de eventos com radiação de fundo (ncrf), o número de eventos, $n$, resultado da subtração da radiação de fundo. o delta n. que define quantos canais estão sendo envolvidos no agrupamento (binned), o canal inicial e final que estão sendo agrupados, e finalmente as linhas iniciais e finais onde se situam os canais envolvidos. 
Tabela 5.5 - Primeira parte de uma planilha para agrupamento de canais de haixo ganho. para cálculo de grandezas microdosimétricas de nêutrons rápidos de reator operando a uma potência de $0.5 \mathrm{~kW}$.

\begin{tabular}{|c|c|c|c|c|c|c|c|c|}
\hline canais & rf & ncrf & $\bar{n}$ & delta $n$ & $\begin{array}{l}\text { Canal } \\
\text { inicial }\end{array}$ & $\begin{array}{l}\text { Canal } \\
\text { final }\end{array}$ & $\begin{array}{l}\text { Linha } \\
\text { inicial }\end{array}$ & $\begin{array}{l}\text { Linha } \\
\text { final }\end{array}$ \\
\hline 0 & 0 & 0 & 0 & 1 & 0 & 0 & 2 & 2 \\
\hline 1 & 0 & 0 & 0 & 1 & 1 & 1 & 3 & 3 \\
\hline 2 & 0 & 0 & 0 & 1 & 2 & 2 & 4 & 4 \\
\hline 3 & 0 & 0 & 0 & 1 & 3 & 3 & 5 & 5 \\
\hline 4 & 0 & 0 & 0 & 1 & 4 & 4 & 6 & 6 \\
\hline 5 & 0 & 0 & 0 & 1 & 5 & 5 & 7 & 7 \\
\hline 6 & 0 & 0 & 0 & 2 & 6 & 7 & 8 & 9 \\
\hline 7 & 0 & 0 & 0 & 2 & 8 & 9 & 10 & 11 \\
\hline 8 & 0 & 11958 & 11958 & 2 & 10 & 11 & 12 & 13 \\
\hline 9 & 125 & 180153 & 180028 & 2 & 12 & 13 & 14 & 15 \\
\hline 10 & 225 & 161693 & 161468 & 2 & 14 & 15 & 16 & 17 \\
\hline 11 & 183 & 138624 & 138441 & 2 & 16 & 17 & 18 & 19 \\
\hline 12 & 174 & 122761 & 122587 & 4 & 18 & 21 & 20 & 23 \\
\hline 13 & 133 & 113159 & 113026 & 4 & 22 & 25 & 24 & 27 \\
\hline 14 & 100 & 106925 & 106825 & 4 & 26 & 29 & 28 & 31 \\
\hline 15 & 84 & 102885 & 102801 & 4 & 30 & 33 & 32 & 35 \\
\hline 16 & 88 & 100026 & 99938 & 4 & 34 & 37 & 36 & 39 \\
\hline$\overline{17}$ & 69 & 98335 & 98266 & 4 & 38 & 41 & 40 & 43 \\
\hline 18 & 60 & 96826 & 96766 & 8 & 42 & 49 & 44 & 51 \\
\hline 19 & 64 & 94047 & 93983 & 8 & 50 & 57 & 52 & 59 \\
\hline 20 & 48 & 93120 & 93072 & 8 & 58 & 65 & 60 & 67 \\
\hline 21 & 52 & $915 \overline{18}$ & 91466 & 8 & $\overline{66}$ & 73 & 68 & 75 \\
\hline 22 & 52 & 89894 & 89842 & 8 & 74 & 81 & 76 & 83 \\
\hline 23 & 40 & 87811 & 87771 & 8 & 82 & 89 & 84 & 91 \\
\hline 24 & 45 & 86731 & 86686 & 16 & 90 & 105 & 92 & 107 \\
\hline 25 & 46 & 85185 & 85139 & 16 & 106 & 121 & 108 & 123 \\
\hline 26 & 45 & 83363 & 83318 & 16 & 122 & 137 & 124 & 139 \\
\hline 27 & 34 & 81914 & 81880 & 16 & 138 & 153 & 140 & 155 \\
\hline 28 & 37 & 79971 & 79934 & 16 & 154 & 169 & 156 & 171 \\
\hline 29 & 46 & 78697 & 78651 & 16 & 170 & 185 & 172 & 187 \\
\hline 30 & 47 & 77031 & 76984 & 32 & 186 & 217 & 188 & 219 \\
\hline 31 & $4 \overline{9}$ & 74928 & 74879 & 32 & 218 & 249 & 220 & 251 \\
\hline 32 & 46 & 73245 & 73199 & 32 & 250 & 281 & 252 & 283 \\
\hline 33 & 49 & 71900 & 71851 & 32 & 282 & 313 & 284 & 315 \\
\hline 34 & 34 & 70162 & 70128 & 32 & 314 & 345 & 316 & 347 \\
\hline 35 & $\overline{27}$ & 68546 & 68519 & 32 & 346 & 377 & 348 & 379 \\
\hline
\end{tabular}


Tabela 5.6 - Segunda parte de uma planilha para agrupamentos (binned) de canais de baixo ganho para nêutrons rápidos de reator operando a uma poténcia de $0.5 \mathrm{~kW}$. São mostrados a energia lineal. y. inicial e timal. referente a um agrupamento de canais. a energia lineal, resultado da média entre as duas anteriores. além do novo n. soma dos eventos de um determinado agrupamento de canais, $f(y)$ delta. $f(y)$. yf $(y), d(y)$ e $y d(y)$.

\begin{tabular}{|c|c|c|c|c|c|c|c|c|}
\hline y inicial & $y$ final & $y$ & novo $n$ & $f(y)$ delta & $f(y)$ & $y f(y)$ & $d(y)$ & $y d(y)$ \\
\hline$-0,50$ & 0,50 & 0,00 & 0 & 0,0000 & 0,0000 & 0,0000 & 0,0000 & 0,0000 \\
\hline 0.50 & 1,50 & 1,00 & 0 & 0,0000 & 0,0000 & 0,0000 & 0,0000 & 0,0000 \\
\hline 1,50 & 2,50 & 2,00 & 0 & 0,0000 & 0,0000 & 0,0000 & 0,0000 & 0,0000 \\
\hline 2,50 & 3,50 & 3,00 & 0 & 0,0000 & 0,0000 & 0,0000 & 0,0000 & 0,0000 \\
\hline 3,50 & 4,50 & 4,00 & 0 & 0,0000 & 0,0000 & 0,0000 & 0,0000 & 0,0000 \\
\hline 4,50 & 5,50 & 5,00 & 0 & 0,0000 & 0,0000 & 0,0000 & 0,0000 & 0,0000 \\
\hline 5,50 & 7,50 & 6,50 & 0 & 0,0000 & 0,0000 & 0,0000 & 0,0000 & 0.0000 \\
\hline 7.50 & 9,50 & 8,50 & 191986 & 0,0368 & 0,0184 & 0,1564 & 0,0220 & 0,1874 \\
\hline 9.50 & 11,50 & 10,50 & 299909 & 0,0575 & 0,0287 & 0,3018 & 0,0425 & 0,4467 \\
\hline 11,50 & 13,50 & 12,50 & 235613 & 0,0452 & 0,0226 & 0,2823 & 0,0398 & 0,4973 \\
\hline 13,50 & 15,50 & 14,50 & 209626 & 0,0402 & 0,0201 & 0,2913 & 0,0411 & 0,5954 \\
\hline 15,50 & 17,50 & 16,50 & 198204 & 0,0380 & 0,0190 & 0,3134 & 0,0442 & 0,7290 \\
\hline 17,50 & 21,50 & 19,50 & 375287 & $0, \overline{0719}$ & 0,0180 & 0,3507 & 0,0494 & 0.9639 \\
\hline 21,50 & 25,50 & 23,50 & 349438 & 0,0670 & 0,0167 & 0,3935 & 0,0555 & 1,3035 \\
\hline 25.50 & 29,50 & 27,50 & 323783 & 0,0621 & 0,0155 & 0,4267 & 0,0601 & 1,6539 \\
\hline 29,50 & 33,50 & 31,50 & 296913 & 0,0569 & 0,0142 & 0,4482 & 0,0632 & 1,9900 \\
\hline 33,50 & 37,50 & 35,50 & 271067 & 0,0520 & 0,0130 & 0,4611 & 0,0650 & 2,3074 \\
\hline 37,50 & 41,50 & 39,50 & 244430 & 0,0469 & 0,0117 & 0,4626 & 0,0652 & 2,5760 \\
\hline 41,50 & 49,50 & 45,50 & 417592 & 0,0800 & 0,0100 & 0,4552 & 0,0642 & 2,9197 \\
\hline 49,50 & 57,50 & 53,50 & 338326 & 0,0648 & 0,0081 & 0,4337 & 0,0611 & 3,2704 \\
\hline 57.50 & 65.50 & 61,50 & 272565 & 0,0522 & 0,0065 & 0,4016 & 0,0566 & 3,4816 \\
\hline 65,50 & 73,50 & 69,50 & 221850 & 0,0425 & 0,0053 & 0,3694 & 0,0521 & 3,6190 \\
\hline 73,50 & 81,50 & 77,50 & 183257 & 0,0351 & 0,0044 & 0,3403 & 0,0480 & 3,7173 \\
\hline 81,50 & 89,50 & 85.50 & 150718 & 0,0289 & 0,0036 & 0,3087 & 0,0435 & 3,7210 \\
\hline 89,50 & 105,50 & 97,50 & 229966 & 0,0441 & 0,0028 & 0,2686 & 0,0379 & 3,6915 \\
\hline 105.50 & 121,50 & 113,50 & 163506 & 0,0313 & 0,0020 & 0,2223 & 0,0313 & 3,5568 \\
\hline 121,50 & 137,50 & 129,50 & 115566 & 0,0222 & 0,0014 & 0,1793 & 0,0253 & 3,2727 \\
\hline 137,50 & 153,50 & 145,50 & 72145 & 0,0138 & 0,0009 & 0,1257 & 0,0177 & 2,5791 \\
\hline 153,50 & $\overline{169,50}$ & 161.50 & 30055 & $0, \overline{0058}$ & 0,0004 & 0,0581 & 0,0082 & 1,3237 \\
\hline 169.50 & 185,50 & 177,50 & 8215 & 0,0016 & 0,0001 & 0,0175 & 0,0025 & 0,4371 \\
\hline 185.50 & 217,50 & 201,50 & 5296 & 0,0010 & 0,0000 & 0,0064 & 0,0009 & 0,1816 \\
\hline 217,50 & 249,50 & 233,50 & 2782 & 0,0005 & 0,0000 & $0, \overline{0039}$ & 0,0005 & 0,1281 \\
\hline 249,50 & 281,50 & 265,50 & 2008 & 0,0004 & 0,0000 & 0,0032 & 0,0005 & 0,1195 \\
\hline 281,50 & 313,50 & 297,50 & 1582 & 0,0003 & $0, \overline{0000}$ & 0,0028 & 0,0004 & 0,1182 \\
\hline
\end{tabular}


y x yf(y) ("binned" de baixo ganho de nêutron rápido de reator) Potência $=0.5 \mathrm{~kW}$

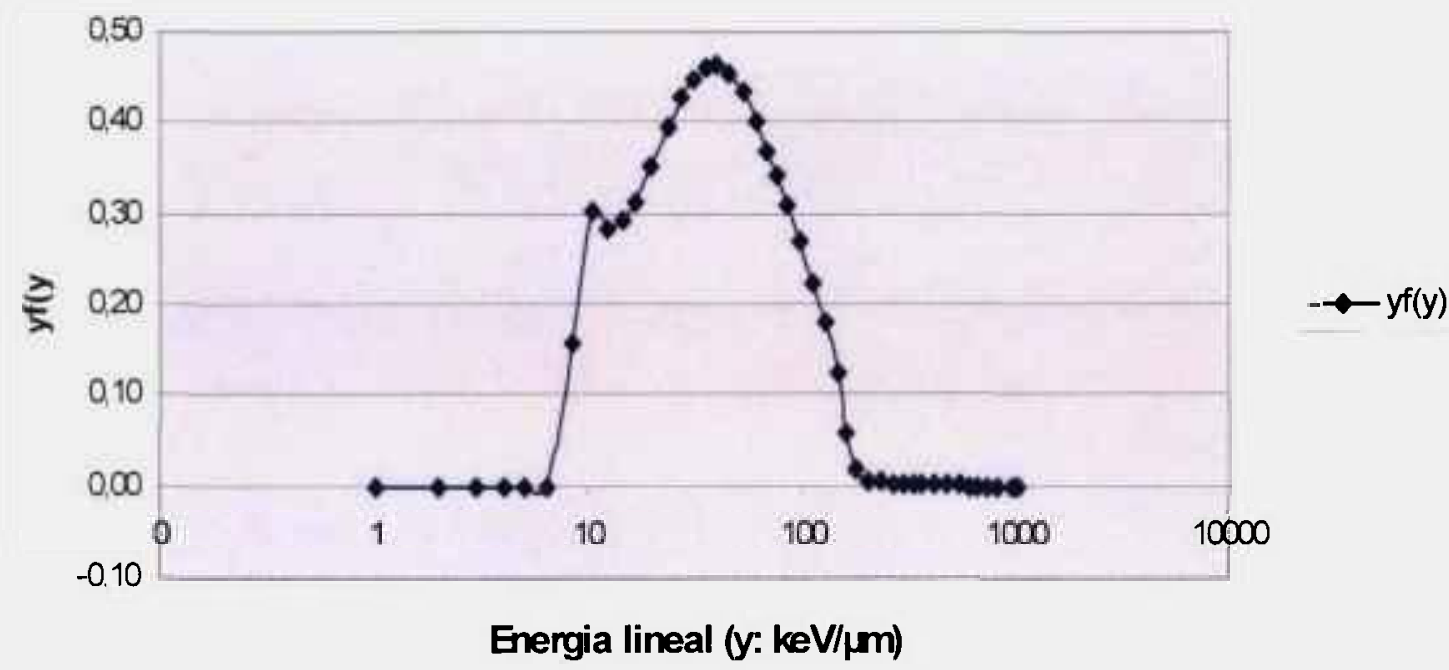

Figura 5.7 - Espectro com os canais agrupados (binned) para baixo ganho da distribuição de freqüência de energia lineal, $\log (\mathrm{y}) \times \mathrm{yf}(\mathrm{y})$, para nêutrons rápidos de reator operando com potência de $0,5 \mathrm{~kW}$.

y $x$ yol(y) ("binned" de baixo ganho de nêutron rápido de reator)

Potência $=0.5 \mathrm{~kW}$

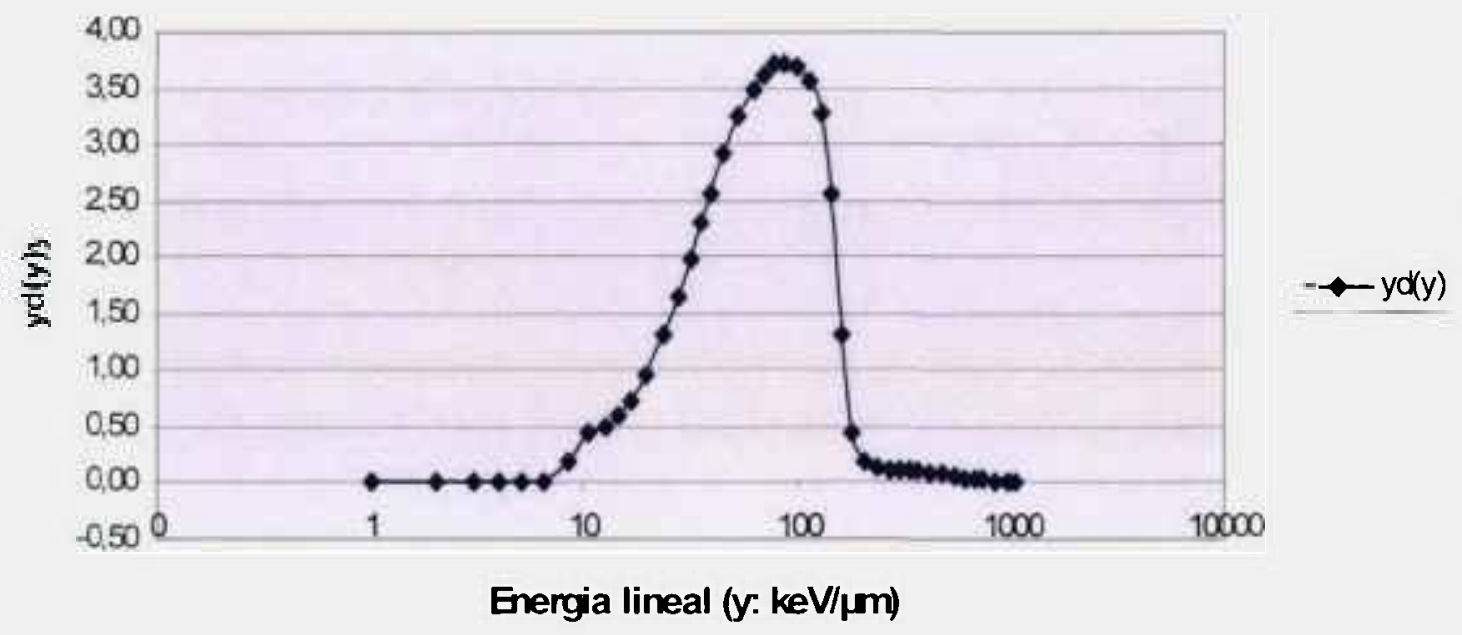

Figura 5.8 - Espectro com os canais agrupados (binned) para baixo ganho da distribuição de dose de energia lineal, $\log (\mathrm{y}) \mathrm{x} \mathrm{yd}(\mathrm{y})$, para nêutrons rápidos de reator operando com potência de $0,5 \mathrm{~kW}$. 


\section{3 - Medidas microdosimétricas para potência do reator de $0,5 \mathrm{~kW}$.}

Nas figuras 5.9 e 5.10 estão representados os espectros microdosimétricos de nêutrons rápidos de reator filtrados pelo sistema de nêutrons rápidos severamente filtrados para a potência de $0.5 \mathrm{~kW}$. Esses dois gráticos apresentam a junção dos gráticos (binned) de baixo e alto ganho mostrados nas figuras 5.3, 5.4, 5.7 e 5.8. sendo que o de distribuição de freqüência de energia lineal. figura 5.9. é produto da reunião entre os espectros das figuras 5.3 e 5.7, enquanto que o de distribuição de dose de energia lineal. figura 5.10. é o resultado da fusào dos espectros das figuras 5.4 e 5.8 .

A tabela 5.7 apresenta a planilha usada para o cálculo dos espectros microdosimétricos finais de nêutrons rápidos de reator para potência de $0.5 \mathrm{~kW}$. a qual envolve as mesmas grandezas da tabela 5.6. A diferença é que nessa nova tabela constam valores de energia tanto de alto ganho e de baixo ganho. que são unidos confrontando os canais onde a energia de um e de outro se confluem. O objetivo é encontrar o ponto onde o valor dos dois pontos extremos de um canal de mínima energia ( $y_{\min }$ ) para alto ganho e outro de máxima energia ( (⿳max) para baixo ganho permitam a conexão entre os dois espectros. Para esse experimento, o $y_{\text {min }}$ se encontra no canal 346 de alto ganho. extremidade inferior do binned, enquanto que o ýmax está no canal 15, extremidade superior do binned responsável pela junção dos dois espectros de alto e baixo ganho. Dos dois canais citados aqui, apenas o canal 15 pode ser visto nas tabelas 5.5 e 5.6 , sendo que o valor da energia lineal é mostrado na tabela 5.6, já o outro só poderá ser visto nas tabelas dos anexos desse trabalho.

As medidas no reator foram feitas na seguinte seqüência:

$1^{(9)}$ Medição da radiação de fundo, por uma hora com a alta tensão desligada.

$\left.2^{0}\right)$ Medição com potência do reator de $1.0 \mathrm{~kW}$ por $1 \mathrm{~h}$ para alto ganho e o mesmo tempo para baixo ganho.

$\left.3^{0}\right)$ Medição com potência do reator de 2,0 $\mathrm{kW}$, o mesmo período de $1 \mathrm{~h}$ para alto e baixo ganho.

$\left.4^{0}\right)$ Medição com potência do reator de $0,5 \mathrm{~kW}$, o mesmo procedimento dos dois últimos anteriores. 
O intervalo de tempo entre as mudanças de potências, de uma para outra. foi em torno de 7 minutos.

A seqüencia da obtenção dos espectros é importante para analisar o comportamento dos espectros, principalmente o de potência de $0,5 \mathrm{~kW}$. o último a ser obtido. O espectro de distribuição de freqüiencia de energia lineal, conforme mostra a figura 5.9. possui um pico proeminente em torno de $1,0 \mathrm{keV} /$ ụm. Esse pico está na região da radiação gama. que se encontra entre $0,1 \mathrm{keV} / \mu \mathrm{m}$ até próximo de $10 \mathrm{keV} / u m$. No espectro de distribuição de freqüiência a contribuição da radiação gama é muito grande.

A explicação para essa maior quantidade de radiação gama nessa potência é que ela é conseqüência do decaimento dos nêutrons provenientes dos experimentos realizados: anteriormente. com potências de níveis mais elevados. Tendo em vista que, as medidas com a potência de $0,5 \mathrm{~kW}$ foram realizadas logo após as medidas realizadas com as potências de $1,0 \mathrm{~kW}$ e $2,0 \mathrm{~kW}$ e em sendo a radiação gama um produto da fissão de nêutron. haverá uma maior concentração de radiação gama no interior da cavidade. aumentando com isso. a contaminação do nêutron por radiação gama durante as medidas com a potência de $0.5 \mathrm{~kW}$.

A radiação gama tem um impacto muito pequeno no espectro de distribuição de dose, e com isso pode-se ver que no gráfico de distribuiçào de dose para a potência de $\quad 0.5 \mathrm{~kW}$. apresentado na figura 5.10 a região referente à radiação gama é muito pequena em relação à do próton de recuo, que vai de cerca de $10 \mathrm{keV} / \mu \mathrm{m}$ até a outra extremidade que é cerca de $150 \mathrm{keV} / \mu \mathrm{m}$. A contribuição da radiação gama na dose é de cerca de $5 \%$. enquanto que o próton de recuo responde por cerca de $95 \%$ do total. Isso mostra que o sistema de filtragem dos nêutrons usado é muito eficiente. e será mostrado que nas outras potências a contaminação é menor ainda.

Não foi possivel comparar esses resultados comentados acima com outros na literatura cientifica, porque um dos trabahos que procurou reduzir a contaminação do néutron pela radiação gama (Srdoc e Marino. 1981). o fez. usando a técnica da subtração do espectro de radiação gama obtido separadamente em outro experimento, ou seja. através da irradiação do TEPC $\operatorname{com}{ }^{60} \mathrm{Co}$, do espectro contendo a radiação de nêutron e gama juntas. 
através da irradiação do TEPC $\operatorname{com}{ }^{60} \mathrm{Co}$. do espectro contendo a radiação de nèutron e gama juntas.

Outra técnica usada é considerar que a presença da radiação gama está entre $1.0 \mathrm{keV}$ e $10.0 \mathrm{keV}$ e eliminar essa parte do espectro de nêutrons, considerando que a sua contribuição é desprezírel fiente à da radiação do nêutron (Nunomiya et al, 2002).

A grande diferença entre o experimento realizado nesse trabalho, e os outros que usam técnicas indiretas de eliminação de radiação gama, é que nos outros. apesar da contribuição para a obtenção do espectro de nêutron livre de contaminaçào. eles não possuem uma aplicação prática, porque não é como a técnica usada aqui, em que a eliminação da contaminação do nêutron pela radiação gama é feita "in loco".

Os espectros de distribuição de freqüência de energ̣ia lineal não são comuns na literatura cientitica, os mais comuns e mais importantes são os de distribuição de dose de energia lineal. O espectro de distribuição de dose de energia lineal de nêutrons rápidos de reator com potência de $0,5 \mathrm{~kW}$, obtido nesse trabalho, foi comparado com o obtido por Srdoc e Marino (Srdoc e Marino, 1981). Esse trabalho foi realizado com vários diâmetros de volumes simulados e diferentes valores de energia de nêutrons monoenergéticos. conforme mostrado na figura 3.14. O espectro que mais se aproxima do que é apresentado $11 \mathrm{a}$

figura 5.10. é, sem dúvida, o de $0.44 \mathrm{MeV}$. Só que o volume simulado para o espectro aqui obtido foi de $1.3 \mu \mathrm{m}$, além de que foi conservado a parte referente à radiação gama. no outro resultado, a radiação gama foi totalmente extraida da forma que já foi explicada acima.

Este experimento foi feito com um valor de energia de nêutron rápido de reator na taixa de $0.5 \mathrm{MeV}$. para a potência de $0.5 \mathrm{~kW}$. o que justifica a proximidade dos resultados entre os dois trabalhos. Isso contribui para corroborar a precisão das medidas feitas nesse trabalho, apesal das diferenças dos equipamentos de irradiação de nêutrons usadas nos experimentos e da técnica de eliminação da contaminaçào do nêutron por radiação gama para a obtenção dos espectros. 
Tabela 5.7- Planilha utilizada para agrupar os espectros de alto e baixo ganho para obter os espectros microdosimétricos definitivos de energia lineal.

\begin{tabular}{|c|c|c|c|c|c|c|c|c|}
\hline y inicial & y final & $y$ & novo $n$ & $f(y)$ delta & $f(y)$ & $y f(y)$ & $d(y)$ & $y d(y)$ \\
\hline$-0,0218$ & 0,0218 & 0,0000 & 785000 & 0,0341 & 0,7845 & 0,0000 & 0,0000 & 0.0000 \\
\hline 0,0218 & 0,0653 & 0,0435 & 775000 & 0,0337 & 0,7745 & 0,0337 & 0,0058 & 0,0003 \\
\hline 0,0653 & $0, \overline{1088}$ & 0,0870 & 760000 & 0,0330 & 0,7595 & 0,0661 & 0,0113 & 0,0010 \\
\hline 0,1088 & 0,1523 & 0,1305 & 745000 & 0,0324 & 0,7445 & $\overline{0,0972}$ & $0,016 \overline{7}$ & 0,0022 \\
\hline 0,1523 & 0,1958 & 0,1740 & 730000 & 0,0317 & 0,7295 & 0,1269 & 0,0218 & 0,0038 \\
\hline 0,1958 & 0,2393 & 0,2175 & 710000 & 0,0309 & 0,7095 & 0,1543 & 0,0265 & 0,0058 \\
\hline 0,2393 & 0,3263 & 0,2828 & 1340000 & 0,0582 & 0,6695 & 0,1893 & 0,0325 & 0,0092 \\
\hline 0,3263 & 0.4133 & 0,3698 & 1250000 & 0,0543 & 0,6246 & 0,2309 & 0,0397 & 0,0147 \\
\hline 0,4133 & 0,5003 & 0,4568 & 1155000 & 0,0502 & 0,5771 & 0,2636 & 0,0453 & 0,0207 \\
\hline 0,5003 & 0,5873 & 0,5438 & 1095000 & 0,0476 & $0,54 \overline{71}$ & 0,2975 & 0,0511 & 0,0278 \\
\hline 0,5873 & 0,6743 & 0,6308 & 1053000 & 0,0458 & 0,5261 & $\overline{0,3319}$ & 0,0570 & 0.0360 \\
\hline 0,6743 & 0,7613 & 0,7178 & 976000 & 0,0424 & 0,4877 & 0,3500 & 0,0601 & 0.0431 \\
\hline 0,7613 & 0,9353 & 0,8483 & 1504761 & 0,0654 & 0,3759 & 0,3189 & 0,0548 & 0,0465 \\
\hline 0,9353 & 1.1093 & 1,0223 & 919029 & 0,0400 & 0,2296 & 0,2347 & 0,0403 & 0,0412 \\
\hline 1.1093 & 1,2833 & 1,1963 & 618030 & 0,0269 & 0,1544 & 0,1847 & 0,0317 & 0.0379 \\
\hline 1,2833 & 1,4573 & 1,3703 & 447369 & 0,0194 & 0,1118 & 0,1531 & 0,0263 & 0,0360 \\
\hline 1,4573 & 1,6313 & 1,5443 & 340330 & 0,0148 & 0,0850 & 0,1313 & 0,0226 & 0,0348 \\
\hline 1,6313 & 1,8053 & 1,7183 & 272485 & 0,0118 & 0,0681 & 0,1170 & 0,0201 & 0,0345 \\
\hline 1,8053 & 2,1533 & 1,9793 & 410877 & 0,0179 & 0,0513 & 0,1016 & 0,0174 & 0,0345 \\
\hline 2,1533 & 2,5013 & 2,3273 & 301695 & 0,0131 & 0,0377 & 0,0877 & 0,0151 & 0,0351 \\
\hline 2,5013 & 2,8493 & 2,6753 & 235039 & 0,0102 & 0,0294 & 0,0785 & 0,0135 & 0,0361 \\
\hline 2,8493 & 3,1973 & 3,0233 & 190824 & 0,0083 & 0,0238 & 0,0721 & 0,0124 & 0,0374 \\
\hline 3,1973 & 3,5453 & 3,3713 & 159818 & 0,0069 & 0,0200 & 0,0673 & 0,0116 & 0,0390 \\
\hline 3,5453 & 3,8933 & 3,7193 & 136777 & 0,0059 & 0,0171 & 0,0635 & 0,0109 & 0,0406 \\
\hline 3,8933 & 4,5893 & 4,2413 & 227726 & 0,0099 & 0,0142 & 0,0603 & 0,0104 & 0.0439 \\
\hline 4,5893 & 5,2853 & 4,9373 & 183835 & 0,0080 & 0,0115 & 0,0567 & 0,0097 & 0,0481 \\
\hline 5,2853 & 5,9813 & 5,6333 & 156904 & 0,0068 & 0,0098 & 0,0552 & 0,0095 & 0.0534 \\
\hline $5, \overline{9813}$ & 6,6773 & 6,3293 & 136771 & 0,0059 & 0,0085 & 0,0541 & 0,0093 & 0,0588 \\
\hline 6,6773 & 7,3733 & 7,0253 & 122035 & 0,0053 & 0,0076 & 0,0535 & 0,0092 & 0.0646 \\
\hline 7.3733 & 8,0693 & 7,7213 & 111169 & 0,0048 & 0,0069 & 0,0536 & 0,0092 & 0.0711 \\
\hline 8,0693 & 9,4613 & 8,7653 & 196309 & 0,0085 & 0,0061 & 0,0537 & 0,0092 & 0,0809 \\
\hline 9,4613 & 10,8533 & 10,1573 & 172882 & 0,0075 & 0,0054 & 0,0548 & 0,0094 & 0.0957 \\
\hline 10,8533 & 12,2453 & 11,5493 & 159523 & 0,0069 & 0,0050 & 0,0575 & 0,0099 & 0.1141 \\
\hline$\overline{12,2453}$ & $13, \overline{6373}$ & 12,9413 & 150911 & 0,0066 & 0,0047 & 0,0610 & 0,0105 & 0,1356 \\
\hline
\end{tabular}


y $x$ yf(y) (Nêutron rápido de reator - Potência $=0.5 \mathrm{~kW}$ )

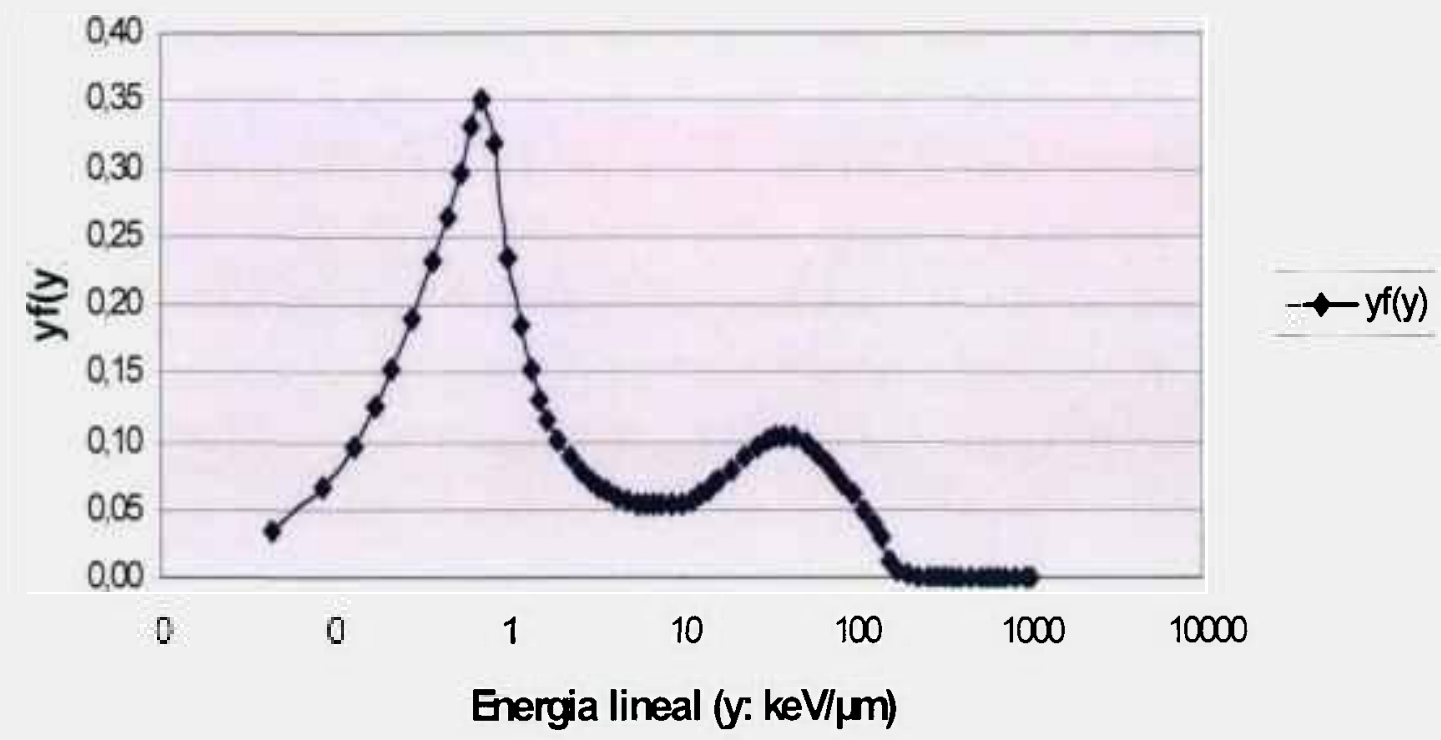

Figura 5.9 - Distribuição de freqüência de energia lineal, logy vs yf(y), para nêutrons rápidos, obtida em reator de pesquisa operando com potência de $0,5 \mathrm{~kW}$.

y $x$ yd(y) (Nêutron rápido de reator - Potência $=0.5 \mathrm{kM}$ )

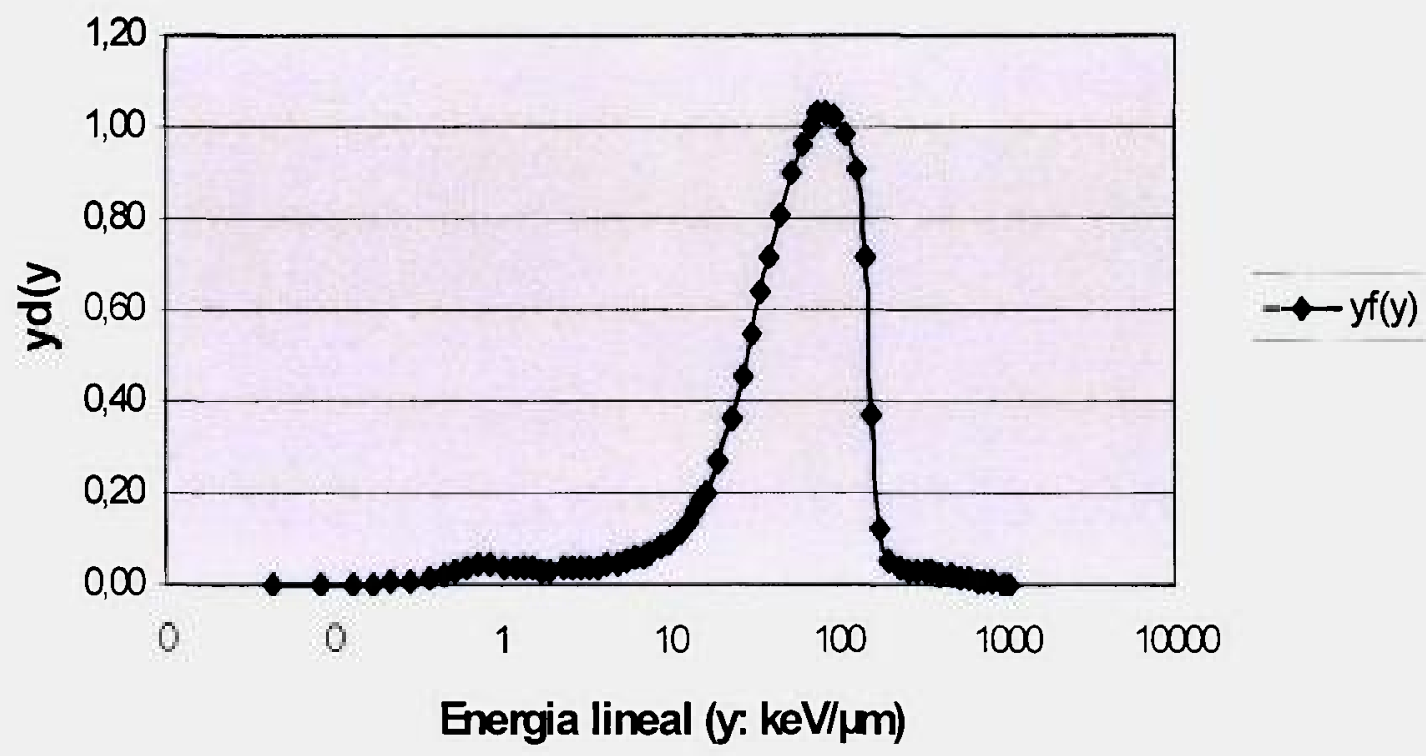

Figura 5.10 - Distribuição de dose de energia lineal, logy vs yd(y), para nêutrons rápidos, obtida em reator de pesquisa operando com potência de $0,5 \mathrm{~kW}$. 


\section{4 - Cálculos microdosimétricos para a Potência do reator de $1,0 \mathrm{~kW}$}

Os resultados dos cálculos microdosimétricos para a potência de $1.0 \mathrm{kll}$ são exibidos da figura de 5.11 até a figura 5.20. As planilhas para o cálculo desses espectros, bem como de todos os outros nessa potência estarão disponíveis nos anexos que acompanham esse trabalho.

Os procedimentos para a determinação de cada espectro nessa potência são os mesmos seguldos para o cálculo de todos os espectros para a potência de $0.5 \mathrm{~kW}$. Por isso não serão repetidos aqui. Mas faremos alguns comentários sobre algumas diferenças entre os resultados aqui obtidos com aqueles da potência anterior.

O primeiro deles. é que o número de canais que não são captados pelo MCA é muito maior que aqueles que se viu na potência de $0.5 \mathrm{~kW}$. Isso é conseqüência de um maior discriminador de nivel mais baixo (LLD). que, enquanto na outra medida foi de $1.88 \%$ para alto ganho, nesta. de $1,0 \mathrm{~kW}$, teve um valor de $2.66 \%$. também para alto ganho. Foi o valor mais apropriado para a obtenção de medidas com um melhor ganhỏ e com um menor ruído possível, evitando dessa forma uma distorção nos espectros obtidos. O nível de atividade de um nêutron proveniente de um reator é muito maior do que aquela proveniente de uma fonte de $\mathrm{AmBe}$, por exemplo, que vai exigir um valor de LLD muito menor também. Não é fácil ajustar um valor de LLD para um nêutron com o nível de atividade presente no reator, qualquer pequena alteração pode provocar um grande aumento no tempo morto e. com isso, uma grande quantidade de eventos não serão percebidos pelo MCA e, portanto, un grande ruido ocorrerá no espectro obtido. O tempo morto tem que se manter sempie abaixo dos $5 \%$ para que o sinal colhido seja o mais pertèito possivel.

O segundo comentário é que o número de eventos ocorridos na cavidade do contador proporcional é cerca de $45 \%$ maior do que a quantidade collida na medida anterior. Isso é conseqüência de um maior número de nêutrons penetrando a cavidade num mesmo periodo de tempo, e, com isso, produzindo uma maior quantidade de prótons de recuo e por conseqüência, mais ionizações a serem contadas pelo contador.

Outro comentário é que. nessa medida é necessário se fazer uma grande extrapolação em alto ganho. já que cerca de 24 canais ou mais não tem seus eventos 
registrados pelo MCA. Eles estão lá. mas foram discriminados pelo LLD. Os resultados para essas medidas microdosimétricas de alto ganho podem ser vistos nas figuras 5.11 e 5.12 .

Nas figuras 5.19 e 5.20 encontram-se os espectros finais de nêutrons rápidos de reator à potência de $1.0 \mathrm{~kW}$. Os espectros são respectiramente. o de distribuição de freqüência de energia lineal e o de distribuição da dose de energia lineal.

A primeira anotação a ser feita em relação aos espectros microdosimétricos finais para essa potência, é que no espectro de distribuição de freqüuência de energ̣ia lineal o pico na região de radiação gama já tem uma acentuada queda. mostrando que nessa medida a contribuição dessa radiação foi reduzida. Essa foi a primeira medida que foi feita e. portanto. os decaimentos provenientes de medidas anteriores não estão presentes nessa potência de $1,0 \mathrm{~kW}$.

A segunda é que. quando se analisa espectro de distribuição de dose de energia lineal da figgura 5.20. pode-se notar uma redução da contaminação de nêutrons por radiação gama, chegando a cerca de $3 \%$, confirmando assim a eficiência do sistema de filtragem usado nesse trabalho.

Nessa medida nào foi possivel comparar com outro espectro da literatura cientifica. já que os dois referidos acima, não possuem um valor de nêutron monoenergético que permita a comparação com os resultados aqui obtidos, apesar da proximidade com o espectro de nêutron monoenergético de $0.55 \mathrm{MeV}$ do trabalho de Nunomiya et al. Mas se comparar com o de potencia de $0.5 \mathrm{~kW}$. pode ser visto que há um deslocamento no pico do próton de recuo, isto pode ter sido provocado pela menor presença da contaminação pela radiação gama no espectro do nêutron. Ou ainda. por uma maior atividade do nêutron no interior da cavidade. 


\section{y $x$ yf(y) (de alto ganho de nêutron rápido de reator) \\ Potência $=1.0 \mathrm{~kW}$}

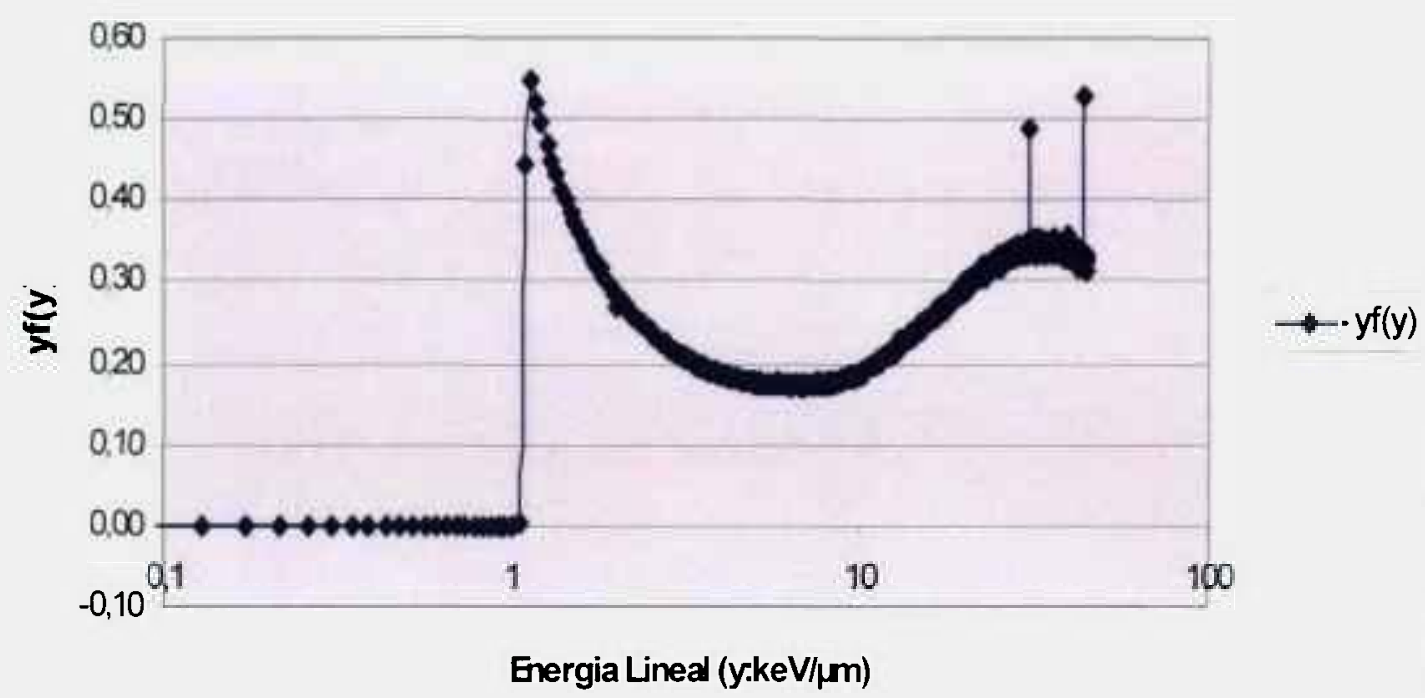

Figura 5.11 - Distribuição de frequeência de energia lineal, $\log (\mathrm{y}) \mathrm{x}$ yf $(\mathrm{y})$, para alto ganho, para nêutrons rápidos de reator operando a uma potência de $1,0 \mathrm{~kW}$.

\section{y $x$ ydly) (de alto ganho de nêutro rápido de reator) \\ Potência $=1.0 \mathrm{~kW}$}

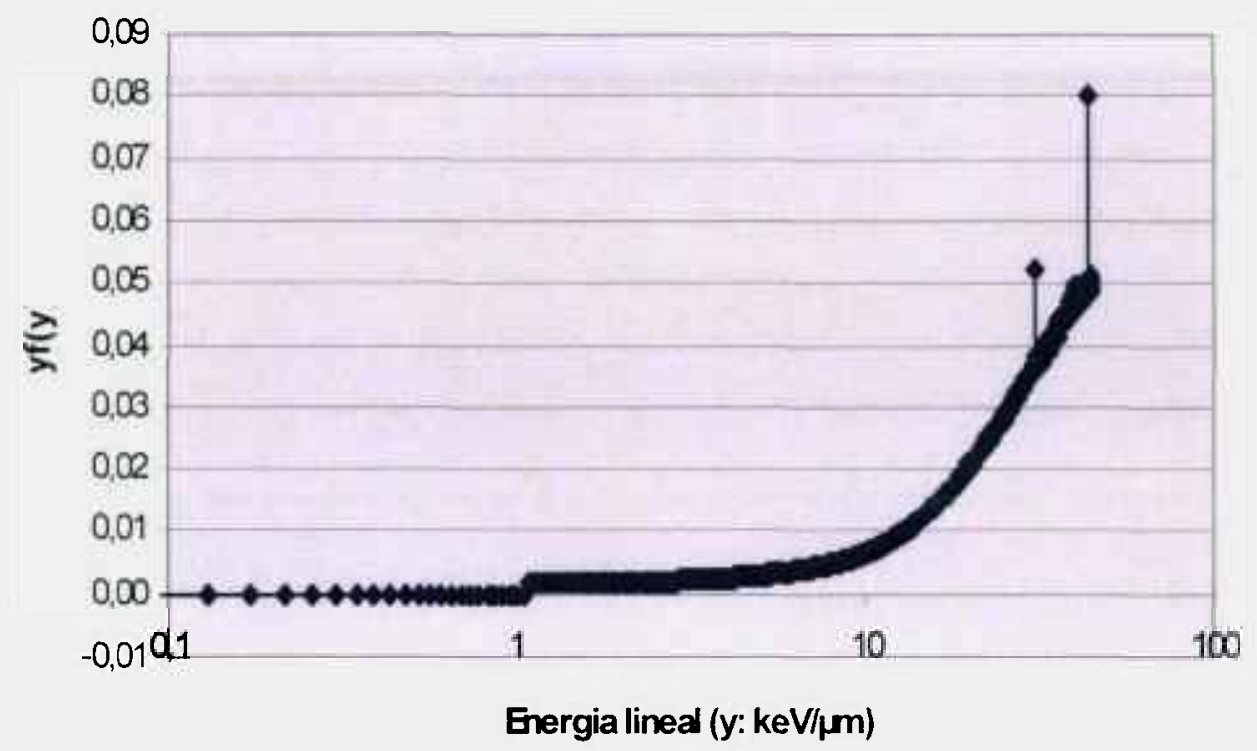

Figura 5.12 - Distribuição de dose de energia lineal. $\log (\mathrm{y}) \mathrm{x} \mathrm{yd}(\mathrm{y})$, para alto ganho, para nêutrons rápidos de reator operando a uma potência de $1,0 \mathrm{~kW}$. 
y $x$ yif(y) ("binned" de alto ganho de nêutron rápido de reator)

Potência $=1.0 \mathrm{~kW}$

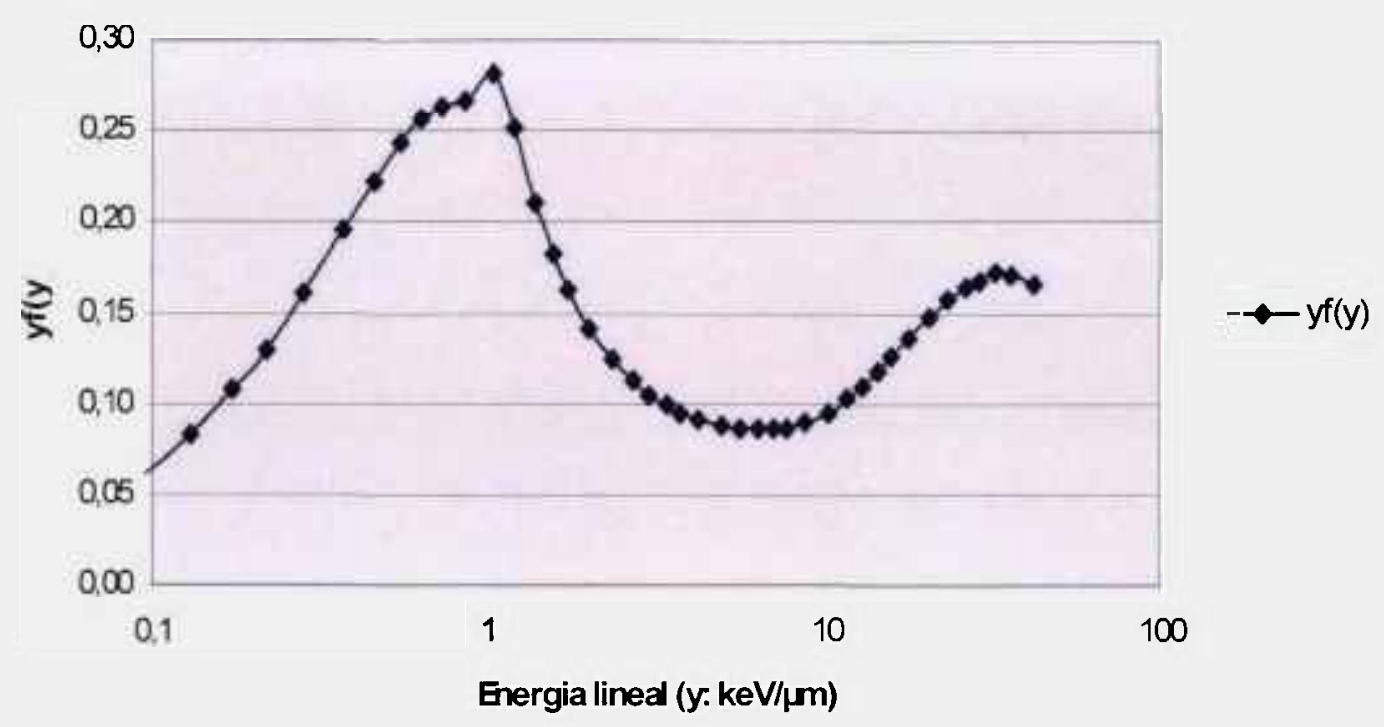

Figura 5.13 - - Espectro com os canais agrupados (binned) para alto ganho da distribuição de freqüência de energia lineal, $\log (\mathrm{y}) \times \mathrm{yf}(\mathrm{y})$, para nêutrons rápidos de reator operando com potência de $1,0 \mathrm{~kW}$.

\section{y $x$ yd(y) ('binned" de alto ganho de nêutron rápido de reator) \\ Potência $=1.0 \mathrm{~kW}$}

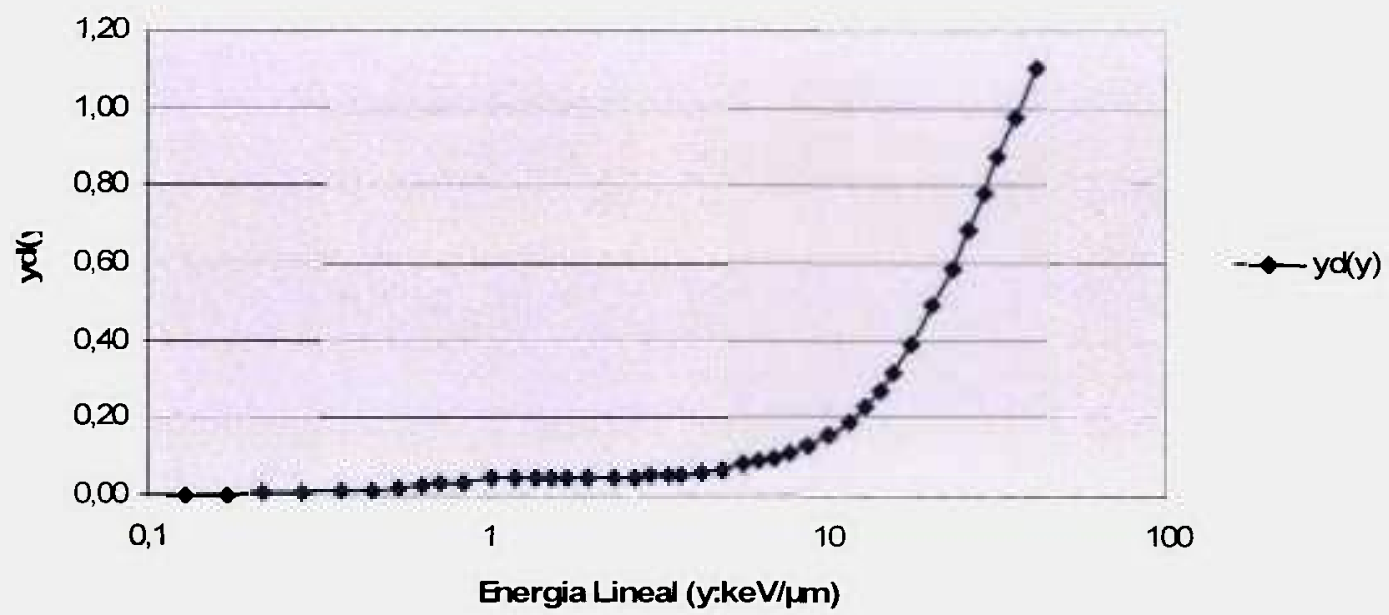

Figura 5.14 - Espectro com os canais agrupados (binned) para alto ganho da distribuição de dose de energia lineal, $\log (\mathrm{y}) \times \mathrm{yd}(\mathrm{y})$, para nêutrons rápidos de reator operando com potência de $1,0 \mathrm{~kW}$. 


\section{y x yf(y) (de baixo ganho de nêutron rápido de reator)}

Potência $=1.0 \mathrm{~kW}$

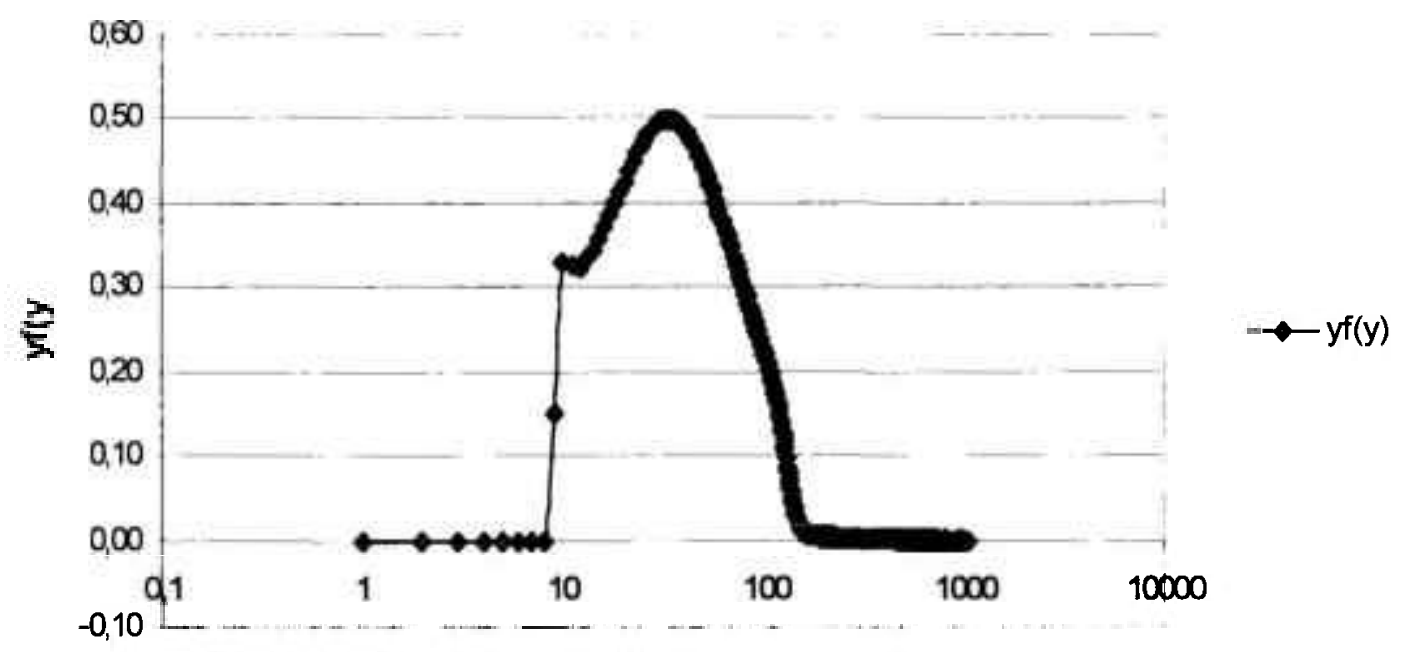

Energia lineal (y: keV//m)

Figura 5.15 - Distribuição de frequêencia de energia lineal, $\log (\mathrm{y})$ x yf(y), para baixo ganho, para nêutrons rápidos de reator operando a uma potência de $1,0 \mathrm{~kW}$.

\section{y $x$ ydly) (de baixo ganho de nêutron rápido de reator) \\ Potência $=1.0 \mathrm{~kW}$}

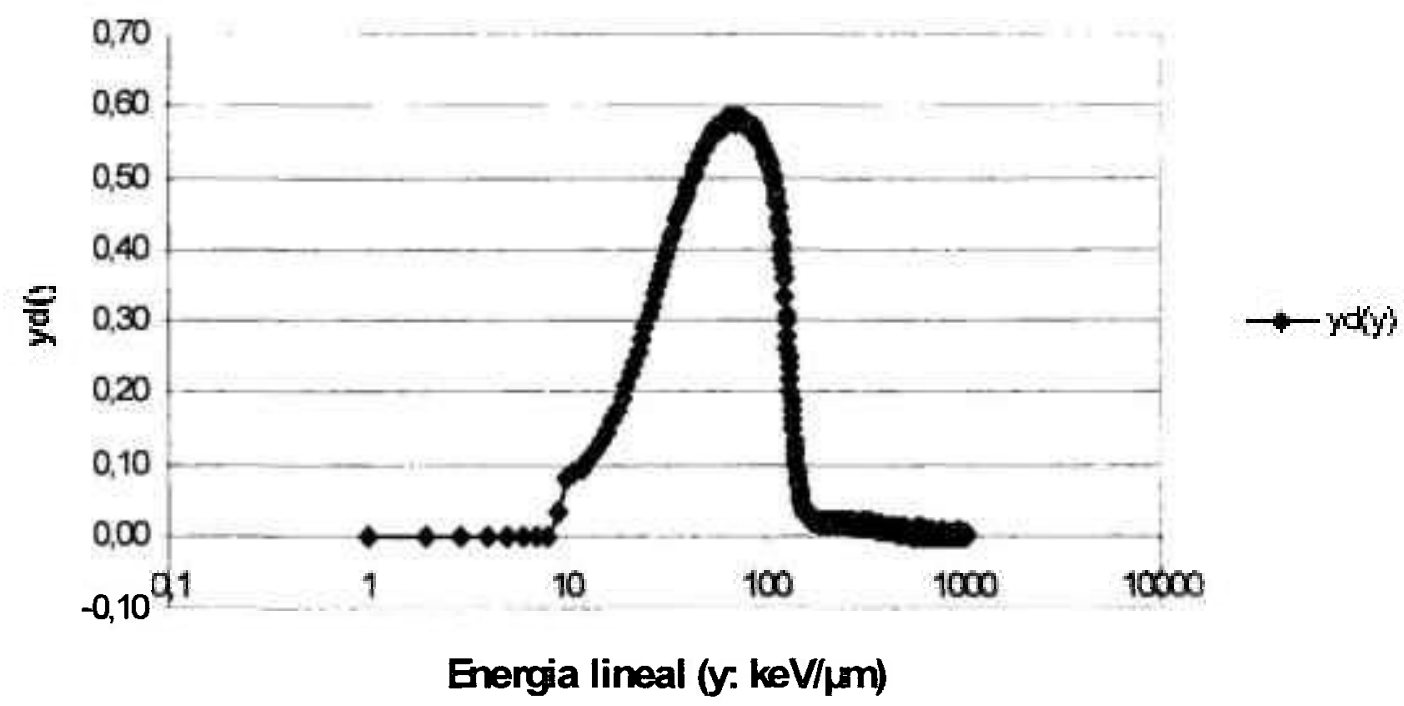

Figura 5.16 - Distribuição de freqüência de energia lineal, $\log (\mathrm{y}) \mathrm{x} \mathrm{yd}(\mathrm{y})$, para baixo ganho, para nêutrons rápidos de reator operando a uma potência de $1,0 \mathrm{~kW}$. 


\section{y $x$ yff(y) ("binned" de baixo ganho de nêutron rápido de reator)}

Potência $=1.0 \mathrm{~kW}$

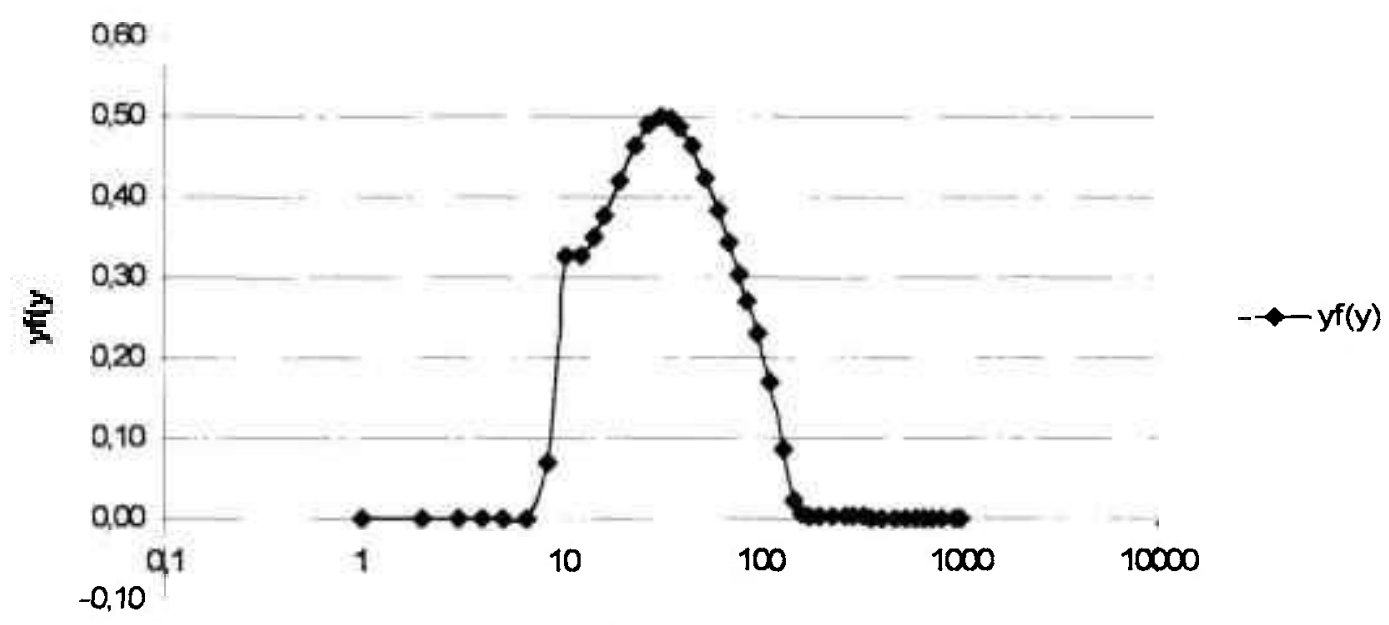

Energia lineal (y: keV/pm)

Figura 5.17 - Espectro com os canais agrupados (binned) para baixo ganho da distribuição de freqüência de energia lineal, $\log (\mathrm{y}) \mathrm{x} \mathrm{y}(\mathrm{y})$, para nêutrons rápidos de reator operando com potência de $1,0 \mathrm{~kW}$

\section{y $x$ yd'(y) ("binned" de baixo ganho de nêutron rápido de reator) Potência $=1.0 \mathrm{~kW}$}

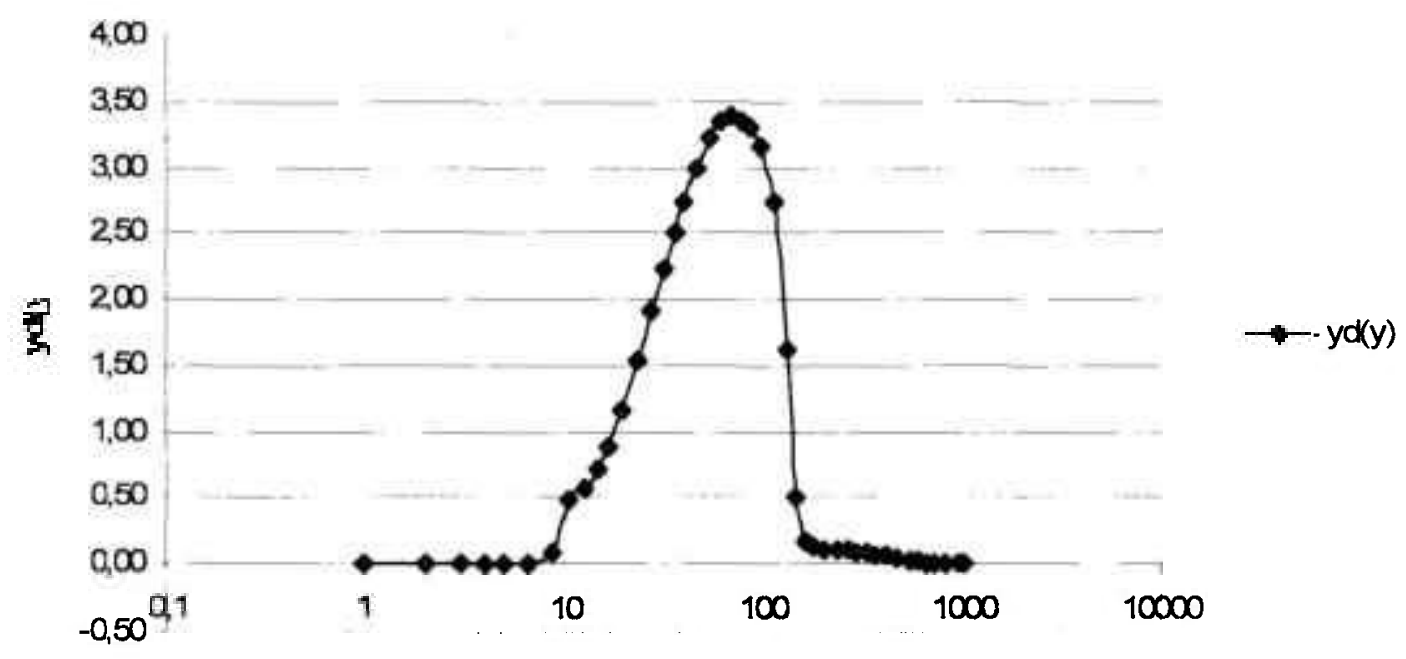

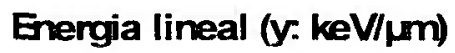

5.18 - Espectro com os canais agrupados (binned) para baixo ganho da distribuição de dose de energia lineal, $\log (\mathrm{y}) \times \mathrm{yd}(\mathrm{y})$, para nêutrons rápidos de reator com potência de 1,0 $\mathrm{kW}$ 


\section{y $x$ yff(y) (Nêutron rápido de reator - Potência $=1 \mathrm{KW}$ )}

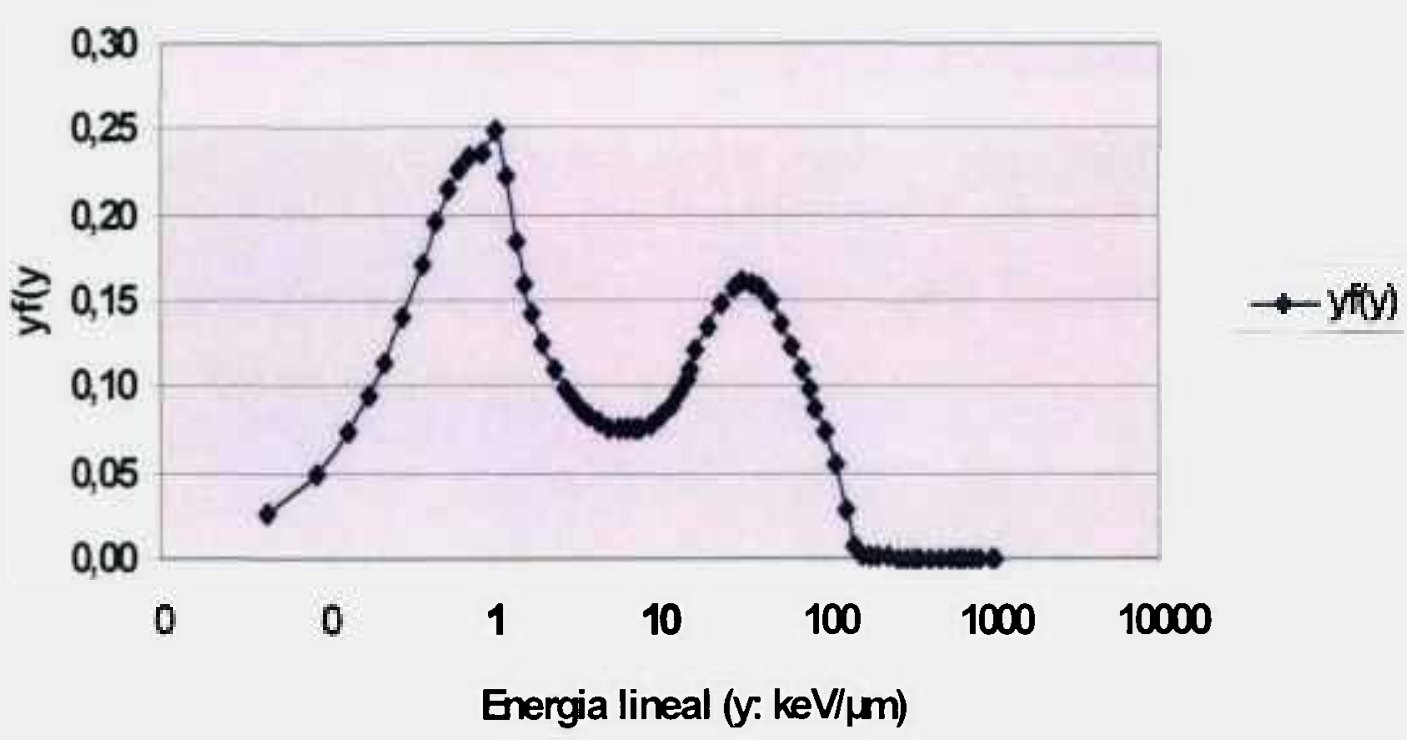

Figura 5.19 - Distribuição de frequiência de energia lineal, logy x yf(y), para nêutrons rápidos obtida em reator de pesquisa operando a uma potência de $1 \mathrm{~kW}$.

y x yol(y) (Nêutron rápido de reator - Potência = $1 \mathrm{~kW}$ )

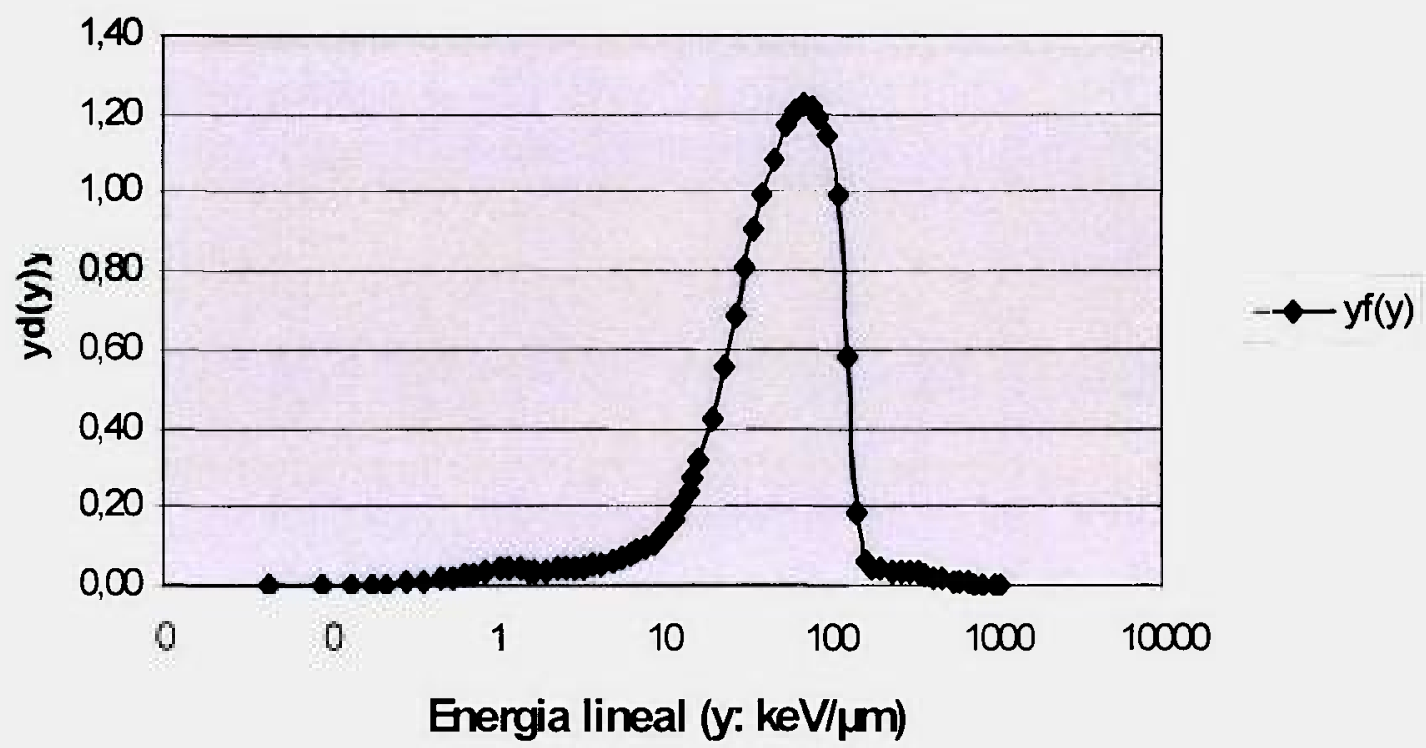

Figura 5.20 - Distribuição de dose de energia lineal, logy x yd(y), para nêutrons rápidos obtida em reator de pesquisa operando a uma potência de $1,0 \mathrm{~kW}$. 


\section{5 - Cálculos microdosimétricos para a potência do reator de $2,0 \mathrm{~kW}$}

Os resultados microdosimétricos para a potência do reator de $2.0 \mathrm{~kW}$ são apresentados da figura 5.21 até a figura 5.30. As primeiras oito figuras. de 5.21 até a figura 5.28. sào os semi-espectros, que ao serem juntados darão origem aos dois espectros microdosimétricos finais, que são mostrados nas Figuras 5.29 e 5.30

Como já foi dito antes. os procedimentos para a determinação de todos os espectros da potência de $2.0 \mathrm{~kW}$ são os mesmos daqueles aplicados à potência de $0.5 \mathrm{~kW}$ e que foram discutidos nos comentários referentes àquelas medidas.

A potência de $2.0 \mathrm{~kW}$ foi a segunda potência utilizada para as mediçōes a serem realizadas durante as araliações dos nêutrons rápidos de reator usando o contador proporcional equivalente a tecido. Como ela é a maior de todas as potências, a quantidade de nêutrons que penetram a cavidade do contador, no mesmo intervalo de tempo, é maior que as outras duas anteriores. Essa potência irá produzir uma maior quantidade de particulas secundárias carregadas, principalmente prótons de recuo, e a conseqüência então, será uma maior formação de pares de íons, que por sua vez serão coletados no anodo do contador, produzindo os pulsos que darão origem aos espectros aqui apresentados.

Com uma alta atividade no interior do contador é evidente que o número de eventos sérá muito grande, e no caso deste trabalho, chègou a mais de $51 \%$ a mais que os produzidos na potência de $1.0 \mathrm{~kW}$. Uma grande atividade necessita de um maior ajuste para evitar um alto ruído ou fenômenos como o empilhamento de pulsos que, se não evitados. produzirão grandes distorções no espectro, não reflętindo o que ocorre no interior da cavidade do contador.

Para evitar o ruido nesta potência foi necessário um alto discriminador de nível mais baixo (LLD), para evitar um tempo morto alto. O ajuste dessa potência foi a mais dificil. O LLD nesta potência foi de 3,810\%. com isso uma grande quantidade de canais não tiveram seus eventos registrados, o que obrigou a realização de uma extrapolação em cerca de 38 canais. 
Como pode ser visto na figura 5.29. o espectro da distribuiçào de frequiência de energia lineal na potência de $2,0 \mathrm{~kW}$ é bem diferente dos obtidos nas potências anteriores. Ele é o primeiro a apresentar um pico da região de nêutron mais proeminente que o da região da radiação gama. Isso significa que. mesmo no espectro onde a radiação gama dá a sua maior contribuição, o espectro de nêutrons é dominante. Isso é consequiência da alta atividade do próton no interior da cavidade do contador. e da não interferência dos produtos de fissão da medida anterior de $1,0 \mathrm{~kW}$, já que um nivel menor de potência não interfere em outro de maior nível. enquanto o contrário é verdadeiro. Se tivéssemos feito as medidas numa outra sequiência. com o de menor potência primeiro, seguido do de potência média e finalmente o de maior potência por último, é bem provável que o pico presente no espectro de $0,5 \mathrm{~kW}$, mostrado na figura 5.9 . não existiria.

Com relação ao espectro da figura 5.30. que exibe a distribuição de dose de energia lineal, pode ser notado, que a contribuição da radiação gama na dose é muito pequena, estando talvez na casa dos $3 \%$. O próton de recuo responde por cerca de $96 \%$ e o restante pode ser computado aos outros produtos do nêutron. principalmente a radiação alfa.

Como pode ser visto, ao observar os espectros de distribuição de dose de energia lineal de cada potência, vide figuras $5.10,5.20$ e 5.30, as ordenadas do pico do próton de recuo. yd(y), vão aumentando de valor de acordo com o aumento da potência do reator. Todos eles são normalizados para facilitar a comparação. e o que possuir a maior área sob o espectro apresentará a maiör dose. Isso será confirmado no próximo item a ser comentado.

Com os resultados obtidos pode-se dizer que o sistema de irradiação de nêutrons raipidos severamente filtrados do reator de pesquisa do Centro de Ciência Nuclear da Texas A\&M University é capaz de eliminar quase totalmente a contaminação do nêutron por radiação gama. favorecendo o uso desse sistema para pesquisas biológicas. 
y $x$ yff(y) (de alto ganho de nêutron rápido de reator)

Potência $=20 \mathrm{~kW}$

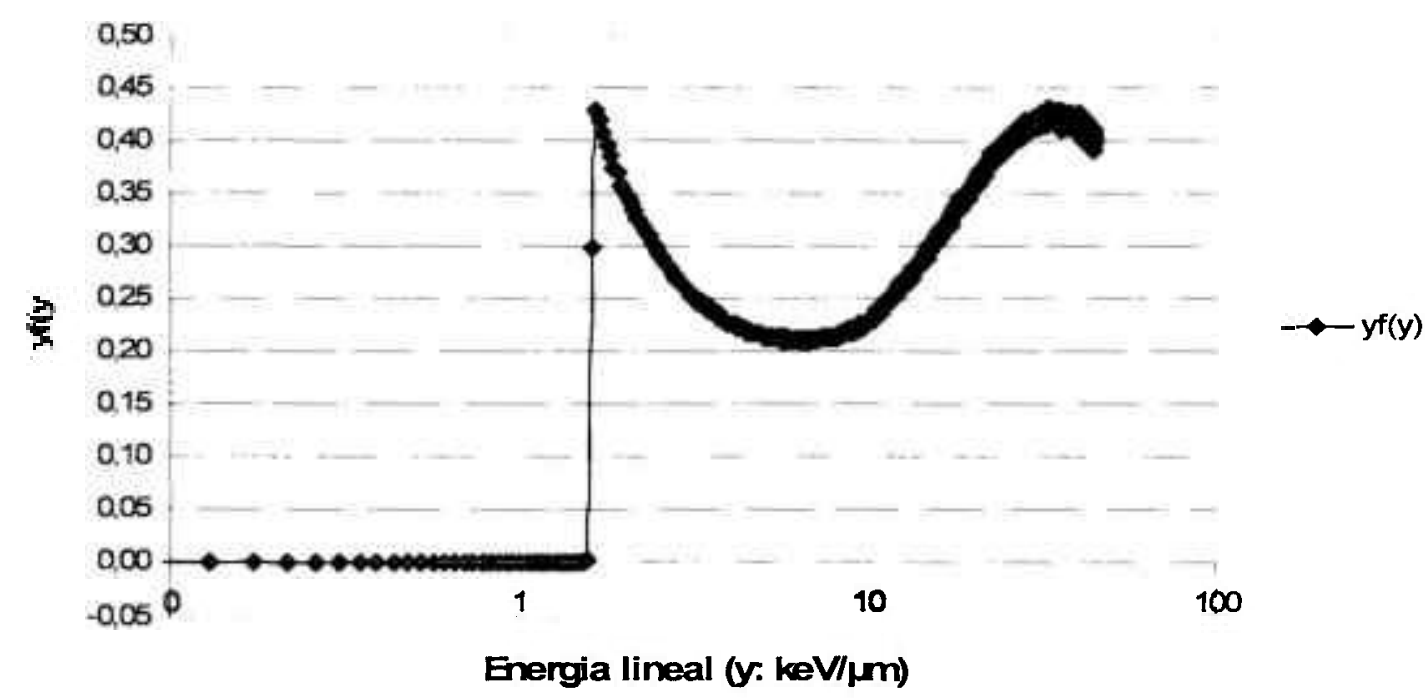

Figura 5.21 - Distribuição de freqüência de energia lineal, $\log (\mathrm{y}) \mathrm{x} \mathrm{yf}(\mathrm{y})$, para alto ganho para nêutrons rápidos de reator operando a uma potência de $2,0 \mathrm{~kW}$.

\section{y $x$ yod(y) (de alto ganho de nêutron rápido de reator) \\ Potência $=20 \mathrm{~kW}$}

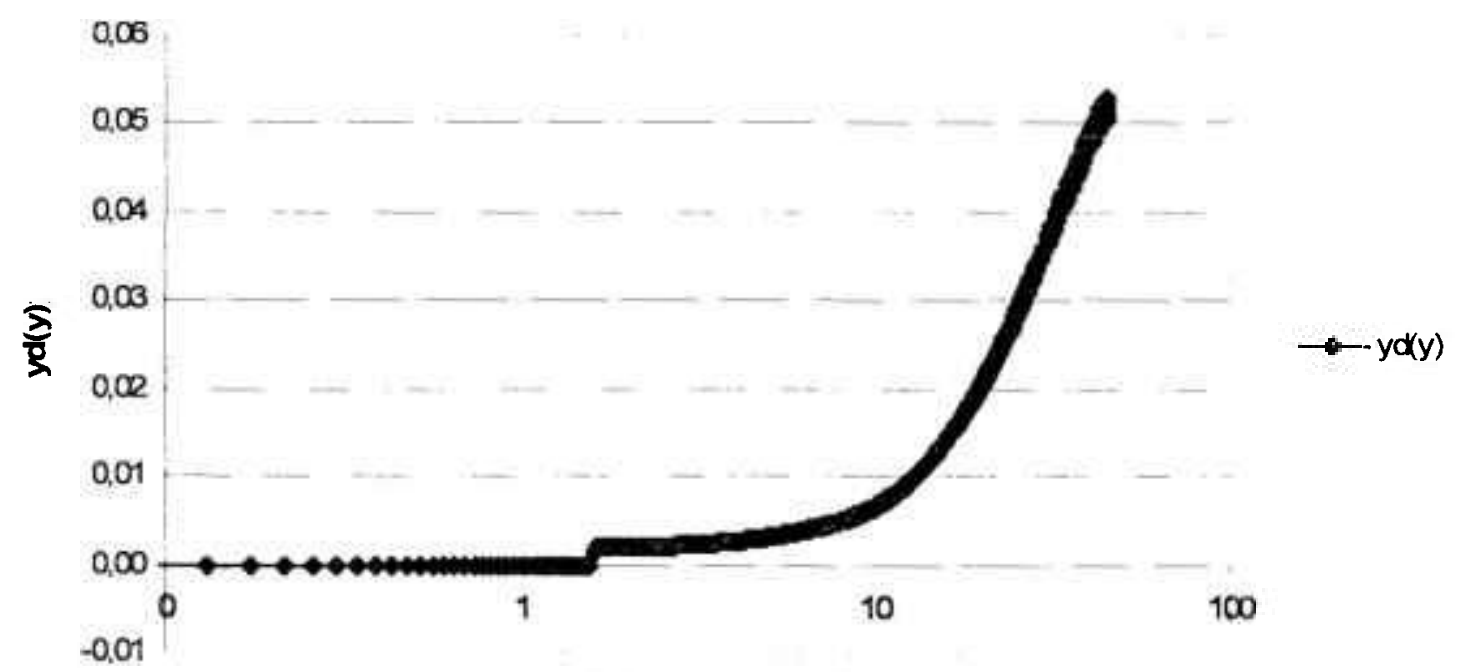

Energia lineal (y: keV/pm)

Figura 5.22 - Distribuição de dose de energia lineal. $\log (\mathrm{y}) \mathrm{x}$ yd(y), para alto ganho para nêutrons rápidos de reator operando a uma potência de $2,0 \mathrm{~kW}$. 


\section{y $x$ yff(y) ("binned" de alto ganho de nêutron rápido de reator) \\ Potência $=20 \mathrm{~kW}$}

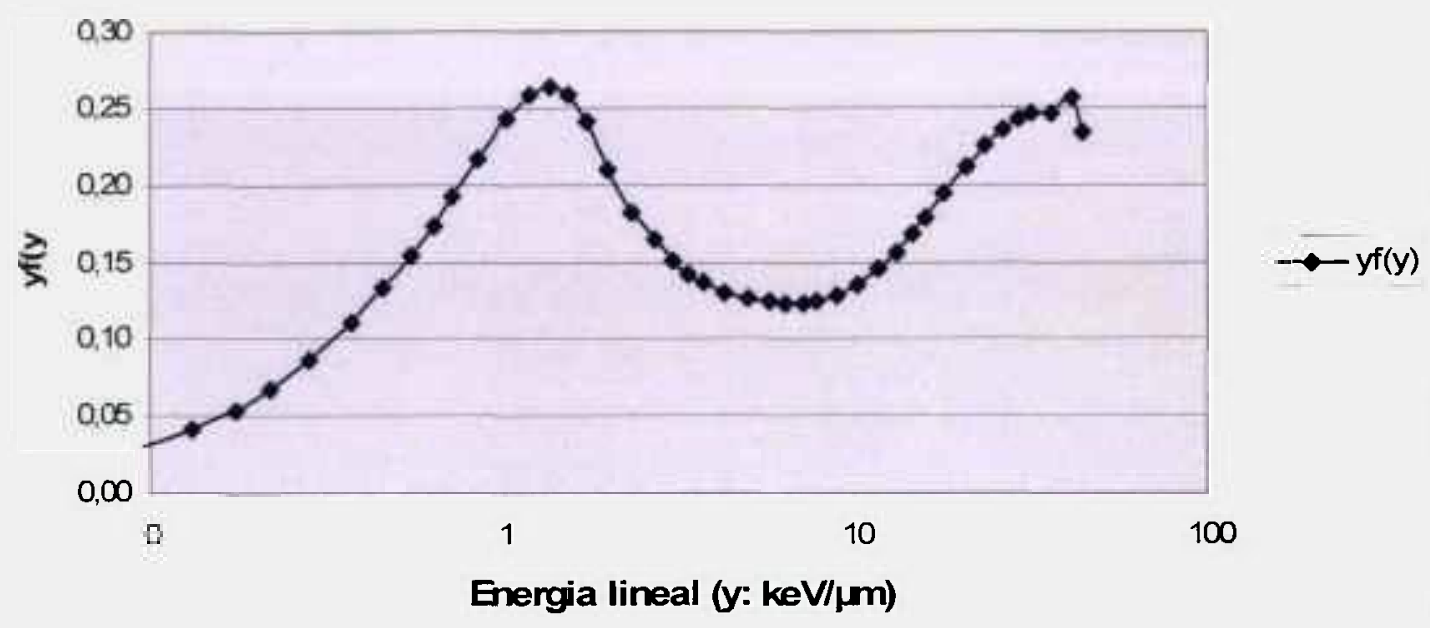

5.23 - Espectro com os canais agrupados (binned), para alto ganho, da distribuição de freqüência de energia lineal, $\log (\mathrm{y})$ x $\mathrm{yf}(\mathrm{y})$, para nêutrons rápidos de reator operando com potência de $2,0 \mathrm{~kW}$.

\section{y $x$ yd(y) ("binned" de alto ganho de nêutron rápido de reator) \\ Potência $=20 \mathrm{~kW}$}

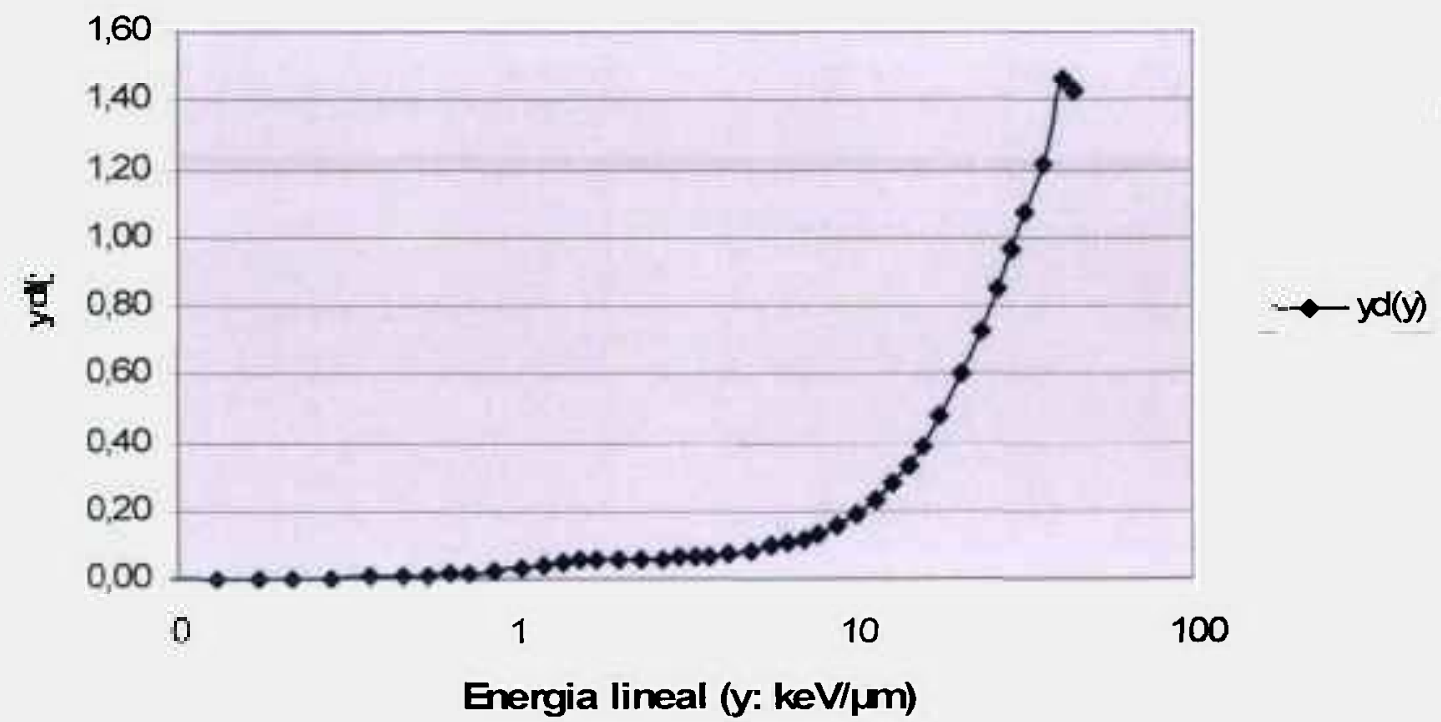

5.24 - Espectro com os canais agrupados (binned) para alto ganho da distribuição de dose de energia lineal, $\log (\mathrm{y}) \mathrm{x} \mathrm{yd}(\mathrm{y})$, para nêutrons rápidos de reator operando com potência de $2,0 \mathrm{~kW}$. 


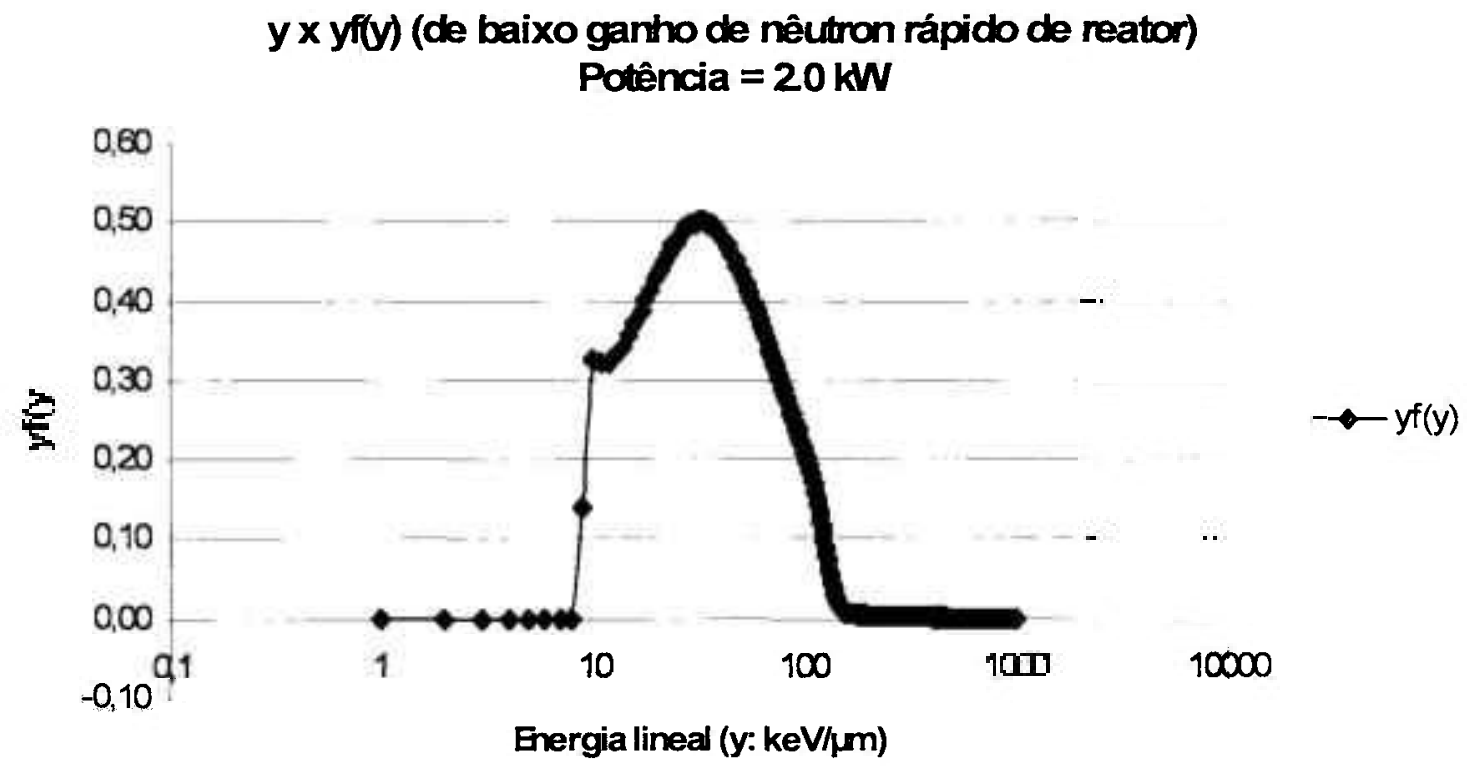

Figura 5.25 - Distribuição de freqüência de energia lineal, $\log (\mathrm{y}) \times \mathrm{yf}(\mathrm{y})$, para baixo ganho, para nêutrons rápidos de reator operando a uma potência de $2,0 \mathrm{~kW}$.

\section{y $x$ yd(y) (de baixo ganho de nêutron rápido de reator) Potência $=20 \mathrm{~kW}$}

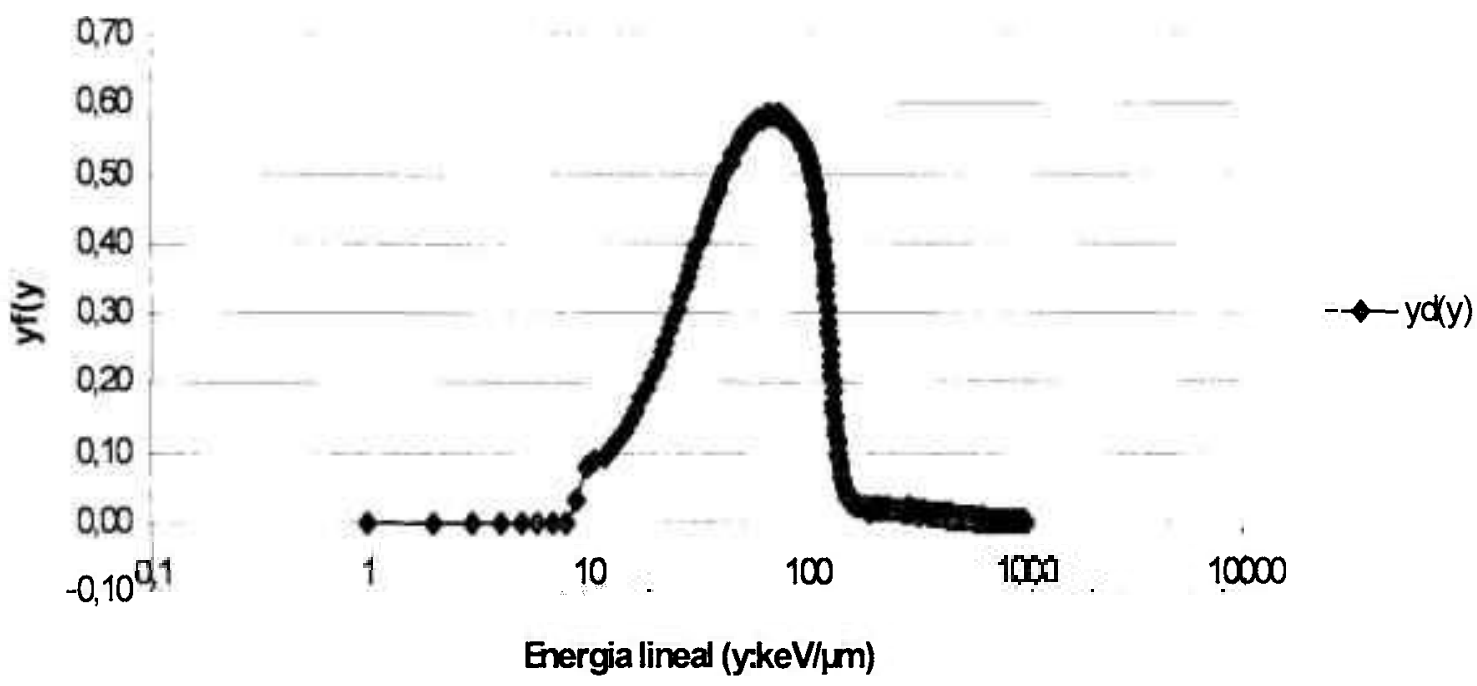

Figura 5.26 - Distribuição de dose de energia lineal. $\log (\mathrm{y}) \mathrm{x}$ yf(y), para baixo ganho, para nêutrons rápidos de reator operando a uma potência de $2,0 \mathrm{~kW}$. 
y $x$ yf(y) ("binned" de baixo ganho de nêutro rápido de reator) Potência $=20$ kW

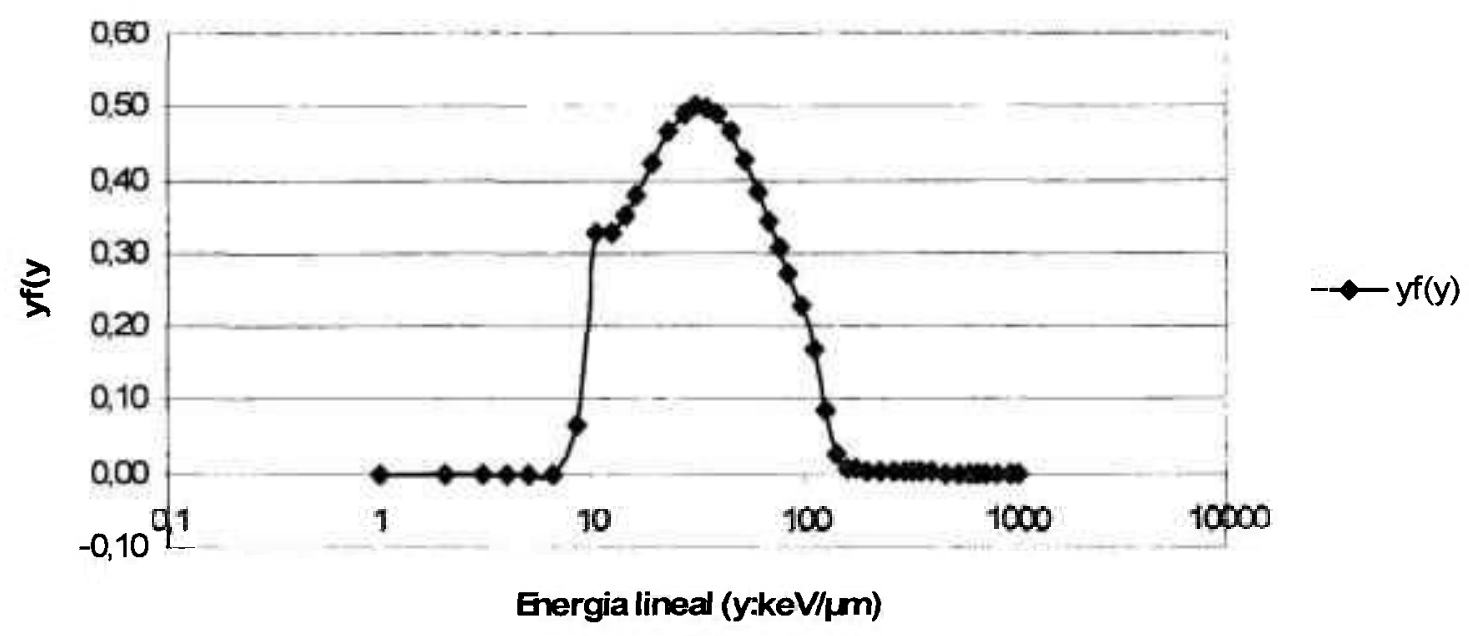

Figura 5.27 - Espectro com os canais agrupados (binned) para baixo ganho da distribuição de freqüência de energia lineal, $\log (\mathrm{y}) \times \mathrm{yf}(\mathrm{y})$, para nêutrons rápidos de reator operando com potência de $2,0 \mathrm{~kW}$.

\section{y x yd(y) ("binned" de baixo ganho de nêutron rápido de reator) Potência $=20 \mathrm{~kW}$}

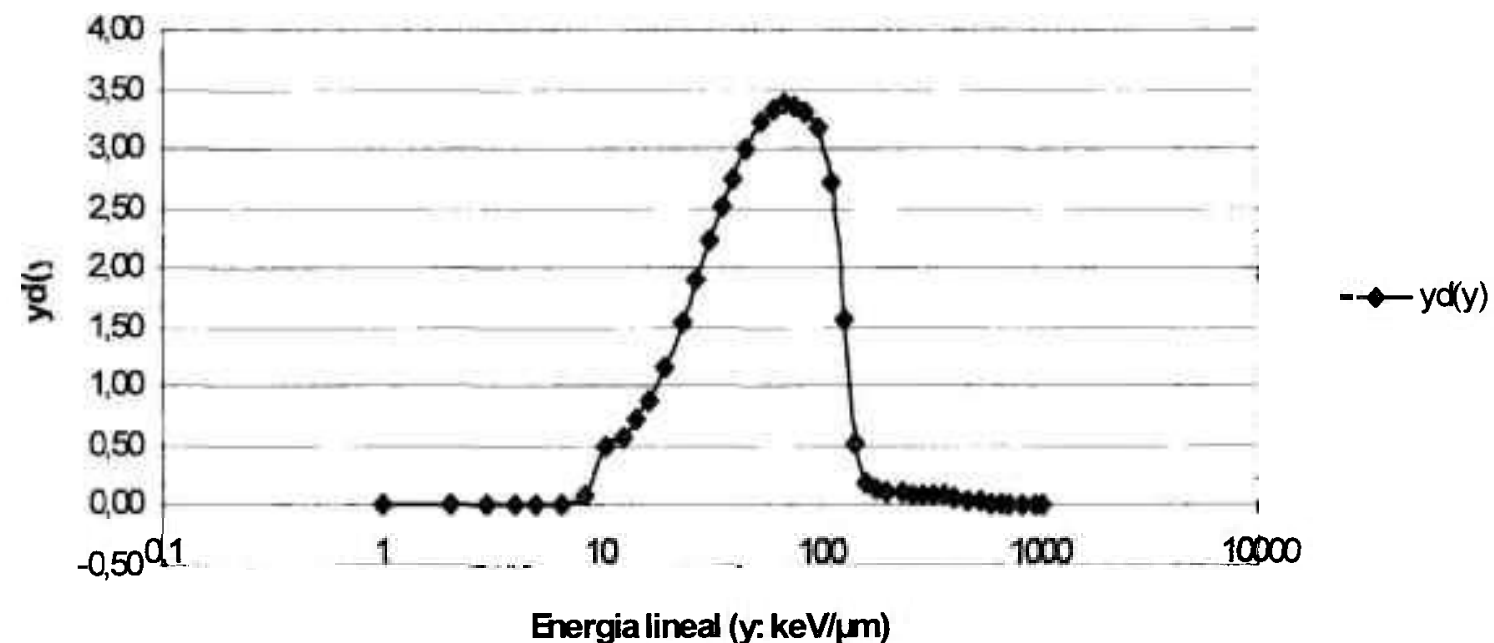

Figura 5.28 - Espectro com os canais agrupados (binned) para baixo ganho da distribuição de dose de energia lineal, $\log (\mathrm{y}) \mathrm{x} \mathrm{yd}(\mathrm{y})$, para nêutrons rápidos de reator operando com potência de $2,0 \mathrm{~kW}$. 
y $x$ yff(y) (Nêutron rápido de reator - Potência $=2 \mathrm{~kW}$ )

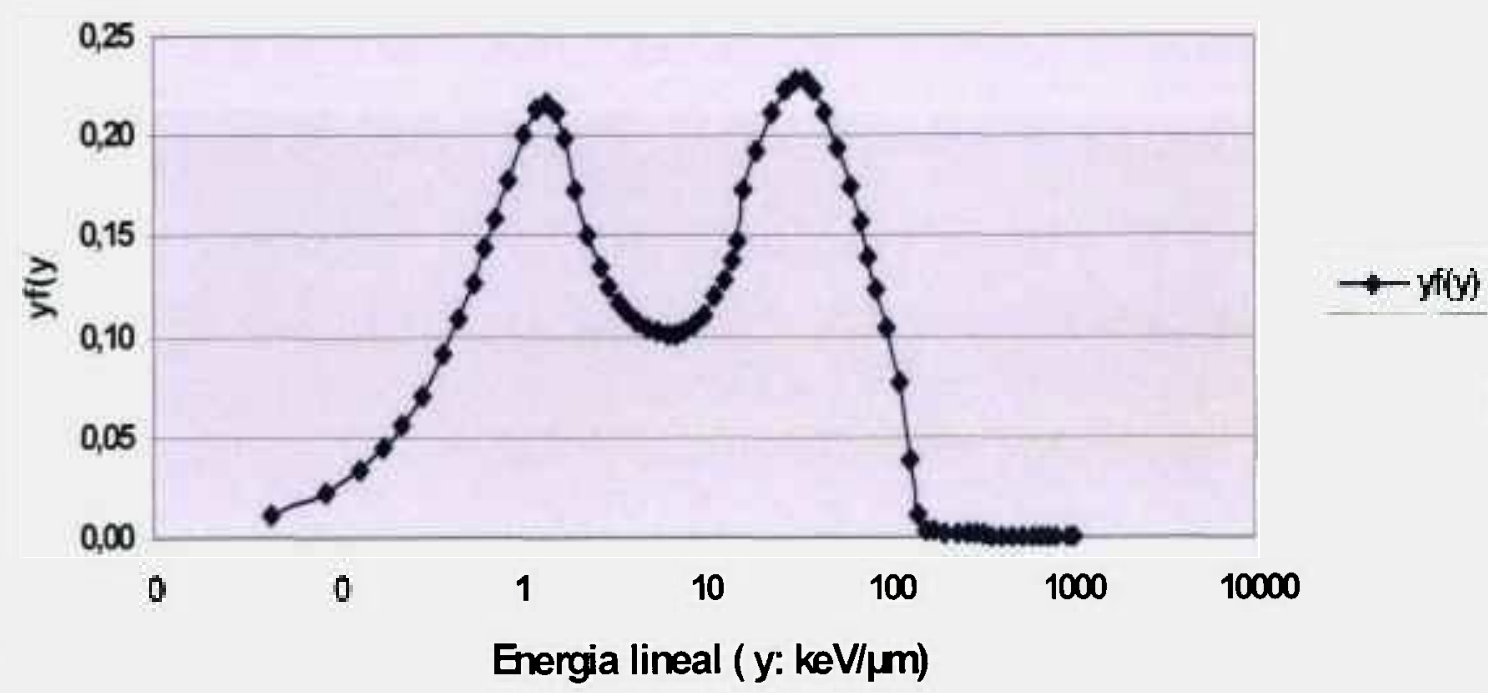

Figura 5.29 - Distribuição de freqüência de energia lineal, logy x yf(y), para nêutrons rápidos obtida em reator de pesquisa operando a uma potência de $2,0 \mathrm{~kW}$.

y $x$ yd(y) (Neutron rápido de reator - Potência $=2 \mathrm{~kW}$ )

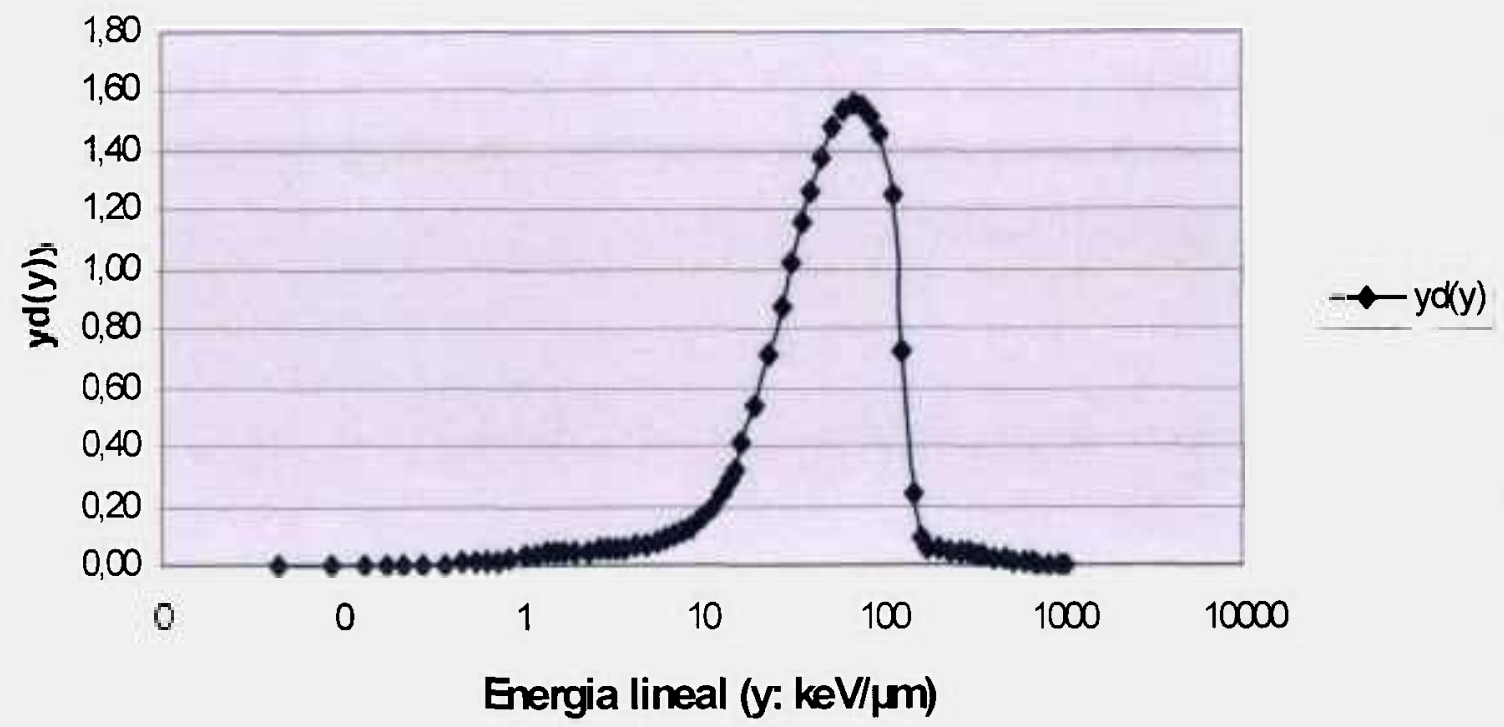

Figura 5.30 - Distribuição de dose de energia lineal, logy x yd(y), para nêutrons rápidos obtida em reator de pesquisa operando a uma potência de $2,0 \mathrm{~kW}$. 


\section{6 - Freqüência média $\left(y_{\mathrm{F}}\right)$ e dose média $\left(y_{0}\right)$ de energia lineal}

As grandezas microdosimétricas Freqüência média de energ̣ia lineal $(y)$ e dose média de energia lineal ( $y_{0}$ ) foram determinadas usando as equações 3.30 e 3.31 . Os resultados são apresentados nas tabelas 5.9 e 5.10 .

\subsection{1 - Frequiência média de energia lineal $\left(y_{F}\right)$}

Tabela 5.8 - Resultados do cálculo da frequêência média de energia lineal de nêutrons rápidos de reator operando nas potèncias de $0.5,1.0$ e $2.0 \mathrm{~kW}$.

\begin{tabular}{|c|c|}
\hline $\begin{array}{c}\text { Potência de reator } \\
(\mathbf{k W})\end{array}$ & $\begin{array}{c}\text { Frequêencia média de energia lineal } \\
(\mathbf{k e V} / \boldsymbol{\mu m})\end{array}$ \\
\hline 0.5 & 11.23 \\
\hline 1.0 & 14,02 \\
\hline 2,0 & 19.57 \\
\hline
\end{tabular}

Os resultados apresentdos na tabela 5.9 para yf são satisfatórios. apesar de não estarem de acordo com os resultados de outros trabalhos, já aqui citados. Nunomiya et al (2002) e Srdoc e Marino (1996). Isto é conseqüência do método utilizado para a eliminação da radiação gama dos espectros de nêutron, da seqüència na qual foram realizadas as médidas, além da influencia da extrapolação feita para alto goanho. que intluenciou os valores de $y_{F}$

\subsection{2-Dose média de energia lineal $\left(y_{0}\right)$}

Tabela 5.9-Resultados do cálculo da dose média de energia lineal de nêutrons rápidos de reator operando nas potências de $0.5,1.0$ e $2.0 \mathrm{~kW}$.

\begin{tabular}{|c|c|}
\hline $\begin{array}{c}\text { Potência de reator } \\
(\mathbf{k W})\end{array}$ & $\begin{array}{c}\text { Dose média de energia lineal } \\
(\mathrm{keV} / \mu \mathrm{m})\end{array}$ \\
\hline 0,5 & $72.02 \pm 10.33$ \\
\hline 1.0 & $60.88 \pm 9.25$ \\
\hline 2.0 & $61.67 \pm 9.89$ \\
\hline
\end{tabular}


Os resultados apresentados na tabela 5.10 para y $_{0}$ são satistatório e estão de acordo com os resultados dos trabalhos de Nunomiya et al (2002) e Srdoc e Marino (1996). após feita a interpolação necessária, já que eles fizeram as medidas para um volume simulado de $2.0 \mu \mathrm{m}$ e $1.0 \mu \mathrm{m}$ e neste trabalho o volume simulado foi de $1.3 . \mathrm{mm}$. A concordància dos resultados para dose média de energia lineal ocorre, porque a intluència do gama nessa grandeza é muito pequena.

5.7 - Cálculos da Dose absorvida, da Taxa de dose, do Fator de qualidade, da Dose equivalente, da Taxa de dose equivalente e Fator de qualidade médio.

As grandezas Dose absorvida. Taxa de dose, Fator de qualidade. Dose equivalente. Taxa de dose equivalente e Fator de qualidade médio foram calculadas a partir dos resultados obtidos das medidas de TEPC.

\subsection{1 - Dose absorvida total (D)}

Para o cálculo da dose absorvida foi usado a seguinte relação:

$$
D=\sum_{1}^{7} 0.204 \times y_{i} n_{1} / d^{2} \times\left(\frac{d}{d c}\right)^{2}
$$

onde , $i_{i}$ é a energia lineal no canal i. $n_{i}$ o númeor de eventos no canal $i$, dé o diâmetro do volume simulado, no nosso caso foi $1.3 \mu \mathrm{m}$, e finalmente $d c$, é o diâmetro da cavidade do contador proporcional equivalente à tecido. A tabela 5.9 apresenta os resultados da dose absorvida calculada para as três potências usadas nesse trabalho.

Tabela 5.10 - Resultados do cálculo da dose absorvida de nêutrons rápidos de reator operando nas potências de $0,5,1,0$ e $2,0 \mathrm{~kW}$.

\begin{tabular}{|c|c|}
\hline $\begin{array}{c}\text { Potência de reator } \\
(\mathbf{k W})\end{array}$ & $\begin{array}{c}\text { Dose absorvida } \\
(\mathbf{G y})\end{array}$ \\
\hline 0.5 & $0.327 \pm 0,038$ \\
\hline 1.0 & $0.582 \pm 0.058$ \\
\hline 2.0 & $1.110 \pm 0.111$ \\
\hline
\end{tabular}


Como podemos observar existe uma coerência nos resultados. já que o valor da dose absorvida para uma potência de $0.5 \mathrm{~kW}$ é um pouco maior que $1 / 4$ da dose absorvida de $2.0 \mathrm{~kW}$. e a de $1.0 \mathrm{~kW}$ é um pouco maior que $1 / 2$ da mesma potência. Isso acontece porque o número de nêutrons gerados com maior potência soferero mais choques com as moléculas do gás propano no interior da cavidade, produzindo mais ionizaçōes e por fïm o sistema observará uma maior dose.

\section{7 .2 - Taxa de dose absorvida $(\mathrm{D} / \mathrm{t})$}

Cada medida foi feita com uma duração de 1 hora. sendo obtida a taxa de dose, dividindo a taxa de dose total absorvida pelo tempo gasto na medida para cada potência. Os resultados são apresentados na tabela 5.10.

Tabela 5.11 - Resultados do cálculo da taxa dose absorvida de nêutrons rápidos de reator operando nas potências de $0,5,1,0$ e $2.0 \mathrm{~kW}$.

\begin{tabular}{|c|c|}
\hline $\begin{array}{c}\text { Potência de reator } \\
(\mathbf{k W})\end{array}$ & $\begin{array}{c}\text { Taxa de dose absorvida } \\
(\mathbf{G y}) / \mathbf{h}\end{array}$ \\
\hline 0.5 & $0,327 \pm 0,033$ \\
\hline 1.0 & $0.582 \pm 0.058$ \\
\hline 2.0 & $1,110 \pm 0.111$ \\
\hline
\end{tabular}

\subsection{3- Fator de qualidade $(\mathrm{Q}(\mathrm{y}))$}

O fator de qualidade foi calculado segruindo orientação do ICRP 60 (ICRP Report. 1991), e seguindo a proposição de substituir LET por Y(Kellerer and Hahn. 1988). quando do cálculo do fator de qualidade. A recomendação feita pelo ICRP 60 é a seguinte:

$$
\begin{aligned}
& \mathrm{E}<10 \mathrm{keV} / \mu \mathrm{m} \quad \mathrm{Q}(\mathrm{L})=1 \\
& 10 \leq E<100 \mathrm{keV} / \mu \mathrm{m} \quad \mathrm{Q}(\mathrm{L})=0.32 \mathrm{~L}-2.2 \quad 5.13 \\
& E>100 \mathrm{keV} / \mu \mathrm{m} \longrightarrow \mathrm{Q}(\mathrm{L})=300 / \sqrt{L}
\end{aligned}
$$


O cálculo executado foi substituir L (LET) por y, energia lineal. Com isso foram obtidos os gráficos de fatores de qualidades, logy x $\mathrm{Q}(\mathrm{y})$, para nêutrons rápidos para as potências do reator de $0,5,1,0$ e $2,0 \mathrm{~kW}$ mostrados nas figuras $5.31,5.32$ e 5.33 .

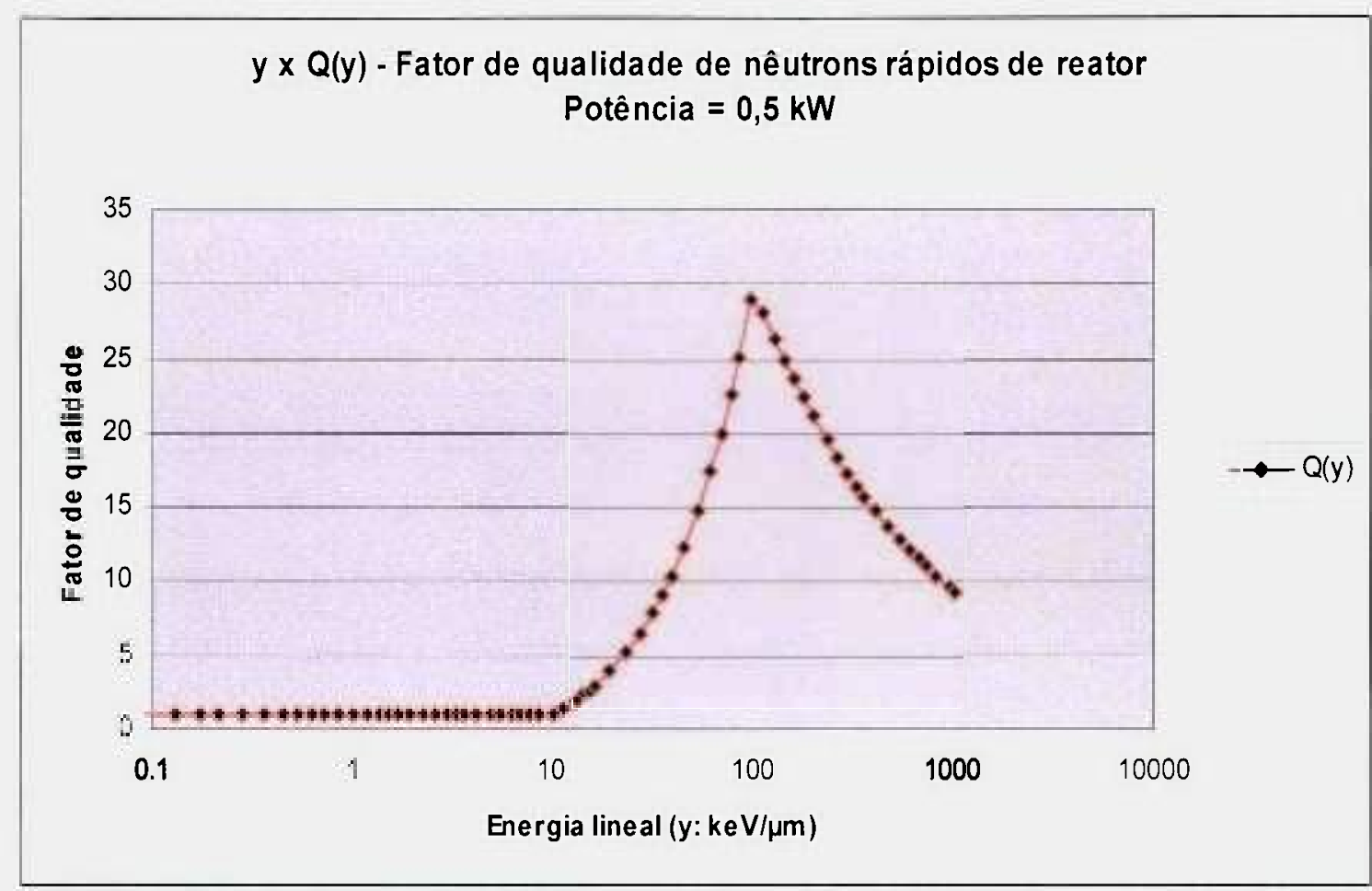

Figura - 5.31 - Fator de qualidade de nêutrons rápidos de reator para a potência de 0,5 $\mathrm{kW}$.

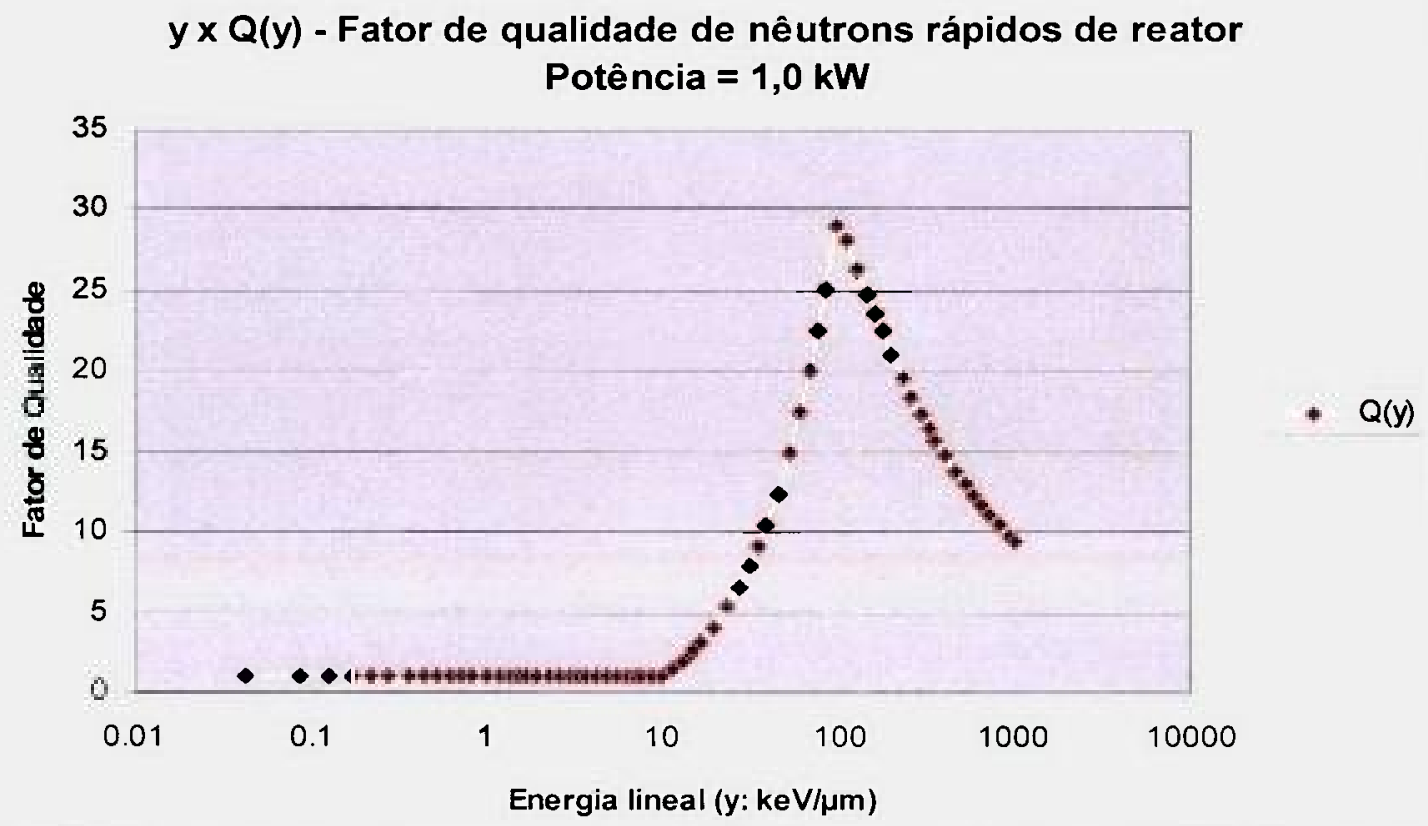

Figura 5.32 - Fator de qualidade de nêutrons rápidos de reator para a potência de $1,0 \mathrm{~kW}$. 


\section{y $\times Q(y)$ - Fator de Qualidade de nêutrons rápidos de reator \\ Potência $=2,0 \mathrm{~kW}$}

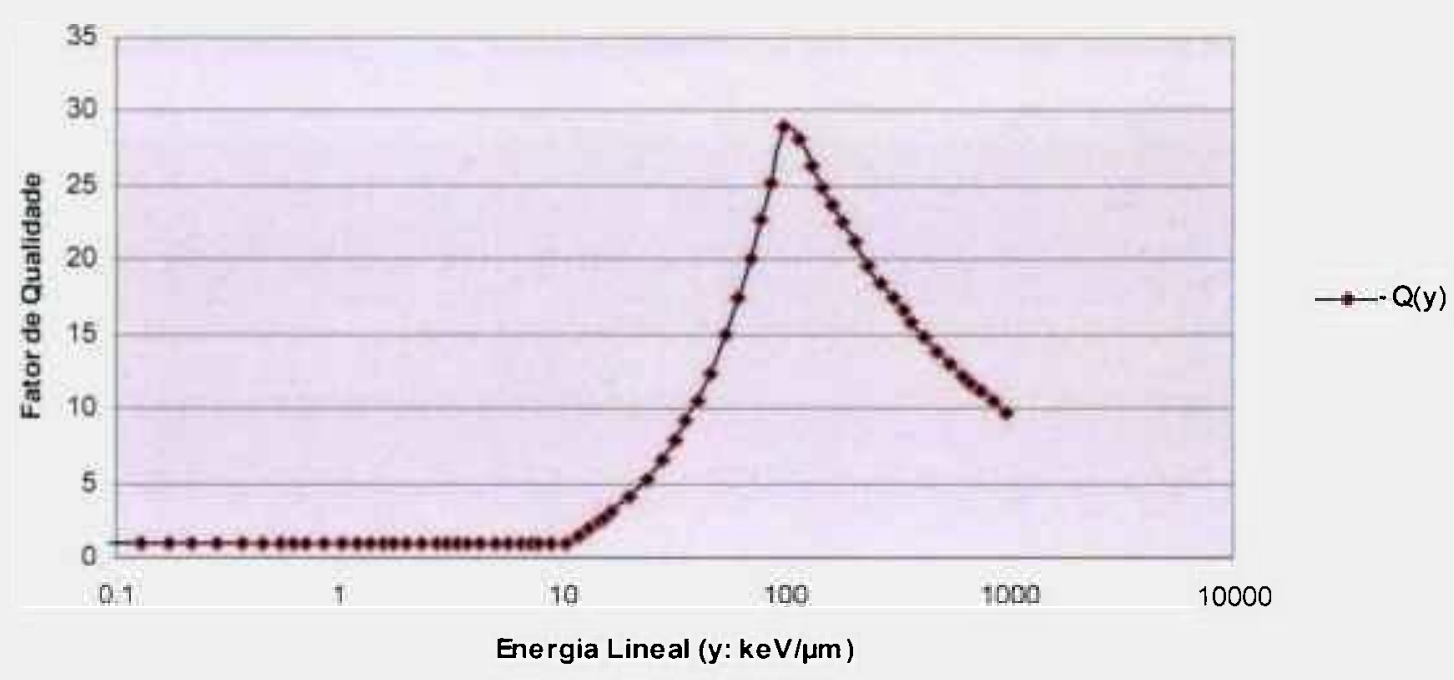

Figura 5.33 - Fator de qualidade de nêutrons rápidos de reator para a potência de $2,0 \mathrm{~kW}$.

\subsection{4) Dose equivalente (H)}

A dose equivalente foi calculada usando a seguinte relação:

$$
H=\sum_{1}^{3} D_{i} \times Q\left(y_{i}\right)
$$

foram obtidos os valores de $H$ para nêutrons rápidos de reator operando nas potências de $0,5,1,0$ e 2,0 kW. Os valores obtidos são apresentados na tabela 5.11 .

Tabela 5.12 - Resultados do cálculo da dose equivalente de nêutrons rápidos de reator operando nas potências de $0,5,1,0$ e $2,0 \mathrm{~kW}$.

\begin{tabular}{|c|c|}
\hline $\begin{array}{c}\text { Potência de reator } \\
(\mathbf{k W})\end{array}$ & $\begin{array}{c}\text { Dose equivalente } \\
(\mathbf{S v})\end{array}$ \\
\hline 0.5 & $5,382 \pm 0,534$ \\
\hline 1,0 & $8,733 \pm 0,874$ \\
\hline 2,0 & $16,854 \pm 1,685$ \\
\hline
\end{tabular}




\section{7 .5 - Taxa de dose equivalente $(\mathrm{H} / \mathrm{t})$}

Cada medida foi feita com uma duração de 1 hora. sendo obtida a taxa de dose equiralente, dividindo a dose equivalente pelo tempo gasto na medida para cada potência. Os resultados são apresentados na tabela 5.12 .

Tabela 5.13 - Resultados do cálculo da taxa de dose equivalente de nêutrons rápidos de reator operando nas potências de $0.5 .1,0$ e $2,0 \mathrm{~kW}$.

\begin{tabular}{|c|c|}
\hline $\begin{array}{c}\text { Potência de reator } \\
(\mathbf{k W})\end{array}$ & $\begin{array}{c}\text { Dose equivalente } \\
\mathbf{( S v}) / \mathbf{h}\end{array}$ \\
\hline 0.5 & $5,382 \pm 0.538$ \\
\hline 1.0 & $-8.733 \pm 0.873$ \\
\hline 2,0 & $16.854 \pm 1.685$ \\
\hline
\end{tabular}

\subsection{6- Fator de qualidade médio $(\vec{Q})$}

Para o cálculo do fator de qualidade médio, foi usada a relação:

$$
\mathrm{H}=\mathrm{D} \times \bar{O}
$$

Os resultados de $\vec{Q}$ obtidos para nêutrons rápidos de reator para as potências de $0.5 .1,0$ e $2.0 \mathrm{~kW}$ são mostrados na tabela 5.13 . Os valores dos fatores de qualidade médios foram obtidos efetuando os cálculos segundo as recomendações do ICRP 60 e estào de acordo com os valores de fator de ponderação da radiação. $1 \mathrm{~T}$, apresentados por Durham (Durham, 2007) que, para nêutrons com energia entre $100 \mathrm{keV}$ e 2 Mev é igaul a 20. 
Tabela 5.14- Resultados de tatores de qualidade médios para néutrons rapidos de reator operando nas potências de $0.5,1,0$ e $2.0 \mathrm{~kW}$.

\begin{tabular}{|c|c|}
\hline $\begin{array}{c}\text { Potência de reator } \\
(\mathbf{k W})\end{array}$ & \begin{tabular}{c} 
Fator de qualidade médio \\
\hline 0.5
\end{tabular} \\
\hline 1,0 & $16.478 \pm 1.648$ \\
\hline 2,0 & $15.008 \pm 1.501$ \\
\hline
\end{tabular}




\section{VI - CONCLUSÕES}

Conforme programado o projeto desenvolvido atingiu os seus objetiros, além do que toi o primeiro trabalho, de medidas microdosimétricas de nêutrons rápidos de reator, usando o sistema de irradiação com nêutrons rápidos fortemente filtrados.

Os resultados obtidos mostraram que:

- O sistema de nêutrons rápidos fortemente filtrados - FNIS é uma ferramenta poderosa para a obtenção de espectros de nêutrons descontaminados de radiação gama in loco. o que o diferencia dos outros métodos de subtração da radiação gama que não apresentam uma aplicação biológica prática.

- A contribuição da radiação gama em todos os espectros de distribuição de dose lineal, $\log (y) \times d(y)$. chegou, no máximo, a $5 \%$.

- A última potência de operação do reator usada durante as medidas. a de $0.5 \mathrm{~kW}$. apresenta uma maior contaminação de radiação gama, conseqüência do decaimento dos nêutrons gerados com um maior nivel de potência do reator, $2 \mathrm{~kW}$, produzindo radiação gama, mesmo após o término das medidas nessa potência, enquanto a cavidade do contador é irradiada por nêutrons rápidos a uma potência de reator de $0,5 \mathrm{~kW}$.

- Se as medidas fossem feitas em outra seqüência de irradiação, realizando as medidas de mais baixa potência primeiro, e a de maior valor por último, é bem provável que a maior contaminação no espectro de menor potência possivelmente não ocorreria.

- Os valores de Dose absorvida, Fator de qualidade. Dose equivalente e Fator de qualidade médio foram calculados a partir das medidas de TEPC e são compatíveis com as condições de irradiação e os valores de fator de qualidade para nêutrons com energias entre lookeV e 2 Mev encontrados na literatura. 
- O FNIS tica qualificado para uso com materiais biológicos, especialmente na determinação da eficência biolóģica relativa (RBE). 


\section{VII - REFERÊNCIAS BIBLIOGRÁFICAS}

ALARD. J.P., BODEZ. V., TCHIRKOV. A.. NÉNOT, M.L., ARNOLD. J.. CRESPIN. S.. RAPP, M., VERRELLE. P., DIONET, C. Simulation of Neutron Interactions at the Single-Cell Level. Radiation Research 158, 650-656 (2002).

ATTIX F.H. - Introduction to radiological physics and radiation dosimetry. New York. U.S.A. John Wiley \& Sons, 1986.

CASWELL. R.R.. COYNE, J.J. - Effects of track structure on neutron microdosimetry and nanodosimetry. Nucl. Tracks Radiat. Meas. Vol. 16 No. 2/3. 187-195 (1989) - Int. J. Radiat. Appl. Instrum. Part D.

CASWELL. R.R.. COYNE. J.J. - Microdosimetric spectra and parameters of fast neutrons. Proceedings of the Symposium on Microdosimetry. Vol. EUR 5452. 97-123 (1976).

CORNELIUS. I. M. AND ROSENFELD, A. B. Verification of Monte Carlo Calculations in Fast Neutron Therapy Using Silicon Microdosimetry. IEEE TRANSACTIONS ON NUCLEAR SCIENCE, Vol. 51, No. 3, June 2004.

DURHAM. J. Concepts, quantities. and dose limits in radiation protection dosimetry. Radiation Measurements 41. (2007) \$28-S35.

FANO. U. - Note on the Bragg-Gray cavity principle for measuring energy dissipation. Radiation Research 1, 237-239 (1954).

FAKIR. H.. HOFMANN, W., CASWELl, R. S.. AND AUBINEAU-L.ANIÈCE, I. Microdosimetry of Inhomogeneous Radon Progeny Distribution in Bronchial Airways. Radiation Protection Dosimetry (2005) Vol. 113, No. 2, pp. 129-139.

GLASS, W.A., BRABY, L.A., A wall-less detector for measuring energy deposition spectra. Radiation Research 39. 230-240 (1969).

GOODHEAD. D.T. Relationship of Microdosimetric Techniques to Applications in Biological Systems, in The Dosimetry of Ionizing Radiation, v.II, Academic Press. 1987. 
GOWRISHANKAR, T.R., ESSER. A.T., VASILKOSKI, Z., SMITH, K.C.. WEAVER, I.C. Microdosimetry for conventional and supra-electroporation in cells with organelles. Biochemical and Biophysical Research Communication 341 (2006) 1266-1276.

HALL. E.J.. GIACCIA. A.J. - Radiobiology for the Radiologist, $6^{\text {th }}$ edition. Lippincott Willians \& Wilkins. USA, 2006.

INTERNATIONAL COMMISSION ON RADIATION UNITS AND MEASURENENT. Radiation Quantities and Units. ICRU Report 33, Bethesda, MD, USA, 1980.

INTERNATIONAL COMMISSION ON RADIATION UNITS AND MEASUREMENT. Microdosimetry. ICRU REPORT 36, Bethesda, MD. USA, 1983.

INTERNATIONAL COMMISSION ON RADIATION UNITS AND MEASUREMENT. Stopping Powers and Ranges for Protons and Alpha Particles. ICRU REPORT 49. Bethesda. MD, USA, 1993.

INTERNATIONAL COMMISION ON RADIALOGICAL PROTECTION. 1990 Recommendation of the ICRP . ICRP Publication 60 (Oxford: Pergamon Press) (1991)

JANG. S.Y.. KIM, C.H.. REECE, W.D., BRABY, L.A. Filtered fast neution irradiation system using Texas A\&M University Nuclear Science Center Reactor. Nuclear Instruments and Methods in Physics Research A 530, 493-504 (2004).

KELLERER. A.M. -An Assesment of Wall Efects in Microdosimetric Measurements. Radiation Research 47, 377-386 (1971).

KELLERER. A.M. Fundamentals of Microdosimetry in The Dosimetry of Ionizing Radiation, v.I. Ed. K.R. Kase, B.E. Bjarngard, F.H. Attix. Academic Press. 1985.

KELLERER. A.M. Microdosimetric data and the biological effectiveness of neutrons. Proceedings of the Second Symposium on neutron dosimetry in biology and medicine; Neuherberg/Munïchen, 1974. Pages 71-91.

KELLERER, A.M. AND HAHN, K. Consideration on a Revision of the Quality Factor. Radiation Research. 114, 480-488 (1988).

KELLERER. A. M., ROSSI, H. H. - Summary of quantities and functions employed in microdosimetry. Proceedings. Edited by H.G. Ebert. Vol. Euraton, 4452 d-e-t. 1969. 
KLIAUGA, P.. WAKER, A.J.. BARTHE. J. - Design of Tissue-Equivalent Proportional Counters. Radiation Protection Dosimetry, Vol. 61. No. 4, pp. 309-322 (1995).

KNOLL, G.F. Radiation Detection and Measurement. 3 ed. John Wiley \& Sons. Inc.. 2000.

KVINNSLAND. Y.; STOKKE, T. E AURLIEN, E. Radioimmunotherapy with AlphaParticle Emitters: Microdosimetry of Cells with a Heterogeneous Antigen Expression and with Various Diameters of Cells and Nuclei. Rad. Res.. n. 155, p. 288-296, 2001.

LANGEN. K.M. Microdosimetric Investigation at the Fast Neutron Therapy Facility at Fermilab. 1997. PhD thesis. Department of Medical Physics. University of Wisconsin, Madison. USA.

LEONARD. B. E., Adaptative response and human benefit: Part I. A microdosimetry dose-dependent model. Int. J. Radiat. Biol. Vol. 83, No. 2. Febraury 2007. pp. 115-131.

MAINARDI, E.. DONAHUE. R. J.. WILSON. W. E. AND BLAKELY. E. A. Comparison of Microdosimetric Simulation Using PENELOPE and PITS for a $25 \mathrm{keV}$. Electron Microbeam in Water. Radiation Research 162. 326-331 (2004).

MARTIN. G.. GERDUNG, S., RAABE, M., AREND. E. A practical design of a cylindrical tissue-equivalent proportional counter for microdosimetry. Radiation Protection Dosimetry, Vol. 99. N. 1-4, pp. 379-380 (2002).

MORSTIN. K. BOND; V.P. E BAUM, J.W. Probabilistic Approach to Obtain Hit-Size Elfectiveness Functions Which Relate Microdosimetry and Radiobiology. Rad. Res., n. 120, p. 383-402, 1989.

NUNOMIYA, T., KIM, E., KUROSAWA. S., TANIGLCHI. T.. NAKAMURA. T., NAKANE, Y. Measurement of lineal-Energy distributions for neutrons of $8 \mathrm{keV}$ to 65 $\mathrm{MeV}$ by using a tissue- equivalent proportional counter. Radiation Protection Dosimetry, Vol.102, No. 1, pp. 49-59 (2002).

PIGNOL. J. P., SLABBERT, J. AND BINNS, P. Monte Carlo Simulation of Fast Neutron Spectra: Mean Lineal Energy Estimation with an Effectiveness Function and Correlation to RBE. Int. J. Radiation Oncology Biol. Phys., Vol. 49. No I pp. 25 I-260. 2001.

RAYADURGAM. S. - Design of A Wall-Less Proportional Counter For Microdosimetry in Nanometer Dimensions. College Station, TX. Texas A\&M University. U.S.A.. 2005. 
ROSSI. H.H.. ROSENZWEIG. W. A device for a measurement of Dose as a function of specific ionization. vol. 64. 404-411 (1955).

ROSSI. H.H. E ROSENZWEIG. W. Measurement of neutron dose as a function of linear energy transfer. Radiation Research 2. 417-425 (1955).

ROSSI, H.H.. BIAVATI, M.H.. GROSS. SW. - Local Energy Density in Irradiated Tissues, 1. Radiobiological Significance. Radiation Research 15.431-439 (1961).

ROSSI. H.H. Specification of radiation quality. Radiation Research 10. 522-531 (1959).

ROSSI, H.H., ZAIDER, M. Microdosimetry and its applications. Springer-Verlag. Berlin Heidelberg. 1996.

SCOTT. B.R. E SCHÖLLNBERGER. H. Introducing Biological Microdosimetrỵ for Ionising Radiation. Rad. Prot. Dosim.. n. 91(4), p. 377-384), 2000.

SHEN. Z.: YE, C E WU, D. Microdosimetry of Rat Alveolar Type II Cells Irradiated With $\alpha$ Particle from ${ }^{239} \mathrm{PuO}_{2}$. Rad. Res., n. 120, p. 234-250, 1989.

SHUHMACHER, H; MENZEL. H.G.: BLATTMANN. H. E MUTH. H. Proportional Counter Dosimetry and Microdosimetry for Radiotherapy with Multiple Pion Beams. Rad. Res.. n. 101, p. 177-196, 1985.

SRDOC. D., GOODMAN, L.J.. MARINO, S.A., MILLS, R.E., ZAIDER, M.. ROSSI, H.H. Microdosimetry of Monoenergetic Neutron Radiation. Proceedings of the Seventh Symposium on Microdosimetry. Oxford, England, 1980. Vol. EUR 7147. Pages: 765-774 (1981).

SRDOC, D., MARINO, S.A. Microdosimetry of Monoenergetic Neutrons. Radiation Research 146. 466-474 (1996).

STANTON. J.: TAUCHER-SCHOLZ. G.; Schneider. M. e Kraft. G. Comparison Between Indirect and Direct Effects for High and Low LET Radiations in SV40 DNA Strand Break Induction. Rad. Prot. Dosim., v. 31, n. (1-4). p. 253-256. 1990.

TILIKIDIS, A.; LIND, B.; NÄFSTADIUS. P.E., BRAHME, A. Microdosimetric Investigation on the Biological Effectiveness of $50 \mathrm{MV}$ Scamned Bremsstrahlung Beams. 
Department of Medical Radiation Physics. Karolinska Institutet and Stockholm University. Sweden. 1994.

VLIET-VROEGINDEWEIJ. C.; WHEELER, F.; STECHER-RASMUSSEN. F.; MOSS. R. E HUISKAMP, R. Microdosimetry Model for Boron Neutron Capture Therapy: I. Determination of Microscopic Quantities of Heavy Particles on a Cellular Scale. Rad. Res.. n. 155. p. 490-497.2001.

WALICKA. M.A.; ADELSTEIN, S.J. E KASSIS, A.I. Indirect Mechanisms Contribute to Biological Effects Produced by Decay of DNA-Incorporated Iodine-125 in Mammalian Cells In Vitro: Double-Strand Breaks. Rad. Res., n. 149, p. 134-141, 1998.

WAKER. A.J. - Principles of Experimental Microdosimetry. - Radiation Protection Dosimetry. Vol. 61, No. 4. pp. 297-308 (1995). Nuclear Technology Publishing. 


\section{ANEXO A - Parte das planilhas de cálculo das grandezas microdosimétricas de nêutrons rápidos de reator com potência de $1,0 \mathrm{~kW}$}

Tabela I - Dados provenientes do TEPC para nêutrons rápidos de reator operando a uma potência de $1.0 \mathrm{~kW}$ e alto ganho. número de eventos com radiação de fundo (ncrf). número de eventos de radiação de fundo (rf). número de eventos. n. subtraídos a radiação de fundo. energia lineal (y) e outras grandezas microdosimétricas calculadas como, $f(y)$, $y f(y) . d(y)$ e $y d(y)$.

\begin{tabular}{|c|c|c|c|c|c|c|c|c|c|}
\hline canais & r.f. & nerf & $n$ & $y$ & $f(y)$ delta & $f(y)$ & $y f(y)$ & $d(y)$ & $y d(y)$ \\
\hline 0 & 0 & 0 & 0 & 0,0000 & 0,0000 & 0,0000 & 0,0000 & 0,0000 & 0,0000 \\
\hline 1 & 0 & 0 & 0 & 0,0435 & 0,0000 & 0,0000 & 0,0000 & 0,0000 & 0,0000 \\
\hline 2 & 0 & 0 & 0 & $0, \overline{0870}$ & $0, \overline{0000}$ & 0,0000 & 0,0000 & $\overrightarrow{0,0000}$ & 0,0000 \\
\hline 3 & 0 & 0 & 0 & 0,1305 & 0,0000 & 0,0000 & 0,0000 & 0,0000 & 0,0000 \\
\hline 4 & 0 & 0 & 0 & 0,1740 & 0,0000 & 0,0000 & 0,0000 & 0,0000 & 0,0000 \\
\hline 5 & 0 & 1 & 1 & 0,2175 & 0,0000 & 0,0000 & 0,0000 & 0,0000 & 0,0000 \\
\hline 6 & 0 & 0 & 0 & 0,2610 & 0,0000 & 0,0000 & 0,0000 & 0,0000 & 0,0000 \\
\hline 7 & 0 & 0 & 0 & 0,3045 & 0.0000 & 0,0000 & 0,0000 & 0,0000 & 0,0000 \\
\hline 8 & 0 & 0 & 0 & 0,3480 & 0,0000 & 0,0000 & 0,0000 & 0,0000 & 0,0000 \\
\hline 9 & 125 & 0 & 0 & 0,3915 & 0,0000 & 0,0000 & 0,0000 & 0,0000 & 0,0000 \\
\hline 10 & 225 & 0 & 0 & 0,4350 & 0,0000 & 0,0000 & 0,0000 & 0,0000 & 0,0000 \\
\hline 11 & 183 & 0 & 0 & 0,4785 & 0,0000 & 0,0000 & 0,0000 & 0,0000 & 0,0000 \\
\hline 12 & 174 & 0 & 0 & 0,5220 & 0.0000 & 0,0000 & 0,0000 & 0,0000 & 0,0000 \\
\hline 13 & 133 & 0 & 0 & 0,5655 & 0,0000 & 0,0000 & 0,0000 & 0,0000 & 0,0000 \\
\hline 14 & 100 & 0 & 0 & 0,6090 & 0,0000 & 0,0000 & 0,0000 & 0,0000 & 0,0000 \\
\hline 15 & 84 & 0 & 0 & 0,6525 & 0,0000 & 0,0000 & 0,0000 & 0,0000 & 0,0000 \\
\hline 16 & 88 & 0 & 0 & 0,6960 & 0,0000 & 0,0000 & 0,0000 & 0,0000 & 0,0000 \\
\hline 17 & 69 & 0 & 0 & 0,7395 & 0,0000 & 0,0000 & 0,0000 & 0,0000 & 0,0000 \\
\hline 18 & 60 & 0 & 0 & 0,7830 & 0.0000 & 0,0000 & 0,0000 & 0,0000 & 0,0000 \\
\hline 19 & 64 & 0 & 0 & 0,8265 & 0,0000 & 0,0000 & 0,0000 & 0,0000 & 0,0000 \\
\hline 20 & 48 & 0 & 0 & 0,8700 & 0,0000 & 0,0000 & 0,0000 & 0,0000 & 0,0000 \\
\hline 21 & 52 & 0 & 0 & 0,9135 & 0,0000 & 0,0000 & 0,0000 & 0,0000 & 0,0000 \\
\hline 22 & 52 & 0 & 0 & 0,9570 & 0,0000 & 0,0000 & 0,0000 & 0,0000 & 0,0000 \\
\hline 23 & 40 & 112 & 72 & 1,0005 & 0,0000 & 0,0001 & 0,0001 & 0,0000 & 0,0000 \\
\hline 24 & 45 & 3240 & 3195 & 1,0440 & 0,0002 & 0,0051 & 0,0054 & 0,0000 & 0,0000 \\
\hline 25 & 46 & 253543 & 253497 & 1,0875 & 0,0178 & 0,4082 & 0,4439 & 0,0015 & 0,0017 \\
\hline 26 & 45 & 300931 & 300886 & 1,1310 & 0,0211 & 0,4845 & 0,5479 & 0,0019 & 0,0022 \\
\hline 27 & 34 & 275401 & 275367 & 1,1745 & 0,0193 & 0,4434 & 0,5208 & 0,0018 & 0,0021 \\
\hline 28 & 37 & 252618 & 252581 & 1,2180 & 0,0177 & 0,4067 & 0,4954 & 0,0017 & 0,0021 \\
\hline 29 & 46 & 231649 & 231603 & 1,2615 & 0,0162 & 0,3729 & 0,4704 & 0,0016 & 0,0021 \\
\hline 30 & 47 & 214087 & 214040 & 1,3050 & 0,0150 & 0,3446 & 0,4498 & 0,0016 & 0,0020 \\
\hline 31 & 49 & 199159 & 199110 & 1,3485 & 0,0139 & 0,3206 & 0,4323 & 0,0015 & 0,0020 \\
\hline 32 & 46. & 185179 & 185133 & 1,3920 & 0,0130 & 0,2981 & 0,4150 & 0,0014 & 0,0020 \\
\hline 33 & 49 & 172863 & 172814 & 1,4355 & 0,0121 & 0,2783 & 0,3994 & 0,0014 & 0,0020 \\
\hline
\end{tabular}


Tabela 2 - Primeira parte de una planilha para agrupamento (binned) de canais de alto ganho, para nêutrons rápidos de reator operando a uma potência de $1.0 \mathrm{~kW}$. São apresentados os canais, o número de eventos sem radiação de fundo (nsrf). o número de eventos com extrapolação, n. o delta n. que define quantos canais estão sendo envolvidos no agrupamento (binned). o canal inicial e final que estão sendo agrupados. e as linhas iniciais e finais onde se situam os canais envolvidos.

\begin{tabular}{|c|c|c|c|c|c|c|c|c|}
\hline canais & r.f. & ncrf & $n$ & delta $n$ & $\begin{array}{l}\text { canal } \\
\text { inicial }\end{array}$ & $\begin{array}{l}\text { canal } \\
\text { final }\end{array}$ & $\begin{array}{l}\text { linha } \\
\text { inicial }\end{array}$ & $\begin{array}{l}\text { linha } \\
\text { final }\end{array}$ \\
\hline 0 & 0 & 0 & 875000 & 1 & 0 & 0 & 2 & 2 \\
\hline 1 & 0 & 0 & 850000 & 1 & 1 & 1 & 3 & 3 \\
\hline 2 & 0 & 0 & 825000 & 1 & 2 & 2 & 4 & 4 \\
\hline 3 & 0 & 0 & 800000 & 1 & 3 & 3 & 5 & 5 \\
\hline 4 & 0 & 0 & 775000 & 1 & 4 & 4 & 6 & 6 \\
\hline 5 & 0 & 1 & 750000 & 1 & 5 & 5 & 7 & 7 \\
\hline 6 & 0 & 0 & 725000 & 2 & 6 & 7 & 8 & 9 \\
\hline 7 & 0 & 0 & 700000 & 2 & 8 & 9 & 10 & 11 \\
\hline 8 & 0 & 0 & 675000 & 2 & 10 & 11 & 12 & 13 \\
\hline 9 & 125 & 0 & 650000 & 2 & 12 & 13 & 14 & 15 \\
\hline 10 & 225 & 0 & 625000 & 2 & 14 & 15 & 16 & 17 \\
\hline 11 & 183 & 0 & 600000 & 2 & 16 & 17 & 18 & 19 \\
\hline 12 & 174 & 0 & 575000 & 4 & 18 & 21 & 20 & 23 \\
\hline 13 & 133 & 0 & 550000 & 4 & 22 & 25 & 24 & 27 \\
\hline 14 & 100 & 0 & 525000 & 4 & 26 & 29 & 28 & 31 \\
\hline 15 & 84 & 0 & 500000 & 4 & 30 & 33 & 32 & 35 \\
\hline 16 & 88 & 0 & 475000 & 4 & 34 & 37 & 36 & 39 \\
\hline 17 & 69 & 0 & 450000 & 4 & 38 & 41 & 40 & 43 \\
\hline 18 & 60 & 0 & 425000 & 8 & 42 & 49 & 44 & 51 \\
\hline 19 & 64 & 0 & 400000 & 8 & 50 & 57 & 52 & 59 \\
\hline 20 & 48 & 0 & 385000 & 8 & 58 & 65 & 60 & 67 \\
\hline 21 & 52 & 0 & 375000 & 8 & 66 & 73 & 68 & 75 \\
\hline 22 & 52 & 0 & 365000 & 8 & 74 & 81 & 76 & 83 \\
\hline 23 & 40 & 112 & 355000 & 8 & 82 & 89 & 84 & 91 \\
\hline 24 & 45 & 3240 & 340000 & 16 & 90 & 105 & 92 & 107 \\
\hline 25 & 46 & 253543 & 325000 & 16 & 106 & 121 & 108 & 123 \\
\hline 26 & 45 & 300931 & 300886 & 16 & 122 & 137 & 124 & 139 \\
\hline 27 & 34 & 275401 & 275367 & 16 & 138 & 153 & 140 & 155 \\
\hline 28 & 37 & 252618 & 252581 & 16 & 154 & 169 & 156 & 171 \\
\hline 29 & 46 & 231649 & 231603 & 16 & 170 & 185 & 172 & 187 \\
\hline 30 & 47 & 214087 & 214040 & 32 & 186 & 217 & 188 & 219 \\
\hline 31 & 49 & 199159 & 199110 & 32 & 218 & 249 & 220 & 251 \\
\hline 32 & 46 & 185179 & 185133 & 32 & 250 & 281 & 252 & 283 \\
\hline 33 & 49 & 172863 & 172814 & 32 & 282 & 313 & 284 & 315 \\
\hline 34 & 34 & 161722 & 161688 & 32 & 314 & 345 & 316 & 347 \\
\hline 35 & 27 & 152060 & 152033 & 32 & 346 & 377 & 348 & 379 \\
\hline
\end{tabular}


Tabela 3 - Segunda parte de uma planilha para agrupamento (binned) de canais de alto ganho, para nêutrons rápidos de reator operando a uma potência de $1,0 \mathrm{~kW}$. Sào mostrados a energia lineal, $y$, inicial e final referente a um agrupamento de canais, a energia lineal. resultado da média entre as duas anteriores, além do novo $n$, soma dos eventos de um determinado agrupamento de canais. $f(y)$ delta. $f(y)$. yf $(y)$. $d(y)$ e $y d(y)$.

\begin{tabular}{|c|c|c|c|c|c|c|c|c|}
\hline$y$ inicial & $y$ final & $y$ & novo $n$ & $f(y)$ delta & $f(y)$ & $y f(y)$ & $d(y)$ & $y d(y)$ \\
\hline$-0,0218$ & 0,0218 & 0,0000 & 875000 & 0,0303 & 0,6964 & 0,0000 & 0,0000 & 0,0000 \\
\hline 0,0218 & 0,0653 & 0,0435 & 850000 & 0,0294 & 0,6765 & 0,0294 & 0,0047 & 0,0002 \\
\hline 0,0653 & 0,1088 & 0,0870 & 825000 & 0,0286 & $\overline{0,6566}$ & 0,0571 & 0,0092 & 0,0008 \\
\hline 0,1088 & 0,1523 & 0,1305 & 800000 & 0,0277 & 0,6367 & 0,0831 & 0,0133 & 0,0017 \\
\hline 0,1523 & 0,1958 & 0,1740 & 775000 & 0,0268 & 0,6168 & 0,1073 & 0,0172 & 0,0030 \\
\hline$\overline{0,1958}$ & 0,2393 & 0,2175 & 750000 & 0,0260 & 0,5969 & 0,1298 & 0,0209 & 0,00045 \\
\hline $0, \overline{2393}$ & 0,3263 & 0,2828 & 1425000 & 0,0493 & 0,5671 & 0,1603 & 0,0258 & 0,0073 \\
\hline 0,3263 & 0,4133 & 0,3698 & 1325000 & 0,0459 & 0,5273 & 0,1950 & 0,0313 & 0,0116 \\
\hline 0,4133 & 0,5003 & 0,4568 & 1225000 & 0,0424 & 0,4875 & 0,2227 & 0,0358 & 0,0163 \\
\hline 0,5003 & 0,5873 & 0,5438 & 1125000 & 0,0390 & 0,4477 & 0,2434 & 0,0391 & 0,0213 \\
\hline 0,5873 & 0,6743 & 0,6308 & 1025000 & 0,0355 & 0,4079 & 0,2573 & 0,0413 & 0,0261 \\
\hline 0,6743 & 0,7613 & 0,7178 & 925000 & 0,0320 & 0,3681 & 0,2642 & 0,0424 & 0,0305 \\
\hline 0.7613 & 0,9353 & 0,8483 & 1585000 & 0,0549 & 0,3154 & 0,2675 & 0,0430 & 0,0365 \\
\hline 0,9353 & 1,1093 & 1,0223 & 1385000 & 0,0480 & 0,2756 & 0,2817 & 0,0453 & 0,0463 \\
\hline 1,1093 & 1,2833 & 1,1963 & 1060437 & 0,0367 & 0,2110 & 0,2524 & 0,0405 & 0,0485 \\
\hline 1,2833 & 1,4573 & 1,3703 & 771097 & 0,0267 & 0,1534 & 0,2102 & 0,0338 & 0,0463 \\
\hline 1,4573 & 1,6313 & 1,5443 & 592238 & 0,0205 & 0,1178 & 0,1820 & 0,0292 & 0,0451 \\
\hline 1,6313 & 1,8053 & 1,7183 & 474304 & 0,0164 & 0,0944 & 0,1622 & 0,0260 & 0,0448 \\
\hline 1,8053 & 2,1533 & 1,9793 & 718412 & 0,0249 & 0,0715 & 0,1415 & 0,0227 & 0,0450 \\
\hline 2,1533 & 2,5013 & 2,3273 & 538441 & 0,0186 & 0,0536 & 0,1247 & 0,0200 & 0,0466 \\
\hline 2,5013 & 2,8493 & 2,6753 & 423689 & 0,0147 & 0,0422 & 0,1128 & 0,0181 & 0,0485 \\
\hline 2,8493 & 3,1973 & 3,0233 & 347966 & 0,0120 & 0,0346 & 0,1047 & 0,0168 & 0,0508 \\
\hline 3,1973 & 3,5453 & 3,3713 & 294950 & 0,0102 & 0,0293 & 0,0989 & 0,0159 & 0,0536 \\
\hline 3.5453 & 3,8933 & 3,7193 & 255457 & 0,0088 & 0,0254 & 0,0945 & 0,0152 & 0,0565 \\
\hline 3,8933 & 4,5893 & 4,2413 & 431538 & 0,0149 & 0,0215 & 0,0910 & 0,0146 & 0,0620 \\
\hline 4,5893 & 5,2853 & 4,9373 & 355480 & 0,0123 & 0,0177 & 0,0873 & 0,0140 & 0,0692 \\
\hline $5, \overline{2853}$ & 5,9813 & 5,6333 & 307955 & 0,0107 & 0,0153 & 0,0863 & 0,0139 & 0,0781 \\
\hline 5,9813 & 6,6773 & 6,3293 & 272869 & 0,0094 & 0,0136 & 0,0859 & 0,0138 & 0,0873 \\
\hline 6,6773 & 7,3733 & 7,0253 & 246151 & 0,0085 & 0,0122 & 0,0860 & 0,0138 & 0,0971 \\
\hline 7,3733 & 8,0693 & 7,7213 & 225956 & 0,0078 & 0,0112 & 0,0868 & 0,0139 & 0,1076 \\
\hline 8,0693 & 9,4613 & 8,7653 & 407755 & 0,0141 & 0,0101 & 0,0889 & 0,0143 & 0,1252 \\
\hline 9,4613 & 10,8533 & 10,1573 & 373296 & 0,0129 & 0,0093 & 0,0943 & 0,0151 & 0,1539 \\
\hline 10,8533 & 12,2453 & 11,5493 & 355197 & 0,0123 & 0,0088 & 0,1020 & 0,0164 & 0,1893 \\
\hline 12,2453 & 13,6373 & 12,9413 & 341055 & 0,0118 & 0,0085 & 0,1098 & 0,0176 & 0,2282 \\
\hline
\end{tabular}


Tabela + - Dados provenientes do TEPC para nêutrons rápidos de reator operando com potência de $1.0 \mathrm{~kW}$ em baixo ganho como os canais. o número de eventos com radiação de fundo (ncrf). e o número de eventos. $n$, subtraidos a radiação de fundo. São apresentados, também, a energia lineal, $y$, e outras grandezas microdosimétricas calculadas como, $f(y), y f(y), d(y)$ e $y d(y)$.

\begin{tabular}{|c|c|c|c|c|c|c|c|c|}
\hline canais & r.f. & ncrf & $n$ & $y$ & $f(y)$ delta & $y f(y)$ & $d(y)$ & $y d(y)$ \\
\hline 0 & 0 & & 0 & 0 & 0,0000 & 0,0000 & 0.0000 & 0,0000 \\
\hline 1 & 0 & 0 & 0 & 1 & 0,0000 & 0,0000 & 0,0000 & 0,0000 \\
\hline 2 & 0 & 0 & 0 & 2 & 0,0000 & 0,0000 & 0,0000 & 0,0000 \\
\hline 3 & 0 & 0 & 0 & 3 & 0,0000 & 0,0000 & 0,0000 & 0,0000 \\
\hline 4 & 0 & 0 & 0 & 4 & 0,0000 & 0,0000 & 0,0000 & 0,0000 \\
\hline 5 & 0 & 0 & 0 & 5 & 0,0000 & 0,0000 & 0,0000 & 0,0000 \\
\hline 6 & 0 & 0 & 0 & 6 & 0,0000 & 0,0000 & 0,0000 & 0,0000 \\
\hline 7 & 0 & 0 & 0 & 7 & 0,0000 & 0,0000 & 0,0000 & 0,0000 \\
\hline 8 & 0 & 49 & 49 & 8 & 0,0000 & 0,0000 & 0,0000 & 0.0000 \\
\hline 9 & 125 & 176411 & 176286 & 9 & 0,0167 & 0,1500 & 0,0037 & 0,0331 \\
\hline 10 & 225 & 350142 & 349917 & 10 & 0,0331 & 0,3308 & 0,0081 & 0,0811 \\
\hline 11 & 183 & 311849 & 311666 & 11 & 0,0295 & 0,3241 & 0,0079 & 0,0874 \\
\hline 12 & $17 \overline{4}$ & 285583 & 285409 & 12 & 0,0270 & 0,3237 & 0,0079 & 0,0953 \\
\hline 13 & 133 & 270168 & 270035 & 13 & 0,0255 & 0,3318 & 0,0081 & 0,1058 \\
\hline 14 & 100 & 259579 & 259479 & 14 & 0,0245 & $\overline{0,3434}$ & 0,0084 & $0,1 \overline{179}$ \\
\hline 15 & 84 & 251275 & 251191 & 15 & 0,0237 & 0,3562 & 0,0087 & 0,1310 \\
\hline 16 & 88 & 244790 & $244 \overline{702}$ & 16 & 0,0231 & 0,3701 & 0,0091 & 0,1453 \\
\hline 17 & 69 & 239369 & 239300 & 17 & 0,0226 & 0,3845 & 0,0094 & 0,1604 \\
\hline 18 & 60 & 235351 & 235291 & $\overline{18}$ & 0,0222 & $0, \overline{4003}$ & 0,0098 & 0,1768 \\
\hline 19 & 64 & 230604 & 230540 & 19 & 0,0218 & 0,4141 & 0,0102 & 0,1930 \\
\hline 20 & 48 & 224977 & 224929 & 20 & 0,0213 & 0,4252 & 0,0104 & 0,2086 \\
\hline 21 & 52 & 220223 & 220171 & 21 & 0,0208 & 0,4371 & 0,0107 & 0,2251 \\
\hline 22 & 52 & 215114 & 215062 & 22 & 0,0203 & 0,4472 & 0,0110 & 0,2414 \\
\hline 23 & 40 & 210741 & 210701 & 23 & 0,0199 & 0,4581 & 0,0112 & 0,2584 \\
\hline 24 & $\overline{45}$ & 205431 & 205386 & 24 & 0,0194 & 0,4659 & 0,0114 & 0.2743 \\
\hline 25 & 46 & 200908 & 200862 & 25 & 0,0190 & 0,4747 & 0,0116 & 0,2911 \\
\hline 26 & 45 & 195875 & 195830 & 26 & 0,0185 & 0,4813 & 0,0118 & 0,3070 \\
\hline 27 & 34 & 190487 & 190453 & 27 & 0,0180 & 0,4861 & 0,0119 & 0,3219 \\
\hline 28 & 37 & 185341 & 185304 & 28 & 0,0175 & 0,4905 & 0,0120 & 0,3369 \\
\hline 29 & 46 & 180325 & $1 \overline{80279}$ & 29 & 0,0170 & 0,4942 & 0,0121 & 0,3516 \\
\hline 30 & 47 & 175729 & 175682 & 30 & 0,0166 & 0,4982 & 0,0122 & 0,3666 \\
\hline 31 & 49 & 169962 & 169913 & 31 & 0,0161 & 0,4979 & 0,0122 & 0,3786 \\
\hline 32 & 46 & 165100 & 165054 & 32 & 0,0156 & 0,4993 & 0,0122 & $\overline{0,3919}$ \\
\hline 33 & 49 & 160236 & 160187 & 33 & 0,0151 & 0,4997 & 0,0123 & 0,4045 \\
\hline
\end{tabular}


Tabela 5 - Primeira parte de uma planilha para agrupamento de canais de baixo ganho. para cálculo de grandezas microdosimétricas de nêutrons rápidos de reator operando a uma potência de $1,0 \mathrm{~kW}$.

\begin{tabular}{|c|c|c|c|c|c|c|c|c|}
\hline canais & r.f. & ncrf & $n$ & delta $n$ & $\begin{array}{l}\text { Canal } \\
\text { inical }\end{array}$ & $\begin{array}{l}\text { Canal } \\
\text { final }\end{array}$ & $\begin{array}{l}\text { Linha } \\
\text { inicial }\end{array}$ & $\begin{array}{l}\text { Linha } \\
\text { final }\end{array}$ \\
\hline 0 & 0 & & 0 & 1 & 0 & 0 & 2 & 2 \\
\hline 1 & 0 & 0 & 0 & 1 & 1 & 1 & 3 & 3 \\
\hline 2 & 0 & 0 & 0 & 1 & 2 & 2 & 4 & 4 \\
\hline 3 & 0 & 0 & 0 & 1 & 3 & 3 & 5 & 5 \\
\hline 4 & 0 & $\overline{0}$ & 0 & 1 & 4 & 4 & 6 & 6 \\
\hline 5 & 0 & 0 & 0 & 1 & 5 & 5 & 7 & 7 \\
\hline 6 & 0 & 0 & 0 & 2 & 6 & 7 & 8 & 9 \\
\hline 7 & 0 & 0 & 0 & 2 & 8 & 9 & 10 & 11 \\
\hline 8 & 0 & 49 & 49 & 2 & 10 & 11 & 12 & 13 \\
\hline 9 & 125 & 176411 & 176286 & 2 & 12 & 13 & 14 & 15 \\
\hline$\overline{10}$ & 225 & 350142 & 349917 & 2 & 14 & 15 & 16 & 17 \\
\hline 11 & 183 & 311849 & 311666 & 2 & 16 & 17 & 18 & 19 \\
\hline 12 & 174 & 285583 & 285409 & 4 & 18 & 21 & 20 & 23 \\
\hline 13 & 133 & 270168 & 270035 & 4 & 22 & 25 & 24 & 27 \\
\hline 14 & 100 & 259579 & 259479 & 4 & 26 & 29 & 28 & 31 \\
\hline 15 & 84 & 251275 & 251191 & 4 & 30 & 33 & 32 & 35 \\
\hline 16 & 88 & 244790 & 244702 & 4 & 34 & 37 & 36 & 39 \\
\hline 17 & 69 & 239369 & 239300 & 4 & 38 & 41 & 40 & 43 \\
\hline 18 & 60 & 235351 & 235291 & 8 & 42 & 49 & 44 & 51 \\
\hline 19 & 64 & 230604 & 230540 & 8 & 50 & 57 & 52 & 59 \\
\hline 20 & 48 & 224977 & 224929 & 8 & 58 & 65 & 60 & 67 \\
\hline$\overline{21}$ & 52 & 220223 & 220171 & 8 & 66 & 73 & 68 & 75 \\
\hline 22 & 52 & 215114 & 215062 & 8 & 74 & 81 & 76 & 83 \\
\hline 23 & 40 & 210741 & 210701 & 8 & 82 & 89 & 84 & 91 \\
\hline 24 & 45 & 205431 & 205386 & 16 & 90 & 105 & 92 & 107 \\
\hline 25 & 46 & 200908 & 200862 & 16 & 106 & 121 & 108 & 123 \\
\hline 26 & $4 \overline{5}$ & 195875 & 195830 & 16 & 122 & 137 & 124 & 139 \\
\hline 27 & 34 & 190487 & 190453 & 16 & 138 & 153 & 140 & 155 \\
\hline 28 & 37 & 185341 & 185304 & 16 & 154 & 169 & 156 & 171 \\
\hline 29 & 46 & 180325 & 180279 & 16 & 170 & 185 & 172 & 187 \\
\hline 30 & 47 & 175729 & 175682 & 32 & 186 & 217 & 188 & 219 \\
\hline 31 & 49 & 169962 & 169913 & 32 & 218 & 249 & 220 & 251 \\
\hline 32 & 46 & 165100 & 165054 & 32 & 250 & 281 & 252 & 283 \\
\hline 33 & $4 \overline{9}$ & 160236 & 160187 & 32 & 282 & 313 & 284 & 315 \\
\hline 34 & 34 & 154967 & 154933 & 32 & 314 & 345 & 316 & 347 \\
\hline 35 & 27 & 150151 & 150124 & 32 & 346 & 377 & 348 & 379 \\
\hline
\end{tabular}


Tabela 6 - Segunda parte de una planilha para agrupamentos (binned) de canais de baixo ganho, para nêutrons rápidos de reator operando a uma potência de $1.0 \mathrm{~kW}$. São mostrados a energia lineal, y. inicial e final, referente a um agrupamento de canais. a energia lineal, resultado da média entre as duas anteriores, além do novo $\mathrm{n}$, soma dos eventos de um determinado agrupamento de canais, $f(y)$ delta. $f(y), y f(y), d(y)$ e $y d(y)$.

\begin{tabular}{|c|c|c|c|c|c|c|c|c|}
\hline$y$ inicial & $y$ final & $y$ & novo $n$ & $f(y)$ delta & $f(y)$ & $y f(y)$ & $d(y)$ & $y d(y)$ \\
\hline$-0,5000$ & 5000 & 0,0000 & 0 & 0,0000 & 0.0000 & 0,0000 & 0,0000 & 0,0000 \\
\hline 0,5000 & 1,5000 & 1,0000 & 0 & 0,0000 & 0,0000 & 0,0000 &, 0000 & 0,0000 \\
\hline 1,5000 & 2,5000 & 2,0000 & 0 & 0,0000 & 0,0000 & 0,0000 & 0,0000 & 0,0000 \\
\hline 2,5000 & 3,5000 & 3,0000 & 0 & 0,0000 & 0,0000 & 0,0000 & 0,0000 & 0,0000 \\
\hline 3,5000 & 4,5000 & 4,0000 & $\overline{0}$ & 0,0000 & 0,0000 & 0,0000 &, 0000 & 0,0000 \\
\hline 4.5000 & 5,5000 & 5,0000 & 0 & 0,0000 & 0,0000 & 0,0000 & 0,0000 & 0,0000 \\
\hline 5,5000 & 7,5000 & 6,5000 & 0 & 0,0000 & 0,0000 & 0,0000 & 0,0000 & 0,0000 \\
\hline 7.5000 & 9,5000 & 8,5000 & 176335 & 0,0167 & 0,0083 & 0,0708 & 0,0101 & 0,0855 \\
\hline 9,5000 & 11,5000 & 10,5000 & 1583 & 0,0625 & 0,0313 & 0,3283 & $\overline{0.0466}$ & 0,4896 \\
\hline 11,5000 & 13,5000 & 12,5000 & 555444 & 0,0525 & 0,0263 & 0,3282 & 0,0466 & 0,5826 \\
\hline 13,5000 & 15,5000 & 14,5000 & 510670 & 0,0483 & 0,0241 & 0,3500 & 0,0497 & 0,7207 \\
\hline 15,5000 & 17,5000 & 16,5000 & 484002 & 0,0458 & 0,0229 & 0,3774 & 0,0536 & 0,8845 \\
\hline 17,5000 & $\overline{21,5000}$ & 19,5000 & 910931 & 0,0861 & 0,0215 & $0,4 \overline{198}$ & 596 & 1,1626 \\
\hline 21,5000 & 25,5000 & 23,5000 & 832011 & 0,0786 & 0.0197 & 0,4621 & 0,0656 & 1,5422 \\
\hline 25.5000 & 29,5000 & 27,5000 & 1866 & 0,0711 & 0,0178 & 0,4886 & 694 & 9084 \\
\hline 29,5000 & 33,5000 & 31,5000 & 670836 & 0,0634 & 0,0159 & 0,4994 & 0,0709 & 2,2341 \\
\hline 33,5000 & 37,5000 & 35,5000 & 592756 & 0,0560 & 0,0140 & 0,4973 & 0,0706 & 5073 \\
\hline 37,5000 & 41,5000 & 39,5000 & 523110 & 0,0494 & 0,0124 & 0,4883 & 0,0694 & 2,7394 \\
\hline 41,5000 & 49,5000 & 45,5000 & 862734 & 0,0816 & 0,0102 & 0,4638 & 0,0659 & 2,9974 \\
\hline 49,5000 & 57,5000 & 53,5000 & 671497 & 0,0635 & 0,0079 & 0,4245 & 0,0603 & 3,2255 \\
\hline 57,5000 & 65,5000 & 61,5000 & 525968 & 0,0497 & 0,0062 & 0,3822 & 0,0543 & 3,3385 \\
\hline 65.5000 & 73,5000 & 69,5000 & 417103 & 0,0394 & 0,0049 & 0,3425 & 0,0486 & 3,3811 \\
\hline 73,5000 & 81,5000 & 77,5000 & 333030 & 0,0315 & 0,0039 & 0,3050 & 0,0433 & 3,3568 \\
\hline 81,5000 & 89,50 & 85,5000 & 268751 & 0,0254 & 0,0032 & 0,2715 & 0,0386 & 3,2970 \\
\hline 89,5000 & 105,5000 & 97,5000 & 396738 & 0,0375 & 0,0023 & 0,2285 & 0,0325 & 3,1646 \\
\hline 105,5000 & 121,5000 & 113,5000 & 253780 & 0,0240 & 0,0015 & 0,1702 & 0,0242 & 2,7432 \\
\hline 121,5000 & 137,5000 & 129,5000 & 114793 & 0,0109 & 0,0007 & 0,0878 & 0,0125 & 1,6153 \\
\hline 137,5000 & 153,5000 & 145,5000 & 28415 & 0,0027 & 0,0002 & 0,0244 & 0,0035 & 0,5048 \\
\hline 153,5000 & 169,5000 & 161,5000 & 7889 & 0,0007 & 0,0000 & 0,0075 & 0,0011 & 0,1727 \\
\hline 169,5000 & 185,5000 & 177,5000 & 4576 & 0,0004 & 0,0000 & 0,0048 & 0,0007 & 0,1210 \\
\hline 185,5000 & 217,5000 & 201,5000 & 6602 & 0,0006 & 0,0000 & 0,0039 & 0,0006 & 0,1125 \\
\hline 217,5000 & 249,5000 & 233,5000 & 4617 & 0,0004 & 0,0000 & 0,0032 & 0,0005 & 0,1056 \\
\hline 249,5000 & 281,5000 & 265,5000 & 3412 & 0,0003 & 0,0000 & 0,0027 & 0,0004 & 0,1009 \\
\hline 281,5000 & 313,5000 & 297,5000 & 2520 & 0,0002 & 0.0000 & 0,0022 & 0,0003 & 0,0936 \\
\hline
\end{tabular}


Tabela 7 - Planilha usada para agrupar os espectros de alto ganho e baixo ganho nos espectros microdosimétricos definitivos de energia lineal de nêutron rápido de reator para a potência de $1,0 \mathrm{~kW}$.

\begin{tabular}{|c|c|c|c|c|c|c|c|c|}
\hline start $y$ & stop y & $y$ & n news & $f(y)$ delta & $f(y)$ & $y f(y)$ & $d(y)$ & $y d(y)$ \\
\hline$-0,0218$ & 0,0218 & 0,0000 & 875000 & 0,0267 & 0,6131 & 0,0000 & 0,0000 & 0,0000 \\
\hline 0,0218 & 0,0653 & 0,0435 & 850000 & 0,0259 & 0,5956 & 0,0259 & 0,0041 & 0,0002 \\
\hline 0,0653 & 0,1088 & 0,0870 & 825000 & 0,0251 & 0,5781 & 0,0503 & 0,0080 & 0,0007 \\
\hline 0,1088 & 0,1523 & 0,1305 & 800000 & 0,0244 & 0,5606 & 0,0732 & 0,0117 & 0,0015 \\
\hline 0,1523 & 0,1958 & 0,1740 & 775000 & 0,0236 & 0,5431 & 0,0945 & 0,0151 & 0,0026 \\
\hline 0,1958 & 0,2393 & 0,2175 & 750000 & 0,0229 & 0,5256 & 0,1143 & 0,0182 & 0,0040 \\
\hline 0,2393 & 0,3263 & 0,2828 & 1425000 & 0,0434 & 0,4993 & 0,1412 & 0,0225 & 0,0064 \\
\hline 0,3263 & 0,4133 & 0,3698 & 1325000 & 0,0404 & 0,4642 & 0,1717 & 0,0274 & 0,0101 \\
\hline$\overline{0,4133}$ & 0,5003 & 0,4568 & 1225000 & 0,0373 & 0,4292 & 0,1960 & 0,0312 & 0,0143 \\
\hline 0,5003 & 0,5873 & 0,5438 & 1125000 & 0,0343 & 0,3942 & 0,2143 & 0,0341 & 0,0186 \\
\hline 0,5873 & 0,6743 & 0,6308 & 1025000 & 0,0312 & 0,3591 & 0,2265 & 0,0361 & 0,0228 \\
\hline $0, \overline{6743}$ & 0,7613 & 0,7178 & 925000 & 0,0282 & 0,3241 & 0,2326 & 0,0371 & 0,0266 \\
\hline 0,7613 & $0, \overline{9353}$ & 0,8483 & 1585000 & 0,0483 & 0,2777 & 0,2355 & 0,0375 & 0,0318 \\
\hline $0, \overline{9353}$ & 1,1093 & 1,0223 & 1385000 & 0,0422 & 0,2426 & 0,2480 & 0,0395 & 0,0404 \\
\hline 1,1093 & 1,2833 & 1,1963 & 1060437 & 0,0323 & 0,1858 & 0,2222 & 0,0354 & 0,0424 \\
\hline 1,2833 & 1,4573 & 1,3703 & 771097 & 0,0235 & 0,1351 & 0,1851 & 0,0295 & 0,0404 \\
\hline 1,4573 & 1,6313 & 1,5443 & 592238 & 0,0181 & 0,1038 & 0,1602 & 0,0255 & 0.0394 \\
\hline 1,6313 & $1, \overline{8053}$ & 1,7183 & 474304 & 0,0145 & 0,0831 & 0,1428 & 0,0227 & 0,0391 \\
\hline 1,8053 & 2,1533 & 1,9793 & 718412 & 0,0219 & 0,0629 & 0,1245 & 0,0198 & 0,0393 \\
\hline 2,1533 & 2,5013 & 2,3273 & 538441 & 0,0164 & 0,0472 & 0,1098 & 0,0175 & 0,0407 \\
\hline 2,5013 & 2,8493 & 2,6753 & 423689 & 0,0129 & 0,0371 & 0,0993 & 0,0158 & 0,0423 \\
\hline 2,8493 & 3,1973 & 3,0233 & 347966 & 0,0106 & 0,0305 & 0,0921 & 0,0147 & 0,0444 \\
\hline 3,1973 & 3,5453 & 3,3713 & 294950 & 0,0090 & 0,0258 & 0,0871 & 0,0139 & 0,0468 \\
\hline 3,5453 & $\overline{3,8933}$ & 3,7193 & 255457 & 0,0078 & 0,0224 & 0,0832 & 0,0133 & $0,04 \overline{93}$ \\
\hline 3,8933 & 4,5893 & 4,2413 & 431538 & 0,0132 & 0,0189 & 0,0802 & 0,0128 & 0,0542 \\
\hline 4,5893 & 5,2853 & 4,9373 & 355480 & 0,0108 & 0,0156 & 0,0769 & 0,0122 & 0,0605 \\
\hline 5,2853 & 5,9813 & 5,6333 & 307955 & 0,0094 & 0,0135 & 0,0760 & 0,0121 & 0,0682 \\
\hline 5,9813 & 6,6773 & 6,3293 & 272869 & $0, \overline{0083}$ & $\overline{0,0120}$ & 0,0756 & 0,0121 & 0,0763 \\
\hline 6,6773 & $\overline{7}, 3733$ & 7,0253 & 246151 & 0,0075 & 0,0108 & 0,0757 & 0,0121 & 0,0848 \\
\hline 7,3733 & 8,0693 & 7,7213 & 225956 & 0,0069 & 0,0099 & 0,0764 & 0,0122 & 0,0940 \\
\hline 8,0693 & 9,4613 & 8,7653 & 407755 & 0,0124 & 0,0089 & 0,0783 & 0,0125 & 0,1093 \\
\hline 9,4613 & $\overline{10}, 8533$ & 10,1573 & 373296 & 0,0114 & 0,0082 & 0,0830 & 0,0132 & 0,1344 \\
\hline 10,8533 & 12,2453 & 11,5493 & 355197 & 0,0108 & 0,0078 & 0,0898 & 0,0143 & 0,1653 \\
\hline 12,2453 & 13,6373 & 12,9413 & 341055 & 0,0104 & 0,0075 & 0,0967 & 0,0154 & $0, \overline{1993}$ \\
\hline
\end{tabular}




\section{ANEXO B - Parte das planilhas de cálculo de grandezas microdosimétricas de nêutrons rápidos de reator operando com potência de $2,0 \mathrm{~kW}$.}

Tabela 1 - Dados provenientes do TEPC para nêutrons rápidos de reator operando a uma potência de $2.0 \mathrm{~kW}$ e alto ganho, número de eventos com radiação de fundo (ncrf). número de eventos de radiação de fundo $(\mathrm{rf})$, número de eventos, n. subtraídos a radiaçào de fundo, energia lineal (y) e outras grandezas microdosimétricas calculadas como. $f(y)$. yf(y).d(y) è $y d(y)$.

\begin{tabular}{|c|c|c|c|c|c|c|c|c|c|}
\hline canais & r.f. & nerf & $n$ & $y$ & $f(y)$ delta & $f(y)$ & $y f(y)$ & $d(y)$ & $y d(y)$ \\
\hline 0 & 0 & 0 & 0 & 0,0000 & 0,0000 & 0,0000 & 0,0000 & 0.0000 & 0,0000 \\
\hline 1 & 0 & 0 & 0 & 0,0435 & 0,0000 & 0,0000 & 0,0000 & 0,0000 & 0,0000 \\
\hline 2 & 0 & 0 & 0 & 0,0870 & 0,0000 & 0,0000 & 0,0000 & 0,0000 & 0,0000 \\
\hline 3 & 0 & 0 & 0 & 0,1305 & 0,0000 & 0,0000 & 0,0000 & 0,0000 & 0,0000 \\
\hline 4 & 0 & 0 & 0 & 0,1740 & 0,0000 & 0,0000 & 0,0000 & 0,0000 & 0,0000 \\
\hline 5 & 0 & 0 & 0 & 0,2175 & 0,0000 & 0,0000 & 0,0000 & 0.0000 & 0,0000 \\
\hline 6 & 0 & 0 & 0 & 0,2610 & 0,0000 & 0,0000 & 0,0000 & 0,0000 & 0,0000 \\
\hline 7 & 0 & 0 & 0 & 0,3045 & 0,0000 & 0,0000 & 0,0000 & 0,0000 & 0,0000 \\
\hline 8 & $\overline{0}$ & 0 & 0 & 0,3480 & 0,0000 & 0,0000 & 0,0000 & 0,0000 & 0,0000 \\
\hline 9 & 125 & 0 & 0 & 0,3915 & 0,0000 & 0,0000 & 0,0000 & 0,0000 & 0,0000 \\
\hline 10 & 225 & 0 & 0 & 0,4350 & 0,0000 & 0,0000 & 0,0000 & 0,0000 & 0,0000 \\
\hline 11 & 183 & 0 & 0 & 0,4785 & 0,0000 & 0,0000 & 0,0000 & 0,0000 & 0,0000 \\
\hline 12 & 174 & 0 & 0 & 0,5220 & 0,0000 & 0,0000 & 0,0000 & 0,0000 & 0,0000 \\
\hline 13 & 133 & 0 & 0 & 0,5655 & 0,0000 & 0,0000 & $\overline{0.0000}$ & 0,0000 & 0,0000 \\
\hline 14 & 100 & $\overline{0}$ & 0 & 0,6090 & 0,0000 & 0,0000 & 0,0000 & 0,0000 & 0,0000 \\
\hline 15 & 84 & 0 & 0 & 0,6525 & 0,0000 & 0,0000 & 0,0000 & $0, \overline{0000}$ & 0,0000 \\
\hline 16 & 88 & 0 & 0 & 0,6960 & 0,0000 & 0,0000 & 0,0000 & 0,0000 & 0,0000 \\
\hline 17 & $\overline{69}$ & 0 & 0 & 0,7395 & 0,0000 & 0,0000 & 0,0000 & 0,0000 & 0,0000 \\
\hline 18 & $\overline{60}$ & 0 & 0 & 0,7830 & 0,0000 & 0,0000 & 0,0000 & 0,0000 & $0,00 \overline{00}$ \\
\hline 19 & 64 & 0 & 0 & 0,8265 & 0,0000 & 0,0000 & 0,0000 & 0,0000 & 0,0000 \\
\hline 20 & 48 & 0 & 0 & 0,8700 & 0,0000 & 0,0000 & 0,0000 & 0.0000 & 0,0000 \\
\hline 21 & 52 & 0 & 0 & 0,9135 & 0,0000 & 0,0000 & 0,0000 & 0,0000 & 0,0000 \\
\hline 22 & 52 & $\overline{0}$ & 0 & 0,9570 & 0,0000 & 0,0000 & 0,0000 & 0,0000 & 0,0000 \\
\hline 23 & 40 & $\overline{0}$ & 0 & 1,0005 & 0,0000 & 0,0000 & 0,0000 & 0,0000 & 0,0000 \\
\hline 24 & 45 & 0 & 0 & 1,0440 & 0,0000 & 0,0000 & 0,0000 & 0,0000 & 0,0000 \\
\hline 25 & 46 & 0 & 0 & 1,0875 & 0,0000 & 0,0000 & 0,0000 & 0,0000 & 0,0000 \\
\hline 26 & 45 & 0 & $\overline{0}$ & 1,1310 & 0,0000 & 0,0000 & 0,0000 & 0,0000 & 0,0000 \\
\hline $2 \overline{7}$ & 34 & $\overline{0}$ & 0 & 1,1745 & 0,0000 & 0,0000 & 0,0000 & 0,0000 & 0,0000 \\
\hline 28 & 37 & 0 & 0 & 1,2180 & 0,0000 & 0,0000 & 0,0000 & 0,0000 & 0,0000 \\
\hline 29 & 46 & 0 & 0 & 1,2615 & 0,0000 & 0,0000 & 0,0000 & 0,0000 & 0,0000 \\
\hline 30 & 47 & 0 & 0 & 1,3050 & 0,0000 & 0,0000 & 0,0000 & $0, \overline{0000}$ & 0,0000 \\
\hline 31 & 49 & 1 & 0 & $1, \overline{3485}$ & 0,0000 & 0,0000 & 0,0000 & 0,0000 & 0,0000 \\
\hline 32 & 46 & 0 & 0 & 1,3920 & 0,0000 & 0,0000 & 0,0000 & 0,0000 & 0,0000 \\
\hline 33 & 49 & 0 & 0 & 1,4355 & 0,0000 & 0,0000 & 0,0000 & 0,0000 & 0,0000 \\
\hline 34 & 34 & 0 & 0 & 1,4790 & 0,0000 & 0,0000 & 0,0000 & 0,0000 & 0,0000 \\
\hline 35 & 27 & 110 & 83 & 1,5225 & 0,0000 & 0,0001 & 0,0001 & 0,0000 & 0,0000 \\
\hline 36 & 39 & 1037 & 998 & 1,5660 & 0,0000 & 0,0011 & 0,0017 & 0,0000 & $\overline{0}, 0 \overline{000}$ \\
\hline 37 & 34 & 174253 & 174219 & 1,6095 & 0,0081 & 0,1856 & 0,2988 & 0,0009 & 0,0014 \\
\hline
\end{tabular}


Tabela 2 - Primeira parte de uma planilha para agrupamento (binned) de canais de alto ganho. para nêutrons rápidos de reator operando a uma potência de $2,0 \mathrm{~kW}$. São apresentados os canais, o número de eventos sem radiação de fundo (nsrf), o número de eventos com extrapolação, n. o delta n, que define quantos canais estâo sendo envolvidos no agrupamento (binned). o canal inicial e final que estão sendo agrupados. e as linhas iniciais e finais onde se situam os canais envolvidos.

\begin{tabular}{|c|c|c|c|c|c|c|c|c|}
\hline Canais & r.f. & ncrf & $n$ & delta $n$ & $\begin{array}{l}\text { canal } \\
\text { Inicial }\end{array}$ & $\begin{array}{c}\text { Canal } \\
\text { final }\end{array}$ & $\begin{array}{l}\text { Linha } \\
\text { Inicial }\end{array}$ & $\begin{array}{l}\text { Linha } \\
\text { final }\end{array}$ \\
\hline 0 & 0 & 0 & 521000 & 1 & 0 & 0 & 2 & 2 \\
\hline 1 & 0 & 0 & 516000 & 1 & 1 & 1 & 3 & 3 \\
\hline 2 & 0 & 0 & 510000 & 1 & 2 & 2 & 4 & 4 \\
\hline 3 & 0 & 0 & 505000 & 1 & 3 & 3 & 5 & 5 \\
\hline 4 & 0 & 0 & 500000 & 1 & 4 & 4 & 6 & 6 \\
\hline 5 & 0 & 0 & 496000 & 1 & 5 & 5 & 7 & 7 \\
\hline 6 & $\overline{0}$ & 0 & 491000 & 2 & 6 & 7 & 8 & 9 \\
\hline 7 & 0 & 0 & 486000 & 2 & 8 & 9 & 10 & 11 \\
\hline 8 & 0 & 0 & 481000 & 2 & 10 & 11 & 12 & 13 \\
\hline 9 & 125 & 0 & 476000 & 2 & 12 & 13 & 14 & 15 \\
\hline 10 & 225 & 0 & 471000 & 2 & 14 & 15 & 16 & 17 \\
\hline 11 & 183 & 0 & 466000 & 2 & 16 & 17 & 18 & 19 \\
\hline 12 & 174 & 0 & 460000 & 4 & 18 & 21 & 20 & 23 \\
\hline 13 & 133 & 0 & 453000 & 4 & 22 & 25 & 24 & 27 \\
\hline 14 & 100 & 0 & 447000 & 4 & 26 & 29 & 28 & 31 \\
\hline 15 & 84 & 0 & 440000 & 4 & 30 & 33 & 32 & 35 \\
\hline 16 & 88 & 0 & 434000 & 4 & 34 & 37 & 36 & 39 \\
\hline 17 & 69 & 0 & 427000 & 4 & 38 & 41 & 40 & 43 \\
\hline 18 & 60 & $\overline{0}$ & 420000 & 8 & 42 & 49 & 44 & 51 \\
\hline 19 & 64 & 0 & 413000 & 8 & 50 & 57 & 52 & 59 \\
\hline 20 & 48 & 0 & 407000 & 8 & 58 & 65 & 60 & 67 \\
\hline 21 & 52 & 0 & 400000 & 8 & 66 & 73 & 68 & 75 \\
\hline 22 & 52 & 0 & 392000 & 8 & 74 & 81 & 76 & 83 \\
\hline 23 & 40 & 0 & 385000 & 8 & 82 & 89 & 84 & 91 \\
\hline 24 & 45 & 0 & 378000 & 16 & 90 & 105 & $\overline{92}$ & 107 \\
\hline 25 & 46 & 0 & 373000 & 16 & 106 & 121 & 108 & 123 \\
\hline 26 & 45 & 0 & 363000 & 16 & 122 & 137 & 124 & 139 \\
\hline 27 & 34 & 0 & 353000 & 16 & 138 & 153 & 140 & 155 \\
\hline 28 & 37 & 0 & 343000 & 16 & 154 & 169 & 156 & 171 \\
\hline 29 & 46 & 0 & 333000 & 16 & 170 & 185 & 172 & 187 \\
\hline 30 & 47 & 0 & 323000 & 32 & 186 & 217 & 188 & 219 \\
\hline 31 & 49 & 1 & 313000 & 32 & 218 & 249 & 220 & 251 \\
\hline 32 & 46 & 0 & 303000 & 32 & 250 & 281 & 252 & 283 \\
\hline 33 & 49 & 0 & 293000 & 32 & 282 & 313 & 284 & 315 \\
\hline 34 & 34 & 0 & 283000 & 32 & 314 & 345 & 316 & 347 \\
\hline 35 & 27 & 110 & 273000 & 32 & 346 & 377 & 348 & 379 \\
\hline
\end{tabular}


Tabela 3 - Segunda parte de uma planilha para agrupamento (binned) de canais de alto ganho. para néutrons rápidos de reator operando a uma potência de $2.0 \mathrm{~kW}$. Sào mostrados a energia lineal, $y$, inicial e final referente a um agrupamento de canais, a energia lincal. resultado da média entre as duas anteriores, além do novo n. soma dos eventos de um determinado agrupamento de canais. $f(y)$ delta. $f(y)$, yf $(y), d(y)$ e $y d(y)$.

\begin{tabular}{|c|c|c|c|c|c|c|c|c|}
\hline$y$ inicial & $Y$ final & $y$ & novo $n$ & $f(y)$ delta & $f(y)$ & $y f(y)$ & $d(y)$ & $y d(y)$ \\
\hline$-0,0218$ & 0,0218 & 0,0000 & 521000 & 0,0141 & 0,3244 & 0,0000 & 0,0000 & 0,0000 \\
\hline 0,0218 & 0,0653 & 0,0435 & 516000 & 0,0140 & 0,3213 & 0,0140 & 0,0019 & 0.0001 \\
\hline 0,0653 & 0,1088 & 0,0870 & 510000 & 0,0138 & 0,3175 & 0,0276 & 0,0038 & 0.0003 \\
\hline 0,1088 & 0,1523 & 0,1305 & 505000 & 0,0137 & 0,3144 & 0,0410 & 0,0056 & 0,0007 \\
\hline 0,1523 & 0,1958 & 0,1740 & 500000 & 0,0135 & 0,3113 & 0,0542 & 0,0074 & 0,0013 \\
\hline 0,1958 & 0,2393 & 0,2175 & 496000 & 0,0134 & 0,3088 & 0,0672 & 0,0092 & 0,0020 \\
\hline 0,2393 & 0,3263 & 0,2828 & 977000 & 0,0265 & 0,3042 & 0,0860 & 0,0118 & 0,0033 \\
\hline 0,3263 & 0,4133 & 0,3698 & 957000 & 0,0259 & 0,2979 & 0,1102 & 0,0151 & 0,0056 \\
\hline 0,4133 & 0,5003 & 0,4568 & 937000 & 0,0254 & 0,2917 & 0,1332 & 0,0183 & 0,0084 \\
\hline 0,5003 & 0,5873 & 0,5438 & 913000 & 0,0247 & 0,2842 & 0,1546 & 0,0212 & 0,0115 \\
\hline 0,5873 & 0,6743 & 0,6308 & 887000 & 0,0240 & 0,2761 & 0,1742 & 0,0239 & 0.0151 \\
\hline 0,6743 & 0,7613 & 0,7178 & 861000 & 0,0233 & 0,2680 & $0, \overline{1924}$ & 0,0264 & 0.0190 \\
\hline 0,7613 & 0,9353 & $\overline{0,8483}$ & 1640000 & 0,0444 & 0,2553 & 0,2165 & 0,0298 & 0.0252 \\
\hline 0,9353 & 1,1093 & 1,0223 & 1528000 & 0,0414 & 0,2378 & 0,2431 & 0,0334 & 0,0341 \\
\hline 1,1093 & 1,2833 & 1,1963 & 1392000 & 0,0377 & 0,2167 & 0,2592 & 0,0356 & 0,0426 \\
\hline 1,2833 & 1,4573 & 1,3703 & 1232000 & 0,0334 & 0,1918 & 0,2628 & 0,0361 & 0.0495 \\
\hline 1,4573 & 1,6313 & 1,5443 & 1072000 & 0,0290 & 0,1669 & 0,2577 & 0,0354 & 0,0547 \\
\hline 1,6313 & 1,8053 & 1,7183 & 902552 & 0,0244 & 0,1405 & 0,2414 & 0,0332 & 0.0570 \\
\hline 1,8053 & 2,1533 & 1,9793 & 1361674 & 0,0369 & 0,1060 & 0,2098 & 0,0288 & 0,0570 \\
\hline 2,1533 & 2,5013 & 2,3273 & 1005371 & 0,0272 & 0,0782 & 0,1821 & 0,0250 & 0,0582 \\
\hline 2,5013 & 2,8493 & 2,6753 & 787536 & 0,0213 & 0,0613 & 0,1640 & 0,0225 & 0,0603 \\
\hline 2,8493 & 3,1973 & 3,0233 & 643153 & 0,0174 & 0,0501 & 0,1513 & 0,0208 & 0,0629 \\
\hline 3,1973 & 3,5453 & 3,3713 & 544628 & 0,0148 & 0,0424 & 0,1429 & 0,0196 & 0,0662 \\
\hline 3,5453 & 3,8933 & 3,7193 & 472864 & 0,0128 & 0,0368 & 0,1369 & 0,0188 & 0,0699 \\
\hline 3,8933 & 4,5893 & 4,2413 & 792383 & 0,0215 & $0,0 \overline{308}$ & 0,1308 & 0,0180 & 0,0762 \\
\hline 4,5893 & 5,2853 & 4,9373 & 656223 & 0,0178 & 0,0255 & 0,1261 & 0,0173 & 0.0855 \\
\hline 5,2853 & 5,9813 & 5,6333 & 565940 & 0,0153 & 0,0220 & 0,1241 & 0,0170 & 0,0960 \\
\hline 5,9813 & 6,6773 & 6,3293 & 500819 & 0,0136 & 0,0195 & 0,1234 & 0,0169 & 0,1073 \\
\hline 6,6773 & 7,3733 & 7,0253 & 450738 & 0,0122 & 0,0175 & 0,1232 & 0,0169 & 0,1189 \\
\hline 7,3733 & 8,0693 & 7,7213 & 414996 & 0,0112 & 0,0161 & 0,1247 & 0,0171 & 0,1323 \\
\hline 8,0693 & 9,4613 & 8,7653 & 748320 & 0,0203 & 0,0146 & 0,1276 & 0,0175 & 0.1537 \\
\hline 9,4613 & 10,8533 & 10,1573 & 681016 & 0,0184 & 0,0133 & 0,1346 & 0,0185 & 0,1878 \\
\hline 10,8533 & 12,2453 & 11,5493 & 645708 & 0,0175 & 0,0126 & 0,1451 & 0,0199 & 0,2303 \\
\hline 12,2453 & 13.6373 & 12,9413 & 621490 & 0,0168 & 0,0121 & 0,1565 & 0,0215 & 0.2783 \\
\hline
\end{tabular}


Tabela 4 - Dados provenientes do TEPC para nêutrons rápidos de reator operando com potência de $2.0 \mathrm{~kW}$ baixo ganho como os canais. o número de eventos com radiaçào de fundo (ncrf). e o número de eventos. n, subtraídos a radiação de fundo. São apresentados. também. a energia lineal, $y$, e outras grandezas microdosimétricas calculadas como. $f(y)$. $y f(y) \cdot d(y)$ e $y d(y)$.

\begin{tabular}{|c|c|c|c|c|c|c|c|c|}
\hline canais & r.f. & ncrf & $n$ & $y$ & $f(y)$ delta & $y f(y)$ & $d(y)$ & $y d(y)$ \\
\hline 0 & 0 & 0 & 0 & 0 & 0,0000 & 0,0000 & 0,0000 & 0,0000 \\
\hline 1 & 0 & 0 & 0 & 1 & 0,0000 & 0,0000 & 0,0000 & 0,0000 \\
\hline 2 & 0 & 0 & 0 & 2 & 0,0000 & 0,0000 & 0,0000 & 0,0000 \\
\hline 3 & 0 & 0 & 0 & 3 & 0,0000 & 0,0000 & 0,0000 & 0,0000 \\
\hline 4 & 0 & 0 & 0 & 4 & 0,0000 & 0,0000 & 0,0000 & 0,0000 \\
\hline 5 & 0 & 0 & 0 & 5 & 0,0000 & 0,0000 & 0,0000 & 0,0000 \\
\hline 6 & 0 & $\overline{0}$ & 0 & 6 & 0,0000 & 0,0000 & 0,0000 & 0,0000 \\
\hline 7 & 0 & 0 & 0 & 7 & 0,0000 & 0,0000 & 0,0000 & 0,0000 \\
\hline 8 & $\overline{0}$ & 146 & 146 & 8 & 0,0000 & 0,0001 & 0.0000 & 0,0000 \\
\hline 9 & 125 & 318127 & 318002 & 9 & 0,0156 & 0,1402 & 0,0034 & 0,0309 \\
\hline 10 & 225 & 667354 & 667129 & 10 & 0,0327 & 0,3268 & 0.0080 & 0,0801 \\
\hline 11 & 183 & 597828 & 597645 & 11 & 0,0293 & 0,3220 & 0,0079 & 0,0868 \\
\hline$\overline{12}$ & 174 & 548763 & 548589 & 12 & 0,0269 & 0,3224 & 0,0079 & 0,0948 \\
\hline 13 & 133 & 520876 & 520743 & 13 & 0,0255 & 0,3316 & 0,0081 & 0,1056 \\
\hline 14 & 100 & 499517 & $49941 \overline{7}$ & 14 & 0,0245 & 0,3425 & 0,0084 & 0.1175 \\
\hline 15 & 84 & 487165 & 487081 & 15 & 0,0239 & 0,3579 & 0.0088 & 0,1315 \\
\hline 16 & 88 & 475617 & 475529 & 16 & 0,0233 & 0,3727 & 0,0091 & 0,1461 \\
\hline 17 & 69 & 463821 & 463752 & 17 & 0,0227 & 0,3862 & 0,0095 & 0,1608 \\
\hline 18 & 60 & 454410 & 454350 & 18 & 0,0223 & 0,4006 & 0,0098 & 0,1767 \\
\hline 19 & 64 & 445817 & 445753 & 19 & 0,0218 & 0,4148 & 0.0102 & 0,1931 \\
\hline 20 & 48 & 436852 & 436804 & 20 & 0,0214 & 0,4279 & 0,0105 & 0,2097 \\
\hline 21 & 52 & 428606 & 428554 & 21 & 0,0210 & 0,4408 & 0,0108 & 0,2268 \\
\hline 22 & 52 & 416872 & 416820 & 22 & 0,0204 & $0, \overline{4492}$ & $0, \overline{0110}$ & $\overline{0,2421}$ \\
\hline 23 & 40 & 407511 & 407471 & 23 & 0,0200 & 0,4590 & 0,0112 & 0,2587 \\
\hline 24 & 45 & 399364 & 399319 & 24 & 0,0196 & 0,4694 & 0.0115 & 0,2760 \\
\hline 25 & 46 & 388818 & 388772 & 25 & 0,0190 & 0,4761 & 0,0117 & 0,2916 \\
\hline 26 & 45 & 377734 & 377689 & 26 & 0,0185 & 0,4810 & 0,0118 & 0,3064 \\
\hline 27 & 34 & 367555 & 367521 & 27 & 0,0180 & 0,4860 & 0,0119 & 0,3215 \\
\hline 28 & 37 & 358653 & 358616 & 28 & 0,0176 & 0,4918 & 0,0121 & 0,3374 \\
\hline 29 & 46 & 349211 & 349165 & 29 & 0,0171 & 0,4960 & 0,0122 & 0,3524 \\
\hline 30 & 47 & 338261 & 338214 & 30 & 0,0166 & 0,4970 & 0,0122 & 0,3653 \\
\hline 31 & 49 & 327611 & 327562 & 31 & 0,0160 & 0,4974 & 0,0122 & 0,3778 \\
\hline 32 & 46 & 320101 & 320055 & 32 & 0.0157 & 0,5017 & 0,0123 & 0,3933 \\
\hline 33 & 49 & 310326 & 310277 & 33 & 0,0152 & 0,5015 & 0.0123 & 0,4055 \\
\hline 34 & 34 & 300833 & 300799 & 34 & 0,0147 & 0,5009 & 0,0123 & 0,4173 \\
\hline 35 & 27 & 290658 & 290631 & 35 & 0,0142 & 0,4982 & 0,0122 & 0,4273 \\
\hline
\end{tabular}


Tabela 5 - Primeira parte de uma planilha para agrupamento de canais de baiso ganho. para cálculo de grandezas microdosimétricas de nêutrons rápidos de reator operando a uma potência de $2.0 \mathrm{~kW}$.

\begin{tabular}{|c|c|c|c|c|c|c|c|c|}
\hline Canais & rf & ncrf & $n$ & delta $n$ & $\begin{array}{l}\text { Canal } \\
\text { inicial }\end{array}$ & $\begin{array}{l}\text { Canal } \\
\text { final }\end{array}$ & $\begin{array}{l}\text { Linha } \\
\text { inicial }\end{array}$ & $\begin{array}{l}\text { Linha } \\
\text { final }\end{array}$ \\
\hline 0 & 0 & 0 & 0 & 1 & 0 & 0 & 2 & 2 \\
\hline 1 & 0 & 0 & 0 & 1 & 1 & 1 & 3 & 3 \\
\hline 2 & 0 & 0 & 0 & 1 & 2 & 2 & 4 & 4 \\
\hline 3 & 0 & 0 & 0 & 1 & 3 & 3 & 5 & 5 \\
\hline 4 & 0 & 0 & 0 & 7 & 4 & 4 & 6 & 6 \\
\hline 5 & 0 & 0 & 0 & 1 & 5 & 5 & 7 & 7 \\
\hline 6 & 0 & 0 & 0 & 2 & 6 & 7 & 8 & 9 \\
\hline 7 & 0 & 0 & 0 & 2 & 8 & $\overline{9}$ & 10 & 11 \\
\hline 8 & 0 & 146 & 146 & 2 & 10 & 11 & 12 & 13 \\
\hline 9 & 125 & 318127 & 318002 & 2 & 12 & 13 & 14 & 15 \\
\hline 10 & 225 & 667354 & 667129 & 2 & 14 & 15 & 16 & 17 \\
\hline 11 & 183 & 597828 & 597645 & 2 & 16 & 17 & 18 & 19 \\
\hline 12 & 174 & 548763 & 548589 & 4 & 18 & 21 & 20 & 23 \\
\hline 13 & 133 & 520876 & 520743 & 4 & 22 & 25 & 24 & 27 \\
\hline 14 & 100 & 499517 & 499417 & 4 & 26 & 29 & 28 & 31 \\
\hline 15 & 84 & 487165 & 487081 & 4 & 30 & 33 & 32 & 35 \\
\hline 16 & 88 & 475617 & 475529 & 4 & 34 & 37 & 36 & 39 \\
\hline 17 & 69 & 463821 & 463752 & 4 & 38 & 41 & 40 & 43 \\
\hline 18 & 60 & 454410 & 454350 & 8 & 42 & 49 & 44 & 51 \\
\hline 19 & 64 & $\overline{445817}$ & $4 \overline{45753}$ & 8 & 50 & 57 & 52 & 59 \\
\hline 20 & 48 & 436852 & 436804 & 8 & 58 & 65 & 60 & 67 \\
\hline 21 & 52 & 428606 & 428554 & 8 & 66 & 73 & 68 & 75 \\
\hline 22 & 52 & 416872 & 416820 & 8 & 74 & 81 & 76 & 83 \\
\hline 23 & 40 & 407511 & $407 \overline{471}$ & 8 & 82 & 89 & 84 & 91 \\
\hline 24 & 45 & 399364 & 399319 & 16 & 90 & 105 & $\overline{92}$ & 107 \\
\hline 25 & $\overline{46}$ & 388818 & 388772 & 16 & 106 & 121 & 108 & 123 \\
\hline 26 & 45 & $37 \overline{7734}$ & 377689 & 16 & 122 & 137 & 124 & 139 \\
\hline 27 & 34 & 367555 & 367521 & $1 \overline{16}$ & 138 & $\overline{153}$ & 140 & 155 \\
\hline 28 & 37 & 358653 & 358616 & 16 & 154 & 169 & 156 & 171 \\
\hline 29 & 46 & 349211 & 349165 & 16 & 170 & 185 & 172 & 187 \\
\hline 30 & 47 & 338261 & $33 \overline{8214}$ & 32 & 186 & 217 & 188 & 219 \\
\hline 31 & 49 & 327611 & 327562 & 32 & 218 & 249 & 220 & 251 \\
\hline 32 & 46 & 320101 & 320055 & 32 & 250 & 281 & 252 & 283 \\
\hline 33 & 49 & 310326 & 310277 & 32 & 282 & 313 & 284 & 315 \\
\hline 34 & 34 & 300833 & 300799 & $\overline{32}$ & $\overline{314}$ & 345 & 316 & 347 \\
\hline 35 & 27 & 290658 & $\overline{290631}$ & $\overline{32}$ & 346 & 377 & 348 & 379 \\
\hline
\end{tabular}


Tabela 6 - Segunda parte de uma planilha para agrupamentos (binned) de canais de baixo ganho. para nêutrons rápidos de reator operando a uma potência de $1.0 \mathrm{~kW}$. São mostrados a energia lineal. y. inicial e final, referente a um agrupamento de canais. a energia lineal. resultado da média entre as duas anteriores. além do novo $n$, soma dos eventos de um determinado agrupamento de canais. $f(y)$ delta. $f(y)$. yf $(y), d(y)$ e $y d(y)$.

\begin{tabular}{|c|c|c|c|c|c|c|c|c|}
\hline y inicial & $y$ final & $y$ & novo $n$ & $f(y)$ delta & $f(y)$ & $y f(y)$ & $d(y)$ & $y d(y)$ \\
\hline 5000 & 5000 & 0,0000 & 0 & 0.0000 & 0,0000 &, 0000 &, 0000 & 0,0000 \\
\hline 5000 & 5000 & 1,0000 & 0 & 0.0000 & 0,0000 & 0000 & 0000 & 0,0000 \\
\hline 5000 & 5000 & 2,0000 & 0 & 0.0000 & 0,0000 &, 0000 &, 0000 & 0,0000 \\
\hline 5000 & 5000 & 3,0000 & 0 & 0.0000 & 0,0000 & 0000 & .0000 & 0,0000 \\
\hline 5000 & 5000 & 4,0000 & 0 & 0,0000 & 0,0000 & .0000 &, 0000 & 0,0000 \\
\hline 5000 & 5,5000 & 5,0000 & 0 & 0,0000 & 0,0000 & 0000 & 0,0000 & 0,0000 \\
\hline 5000 & 5000 & 6,5000 & 0 & 0,0000 & 0,0000 &, 0000 & 0000 & 0000 \\
\hline 5000 & 9,5000 & 8,5000 & 318148 & 0,0156 & 0,0078 & 0,0662 & 0,0094 & 0,0799 \\
\hline 9,5000 & 11,5000 & 10,5000 & 774 & 20 & 0,0310 & 3252 &, 0462 & 0,4847 \\
\hline 11,5000 & 3,5000 & 12,5000 & 1069332 & 0,0524 & 0,0262 & 0,3274 & 0,0465 & 0,5808 \\
\hline 5000 & 5000 & 14,50 & 498 & & 0,0242 & 503 & 0,0497 & 0,7210 \\
\hline 5000 & 17,5000 & 16,5000 & 939281 & 0.0460 & 0,0230 & 0,3796 & 0,0539 & 0,8889 \\
\hline 5000 & 21,5000 & 19,5000 & 461 & 65 & 0,0216 & 216 & 5598 & 668 \\
\hline 21.5000 & 25,5000 & 23,5000 & 1612382 & 0,0790 & 0,0197 & 0,4640 & 0,0659 & 1,5476 \\
\hline 25,5000 & 29,5000 & 27,5 & & 12 & 0,0178 & 393 & 694 & 398 \\
\hline 29,5000 & 33,5000 & 31,5000 & 1296108 & 0,0635 & 0,0159 & 4999 & 0,0710 & 352 \\
\hline 33.5000 & 37,5000 & 35,50 & 114 & & 0,0141 & 989 & 0708 & 137 \\
\hline 37,5000 & 41,5000 & 39,5000 & 1009905 & 0,0495 & 0,0124 & 4885 & $0,069 \overline{3}$ & 386 \\
\hline 41,5000 & 49,5000 & 45,5000 & 166 & 17 & 0,0102 & 646 & 0659 & 004 \\
\hline 49,5000 & 57,5000 & 53,5000 & 129 & 0,0635 & 0,0079 & 244 & 0,0602 & 228 \\
\hline 57,5000 & 65,5000 & 61,5000 & 101 & $0,0 \overline{498}$ & 0,0062 & 829 & 543 & 424 \\
\hline 65,5000 & 73.5000 & 69,5000 & 125 & 0,0395 & 0,0049 & 3435 & 0,0487 & 879 \\
\hline 73,5000 & 81,5000 & 77,5000 & 846 & 0,0316 & 0,0039 & 3060 & 0,0434 & 658 \\
\hline 81,5000 & 89,5000 & 85,5000 & 655 & 0,0255 & 0,0032 & 726 & 3387 & 076 \\
\hline 89,5000 & 105,5000 & 97,5000 & 270 & 0,0376 & 0,0024 & 2293 & 0,0325 & 733 \\
\hline 105,5000 & 121,5000 & 113,5000 & & & 0,0015 & 1685 & 0,0239 & 2.7141 \\
\hline 121,5000 & $13 \overline{7,5000}$ & 129,5000 & 216909 & 0,0106 & 0,0007 & 0860 & 0,0122 & 1,5806 \\
\hline 137,5000 & 153,5000 & 145,5000 & 56312 & 0,0028 & 0,0002 & 0251 & 0,0036 & 0,5180 \\
\hline 153,5000 & 169,5000 & 161,5000 & 17095 & 0,0008 & 0,0001 & 0,0085 & 0,0012 & 0,1937 \\
\hline 169,5000 & 185,5000 & 177,5000 & 9853 & 0,0005 & 0,0000 & 0,0054 & 0,0008 & 0,1349 \\
\hline $185, \overline{5000}$ & 217,5000 & 201,5000 & $13 \overline{183}$ & $\overline{0,0006}$ & 0,0000 & 0,0041 & 0,0006 & 0,1163 \\
\hline 217,5000 & 249,5000 & 233,5000 & 9043 & 0,0004 & 0,0000 & 0,0032 & 0,0005 & 0,1071 \\
\hline 249,5000 & 281,5000 & 265,5000 & 6531 & 0,0003 & 0,0000 & 0,0027 & 0,0004 & 0,1000 \\
\hline 281,5000 & 313,5000 & 297,5000 & 4782 & 0,0002 & 0,0000 & 0,0022 & 0,0003 & 0,0919 \\
\hline 313,5000 & 345,5000 & 329,5000 & 3608 & 0,0002 & 0,0000 & 0,0018 & 0,0003 & $0, \overline{0851}$ \\
\hline 345,5000 & $3 \overline{77,5000}$ & 361,5000 & 2679 & 0,0001 & 0,0000 & 0,0015 & 0,0002 & 0,0761 \\
\hline
\end{tabular}


Tabela 7 - Planilha usada para juntar os espectros de alto ganho e baixo ganho nos espectros microdosimétricos definitivos de energia lineal de nêutron rápido de reator para a potència de $2.0 \mathrm{~kW}$.

\begin{tabular}{|c|c|c|c|c|c|c|c|c|}
\hline y inicial & $y$ final & $y$ & novo $n$ & $f(y)$ delta & $f(y)$ & $y f(y)$ & $d(y)$ & $y d(y)$ \\
\hline$-0,0218$ & 0.0218 & 0,0000 & 521000 & 0,0116 & 0.2672 & 0,0000 & 0,0000 & 0,0000 \\
\hline 0,0218 & 0.0653 & 0,0435 & 516000 & 0,0115 & 0.2646 & 0,0115 & 0.0016 & 0,0001 \\
\hline 0,0653 & 0.1088 & 0,0870 & 510000 & 0,0114 & 0,2616 & 0,0228 & 0,0033 & 0,0003 \\
\hline 0,1088 & 0,1523 & 0,1305 & 505000 & 0,0113 & 0,2590 & 0,0338 & 0,0048 & 0,0006 \\
\hline 0,1523 & 0.1958 & 0,1740 & 500000 & 0,0112 & 0.2564 & 0,0446 & 0,0064 & 0,0011 \\
\hline 0,1958 & 0,2393 & 0,2175 & 496000 & 0,0111 & 0,2544 & $0,0,0553$ & 0,0079 & 0,0017 \\
\hline 0,2393 & $0, \overline{3263}$ & 0,2828 & 977000 & 0,0218 & 0,2505 & 0,0708 & 0,0101 & 0,0029 \\
\hline 0,3263 & 0,4133 & 0,3698 & 957000 & 0,0214 & 0,2454 & 0,0907 & 0,0130 & 0,0048 \\
\hline 0,4133 & 0,5003 & 0,4568 & 937000 & 0,0209 & 0,2403 & 0,1098 & 0,0157 & $0, \overline{0072}$ \\
\hline 0,5003 & 0,5873 & 0,5438 & 913000 & 0,0204 & 0,2341 & 0,1273 & 0,0182 & 0,0099 \\
\hline 0,5873 & 0,6743 & 0,6308 & 887000 & 0,0198 & 0,2275 & 0,1435 & 0,0205 & 0,0129 \\
\hline 0,6743 & 0,7613 & 0,7178 & 861000 & 0,0192 & 0,2208 & 0,1585 & 0,0227 & 0,0163 \\
\hline 0,7613 & 0,9353 & 0,8483 & 1640000 & 0,0366 & 0,2103 & 0,1784 & 0,0255 & 0,0216 \\
\hline 0,9353 & 1,1093 & 1,0223 & 1528000 & 0,0341 & 0,1959 & 0,2003 & 0,0286 & 0,0293 \\
\hline 1,1093 & 1,2833 & 1,1963 & 1392000 & 311 & 0,1785 & 0,2135 & 0,0305 & 0,0365 \\
\hline 1,2833 & 1,4573 & 1,3703 & 1232000 & 0,0275 & 0,1580 & 0,2165 & 0,0310 & 0,0424 \\
\hline 1,4573 & 1,6313 & 1,5443 & 1072000 & 39 & 0,1375 & 0,2123 & 0,0304 & 0,0469 \\
\hline 1,6313 & 1,8053 & 1,7183 & 902552 & 0,0201 & 0,1157 & 0,1988 & 0,0284 & 0,0489 \\
\hline 1,8053 & 2.1533 & 1,9793 & 1361674 & 304 & 0,0873 & 0,1728 & 0,0247 & 0,0489 \\
\hline 2,1533 & 2.5013 & 2,3273 & 1005371 & 0,0224 & 0.0645 & 0,1500 & 0,0215 & 0,0499 \\
\hline 2,5013 & 2,8493 & 2,6753 & 787536 & 0,0176 & 0,0505 & $0,1351^{\circ}$ & 0,0193 & 0,0517 \\
\hline 2,8493 & 3,1973 & 3,0233 & 643153 & 0,0143 & 0,0412 & 0,1247 & 0,0178 & 0,0539 \\
\hline 3,1973 & 3,5453 & 3,3713 & 544628 & 0,0122 & 0,0349 & 0,1177 & 0,0168 & 0,0567 \\
\hline 3,5453 & 3,8933 & 3,7193 & 472864 & 0,0105 & 0,0303 & 0,1128 & 0,0161 & 0,0600 \\
\hline 3,8933 & 4.5893 & 4,2413 & 792383 & 0,0177 & 0,0254 & 0,1077 & 0,0154 & 0,0653 \\
\hline 4,5893 & 5,2853 & 4,9373 & 656223 & 0,0146 & 0,0210 & 0,1039 & 0,0149 & 0,0733 \\
\hline 5,2853 & 5,9813 & 5,6333 & 565940 & 0,0126 & 0,0181 & 0,1022 & 0.0146 & 0,0823 \\
\hline 5,9813 & 6.6773 & 6,3293 & 500819 & 0,0112 & 0,0161 & 0,1016 & 0,0145 & 0,0920 \\
\hline 6,6773 & 7,3733 & 7,0253 & 450738 & 0,0101 & 0,0144 & 0,1015 & 0,0145 & 0,1020 \\
\hline 7,3733 & 8,0693 & 7,7213 & 414996 & 0,0093 & 0,0133 & 0,1027 & 0,0147 & 0,1134 \\
\hline 8,0693 & 9,4613 & 8,7653 & 748320 & 0,0167 & 0,0120 & 0,1051 & 0,0150 & 0,1318 \\
\hline 9,4613 & 10,8533 & 10,1573 & 681016 & 0,0152 & 0.0109 & 0,1109 & 0,0159 & 0,1610 \\
\hline 10,8533 & 12.2453 & 11,5493 & 645708 & 0,0144 & 0,0103 & 0,1195 & 0,0171 & 0,1974 \\
\hline 12.2453 & 13,6373 & 12,9413 & 621490 & 0,0139 & 0,0100 & 0,1289 & 0,0184 & 0,2386 \\
\hline 13,6373 & 15,0293 & 14,3333 & 602225 & 0,0134 & 0,0097 & 0,1383 & 0,0198 & 0,2836 \\
\hline 15,0293 & 15,5000 & 15,2646 & 203172 & 0,0045 & 0,0096 & 0,1470 & 0,0210 & 0,3208 \\
\hline
\end{tabular}

